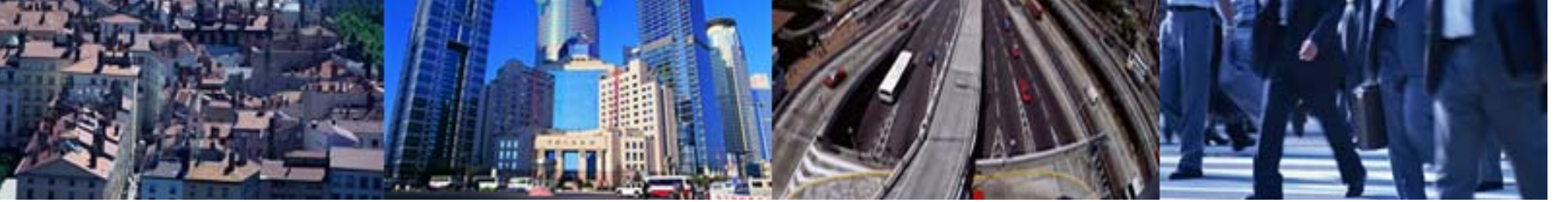

\title{
Competitive Cities and Climate Change
}

Lamia Kamal-Chaoui and Alexis Robert (eds.)
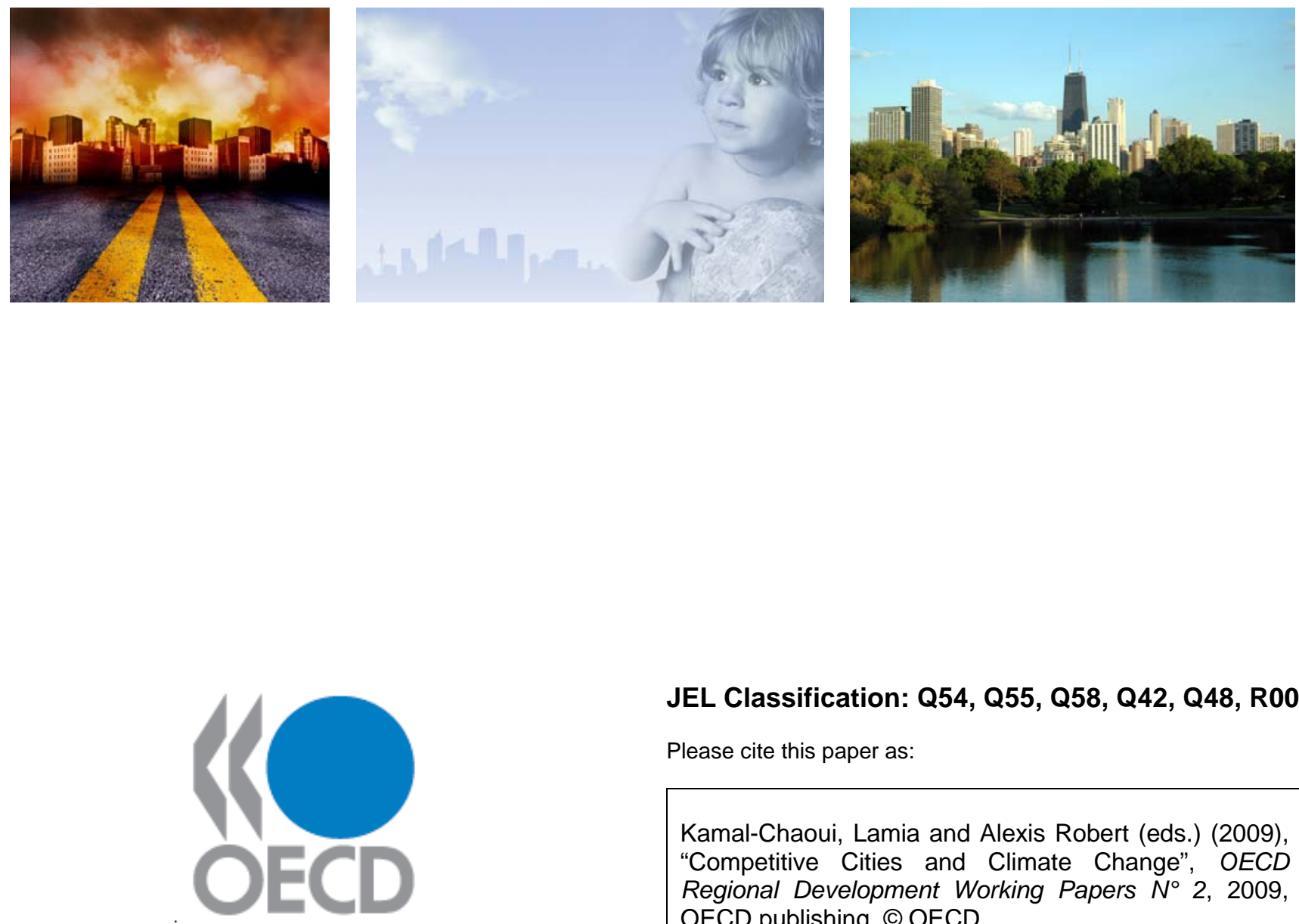

JEL Classification: Q54, Q55, Q58, Q42, Q48, R00

Please cite this paper as:

Kamal-Chaoui, Lamia and Alexis Robert (eds.) (2009),

"Competitive Cities and Climate Change", OECD

Regional Development Working Papers $N^{\circ}$ 2, 2009, OECD publishing, (c) OECD. 


\section{OECD REGIONAL DEVELOPMENT WORKING PAPERS}

This series is designed to make available to a wider readership selected studies on regional development issues prepared for use within the OECD. Authorship is usually collective, but principal authors are named.

The papers are generally available only in their original language English or French with a summary in the other if available.

The opinions expressed in these papers are the sole responsibility of the author(s) and do not necessarily reflect those of the OECD or the governments of its member countries.

Comment on the series is welcome, and should be sent to either gov.contact@oecd.org or the Public Governance and Territorial Development Directorate, 2, rue André Pascal, 75775 PARIS CEDEX 16, France.

OECD Regional Development Working Papers are published on

www.oecd.org/gov/regional/workingpapers

Applications for permission to reproduce or translate all or part of this material should be made to: OECD Publishing, rights@oecd.org or by fax 33145249930.

(C) OECD 2009 


\begin{abstract}
Cities are part of the climate change problem, but they are also a key part of the solution. This report offers a comprehensive analysis of how cities and metropolitan regions can change the way we think about responding to climate change. Cities consume the vast majority of global energy and are therefore major contributors of greenhouse gas emissions. At the same time, the exposed infrastructure and prevalent coastal location of many cities makes them common targets for climate change impacts such as sea level rise and fiercer storms. This report illustrates how local involvement through "climate-conscious" urban planning and management can help achieve national climate goals and minimise tradeoffs between environmental and economic priorities. Six main chapters analyse the link between urbanisation, energy use and $\mathrm{CO}_{2}$ emissions; assess the potential contribution of local policies in reducing global energy demand and the trade-offs between economic and environmental objectives at the local scale; discuss complementary and mutually reinforcing policies such as the combination of compact growth policies with those that improve mass transit linkages; and evaluate a number of tools, including the "greening" of existing fiscal policies, financing arrangements to combat climate change at the local level, and green innovation and jobs programmes. One of the main messages of this report is that urban policies (e.g. densification or congestion charges) can complement global climate policies (e.g. a carbon tax) by reducing global energy demand, $\mathrm{CO}_{2}$ emissions and the overall abatement costs of reducing carbon emissions. To inform the groundswell of local climate change action planning, the report highlights best practices principally from OECD member countries but also from certain non-member countries.
\end{abstract}

JEL classification: Q54, Q55, Q58, Q42, Q48, R00

Keywords: Climate; Global Warming; Sustainable Development; Government Policy; Planning;

Regional, Urban, Cities, Territorial, Regional Economics, Urban Sustainability 


\section{FOREWORD}

This working paper is one in a series of OECD Working Papers on Regional Development of the OECD Public Governance and Territorial Development Directorate.

This report has been produced and coordinated by Lamia Kamal-Chaoui (Head of the Urban Development Unit) and Alexis Robert (Policy Analyst) under the supervision of Joaquim Oliveira Martins (Head of the Regional Competitiveness and Governance Division). It draws on a number of internal contributions, including from Tadashi Matsumuto, Olaf Merk, Javier Sanchez-Reaza, Daniel SanchezSerra and Mario Piacentini. Marcos Bonturi (Deputy Chief of Staff of the Secretary-General, former Head of the Regional Competitiveness and Governance Division) provided valuable support in the report's early stages.

The report has also benefitted from contributions outside the OECD Secretariat, including from Mathias Ruth and Rebecca Gasper (Center for Integrative Environmental Research, University of Maryland, College Park), Benoit Lefevre and Vincent Renard (IDDRI), and Fredrich Kahrl (Energy and Resources Group, University of California, Berkeley). Special thanks are given to Fabio Grazi and Henri Waisman (CIRED) for modelling work with IMACLIM-R and the urban module that incorporates the OECD metropolitan database.

We would also like to acknowledge those who have provided valuable comments on the report and relevant background material. In the OECD, they are Jan Corfee-Morlot, Shardul Agrawala, Jean-Marc Burniaux and Jean Chateau (Environment Directorate), Nigel Jollands and Sara Pasquier (International Energy Agency), Mary Crass and Phlippe Crist (International Transport Forum), Arthur Mickoleit and Tomoo Machiba (Directorate for Science, Technology and Industry), and Hiroshi Kobayashi, Aziza Akhmouch, Michael Donovan and Xiao Wang (Public Governance and Territorial Development Directorate). We are also grateful to Dale Medearis (Northern Virginia Regional Commission), Keith Thorpe (Communities and Local Government, Government of the United Kingdom), and Vincent Fouchier (Institut d'Aménagement et d'Urbanisme de la région d'Île-De-France).

The paper can be downloaded on the OECD website: www.oecd.org/gov/cities

Further enquiries about this work in this area should be addressed to:

- Lamia Kamal-Chaoui (lamia.kamal-chaoui@oecd.org) and Alexis Robert (Alexis.robert@oecd.org) of the OECD Public Governance and Territorial Development Directorate.

Mario Pezzini, Deputy Director, Directorate for Public Governance and Territorial Development

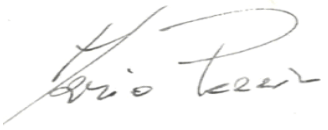




\section{TABLE OF CONTENTS}

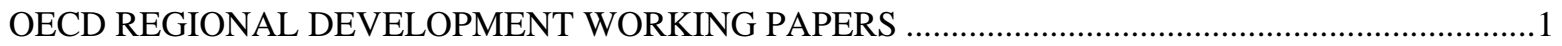

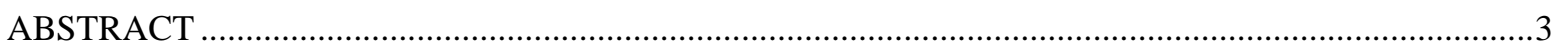

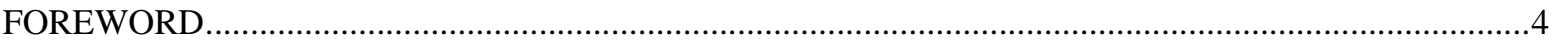

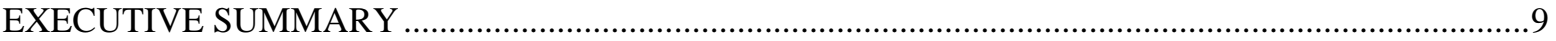

1. Cities and climate change: a two way relationship ...............................................................................

2. Cities are not to be blamed - Urban form, lifestyles and energy sources are what count ......................9

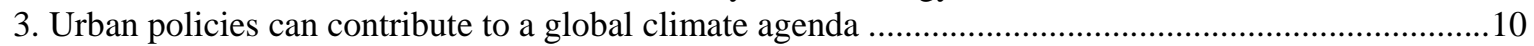

4. Urban climate actions need a smart mix of policy instruments .........................................................11

5. Finance is an issue - Greening local revenues and financing local green activities..............................13

6. Cities have a key role in fostering a green growth agenda ............................................................15

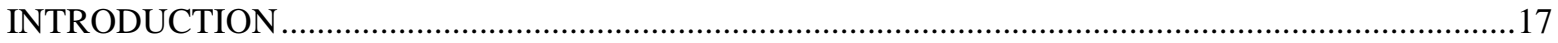

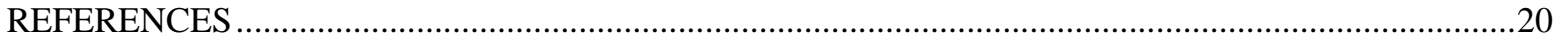

1. URBANISATION, ECONOMIC GROWTH AND CLIMATE CHANGE ….......................................21

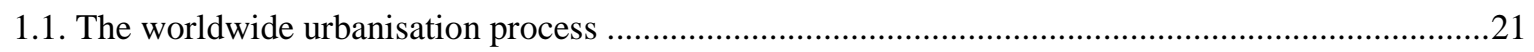

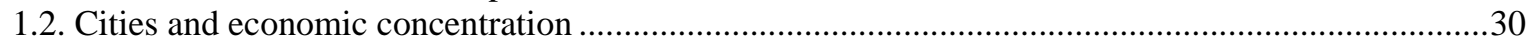

1.3. Economic growth, energy use and greenhouse gas emissions ..........................................................34

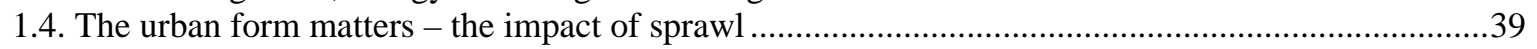

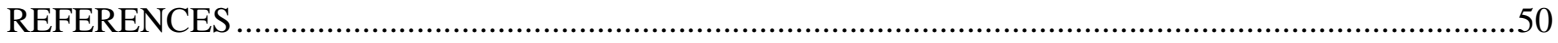

2. CLIMATE CHANGE IMPACTS SPECIFIC TO URBAN REGIONS ................................................51

2.1 Complex and fixed nature of urban infrastructure ............................................................................51

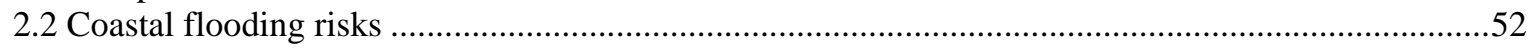

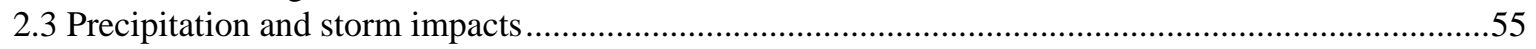

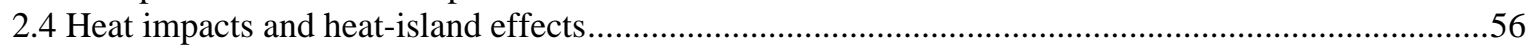

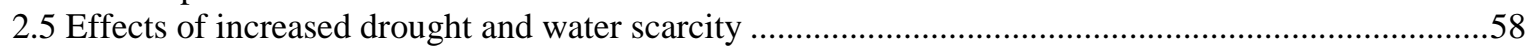

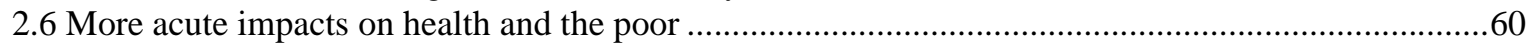

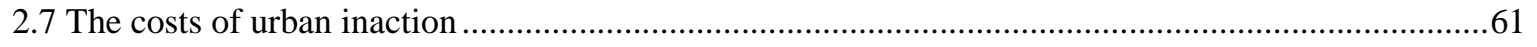

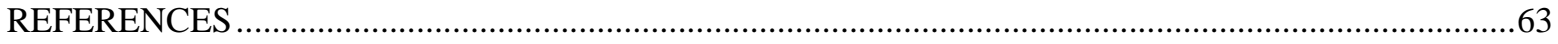

3. ECONOMIC BENEFITS OF CLIMATE ACTION: THE URBAN DIMENSION ................................65

3.1. Impact of urban policies on global energy demand and carbon emissions .......................................65

3.2. Environment and economic growth at the urban scale: from trade-offs to complementarity ..............67

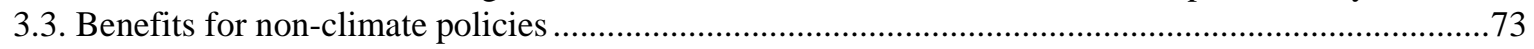

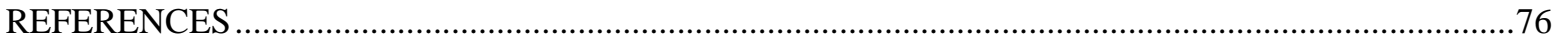

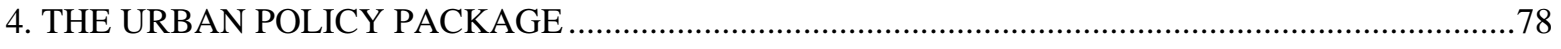

4.1 Urban governance and policy complementarities ................................................................................78 


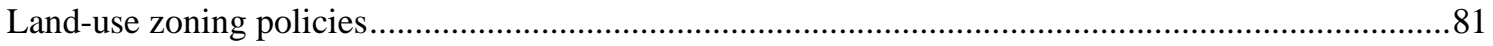

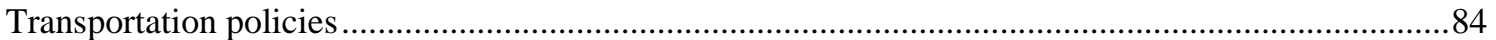

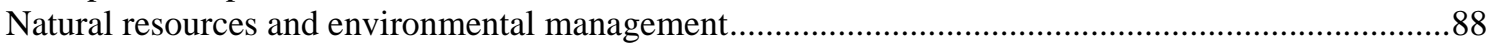

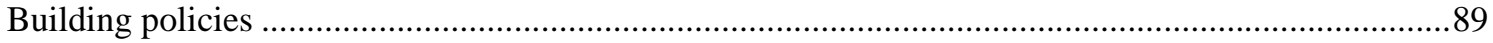

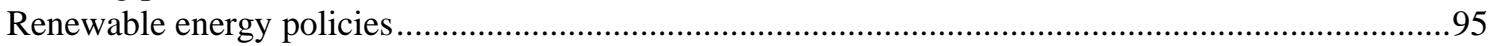

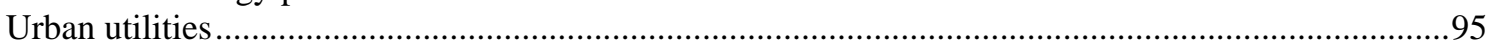

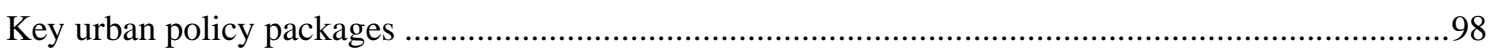

4.2 Density and spatial urban form in combating climate change ....................................................101

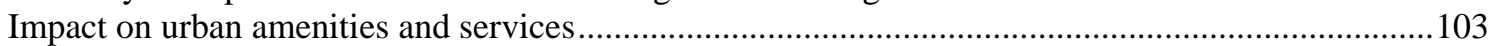

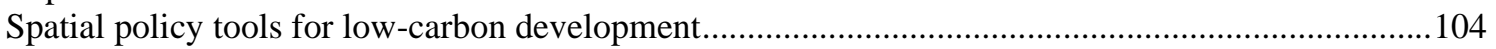

4.3 Strategic urban planning for climate change........................................................................................106

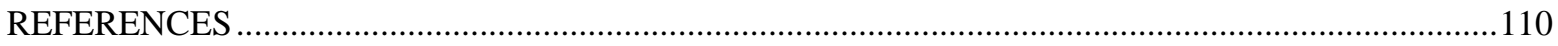

5. FINANCIAL INSTRUMENTS AND FUNDING NEW EXPENDITURE NEEDS............................116

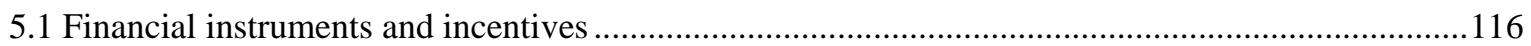

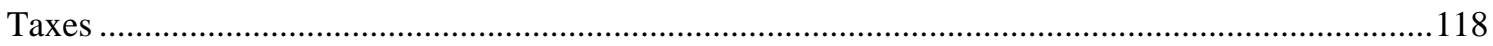

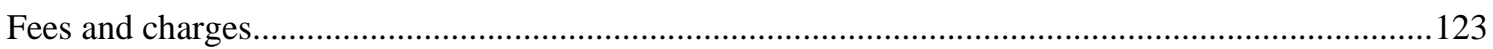

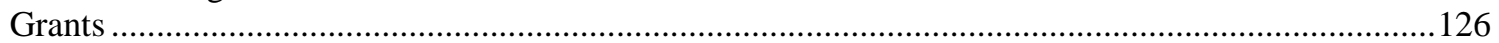

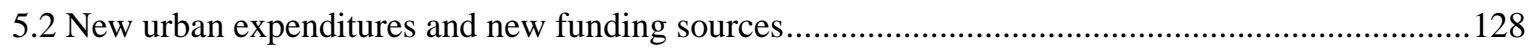

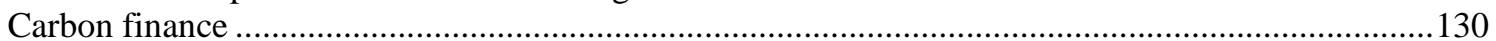

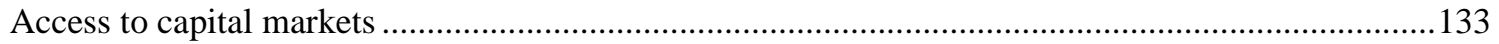

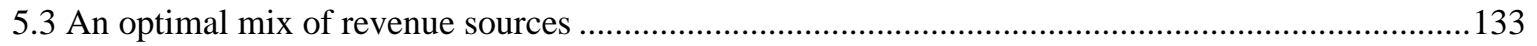

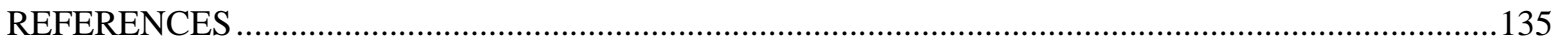

6. CONTRIBUTION OF CITIES TO A GREEN GROWTH MODEL ...............................................138

6.1. Facilitating job creation in the green economy: the role of cities and regions...................................139 Investments in greener infrastructure and greener service provision ..............................................140

Urban energy management strategies for employment creation .........................................................145

Greening preferences to raise the size of green markets ..................................................................150

6.2. Systemic changes through regional eco-innovation.........................................................................152

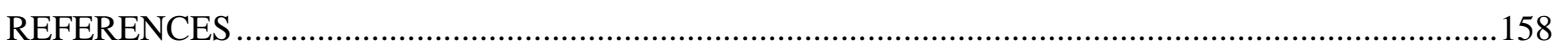

ANNEX A: COMPUTABLE GENERAL EQUILIBRIUM MODEL OF CITIES AND CLIMATE CHANGE (IMACLIM-R AND OECD METROPOLITAN DATABASE) ...............................................162

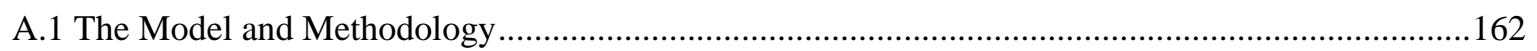

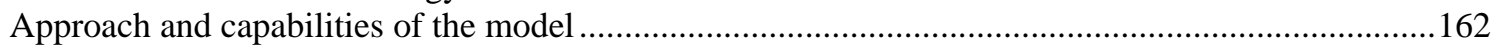

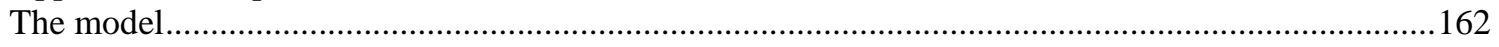

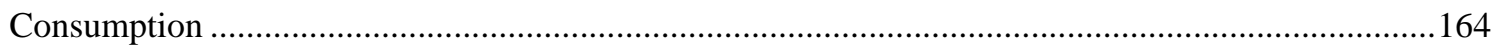

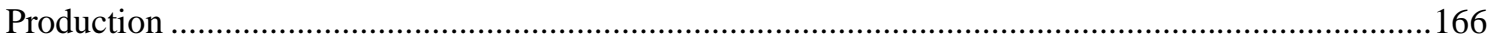

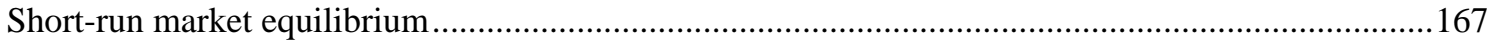

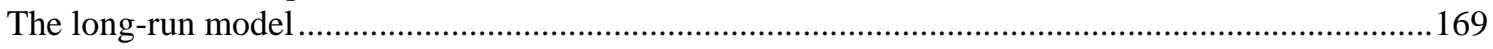

A. 2 Main results of the model with a climate policy only …….............................................................171

\section{Tables}

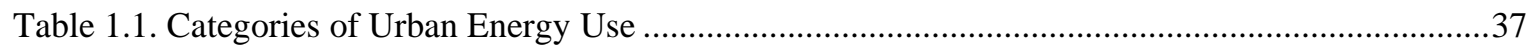

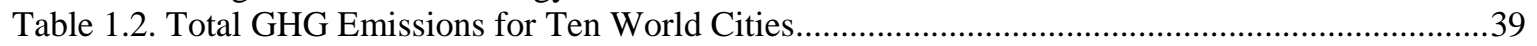

Table 2.1. Cities are highly concentrated in coastal zones ..........................................................................53

Table 3.1. GDP changes under implementation of alternative climate policy packages ...........................71 
Table 3.2. Related aims and co-benefits of sector policies to reduce GHGs at urban scale ......................74

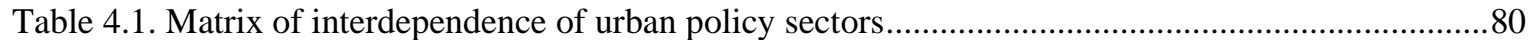

Table 4.2. Policy tools for local-level action on climate change .............................................................99

Table 4.3. Compact city characteristics ..................................................................................................102

Table 4.4. Policy instruments to manage urban sprawl ..........................................................................106

Table 5.1. Financial instruments in selected city's climate change plans .............................................117

Table 5.2. Main urban congestion charges in operation and their environmental outcomes....................125

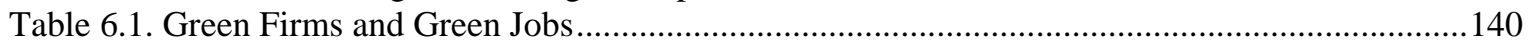

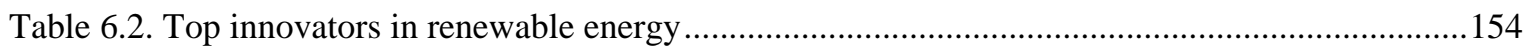

\section{Figures}

Figure 1.1 Urban and Rural Population in the World and the OECD.....................................................22

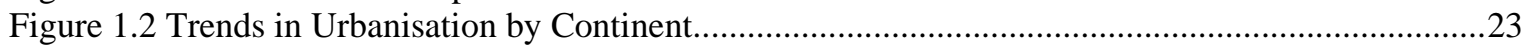

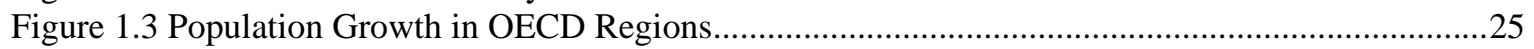

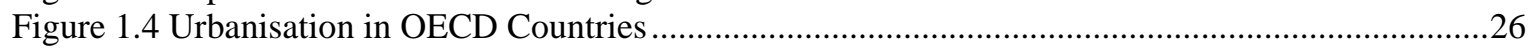

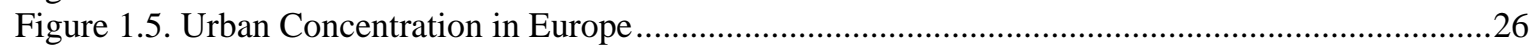

Figure 1.6 Urban Concentration in Asian OECD Countries....................................................................27

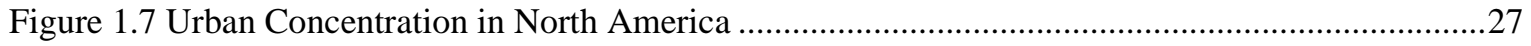

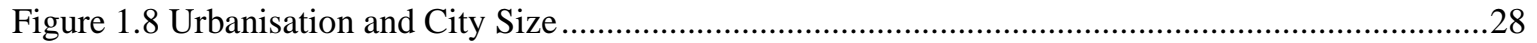

Figure 1.9 Population Growth in OECD Metropolitan areas...................................................................29

Figure 1.10. Urbanisation and Income..................................................................................................

Figure 1.11. Factors determining per capita GDP Differentials ..............................................................32

Figure 1.12. Economic Concentration in Europe.....................................................................................33

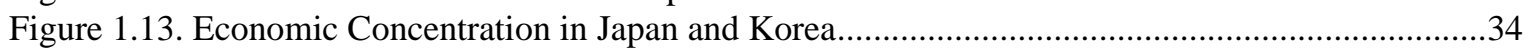

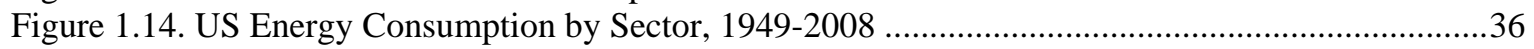

Figure 1.15. Total Energy Consumption in OECD Countries, 2007 .................................................38

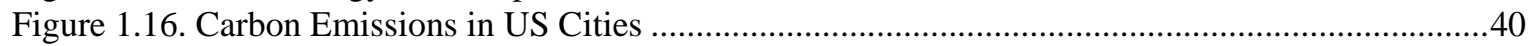

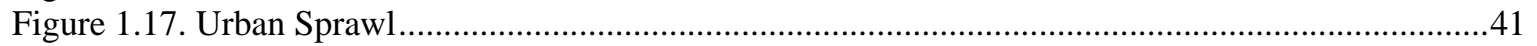

Figure 1.18. Suburbanisation and Gentrification in OECD Metro-regions .............................................42

Figure 1.19. Urbanisation and Energy Consumption...............................................................................43

Figure 1.20. Urban Density and Electricity Consumption.......................................................................4

Figure 1.21. Urbanisation and Carbon Emissions.................................................................................45

Figure 1.22. Urban Density and Carbon Emissions in Transport ...........................................................46

Figure 1.23. Urbanisation, Density and Carbon Emissions ..............................................................4

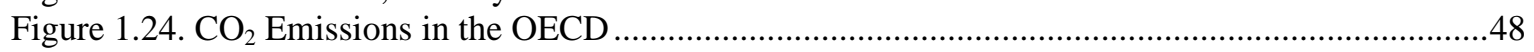

Figure 1.25. Concentration of Carbon Emissions in the USA ...............................................................49

Figure 2.1. Top 20 port cities’ exposed assets (a) and exposed population (b) ........................................54

Figure 2.2. Apparent southward shift of European cities due to climate change, 2070-2100 ..................56

Figure 3.1. Energy Demand with a Densification Policy ……..................................................................66

Figure 3.2. Carbon Emission Reductions with a Densification Policy ......................................................67

Figure 3.3. Economic Growth with Local Policies ...................................................................................68

Figure 3.4. Trends in carbon emissions under climate policy compared with the baseline........................70

Figure 3.5. Attractiveness and Carbon Emissions related to Automobiles across Metro-regions ..............72

Figure 3.6. Changes in Attractiveness and Local Pollution Emissions across Metro-regions....................73

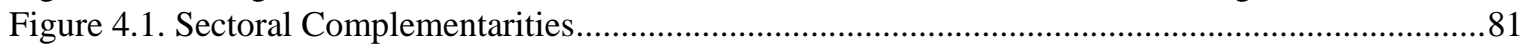

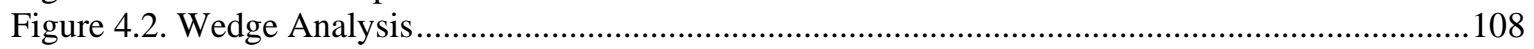

Figure 5.1. Main revenue sources of selected cities within the OECD..................................................118

Figure 5.2. Main taxes of selected cities within the OECD ...............................................................119 
Figure 5.3. National, state and local motor vehicle taxes in unitary OECD countries (2006)................122

Figure 5.4. National, state and local fuel taxes in unitary OECD countries (2006)..............................122

Figure 5.5. National and sub-national expenditures on environmental protection in OECD countries

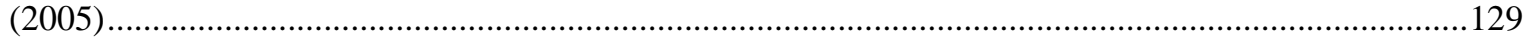

Figure 6.1. Employment effects of renewable energies.................................................................146

Figure 6.2. Estimated Levelised Cost of Generation, Various Technologies .......................................147

Figure A.1. Economic Impact of a Climate Policy Alone using the Baseline Scenario ............................171

\section{Boxes}

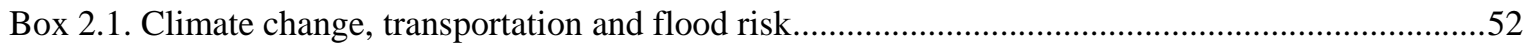

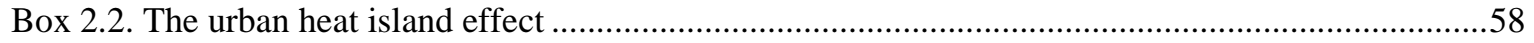

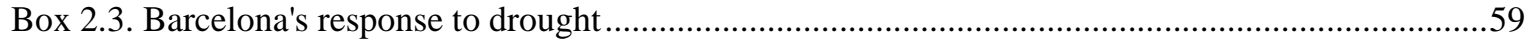

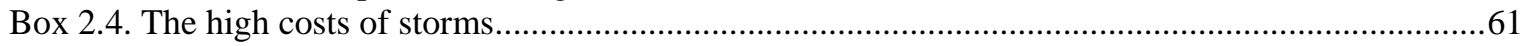

Box 3.1. A CGE Model of Metropolitan Economies......................................................................66

Box 3.2. Emission Targets and Modelling of Climate Policy ..........................................................69

Box 4.1 Integrating adaptation into development planning ........................................................................83

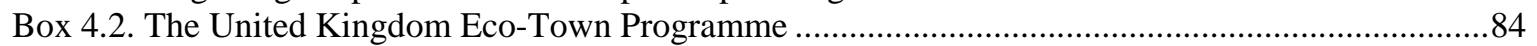

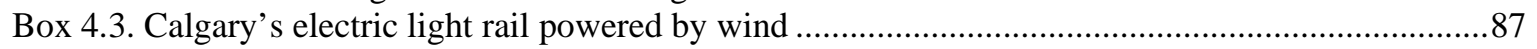

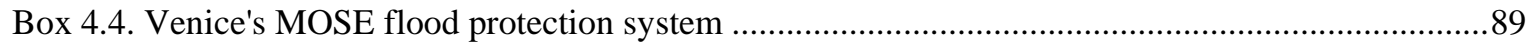

Box 4.5. Multilevel governance building efficiency programmes...........................................................92

Box 4.6. The Merton Borough initiative.................................................................................................

Box 4.7. Ile-de-France's Regional Master Plan to become first "Eco-Region" ......................................105

Box 4.8. The Sustainable Shoreline Community Management in Northern Virginia project ..................107

Box 4.9. The Bay Area Metropolitan Transportation Commission Transportation 2035 Plan ................109

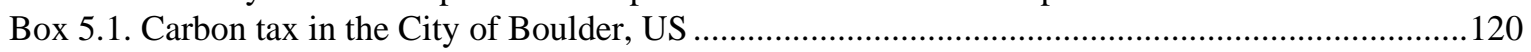

Box 5.2. Environmental indicators in tax shares to local governments in Brazil ..................................127

Box 5.3. Metropolitan emission trading programmes..............................................................................130

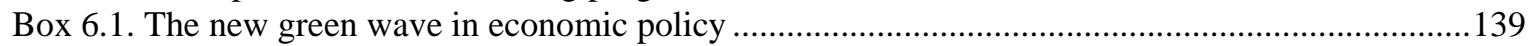

Box 6.2. Fiscal stimulus for investments in infrastructure, examples from OECD countries .................141

Box 6.3. Strategic urban economic policy in the recycling sector, Kitakyushu city's example................143 


\section{EXECUTIVE SUMMARY}

\section{Cities and climate change: a two-way relationship}

- Cities are major contributors to $\mathrm{CO}_{2}$ emissions. Roughly half of the world's population lives in urban areas, and this share is increasing over time, projected to reach $60 \%$ by 2030 . Cities consume a great majority - between 60 to $80 \%$ - of energy production worldwide and account for a roughly equal share of global $\mathrm{CO}_{2}$ emissions. In the OECD, countries that are more urbanised tend to generate higher levels of $\mathrm{CO}_{2}$ emissions. Greenhouse gas (GHG) emissions in OECD cities are increasingly driven less by industrial activities and more by the energy services required for lighting, heating and cooling, appliance use, electronics use, and mobility. Growing urbanisation will lead to a significant increase in energy use and $\mathrm{CO}_{2}$ emissions, particularly in non-OECD countries in Asia and Africa where urban energy use is likely to shift from $\mathrm{CO}_{2}-$ neutral energy sources (biomass and waste) to $\mathrm{CO}_{2}$-intensive energy sources.

- Climate change poses key threats to urban infrastructure and quality of life. The tendency for cities to be located in coastal areas increases their vulnerability to water-related calamities, increasing the risk to property, livelihoods and urban infrastructure. Rising sea levels are a critical issue for major cities - for example, in Europe, $70 \%$ of the largest cities have areas that are less than 10 meters above sea level. Port cities most at risk for coastal flooding are located both in rapidly growing developing countries such as India and China (e.g. Kolkata, Shanghai, Guangzhou) and in wealthy of countries such as the United States (e.g. Miami, New York City), the Netherlands (e.g. Rotterdam, Amsterdam) and Japan (e.g. Tokyo, Osaka). Heat waves will be felt more strongly in urban areas due to urban heat island effects. Due to the large amount of concrete and asphalt in cities, the difference in average annual temperature with rural areas ranges from 3.5 to $4.5^{\circ} \mathrm{C}$, and is expected to increase by $1^{\circ} \mathrm{C}$ per decade (up to a difference of $10^{\circ} \mathrm{C}$ with large cities). Poor populations in both rich and poor nations are the most vulnerable to climate change, in part because they lack the resources to quickly and effectively protect themselves from extreme weather patterns. The poor are also more vulnerable as they may use cheaper materials to build dwellings, or may reside in floodplain areas where land is cheaper, as was demonstrated during Hurricane Katrina (2005) and Hurricane Mitch (1998).

\section{Cities are not to be blamed - Urban form, lifestyles and energy sources are what count}

- How cities grow and operate matters for energy demand and thus for GHG emissions. Energy use, and thus carbon emissions, are chiefly driven by how electricity is produced, use of energy in buildings and to move around the city. Urban density and spatial organization are key factors that influence energy consumption, especially in the transportation and building sectors. The acceleration of urbanisation since the mid-half of the last century has been accompanied by urban sprawl, with urban land area doubling in the OECD and growing by a factor of five in the rest of the world. The expansion of built-up areas through suburbanisation has been particularly prominent among OECD metropolitan areas (66 out of the 78 largest OECD cities experienced a faster growth of their suburban belt than their urban core over 1995-2005). Increasing density could significantly reduce energy consumption in urban areas. For instance, Japan's urban areas 
are around five times denser than Canada's, and the consumption of electricity per capita in the former is around $40 \%$ that of the latter. If we take countries in the same geographical context with similar heating needs, such as Denmark and Finland, the proportions are quite similar. Denmark's urban areas are denser than Finland's by a factor of four and people there only consume around $40 \%$ of the electricity than the Finns.

- Lifestyles, in particular the way in which people commute, are also crucial in the generation of $\mathbf{C O}_{2}$ emissions. Cities' emissions can vary depending on their lifestyles, spatial form and public transport availability. In other words, it is not cities, or urbanisation per se, that contribute to GHG emissions, but rather the way in which people move around the city, the sprawl that they produce, the way in which people use energy at home and how buildings are heated that make cities the great consumers of energy and polluters that they are. As urban areas become denser and rely more on public transport, carbon emissions are reduced. Not surprisingly, among OECD member countries, North American countries - characterised by high personal vehicle use produce $50 \%$ more $\mathrm{CO}_{2}$ emissions than European countries, which in turn pollute twice as much as Asian countries. Similarly, not all cities in the same country are home to the same lifestyles, nor do they contribute to carbon emissions in the same way. Although the USA is the OECD country with the highest per capita carbon emissions, internally, Los Angeles, with very high personal vehicle use, displays higher concentration of $\mathrm{CO}_{2}$ emissions than New York, even though it has the largest population concentration in the country (60\% higher than Los Angeles).

- Cities' energy sources matter. The impact of energy consumption on GHG emissions depends not just on the amount consumed, but also on the GHG emissions generated by the energy source, which in turn depend on the mode of energy production. For example, Cape Town has comparatively low per capital electricity consumption than Geneva, but its consumption has a higher GHG emissions factor, due to South Africa's use of coal for 92\% of its electricity generation whilst Geneva relies on hydropower. Technology also matters: urban areas relying on inefficient or wasteful energy sources contribute more GHG emissions then than those that consume the same amount from more efficient sources.

\section{Urban policies can contribute to a global climate agenda}

- Costs of delaying action on climate change are high. While climate change mitigation and adaptation policies require significant investment, delaying action can increase future costs and limit future options for adapting to climate change impacts or reducing emissions in cities. Direct costs from climate change impacts can be staggeringly high, especially when related to natural disasters and sea level rise. For example, shoreline retreat in the United States is projected to cost between USD 270 billion to 475 billion per metre climb in sea level; analogous costs in developing nations can amount to one-third of annual GDP. Indirect impacts can cripple urban economic activity, when transportation, commercial and industrial activities are interrupted due to severe weather events. Economic impacts can have rebound effects in the job market and reduce tax revenue. These stresses on the local economy may limit investment opportunities and deplete funds for infrastructure innovations, leaving cities more vulnerable to future change. Ripple effects from outside the city can also affect the profitability of many economic sectors in the city and the income of city inhabitants, as well as food security. But most economic loss will come in the form of "hidden" costs, such as the costs of rerouting traffic, lost productivity, provision of emergency and continued aid, relocation and retraining, lost heritage, and urban ecosystem damage. In addition, higher risk and uncertainty stemming from global climate change imposes additional costs on the insurance, banking, financing and investment industries. Changes to the built environment to reduce transportation distances, increase mass transit linkages and 
adapt to climate change can only happen incrementally over the long term, which heightens the urgency of implementing land-use zoning, spatial, building and transportation policies now.

- Urban policy can contribute to national $\mathrm{CO}_{2}$ emissions reduction targets. Findings from a general equilibrium model (CGE model) with an urban module demonstrate that urban policies such as increases in spatial density and congestion charges can lead to a reduction of total OECD global energy demand and, consequently, of $\mathrm{CO}_{2}$ emissions. Interestingly, overall abatement costs of meeting Kyoto emissions reduction objectives, generally observed at the macroeconomic level, can be reduced over time by complementing a global climate policy (e.g., a carbon tax) with urban densification policies and congestion charges.

- The lower tradeoffs between economic growth and environmental priorities at the urban level may be due to complementarities of policies observed only at the local scale. An example is local pollution, which increasingly impacts city attractiveness and competitiveness. Results from the CGE model shows for instance that if cities continue their current GHG emissions and lifestyles trends, by 2030 cities that could become more attractive will do so while also curbing local pollution (e.g. Ankara, Auckland, Barcelona, Krakow, Lille, Melbourne, Montreal, Monterrey, and Toronto). It also highlights that some metro-regions risk losing attractiveness if their current pollution trends continue (e.g. Chicago, Los Angeles, New York, Osaka, Paris, Philadelphia, Seoul and Tokyo).

- Some urban climate policies should be considered as no-regret policies as they can provide additional co-benefits. These include public health improvements, cost savings and increased efficiency, energy security and infrastructure improvements, and improved urban quality of life. These additional non-climate benefits may also help to explain the lower tradeoffs between economic growth and GHG emissions reduction on the metropolitan level. For example, GHG emissions reductions may benefit human health to such a degree as to offset in large part the local costs of emissions reductions. Policies to reduce GHG emissions through increasing energy efficiency can result in significant reductions in energy costs, and the energy savings achieved can compensate for the initial investment costs in as little as a few years.

\section{Urban climate actions need a smart mix of policy instruments}

- Cities serve as policy laboratories for action on climate change. Many cities and metropolitan regions around the world are taking action on climate change - even in the absence of national policies and commitments - not only out of recognition of cities' contributions to and risks from climate change, but also of the opportunities to lower the potential tradeoffs between economic growth and environmental priorities. While large cities have provided landmark policies notably Seoul, Stockholm, Toronto, Copenhagen, New York, London, and Tokyo - mid-size and smaller cities have also created innovative climate policies, such as Mannheim and Freiburg in Germany, Toyama, Japan, Nantes, France and Boulder, USA.

- Cities have key competencies to act on climate change through their responsibilities over urban sectors such as land-use zoning, transportation, natural resources management, buildings, waste and water services. Urban authorities make decisions that determine or influence public transportation systems, the built environment, renewable energy and energy efficiency measures, and the sustainability of services delivery. Cities and metropolitan regions are well positioned to develop policy and programmatic solutions that best meet specific geographic, climatic, economic, and cultural conditions. They are equally well placed to develop innovative policy solutions that can be scaled up into regional or national programmes, or to provide a laboratory for national pilot programmes on the urban level. 
- Effective climate policy packages should seek policy complementarities among and within urban sectors to implement policies that enhance each other's effectiveness. For example, landuse zoning policies that allow for higher densities and greater mixing of residential and commercial uses can enhance transportation climate goals by reducing trip distances and frequency while strategic mass transit linkages can attract development and thus promote compact growth. Long-term growth plans in a number of OECD metropolitan areas aim to maximise these complementarities (e.g. Paris, New York, London). Natural resource policies to increase vegetation and green space can reduce emissions and reduce the impacts of heat extremes and flooding - a prime example being São Paulo's development of linear parks along urban waterways. Within the transportation sector, policies to increase the quality and availability of public transportation, bicycle, and foot travel make policies to discourage or restrict vehicle travel and circulation more politically feasible. For example, congestion fees for driving during peak hours worked well in London because they were combined with improvements in management of the road network and substantial enhancements in bus service. Energy efficiency standards for new buildings are well complemented by projects to retrofit existing buildings with energy efficiency technologies, with models including Berlin's innovative model for contracting with private companies to meet efficiency targets and Toronto's Mayor's Tower Renewal programme. Waste policies to promote waste-to-energy incineration need to be combined with robust support for recycling programmes to enhance the economic viability of recycling programmes to divert waste from landfills (e.g. Kitakyushu, Japan).

- Action on climate change should optimise existing urban modes of governance. Climate action on the urban level happens through local regulations, urban services, programme administration, city purchasing and property management, and convening of local stakeholders. Activities involving government-owned property or operations are common in part because cities have direct control over them - examples include many cities' purchase of hybrid or alternative fuel vehicles and improving the energy efficiency of street and traffic lights (e.g. Los Angeles and Graz, Austria). Important opportunities exist where cities are service providers - such as Melbourne's innovative two-tiered water services system providing both drinkable and recycled water, Monterrey and Toronto's capture of methane gas from landfills for energy, and Copenhagen, Stockholm and Mannheim's use of district heating. Cities generally are still reluctant to make full use of their regulatory authority to achieve climate goals. Notable exceptions include Barcelona's Solar Thermal Ordinance and San Francisco's recent introduction of mandatory recycling.

- Successful compact cities policies rely on well-designed strategic plans. Policies to increase the concentration of urban areas in the long term and manage outward expansion have gained popularity across the OECD, particularly in the Netherlands, United Kingdom and Japan, which has initiated an "Eco-Compact City" policy. While the higher residential densities targeted by these policies have the most direct effect on GHG emissions, transportation linkages particularly between employment centres and residential zones - are crucial to ensuring that increases in density translate into reductions in personal vehicle use. Increasing the mix of land uses in urban neighbourhoods also reduces travel distances between home, work, and activities and promotes non-motorised travel. High quality urban services and amenities, including open space, are also crucial to the long-term attractiveness and effectiveness of compact cities policies.

- Long-term strategic planning needs to take into account urban areas' contributions and vulnerabilities to climate change. Strategic planning - determining future action, identifying implementing roles, and monitoring and evaluating the outcomes - has been increasingly used to coordinate diverse priorities and contributions from multiple levels of government, nongovernmental stakeholders and the private sector. The tools for flexible and strategic public 
intervention that can be used to incorporate climate change responses into long-term growth plans typically analyse urban GHG emissions drivers and urban vulnerabilities. Although many cities have begun to inventory their emissions sources, the need exists for a harmonisation of tools. Vulnerability assessment models, developed by some cities (e.g. Washington, USA) are essential but they remain costly and require scientific expertise that may not be relatively available to urban governments. An assessment of local capacity to respond to urban GHG emissions and climate change vulnerabilities is also critical to planning future responses. Wedge analysis and stakeholder mapping, implemented for instance by the Greater London Authority, are two types of tools to assess local capacity to act. Tools to assess costs and benefits and conduct cost-effectiveness planning also play a key role in strategic planning. Few cities worldwide have real knowledge of the impact of new development on their long-term fiscal condition. Decisions are dominated by immediate capital costs, despite the fact that often over $90 \%$ of lifecycle costs for typical infrastructure are expended during operational maintenance and rehabilitation. Introducing qualitative assessment in cost-benefit analyses can be challenging; one example is the performance-based planning approach in use in the San Francisco Bay Area, USA.

- National governments can play a role in supporting and removing barriers to greater urban governance and enhance cities' capacity to act on climate change issues. Key roles include providing funding and technical assistance to cities and regions, such as in Finland and Sweden. Climate mandates in national urban and regional policies in Australia, Austria, Canada, the Czech Republic, France, Germany, Japan, Mexico and the United Kingdom, and in the Korean "Green New Deal”, can advance local climate action. Strong national targets for adaptation and GHG emissions reductions can help prevent regional competition based on environmental regulations and even promote a "race to the top" through incentives, such as Japan's "Environment-Friendly Model City" award.

\section{Finance is an issue - greening local revenues and financing local green activities}

- Climate change will call for new urban infrastructure investments and thus will create new challenges for urban finance: it puts additional pressure on city budgets related to adaptation, mitigation and price rises in carbon-related energy sources. New transportation systems, service improvements, building retrofits and protections for the built environment are costly, especially when applied at a citywide scale. Cities are now responsible for a range of sectors that impact environmental sustainability and GHG emissions, sometimes as the sole authority, but more often in partnership with other levels of government. For example, local governments in OECD countries are responsible for $70 \%$ of total public investment and amounts of public spending on environmental protection (which includes waste management, waste water management, pollution abatement, protection of biodiversity and landscapes, and research and development (R\&D) on environmental protection), which is almost similar to that of their respective national governments.

- Green local finance - revenues raising means are not climate neutral. Fiscal instruments and incentives at the disposal of cities could be considered instruments for achieving urban sustainability goals, including climate change targets. Local revenue sources are not neutral: their provenance, rates, exemptions and composition all impact the price citizens and firms pay for certain goods and services, such as urban transportation options, land development and housing. There is room for greening sub-national taxes, especially those that have an impact on the city's built environment, transport and energy, such as property taxes and transportation taxes. Currently, sub-national taxes in certain countries promote sprawl. For example, compact housing options, such as multifamily rental housing in the United States, bear an effective tax rate that is considerably higher (18\% in 2001) than the rate for single-family owner-occupied housing. 
Several cities in the world depend on land sales for a large part of their revenues, which also can create incentives for urban sprawl: the contribution of land sales to local revenue in Guangzhou (China) has been estimated to be 55\% in 2006.

- Cities and metropolitan areas could make more use of fees and charges as instruments to influence behaviour and thus mitigate climate change. As they confront users with the real costs of their choices, these instruments could reduce the inefficient use of resources and limit sprawl. An example of a financial instrument to mitigate climate change is the congestion charge, applied in a growing number of cities, which has proved effective in reducing congestion and reducing $\mathrm{CO}_{2}$ emissions from transport (reductions between $10 \%$ and $20 \%$ in London, Stockholm and Milan). Development charges and value-capture taxes, such as used in Miami, Milan and Bogotá, could finance the construction of new infrastructure needed to serve new surburban developments, whereas transport-related revenue sources (fuel taxes, congestion charges, parking fees) could charge for the use of the infrastructure. Congestion charges will arguably be more appropriate for those cities whose parking fees are already high. Fiscal disincentives for car use will be more effective when alternative traffic solutions, such as public transport, are in place, which is why some metropolitan areas, such as London, use these types of revenues to finance public transit.

- Urban areas need new financial instruments. The budget pressures caused by climate change might require additional financial instruments for cities, which could be provided by carbon finance mechanisms and increased access to capital markets. Some cities participate in the capand-trade mechanisms established in different countries (e.g. the Chicago Climate Change Exchange) or at the European level, and have in some cases (Los Angeles, Chicago, Santiago) set up their own urban cap-and-trade mechanisms or are planning to do so (metropolitan Tokyo in 2010). Certain cities, such as London, have explicitly defined emissions trading as a business opportunity that would increase their metropolitan competitiveness. There are several ways in which the use of carbon finance instruments by cities could be increased. If international climate negotiations were to mention transport and buildings as key areas to reduce GHG emissions, this would provide a rationale to involve urban areas. In order to keep transaction costs down and to take systemic dimensions of urban problems into account, these actions should take the form of broad programmes, such as a sectoral crediting mechanism beyond 2012, rather than specific projects. There is a need as well to make sure that future use of these instruments by cities will be integrated within urban planning and financial frameworks to prevent these instruments from financing isolated projects without connection to larger urban sustainability priorities.

- Adaptations of Kyoto financing mechanism as well as new instruments are needed to allow cities to fully take advantage of international carbon financing instruments. Funding from clean development mechanisms (CDM) and joint implementation mechanisms - the two main Kyoto carbon offset instruments - could help to reduce cities' carbon emissions by providing carbon offsets for urban projects such as mass transit expansion. However these mechanisms are complex and have been rarely used by cities, Bogotá being a notable exception. Existing CDM mechanisms would need to be retooled to allow for broader approaches, such as funding for multi-project sectoral initiatives. Other CDM opportunities for the urban sector could be explored, including easily attainable targets for urban GHG sources related to urban transportation planning, urban forestry, street lighting, and waste energy used for transportation purposes. New carbonfinance instruments are currently being discussed, in which the role of both OECD and nonOECD cities could be strengthened. One set of these instruments relates to the national appropriate mitigation actions (NAMA) that were proposed in the Bali Action Plan. If cities' activities were to be included in NAMA inventories, this would clarify cities' potential 
contributions to GHG emissions reductions, such as through buildings and transport policies, and provide incentives for channelling funding sources to key urban-level projects.

- National governments could play a key role in greening urban finance, by re-designing subnational taxes and grants to sub-national governments, especially those that have an impact on the city's built environment, transport and energy. Re-design of sub-national taxation could include property tax reform to correct for biases towards unsustainable behaviour. For instance, property tax reform favouring compact development could be promoted through a split-rate property tax (Sydney, Hong Kong, Pittsburgh), differential taxation, a special area tax applied on suburban properties, or a set of cascading taxes that gradually increase as one moves away from the city centre towards the periphery (Austin). A relatively simple form of such a tax might be a higher standard property rate for suburban inhabitants or preferential rates for multiple dwellings (Denmark, Sweden). In addition, intergovernmental grants, such as those applied in Germany, Portugal and Brazil, could take environmental indicators into account to compensate local governments for the external benefits of their environmental expenditures. A comprehensive greening of urban finance would also increase the coherence between urban finance and urban planning frameworks to enhance urban sustainability and contain outward urban growth. Carbon taxes and climate change levies, although occasionally introduced at the local level (e.g. Boulder), could be considered more suitable instruments for the national or supra-national level rather than the city or regional level, as they could distort competition between regions.

\section{Cities have a key role in fostering a green growth agenda}

- Cities and regions can promote green growth through many levers, including the creative use of procurement, better screening of investments in infrastructure, transport, communication networks and utilities, financial and tax incentives, partnerships and regulation of energy suppliers, consumer awareness and training programs for green jobs. They also have significant responsibilities in leading by example. An effective green growth strategy for cities should search for employment gains in the short-to-medium term through targeted investments, and should pursue systemic changes in the way cities function and grow through the continuous generation and application of new technologies that increase connectivity and reduce resource use. Publicprivate partnerships, leveraged for example through green infrastructure funds, have great potential for reducing the burden on local finances and increasing the efficiency of green investments.

- $\quad$ Cities can help create stronger markets for renewable energies and energy-efficient products and services. Feasible options for public investment that can reduce emissions and sustain employment include: improving the energy efficiency of buildings through retrofitting (Freiburg) and selective public purchasing (Berlin, Helsinki); integrating environmental targets in transportation and planning (Toronto, Chennai, India); and increasing the share of renewable sources in energy supplies, through distributed technologies (e.g. Berkeley's program for individual photovoltaic installations) or centralized utilities (e.g. wind farms in Samsó, Denmark). Green jobs can result from smarter management of energy at the urban level, through regulatory innovations such as local feed-in tariffs for renewable energy (e.g. several German cities) or strong market support for the deployment of ICT and other energy saving technologies (e.g. the Gangnam-gu district of Seoul and the Paris suburb of Issy-les-Moulineaux). The employment benefits of energy efficiency at the local level are largely the result of multiplier effects, as households and businesses shift expenditures from a capital-intensive sector (energy) to more labour-intensive sectors (e.g., local services). 
- $\quad$ Cities can also be effective in greening industrial production by developing one-stop support services for green industry start-ups (Los Angeles); enabling existing businesses to reach energy conservation goals (the Eco-Efficiency Partnership in British Columbia) or realise profits through energy recycling (Kitakyushu and other Japanese "Eco-Towns"); providing training tailored to local labour market needs (Oakland Apollo Alliance); and by developing awareness programs to raise consumers’ preferences for green products (Blacktown, Australia Solar City project).

- Cities and regions can take the lead on long-term, locally tailored eco-innovation and leverage private investments in energy-saving technological solutions. Green-tech innovation is often highly concentrated in a few dynamic clusters, usually located near cities (urban regions in the OECD produced $73 \%$ of green patents in the renewable energy sector over 2004-2006). Cities can play a facilitative role, through the development of networking platforms for enhanced knowledge-sharing in climate change mitigation and adaptation, and an enabling role, through well-designed support for R\&D and for industrial and public research collabouration in ecoinnovation clusters. Cities can also promote the development of green clusters by facilitating synergies and by enabling private R\&D through joint ventures (e.g. the Lahti Cleantech cluster in Finland, with 20 new clean-tech companies and more than EUR 30 million in total investment). Finally, local and regional governments can support the activities that follow the research and development of new environmental technologies, for example by sponsoring environmental technology verification schemes or financing and disseminating results of demonstration tests (e.g. Adelaide Solar City Program, Australia or Research Triangle Park, USA). 


\section{INTRODUCTION}

Climate change has become one of the most pressing issues of our new century. World greenhouse gas emissions (GHG) have roughly doubled since the early 1970s, reaching about 74 gigatons $\mathrm{CO}_{2}$ equivalent (Gt CO2equ) in 2005 (OECD, 2009a). The OECD projects that if we continue on the present trajectory, global greenhouse gas emissions will increase by more than $50 \%$ by mid-century, causing world temperatures to rise from 1.7 to 2.4 degrees Celsius $\left({ }^{\circ} \mathrm{C}\right)$ above pre-industrial levels by 2050, and from 4 to $6{ }^{\circ} \mathrm{C}$ or more in the long-term (OECD, 2009a). Even worse, the planet's natural system to absorb carbon will peak by mid-century and then likely weaken making climate change much more acute (IPCC, 2007a). While there is significantly uncertainty about the costs of inaction, it is generally agreed that failing to tackle climate change will have significant implications for the world economy. Stern (2007) asserts for instance that the total economic and welfare costs of policy inaction could equate to as much as a permanent $14.4 \%$ loss in average world consumption per capita, when both market and non-market impacts are included. Even more worrisome, increasing greenhouse gas emissions are likely to lead to massive upheavals: floods and droughts, more violent storms, more intense heat waves, and escalating conflicts over food and water and resources.

Dealing with climate change will require a broad set of instruments. If we want to meet the objective of cutting emission by at least $30 \%$ by 2050 , i.e. the level generally agreed on to prevent dangerous anthropogenic interference, and minimise the costs involved, a number of policy instruments must be put in place or expanded so as to create the proper incentives to ensure that emissions are reduced first where it is cheapest to do so. The OECD stresses that market-based mechanisms such as cap and trade systems, carbon tax, or both, should be key elements of the policy mix to help build a global carbon market (OECD, 2009a). This will need to be complemented by removal of subsidies to fossil fuel energy and reallocation of the financial resources into increased investment in clean energy R\&D. Moreover, as market imperfections (monitoring, enforcement, and asymmetric information problems) prevent some emitters from responding to price signals, complementary instruments, including standards (e.g. building codes, electrical appliance standards, diffusion of best practices) and information instruments (e.g. eco-labelling) are necessary.

Cities have a key role to play in the global agenda for addressing the challenge of climate change. Today, approximately half of the world's population lives in cities; by 2050, that proportion will probably have increased to two-thirds. Cities are responsible for the bulk of national output, innovation and employment, and they constitute the key gateways of transnational capital flows and global supply chains (OECD, 2006).As key engines of the global economy, cities are responsible for the bulk of national output, innovation and employment, and they constitute the key gateways of transnational capital flows and global supply chains (OECD, 2006). It is therefore not surprising that cities consume a great majority - between 60 to $80 \%$ - of energy production worldwide and account for a roughly equal share of global greenhouse emissions. All projections indicate that this trend will continue as urban populations grow. If urbanisation is contributing to the increase in $\mathrm{CO}_{2}$ emissions, many cities are also likely to be affected by climate change in increasingly detrimental ways. The tendency for cities to be located in coastal areas increases their vulnerability to water-related calamities, increasing the risk to property, livelihoods and urban infrastructure.

How cities develop is part of the climate problem, but it can also be part of the solution. While the international community has been struggling to agree on common objectives and targets to fight global 
warming, a growing number of cities and regions have taken initiatives to reduce their energy use and CO2 emissions. Faced with the two-way relationship between climate change and urban development, cities and regions in many OECD countries have key responsibilities in the urban sectors that can provide valuable strategies for fighting and adapting to climate change, including policies that affect transportation and the built environment.

Yet, in the debate on a global agenda to tackle climate change, the role of cities in addressing the issue has been quite decoupled from national and international policy frameworks (OECD, 2009b). Cities face the challenge of determining the range of local responses that will result in GHG emission reductions, protection against climate change impacts, and economic growth. The effectiveness of local-level policy implementation depends on the potential for policies to meet climate change mitigation and adaptation goals while pursuing economic growth and local fiscal sustainability. Based on statistical data from the OECD regional and metropolitan databases, empirical OECD studies and results from different questionnaires, this report discusses the relationships between cities and climate change, the rationale for taking action at the urban scale, the effectiveness of some local strategic and sectoral policy tools in addressing climate change issues as well as local finance and growth and job opportunities from the green economy.

Section 1 analyzes the relationship between cities and climate change. It shows that concentration of population is clearly linked with concentration in output and energy use, one of the main drivers of $\mathrm{CO}_{2}$ emissions. However, it is not cities, or urbanisation per se, that contribute to GHG emissions, but rather the way in which people move around the city, the sprawl that they produce, the way in which people use energy at home and how buildings are heated that make cities the great consumers of energy and polluters that they are. Cities' emissions can vary depending on their lifestyles, spatial form, public transport availability and sources of energy.

Because of the complex and fixed nature of urban infrastructure, cities - especially those located in coastal areas - will be also be impacted by the change in the global temperatures. This is a well known phenomenon, affecting cities in both developed and developing countries, but adaptation policies at the local level have received little attention. Climate impacts specific to urban areas are discussed in Section 2. Adapting to climate change impacts requires significant public investments to address expected increases in flooding, storms, heat extremes, drought and water scarcity. Inaction now can further increase the costs of climate change damage, as well as of future adaptation measures. Disruptions in infrastructure systems can clearly create inefficiencies and slow down economic progress, imposing costs on the local and national economy.

The benefit of implementing urban policies to tackle climate change is demonstrated in Section 3. The traditional trade-off between economic growth and environmental objectives observed at a macroeconomic level, referred to as abatement costs for climate change policies, can be alleviated when urban policies such as densification or congestion charges are introduced. This is the result of a general equilibrium model that incorporates an urban module. Under a baseline global scenario with Kyoto emissions reduction objectives, the overall economic costs can be reduced over time thanks to additional actions taken at the local level. This is due to complementarities with other objectives, such as lower local pollution and the enhancement of city attractiveness and competitiveness through lower local pollution. The section also discusses other types of local co-benefits of climate change policies, including health improvements and quality of life, cost savings and increased efficiency, energy security, and infrastructure improvements.

With the help of strategic planning tools, policies on the local level can be a focus for complementary policy packages that bring together territorial strategies and sectoral policies. Section 4 will review policy tools to address climate change at the local level such as land-use zoning, natural resources, transportation, building, waste and water policies. Whilst effective policy packages should reflect the specificities of 
individual urban regions and be tailored to local energy consumption patterns, it is essential to identify the impact and benefits that policy sectors can have on each other to promote the cost-effectiveness of public actions. The question of effective urban policy packages intersects with the concept of urban density, a major driver of $\mathrm{CO}_{2}$ emissions. This section also assesses different characteristics of densification policies and their effectiveness in meeting environmental goals whilst remaining attractive in the long term.

Measures to reduce GHG emissions and adapt to expected climate change impacts will put additional pressure on city budgets and increase the need for additional resources. Section 5 discusses the different forms of upward pressures on city budgets that can be anticipated to respond to climate change issues. Although investment in climate change and urban sustainability policies can produce co-benefits, such as increased accessibility and greater city attractiveness, these investments will present an additional burden on most cities' budgets. A number of existing fiscal instruments and incentives already at cities' disposal could be considered as instruments for achieving climate change and urban sustainability goals. Carbon markets and access to financial capital may emerge as promising new funding sources.

Last but not least, the Section 6 discusses the role of cities in contributing to a new global Green Growth model at a time when governments must reduce their carbon footprint while steering the world economy out of an economic crisis. The section highlights the main policy areas through which city and regional governments can contribute to green growth objectives, including developing and maintaining green public infrastructure, improving the eco-efficiency of production, boosting demand by fostering the greening of consumption preferences and facilitating green innovation. Although tools for assessing the effectiveness of such policies in reaching their objectives of job creation and output growth need to be developed, the section provides a solid analytical framework that can orient future research on this crucial issue. 


\section{REFERENCES}

IPCC (Intergovernmental Panel on Climate Change) (2007a), Climate Change 2007: The Physical Science Basis, Contribution of Working Group II to the Fourth Assessment Report of the Intergovernmental Panel on Climate Change, S. Solomon,, D. Qin, M. Manning, Z. Chen, M. Marquis, K.B. Averyt, M. Tignor and H.L. Miller (eds.), Cambridge University Press, Cambridge.

OECD (2006), Competitive Cities in the Global Economy, OECD, Paris.

OECD (2009a) The Economics of Climate Change Mitigation: Policies and Options for Global Act ion beyond 2012, OECD, Paris.

OECD (2009b), “Cities, Climate Change and Multilevel Governance”, Environment Working Papers, OECD, Paris.

Stern, Nicholas (2007), The Stern Review Report, Cambridge University Press, Cambridge, UK. 


\section{URBANISATION, ECONOMIC GROWTH AND CLIMATE CHANGE}

There is an increasing recognition of cities and urban regions' role as key engines of economic growth, job creation and innovation - as well as their role as the major contributors to global warming. Higher concentrations of population are generally linked with higher energy use, which is one of the main drivers of greenhouse gas (GHG) emissions, particularly carbon dioxide $\left(\mathrm{CO}_{2}\right)$ emissions. This worldwide trend will only be reinforced as growing urbanisation - particularly in non-OECD countries - results in increased overall energy demand, and therefore increased GHG emissions. However, cities present great opportunities for reducing countries' contributions to climate change. In OECD countries, where urbanisation is already well advanced, the main drivers of GHG emissions are energy consumption patterns, including how people move around metropolitan regions and the amount of energy they consume for daily home and work activities. Urban density and spatial organization are key factors that influence energy consumption, especially in the transportation and building sectors. This section discusses the relationships between urbanisation, economic concentration, energy use and GHG emissions in OECD countries and provides the main rationale for taking action at the urban scale: urban structure and form do matter for climate change.

\subsection{The worldwide urbanisation process}

Urbanisation is a global phenomenon and is expected to continue for decades to come (OECD 2006; UN 2008). According to the United Nations, roughly half of the world's population lives in urban areas, ${ }^{1}$ and this share is increasing over time, projected to reach $60 \%$ by 2030 (Figure 1.1). However, although urbanisation growth within the OECD is still ongoing, most of the urban population growth up to 2030 will occur in developing countries (Figure 1.2). Developing countries are projected to have urban growth rates roughly double those of OECD countries in the 2005-2030 timeframe (UN, 2008). China, for instance, which is already the largest urban nation in the world, will see its current urban population rising from 600 to 900 million by 2030. As of 2015, the newly added urban population will be larger than the total population of many OECD countries such as Germany, Japan, Mexico, France (Kamal-Chaoui in OECD, 2008a). Though the pace of urban growth will be highest in smaller towns and cities in countries in Africa and Asia, the proportion of the world's population living in so-called megacities, or urban centres with more than 10 million people, is also predicted to rise to $12 \%$ in 2025 , from about $9 \%$ today, and the number of megacities will rise from 19 to 27 (United Nations, 2008).

World urbanisation trends are currently catching up with the transformations that already took place in OECD countries over the last century. Urbanisation is a process that the OECD has already experienced: by 1950, urban population was already greater than rural (Figure 1.1). That same milestone occurred in global urban population in 2006. In a way, the challenges that are brought about by an increasing urban population have already been faced by OECD countries for more than half a century. If global urbanisation in the first half of the 20th century took place predominantly in European cities, population size has made Asia the continent with the highest urban population in the world today (Figure 1.2). Africa is also experiencing important transformations, as it is home to some of the fastest-growing cities. The UN forecasts a decline in rural population after 2020, while in the OECD shrinking rural population has been a

1. This refers to the population living in areas classified as urban according to the criteria used by each country (United Nations Population Database, 2009). 
trend throughout the second half of the $20^{\text {th }}$ century. The UN expects urban population to steadily grow both worldwide and in the OECD, though at a slower pace in the OECD. By 2050, 70\% of world population - and $86 \%$ for OECD countries - will live in urban areas.

Figure 1.1 Urban and Rural Population in the World and the OECD

Absolute population numbers

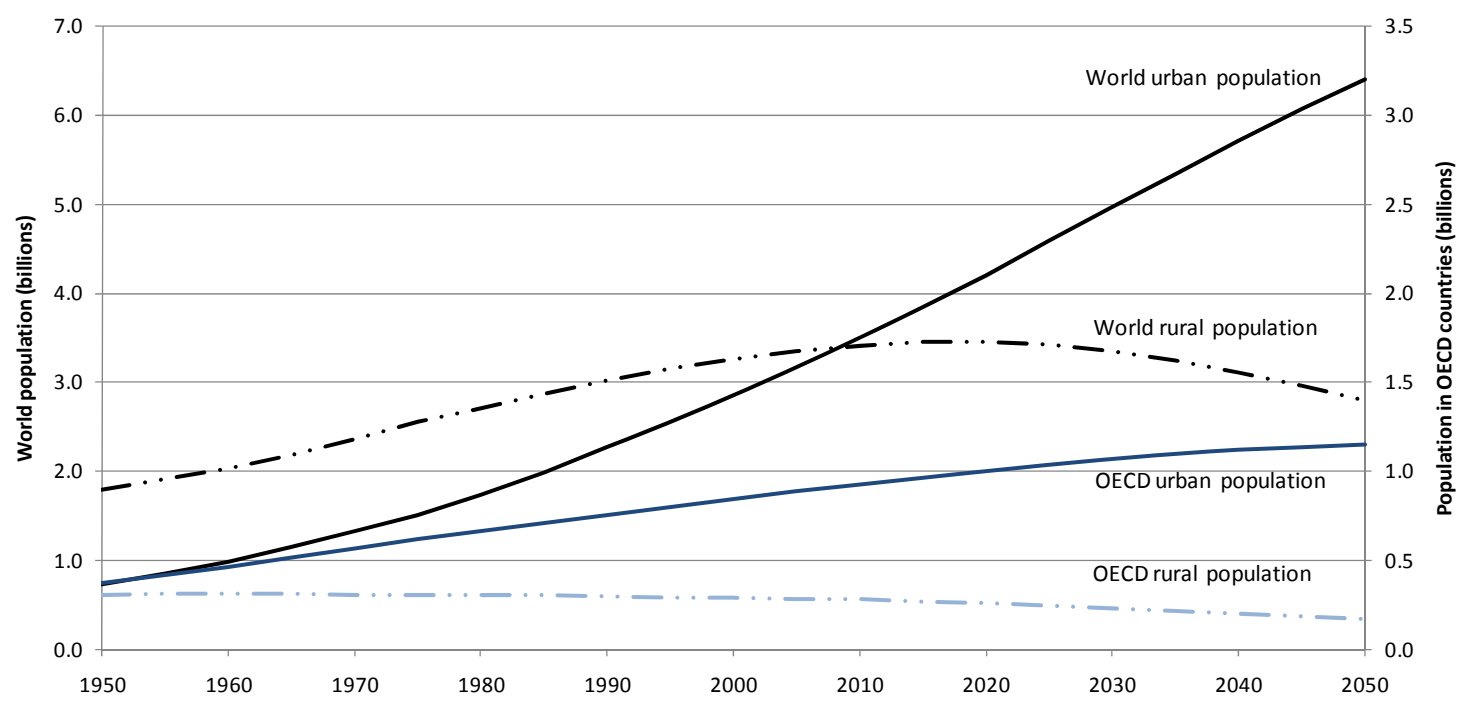

Source: Own calculations based on data from the UN Population Database (2009). 
Figure 1.2 Trends in Urbanisation by Continent

Urban population and growth (1950-2050)

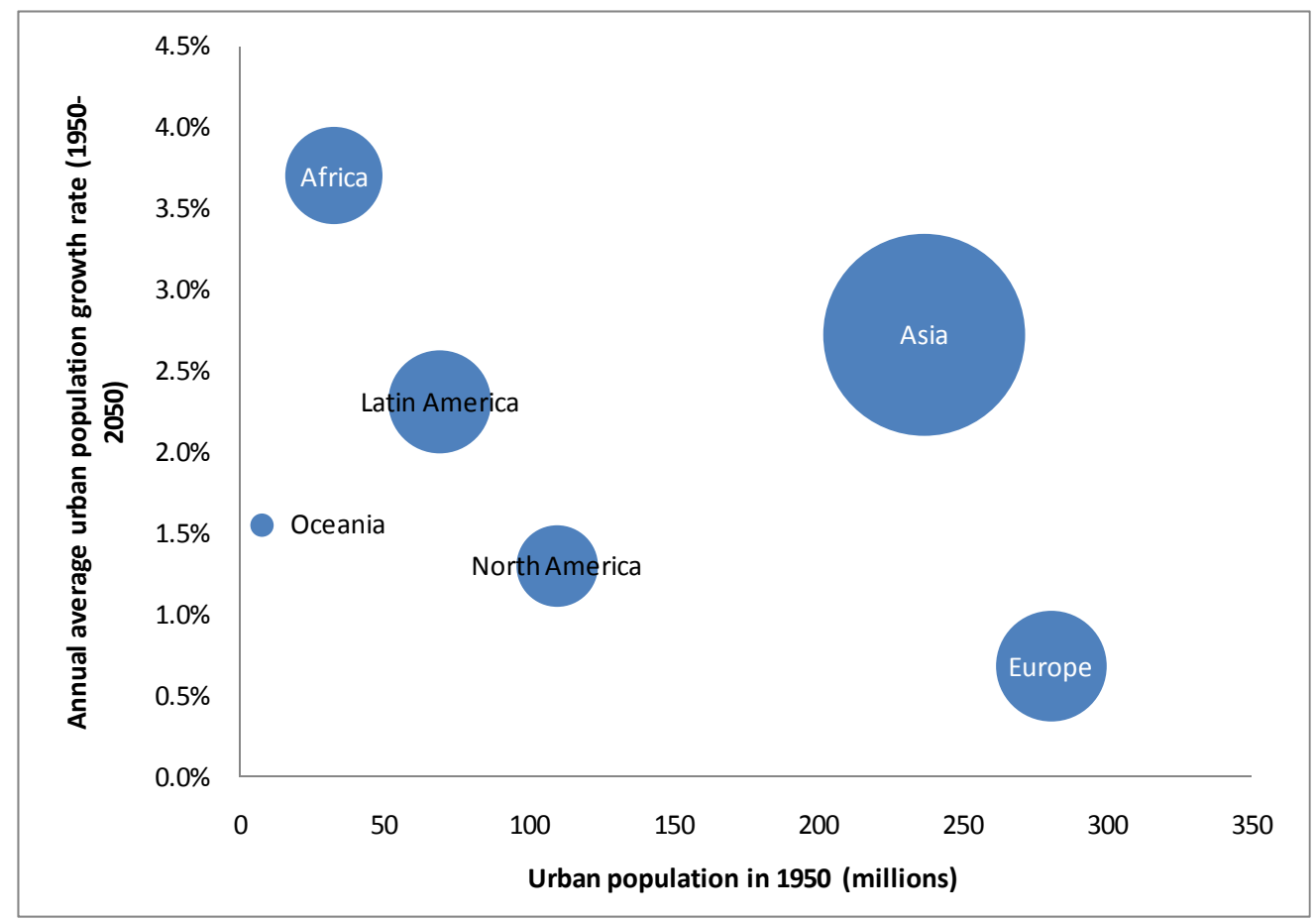

Notes:

Urban areas are defined according to the UN Population Database which takes into account each country's own definition of urban. Bubble size depicts population size in 2010.

Source: Own calculations based on UN Population Database (2009).

There is no agreed-upon definition of an urban area; therefore a number of methods exist to analyse trends in urban areas. In this report, three units of analysis referring to urban areas are used:

- Urban areas. These refer to urban areas as they are defined by the national authorities of each country. In particular, this is used when referring to UN data. As this unit of analysis refers to single county or municipality-level areas they have the advantage that national statistical institutes frequently make data available at that level. However, often these urban areas are too small or too large to account for a city.

- Predominantly urban areas (PU). These are defined by the OECD Regional Typology and used throughout this report. They are regions where the population living in high-density areas (150 inhabitants per square kilometre) represents at least half of the population in that region. Although PU areas are also based on administrative areas, they are larger than a single municipality. The OECD has been able to produce comparisons across regions and countries using PU areas, but they remain too large for medium-sized cities in some case and too small for metropolitan areas. 
- Metropolitan areas (functional areas). These refer to commuting areas as defined by the OECD Metropolitan Database, which takes into account population density, net commuting rates and type of region. These are typically large cities comprised by a number of administrative and adjacent areas where economic relations are intense. Metropolitan areas are typically defined as concentrations of population and economic activity that constitute functional economic areas covering a large number of authorities (OECD, 2006).

In the OECD, urbanisation is on the increase in almost every country. Taking into account predominantly urban areas (PU) in the OECD as defined by the OECD regional typology ${ }^{2}$, today more than $53 \%$ of the total population is living in urban areas; this number rises to almost $83 \%$ if we include intermediate regions (IR) ${ }^{3}$, less densely populated areas characterised by systems of medium-sized cities. Over 1995-2005, population growth in OECD countries has been more dynamic in urban (PU) areas and intermediate (IR) areas than in rural areas. Only two countries (Belgium and Ireland) show stronger demographic expansion in rural areas (Figure 1.3). What is more, with a few exceptions in Eastern European countries, all OECD member countries have positive urbanisation growth rates between 1995 and 2005. If PU areas are taken into account, all countries with urbanisation shares higher to the OECD average are becoming increasingly urbanised (Figure 1.4, see quadrant 1 located above right). As a result, the OECD population is becoming increasingly concentrated in a few places (Figures 1.5, 1.6 and 1.7).

2. Throughout the document OECD definition of urban and rural refers to predominantly urban (PU) and predominantly rural (PR) regions. The former refers to regions in which the share of population living in rural local units is below 15\%; the latter refers to regions in which the share of population living in rural local units is higher than $50 \%$. In order to classify regions as PU or PR it is necessary to define local units within each region to their degree of rurality. A local unit is therefore rural if its density is lower than 150 inhabitants per square kilometer.

3. Intermediate (IN) regions are those with a share of population living in rural local units between $15 \%$ and $50 \%$. 
Figure 1.3 Population Growth in OECD Regions

Annual population growth rates by types of region (1995-2005) according to PU, IN, PR

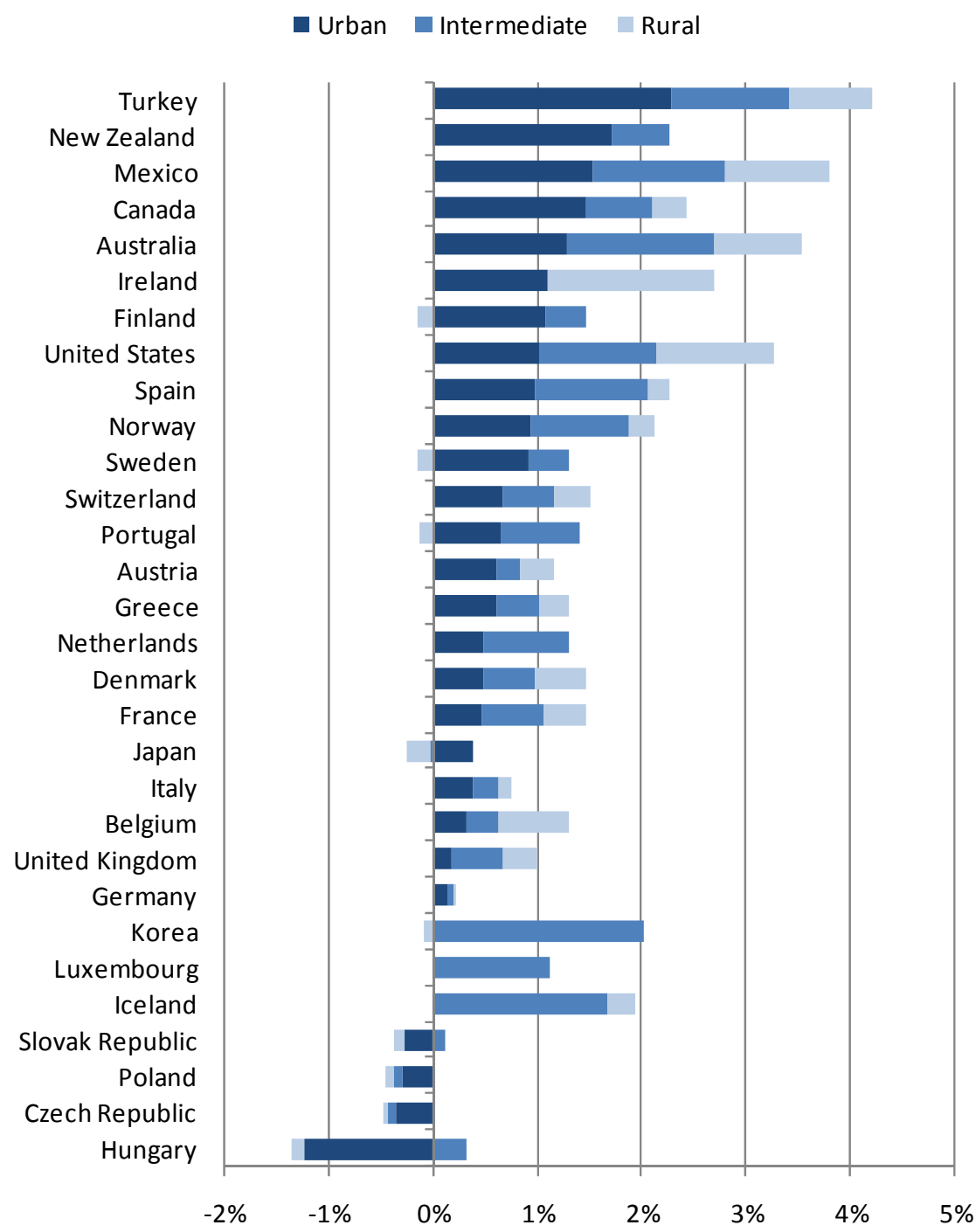

Notes: In some cases like Korea, intermediate regions growth can be accounted by for growth in cities of a smaller size in wider areas that are considered to be intermediate. For instance Gyeonggi-do is an intermediate region that surrounds almost entirely the Seoul area; given that there has been considerable business growth outside the administrative area of Seoul after the deconcentration policy, it is possible that part of that growth has gone to Seoul's suburbs located in Gyeonggi-do.

Source: Own calculations based on data from the OECD Regional Database. 
Figure 1.4 Urbanisation in OECD Countries

Urbanisation levels and growth according to PU areas (1995-2005)

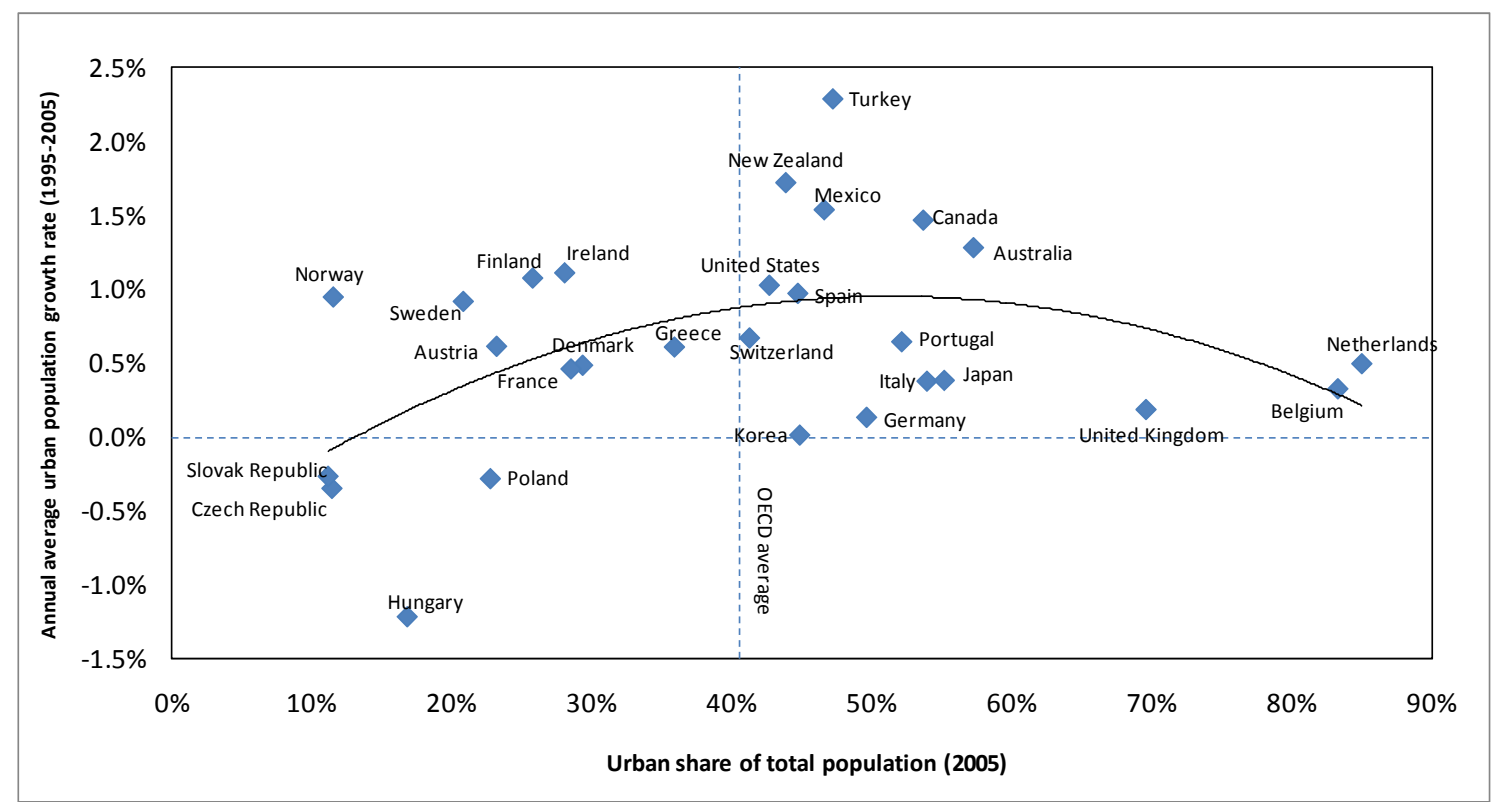

Notes:

Urban share of total population by country refers to population in urban regions as a proportion of total population.

Iceland and Luxemburg were not included in the sample as the OECD Regional Database identifies no predominantly urban (PU) regions in those countries.

Source: Own calculations based on data from the OECD Regional Database

Figure 1.5. Urban Concentration in Europe

Population density at TL3 level (inhabitants per square km) in European countries in 2005

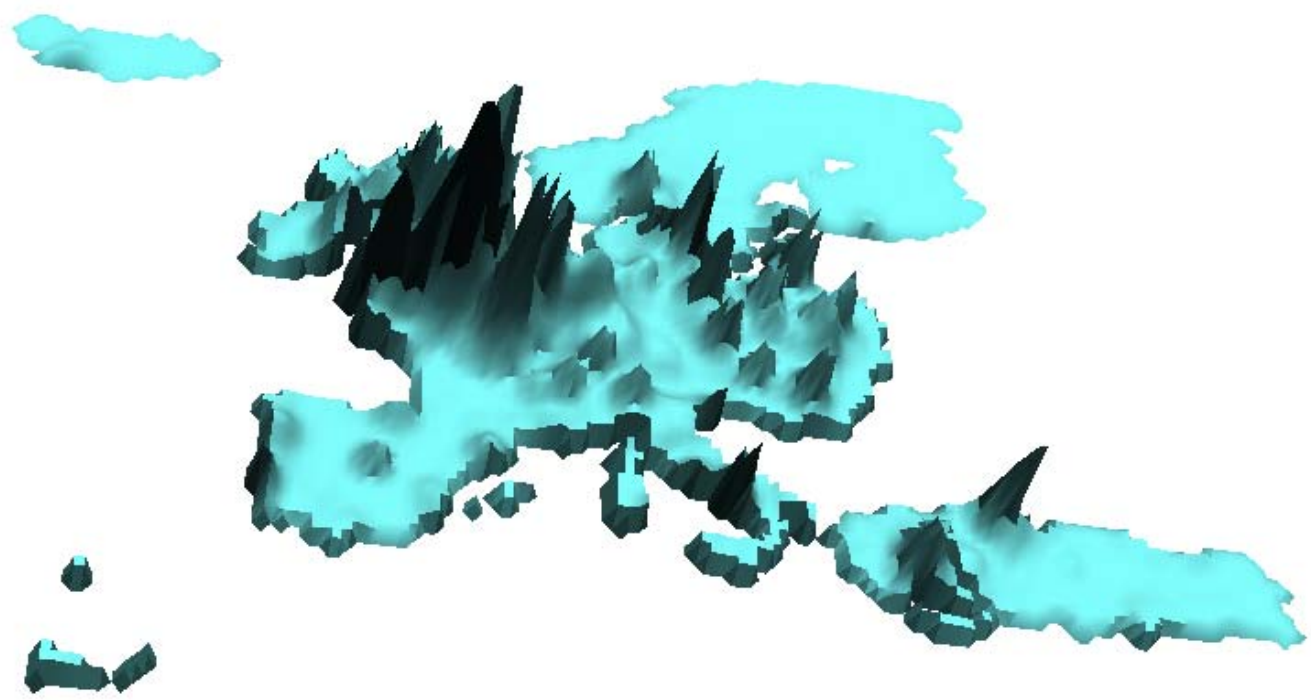

Note: OECD regions are classified at two levels: Territorial Level 2 (TL2) and Territorial Level 3 (TL3).

Source: Own calculations based on data from the OECD Regional Database. 
Figure 1.6 Urban Concentration in Asian OECD Countries

Population density at TL3 level (inhabitants per square km) in Japan and Korea in 2005

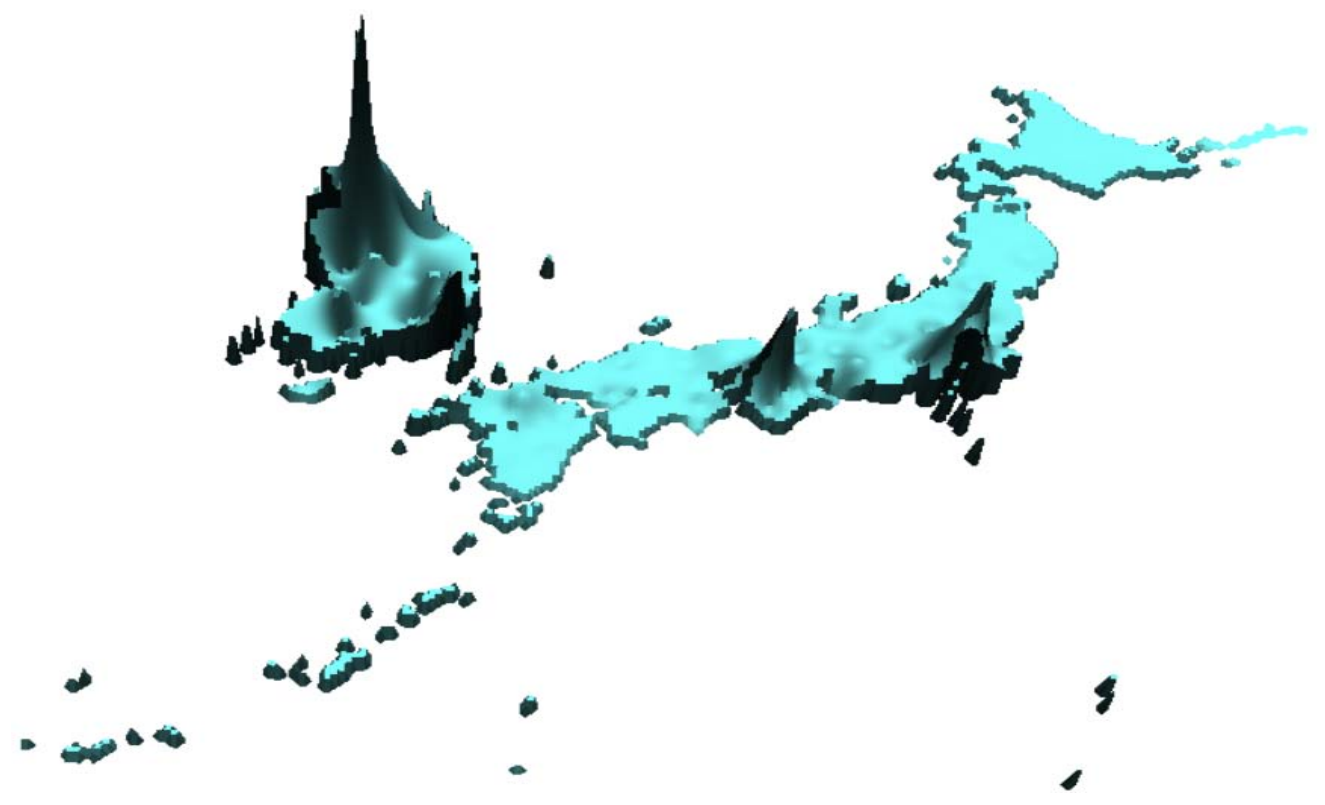

Note: OECD regions are classified at two levels: Territorial Level 2 (TL2) and Territorial Level 3 (TL3).

Source: Own calculations based on data from the OECD Regional Database.

Figure 1.7 Urban Concentration in North America

Population density at TL3 level (inhabitants per square km) in 2005

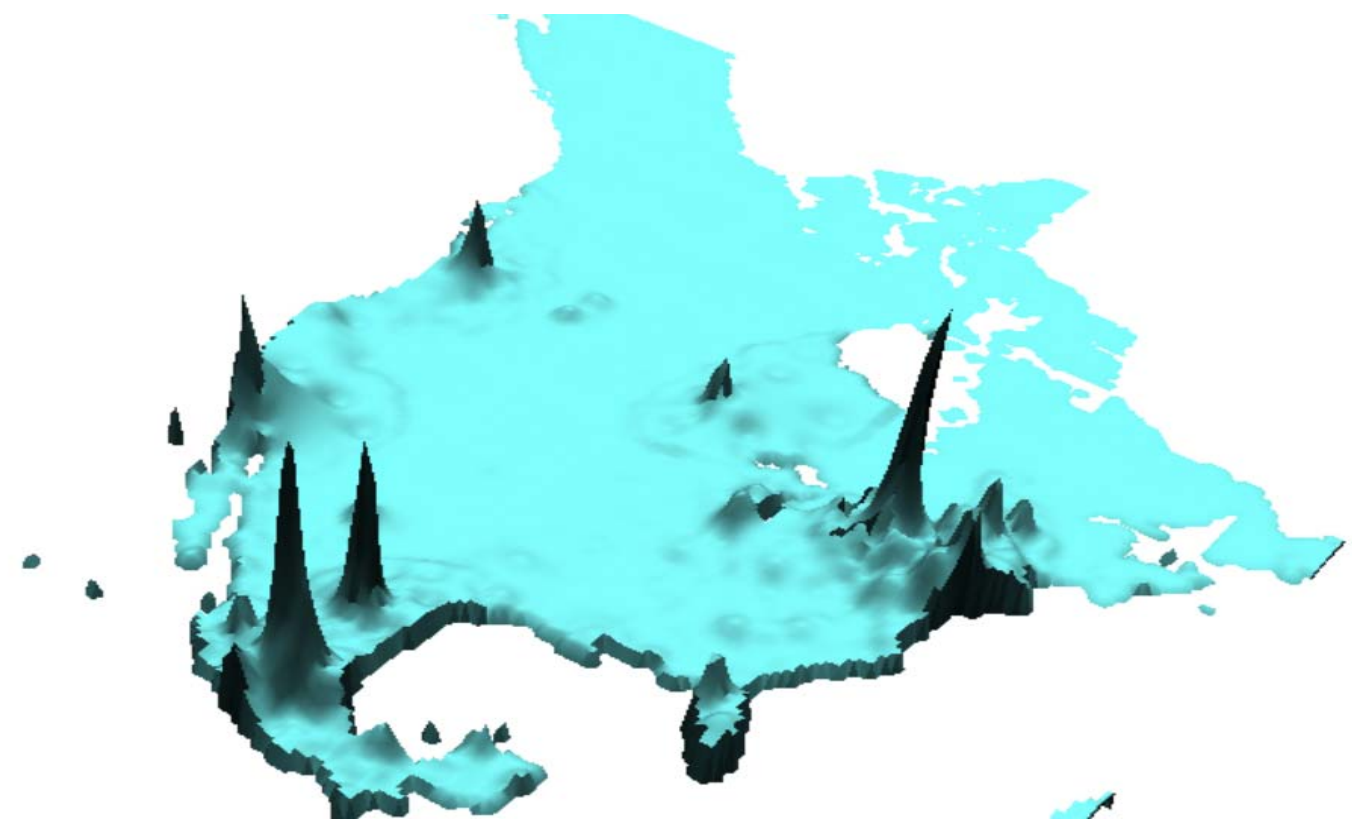

Note: OECD regions are classified at two levels: Territorial Level 2 (TL2) and Territorial Level 3 (TL3).

Source: Own calculations based on OECD Regional Database. 
Over 70\% of people in the OECD who live in PU areas are in areas of more than 1.5 million people. In fact, urban populations locate increasingly according to city size. Thus, the share of total urban population living in smaller cities (between 100,000 and 500,000 people) is lower than the population living in any other type of cities and they also grow slower ( $0.4 \%$ annually on average). Medium-sized cities (between 500,000 and 1 million people) grow faster than smaller cities but more slowly than larger cities (Figure 1.8).

Figure 1.8 Urbanisation and City Size

Urban population and growth (1995-2005) according to population size of PUs

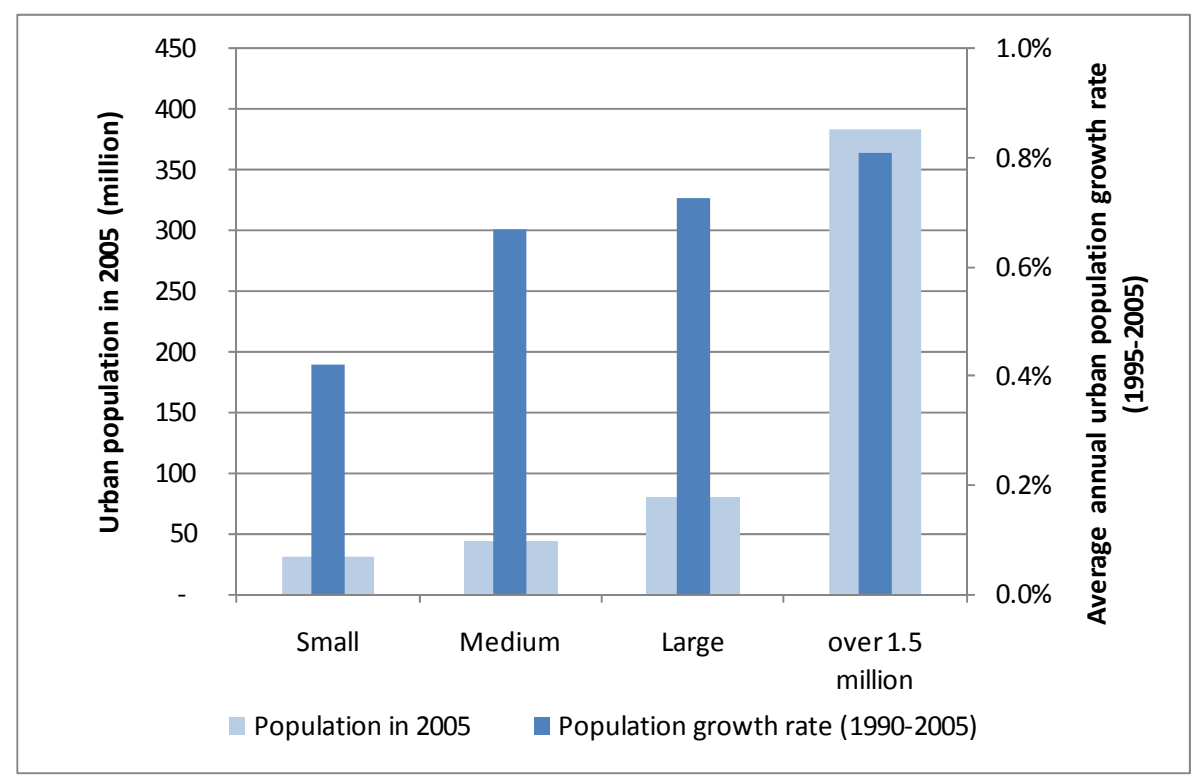

Notes:

This analysis was carried out using only predominantly urban (PU) areas.

Small cities are PUs with population between 100000 and 500000 people. Medium-sized cities are PUs with population between 500000 and 1 million people. Large cities are PUs with population between 1 and 1.5 million people.

Source: Own calculations based on OECD Regional Database.

Trends among metropolitan regions in the OECD show similar results. In some cases, a single metropolitan region accounts for nearly half of the national population. Seoul, Randstad and Copenhagen represent between 44 and $48 \%$ of their respective national populations. With a few exceptions, namely Berlin, Manchester, Cleveland, Birmingham, Budapest and Pittsburgh, metropolitan areas in the OECD have experienced an increase in population between 1995 and 2005 (Figure 1.9). On average, OECD metropolitan areas have been growing at an annual pace of almost $1 \%$ since 1995, but cities such as Phoenix, Atlanta and Toronto have observed growth rates several times the average and in many others such as Ankara, Miami, Guadalajara and Washington, metropolitan population expansion has grown at least twice as fast as the average. Madrid, Seoul, Sydney and Mexico City also have experience aboveaverage population increases. 
Figure 1.9 Population Growth in OECD Metropolitan areas

Average annual growth rates 1995-2005

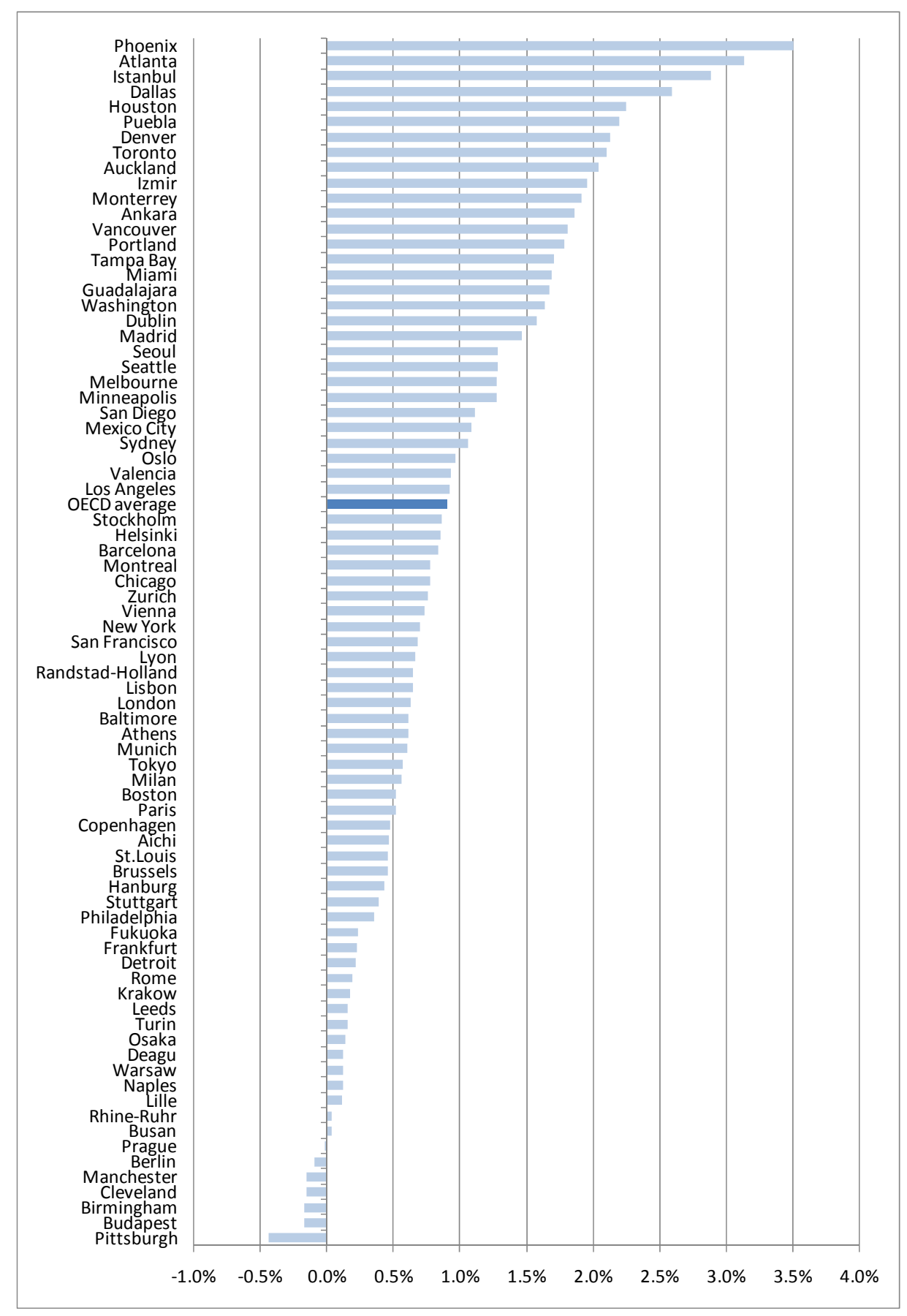

Note: The period of growth in the case of Auckland is 1996-2005.

Source: Own calculations based on data from the OECD Metropolitan Database. 


\subsection{Cities and economic concentration}

Urban areas are home to concentrations not only of people, but also economic density and, often, productivity. This is often the reason for a pooled labour market that increases the possibility of skillsmatching between workers and firms. Firms also agglomerate seeking to reduce risks of contract defaulting, as they have access to a wider set of skills and can establish linkages with suppliers and buyers. Cities are also often places where knowledge spillovers take place, benefiting not only the city but also the wider regional area. Thus, in approximately half of OECD countries, more than $40 \%$ of the national GDP is produced in less than $10 \%$ of all regions, which account for a small share of the country's total surface and a high share of the country's population (OECD, 2009c).

Urbanisation is part of the development process and is generally associated with higher income and productivity levels. In OECD countries, higher urban population shares are associated in most cases with higher per capita GDP than their national average (Figure 1.10). In part, such higher per capita GDP can be attributed to metropolitan areas. In many OECD countries, one single metropolitan area produces one-third (e.g. Oslo, Auckland, Prague, Tokyo, Stockholm, London, Paris) to one-half of the national GDP (Budapest, Seoul, Copenhagen, Dublin, Helsinki, Brussels) (Figure 1.11). Thanks to the benefits of agglomeration economies, most OECD metropolitan regions with more than 1.5 million inhabitants feature a higher GDP per capita, a higher labour productivity and higher employment levels than their national average. Disaggregating GDP into four main factors reveals that, for the most part, higher income in metropolitan areas can be attributed to higher labour productivity levels (Figure 1.11).

However, the effect of labour productivity can be nuanced -or aggravated — by demographic or labour-market factors. In particular, the size of the pooled labour market (working-age population as a proportion of total population) and the way in which labour markets function (depicted for instance by employment rates) are important factors in determining how GDP in metropolitan areas diverge from the national level. Their effect is such that most metropolitan areas are probably held back by labour marketproductivity relationships. The highest GDP differentials with respect to the national level can be found in metro-regions such as Warsaw, Monterrey, Washington DC and Paris to a great extent due to labour productivity, but they could also being held back by poorer performance - when compared to the national level - in labour market indicators such as participation rates. The size of the labour market thus, a relevant factor in determining agglomeration and performance of metro-regions. At the other end of the ranking, metro-regions with below national average GDP levels such as Daegu, Naples or Berlin are lagging behind precisely due to lingering productivity, participation and employment rates and only marginally helped by demographics (Figure 1.11). However, mid-ranking metro-regions such as Chicago, Hamburg or Puebla are mostly being held back by the size of the labour market. 
Figure 1.10. Urbanisation and Income

Urban share of total population (PU) and per capita GDP in OECD countries

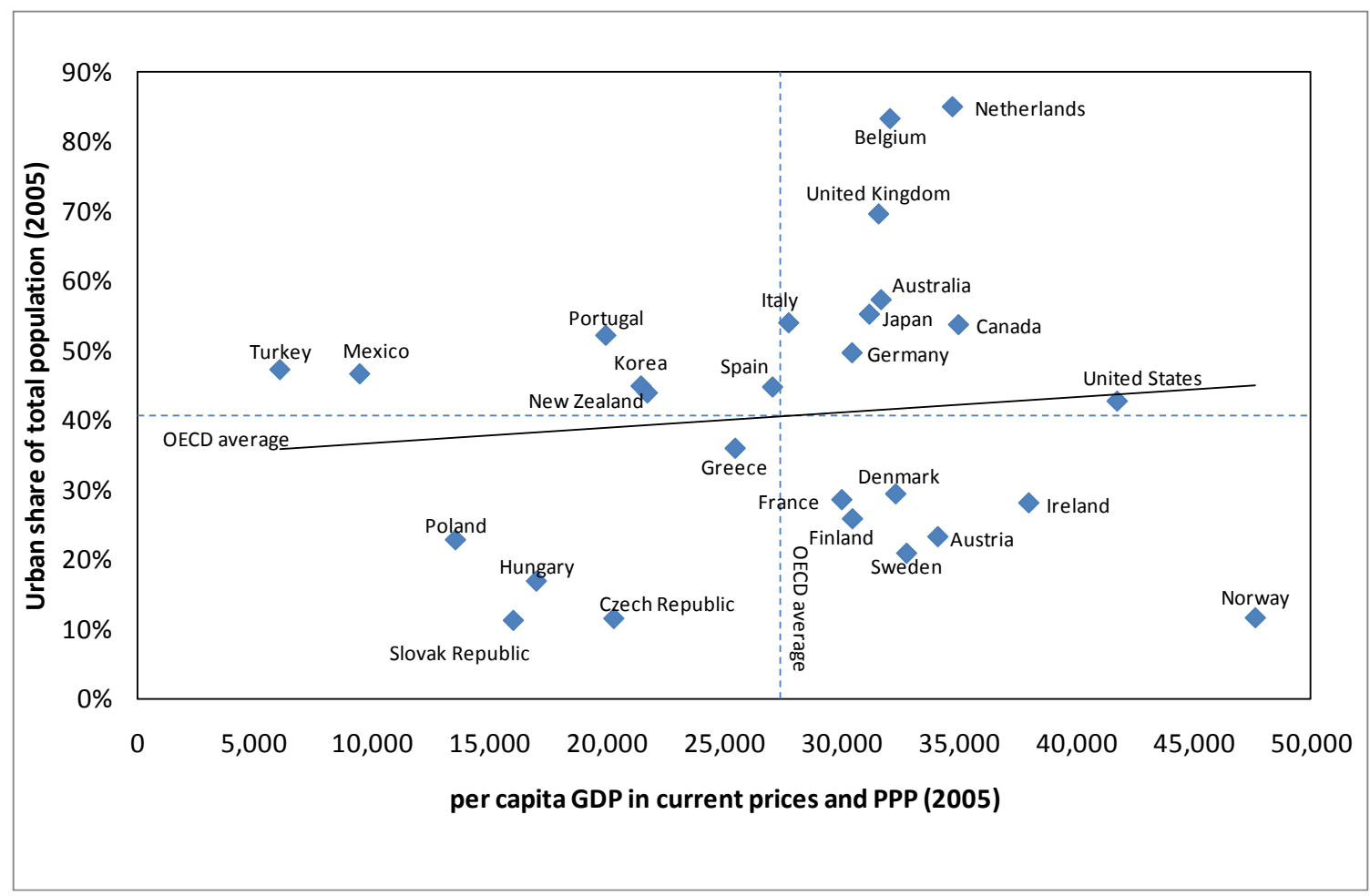

Notes:

Urban share of total population by country refers to population in urban regions as a proportion of total population.

Iceland and Luxemburg were not included in the sample as the OECD Regional Database does not identify predominantly urban (PU) regions in those countries.

Switzerland was not included as GDP figures at sub-national level in that country are not available.

Mexico's per capita GDP data refers to 2004; New Zealand's per capita GDP data refers to 2003; Turkey's per capita GDP refers to 2001.

Source: Own calculations based on data from the OECD Regional Database. 
Figure 1.11. Factors determining per capita GDP Differentials

Labour productivity, employment and participation rates, demographic factors among OECD metro-regions with respect to their national average (2005)
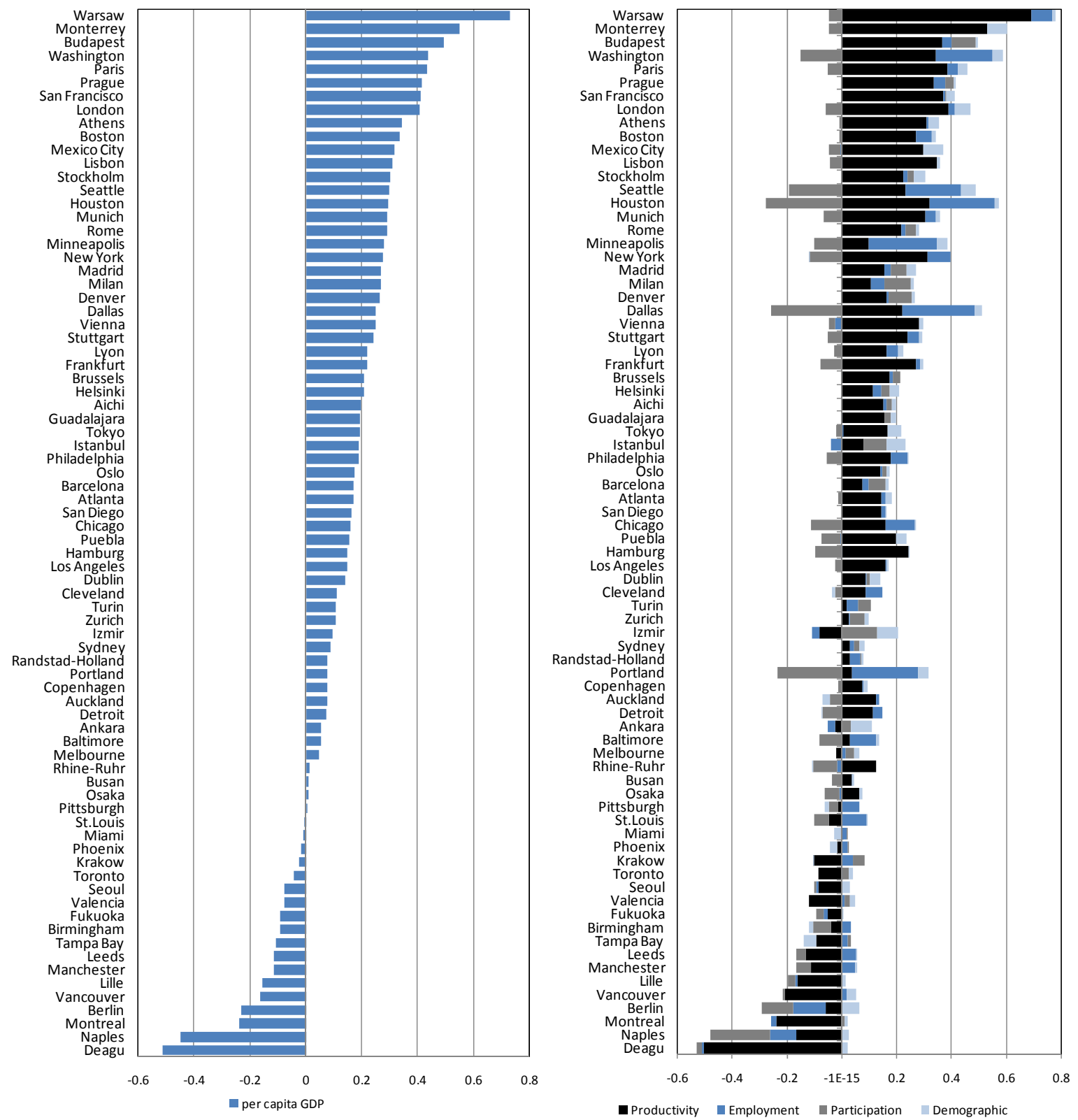

Notes:

Per capita GDP can be disaggregated into four components: Productivity, Employment, Participation and Demographic.

The Demographic component represents the size of the pooled labour market of each metro region compared to the national average. Labour market pool is calculated as the proportion of the working-age population over the total population.

Australia, Germany and US data refers to 2004; New Zealand data refers to 2003; Switzerland data refers to 2002; Turkey and Mexico data refers to 2000.

Source: OECD Metropolitan Database, 2009. 
Trends in urbanisation and population concentration are closely linked with concentration of economic activities and production (OECD 2009d). Concentration of population in predominantly urban (PU) regions has also produced economic agglomeration. For instance, in Europe, economic activity concentrates around the same places than population -an area that seems to stretch from London to western Germany (Figure 1.12). In Japan and Korea, economic density is clear in Osaka, Seoul and Tokyo (Figure 1.13). Such agglomeration effects are fuelled by higher wages that can be paid due to higher productivity levels that in turn attract more workers so that centripetal forces are set in motion.

Figure 1.12. Economic Concentration in Europe

Economic density at TL3 level (GDP per square $\mathrm{km}$ ) in 2005

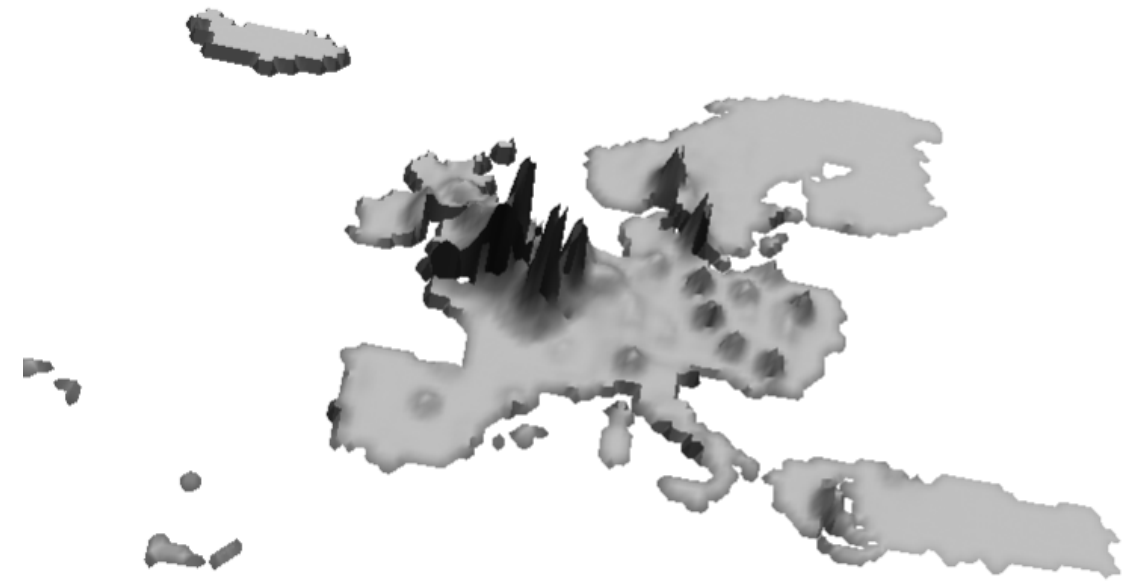

Note: OECD regions are classified at two levels: Territorial Level 2 (TL2) and Territorial Level 3 (TL3).

Source: Own calculations based on data from the OECD Regional Database. 
Figure 1.13. Economic Concentration in Japan and Korea

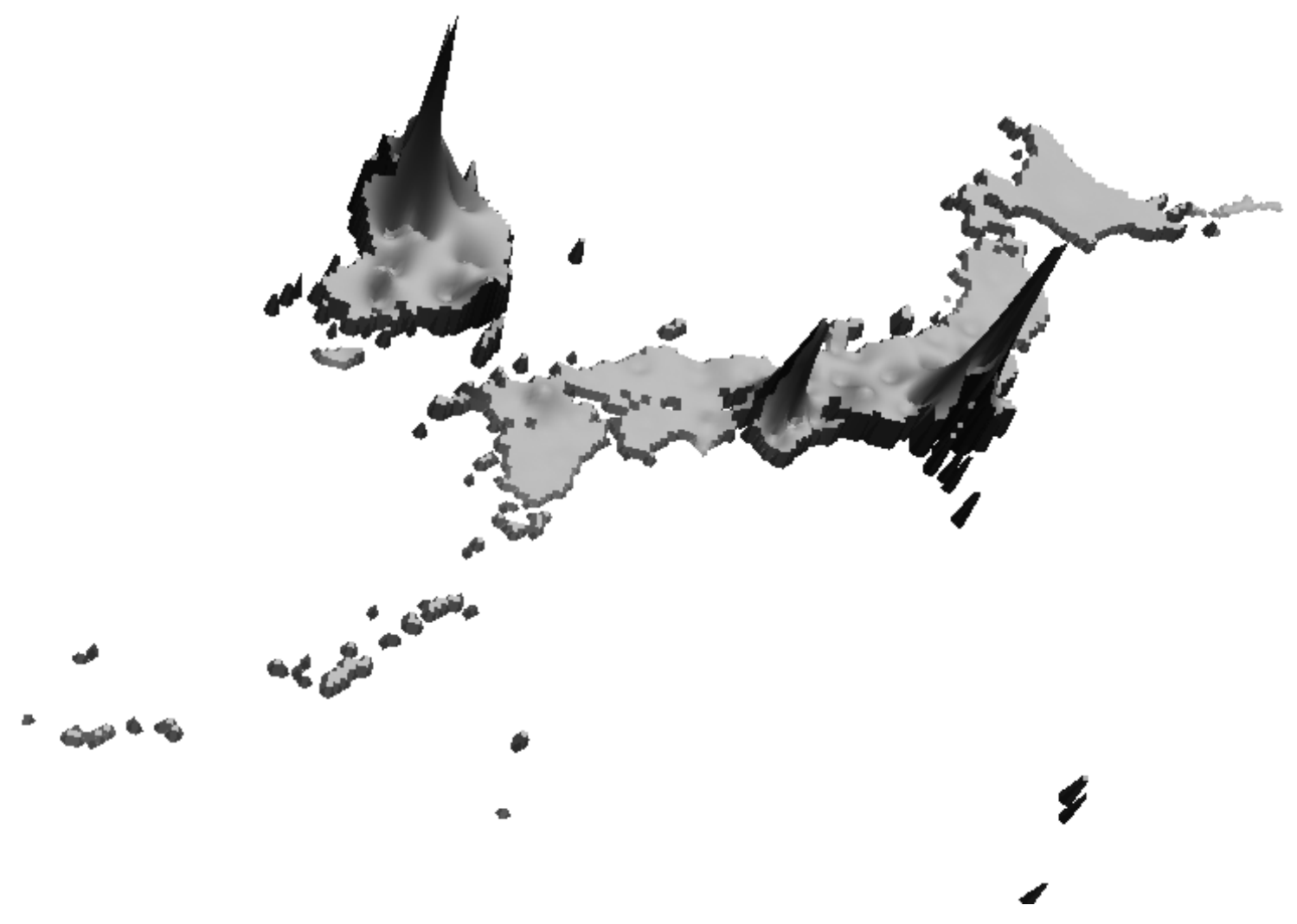

Note: OECD regions are classified at two levels: Territorial Level 2 (TL2) and Territorial Level 3 (TL3).

Source: Own calculations based on data from the OECD Regional Database.

However, the benefits associated with economies of agglomeration are not unlimited. Cities can reach a point where they no longer provide external economies and become less competitive (OECD 2009d). One of the main explanations of such mixed outcomes is linked with the existence of negative externalities, including congestion and other environmental costs such as high carbon-intensities and/or high vulnerability to climate change (these can be thought of as centrifugal forces). Negative externalities associated with large concentrations in urban areas raise the question of whether the costs borne by society as a whole are becoming unsustainable. As externalities, these negative attributes are not internalised by firms and households, and may only show up as direct costs in the long term. They include, for instance, high transportation costs (i.e. congested streets) and loss of productivity due long commuting times, higher health costs, higher carbon emissions and environmental degradation. Taking into account the costs and the benefits of agglomeration, it has been argued that urban concentration may entail a "privatisation of benefits and socialisation of costs" (OECD, 2009c).

\subsection{Economic growth, energy use and greenhouse gas emissions}

Cities use a significant proportion of the world's energy demand. Cities worldwide account for an increasingly large proportion of global energy use and $\mathrm{CO}_{2}$ emissions. Although detailed harmonised data is not available at the urban scale, a recent IEA analysis estimates that $60-80 \%$ of world energy use 
currently emanates from cities (IEA, 2008a). This can be attributed, in part, to changes occurring in urban areas in emerging and developing countries, including increased economic activity. As countries urbanise, they tend to shift from $\mathrm{CO}_{2}$-neutral energy sources (biomass and waste) to $\mathrm{CO}_{2}$-intensive energy sources, leading to an increasing proportion of $\mathrm{CO}_{2}$ emissions from cities (Jollands in OECD, 2008a). Cities (including towns) currently use over two-thirds of the world's energy, an estimated 7900 Mtoe in 2006, even though they only account for approximately $50 \%$ of the world's population.

Projections indicate that cities are likely to increase their share in the total world energy consumption. By 2030, cities are expected to account for more than $60 \%$ of the world's population and $73 \%$ of the world's energy use, or more than 12400 Mtoe in energy (IEA, 2008a). Of the global energy use projected by $2030,81 \%$ is expected to come from non-OECD countries. U.S. cities will likely account for $87 \%$ of U.S. energy consumption in 2030, compared with $80 \%$ in 2006. Urban areas in the European Union will likely account for $75 \%$ of EU energy consumption, up from 69\% in 2006. Cities in Australia could experience an increase from $78 \%$ to $80 \%$ of national energy consumption during the 2006 to 2030 period, and Chinese cities could account for $83 \%$ of national energy consumption compared with $80 \%$ today (IEA, 2007).

Cities contribute to climate change in three main ways: through direct emissions of GHGs that occur within city boundaries; through the GHG emissions that originate outside of city boundaries but are embodied in civil infrastructure and urban energy consumption; and through city-induced changes to the earth's atmospheric chemistry and surface albedo.

- Direct GHG emissions include carbon dioxide $\left(\mathrm{CO}_{2}\right)$, methane $\left(\mathrm{CH}_{4}\right)$, and nitrous oxide $\left(\mathrm{N}_{2} \mathrm{O}\right)$ emissions from energy conversion; $\mathrm{CH}_{4}$ emissions from the landfill decomposition of municipal solid waste, $\mathrm{CH}_{4}$ and $\mathrm{N}_{2} \mathrm{O}$ from anaerobic decomposition and nitrification-denitrification of nitrogen during wastewater treatment; $\mathrm{CO}_{2}$ emissions from waste incineration; flurocarbon (HFC, $\mathrm{PFC}$ ) and sulfur hexafluoride $\left(\mathrm{SF}_{6}\right)$ emissions from refrigerants, semiconductor manufacturing and insulators; and $\mathrm{CO}_{2}$ and $\mathrm{N}_{2} \mathrm{O}$ emissions from rural-urban land conversion.

- Embodied GHG emissions include GHG emissions embedded in the energy required to produce the concrete, steel, glass, and other materials used in civil infrastructure; the $\mathrm{CH}_{4}$ and $\mathrm{N}_{2} \mathrm{O}$ emissions used to provide the food consumed by urban residents; and the $\mathrm{CO}_{2}, \mathrm{CH}_{4}$ and $\mathrm{N}_{2} \mathrm{O}$ emissions from rural power plants and refineries that generate energy for urban consumption.

- Changes to atmospheric chemistry and surface albedo include the direct and indirect GHGs that result from changes in atmospheric composition and surface reflectivity. For instance, the IPCC estimates that tropospheric ozone $\left(\mathrm{O}_{3}\right)$, a secondary pollutant commonly found in cities, is the third most important GHG behind $\mathrm{CO}_{2}$ and $\mathrm{CH}_{4}$ (Forster et al., 2007). Carbon monoxide (CO), an indirect GHG produced predominantly from mobile sources in cities, ${ }^{4}$ lengthens the atmospheric residence time of $\mathrm{CH}_{4}$.

Although cities' impact on the earth's climate is diverse and complex, GHG emissions from direct energy use increasingly account for the bulk of cities' climate impact in OECD countries. In other words, GHG emissions in OECD cities are increasingly driven by the energy services required for lighting, heating and cooling, appliance use, electronics use, and mobility. Industrial energy use and GHG emissions (including GHG emissions embodied in building materials) appear to have become less significant. In the U.S., for instance, industry's share of total energy use fell from a peak of 48.4\% in 1955 to a low of $31.4 \%$

4. In the U.S., for instance, the EPA reports that as much as $95 \%$ of the $\mathrm{CO}$ in typical cities comes from mobile sources. See www.epa.gov/oms/invntory/overview/pollutants/carbonmon.htm. 
in 2008, ${ }^{5}$ and growth in industrial energy use has essentially remained flat since the late 1970s (Figure 1.4). The importance of energy use as a source of GHG emissions is more obvious; fossil fuel energy systems accounted for an estimated 85\% of U.S. GHG emissions in 2007 (EPA, 2009). ${ }^{6}, 7$

Figure 1.14. US Energy Consumption by Sector, 1949-2008

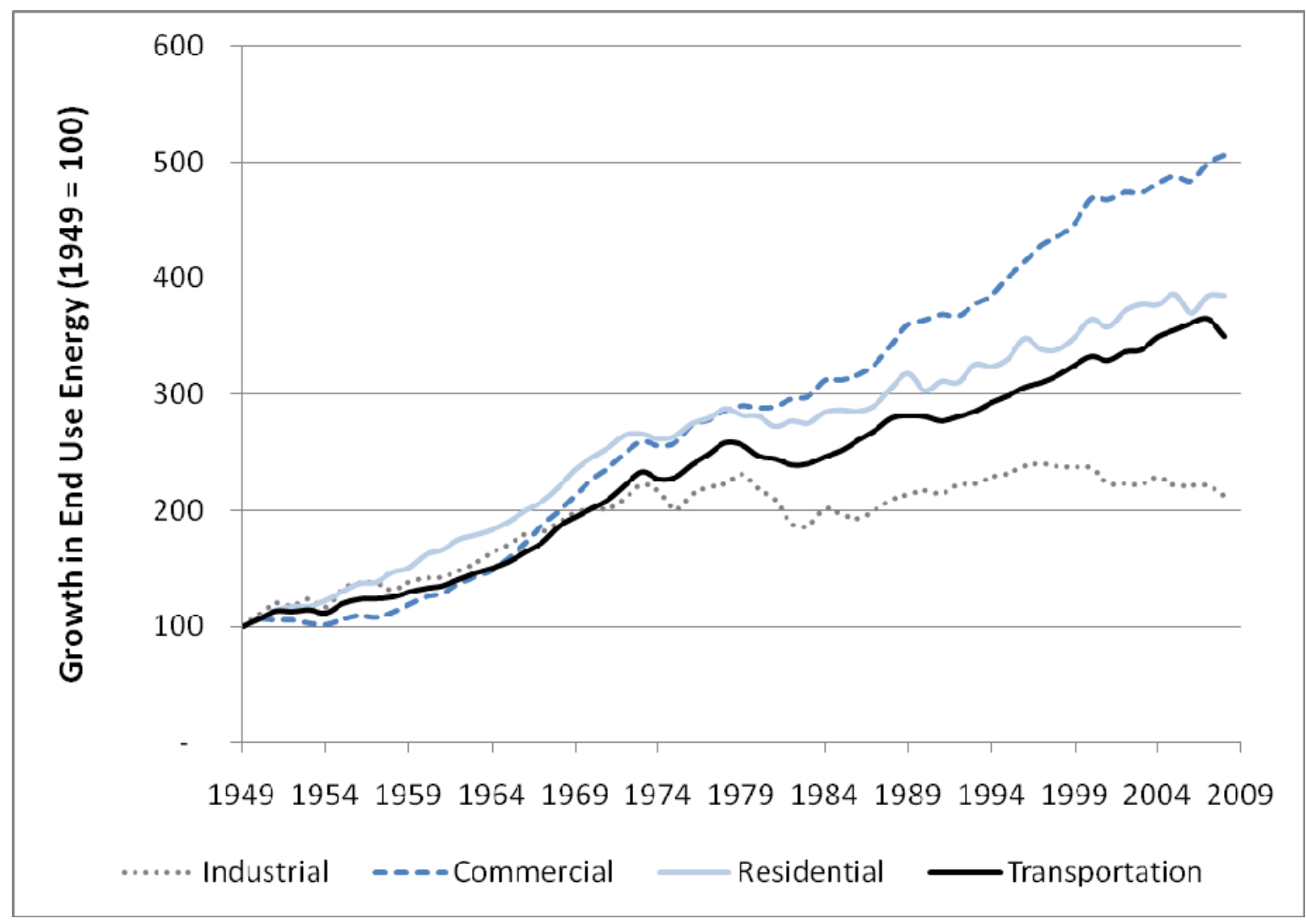

Source: U.S. Energy Information Administration (2009), "Energy Consumption by Sector", Annual Energy Review 2008, Report No. DOE/EIA-0384, release date: June 26, 2009, www.eia.doe.gov/emeu/aer/consump.html.

There are three main categories of final urban energy use: electricity, thermal energy, and transportation energy. These three forms of energy are not exclusive (Table 1.1). Electricity is used to a limited extent for water and space heating, and to a lesser but increasing extent for transportation. Oil, predominantly used as a feedstock for transportation fuels, is also used sparingly for electricity generation

5. Energy Information Administration (EIA) website, “Energy Consumption by Sector.” See: www.eia.doe.gov/emeu/aer/consump.html.

6. This estimate was made by summing all emissions from coal, natural gas and petroleum extraction, distribution and conversion in the EPA's GHG emissions inventory.

7. The EPA GHG inventory includes $\mathrm{CO}_{2}, \mathrm{CH}_{4}, \mathrm{~N}_{2} \mathrm{O}$, HFCs, PFCs and $\mathrm{SF}_{6}$, but does not include gases whose radiative forcing properties are more uncertain, such as $\mathrm{O}_{3}$. The IPCC estimates the radiative forcing of tropospheric $\mathrm{O}_{3}$ at $+0.35[-0.1,+0.3]$, which, at the high end would make tropospheric $\mathrm{O}_{3}$ more important than $\mathrm{CH}_{4}$ (Forster et al., 2007). An increase in the importance of $\mathrm{O}_{3}$ would not change the importance of energy systems; fossil fuel combustion accounts for about half of global $\mathrm{NO}_{\mathrm{x}}$ emissions (Brasseur et al., 2003), and $\mathrm{NO}_{\mathrm{x}}$ is one of two precursors to tropospheric $\mathrm{O}_{3}$ formation. 
and heating. For the purpose of matching goals with appropriate strategies, it is important to keep these different types of uses in mind. Energy efficiency that reduces electricity demand, for instance, does not directly reduce exposure to oil price volatility because so little oil is used to generate electricity. The intensity of energy demand at certain periods, known as peak demand, may also be stronger in cities, which in theory could reduce opportunities to make use of renewable energies. However, in practice, this is not a significant obstacle to renewable energy production because of new technologies that can manage loads.

Table 1.1.Categories of Urban Energy Use

\begin{tabular}{|c|c|c|}
\hline Tyре & $\begin{array}{l}\text { Main energy sources } \\
(\% \text { total) }\end{array}$ & Main use \\
\hline Electricity & $\begin{array}{l}\text { Coal }(41 \%), \text { nuclear }(27 \%) \text {, natural gas } \\
(17 \%) \text {, oil }(5 \%) \\
\text { Percentages are for all OECD countries }\end{array}$ & $\begin{array}{l}\text { Lights, appliances, electronics, industrial } \\
\text { motors }\end{array}$ \\
\hline Thermal energy & $\begin{array}{l}\text { Natural gas, oil, electricity (n/a) } \\
\text { Percentages are unclear }\end{array}$ & $\begin{array}{l}\text { Space heating, water heating, cooking, } \\
\text { industrial process heat }\end{array}$ \\
\hline Transportation energy & $\begin{array}{l}\text { Oil }(97 \%) \\
\text { Percentage is based on U.S. data }{ }^{2}\end{array}$ & Vehicles, transit systems (mobility) \\
\hline \multicolumn{3}{|c|}{$\begin{array}{l}\text { Notes: } \\
\text { Thermal energy sources are difficult to isolate, but natural gas is typically the dominant source of space and water heating in OECD } \\
\text { countries. In the U.S., for instance, natural gas accounted for } 76 \% \text { of residential and commercial primary energy consumption in } 2008 \text {, } \\
\text { most of which was for space and water heating. }\end{array}$} \\
\hline $\begin{array}{l}\text { There are no recent estim } \\
\text { and argue that this percen }\end{array}$ & $\begin{array}{l}\text { the composition of transportation energy use } \\
\text { representative of typical OECD countries }\end{array}$ & ECD countries; we use the U.S. as a proxy here, \\
\hline
\end{tabular}

Many cities have undertaken inventories of their GHG emissions, but comparisons among cities are difficult. There is currently no single protocol ranking for assessing urban areas' per capita GHG or $\mathrm{CO}_{2}$ emissions, making comparisons across cities impossible. Cities have taken different approaches in defining what sectors to include, in establishing the geographic boundaries of the area included, and have aggregated data in different ways. Additional urban GHG inventory differences include:

- $\quad$ different definitions of the urban area (i.e. by the larger metropolitan region, by city limits, or by another unit);

- $\quad$ choice of inventory years presented;

- $\quad$ inventory scope (i.e. whether or not more than city-owned operations are reported, and whether indirect emissions are included); and

- methodological issues.

Comparable GHG inventories and indicators at city-scale would be valuable because they would allow cities to manage emissions in their urban areas and enable national and international policymakers to properly target and assist city authorities to act (OECD, 2009b).

Energy consumption is often used as an indicator of GHG emissions generally, and $\mathrm{CO}_{2}$ emissions in particular, but the relationship is not direct. Energy consumed in cities, be it in the form of electricity, oil or gas heat, or fuel, is produced from a variety sources, each with a different climate footprint (Figure 1.15). Some sources, such as hydropower, nuclear, solar, and wind energies produce no or minimal GHG emissions. Fossil fuel sources - coal, oil, and natural gas - do contribute to GHG emissions, but to different degrees; for example, coal contributes more GHG emissions in the power sector than natural gas 
(IEA, 2009). The efficiency of energy production is another determinant of the degree to which energy consumption contributes to GHG emission. Some energy is always lost between production and end use, but the amount lost (often dependent on infrastructure quality) varies greatly depending on the efficiency of production and quality of transmission infrastructure. Urban areas relying on inefficient or wasteful energy sources contribute more GHG emissions then than those that consume the same amount from more efficient sources. OECD countries face a challenge in moving to low-emissions urban energy production. In 2005 fossil fuels accounted for 83\% of primary energy use in OECD countries. Renewable energy, alternatively, accounted for less than $5 \%$. The shares of oil and natural gas in total primary energy consumption in OECD countries also illustrate the importance of thermal and transportation energy in OECD countries.

Figure 1.15. Total Energy Consumption in OECD Countries, 2007

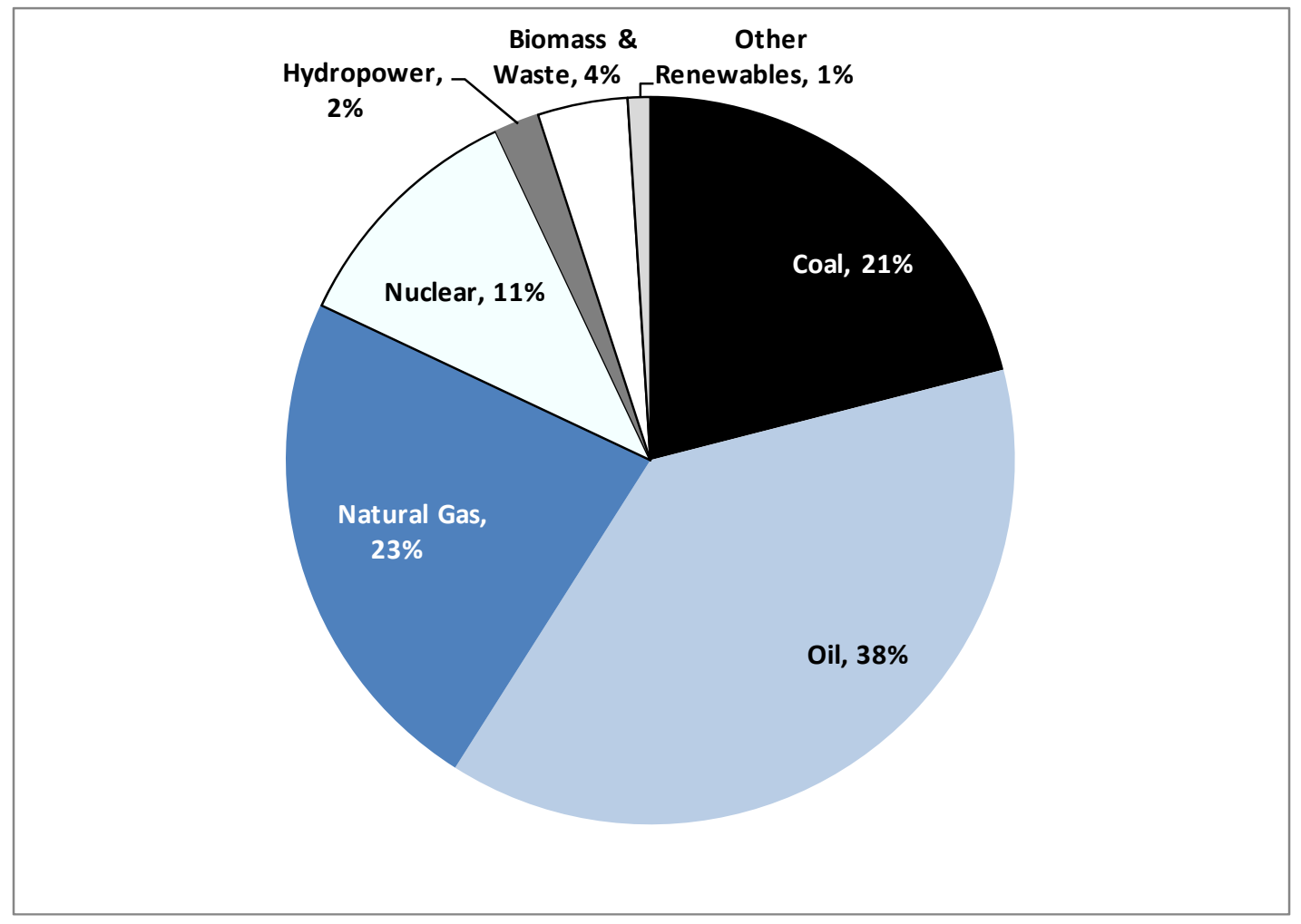

Source: IEA (2009) Energy Statistics Division historical data, IEA, Paris.

The impact of energy consumption on GHG emissions depends not just on the amount consumed, but also on the GHG intensity, or GHG emissions factor, of all the activities involved in processing and producing it. When total life-cycle emissions, such as resulting from the extraction, processing, and transporting of fossil fuels, were taken into account in an inventory of 10 large cities, ${ }^{8}$ the intensity of GHG emissions was 7-24\% greater than that for end-use activities only (including energy production and air and sea activities outside of city boundaries) (Table 1.2). For example, Cape Town's per capita electricity consumption is lower than that of Geneva, but the GHG intensity of its electricity supply is significantly higher, due to South Africa's use of coal for $92 \%$ of its electricity generation and Geneva's reliance on

8. Bangkok, Barcelona, Cape Town, Denver, Geneva, London, Los Angeles, New York City, Prague and Toronto (Kennedy et al., 2009). 
hydropower. Thus, an important distinction must be made between urban inventories that capture emissions from city energy consumption and those that capture total life-cycle emissions associated with a city’s energy supply (Kennedy et al., 2009).

Table 1.2. Total GHG Emissions, Including End-Use, Life Cycle, and within City Measures, for Ten World Cities

\begin{tabular}{llll}
\hline Emissions within city & \multicolumn{1}{c}{$\begin{array}{c}\text { Emissions from end-use } \\
\text { activities }^{1,2}\end{array}$} & \multicolumn{1}{c}{$\begin{array}{c}\text { End-use emissions including } \\
\text { life-cycle emissions for } \\
\text { fuels }^{1,2,3}\end{array}$} \\
\hline Bangkok & 4.8 & 10.7 & not determined \\
Barcelona & 2.4 & 4.2 & 4.6 \\
Cape Town & not determined & 11.6 & not determined \\
Denver & not determined & 21.5 & 24.3 \\
Geneva & 7.4 & 7.8 & 8.7 \\
London & not determined & 9.6 & 10.5 \\
Los Angeles & not determined & 13 & 15.5 \\
New York & not determined & 10.5 & 12.2 \\
City & 4.3 & 9.4 & 10.1 \\
Prague & 8.2 & 11.6 & 14.4 \\
Toronto & & &
\end{tabular}

Notes:

1. Figures indicate global warming potential, expressed in carbon dioxide equivalents (t e $\mathrm{CO}_{2}$ ) per capita.

2. Includes activities occurring outside city boundaries (e.g. from power generation, air and marine activities).

3. Includes upstream emissions such as those caused by the extraction, processing, and transporting of fossil fuels.

Source: Kennedy, Christopher et al. (2009), "Greenhouse Gas Emissions from Global Cities", Environmental Science \& Technology, Vol. 43, No. 19, American Chemical Society, Washington, US, pp. 7297-7302.

\subsection{The urban form matters - the impact of sprawl}

Energy use, and thus carbon emissions, are chiefly driven by how electricity is produced, the uses of such energy in households and the way in which people move around the city. Roughly two-thirds of all emissions in the US come from electricity and road transport activities in urban and intermediate regions, with an additional one-quarter produced by industrial and residential uses (Figure 1.16). Predominantly urban (PU) regions home to the largest cities and intermediate (IN) regions that contain medium-sized cities are responsible for more than half of those emissions, but they are also likely to be responsible for some emissions in rural areas as consumers of electricity produced in rural regions. Therefore, policies that induce households to use energy more efficiently, including through building codes and policies that favour reduced commuting journeys and public transportation such as densification and congestion charges, might be useful in stimulating changes in the amount of carbon emissions. 
Figure 1.16. Carbon Emissions in US Cities

Produced in urban areas (PU) by type of activity (2002)

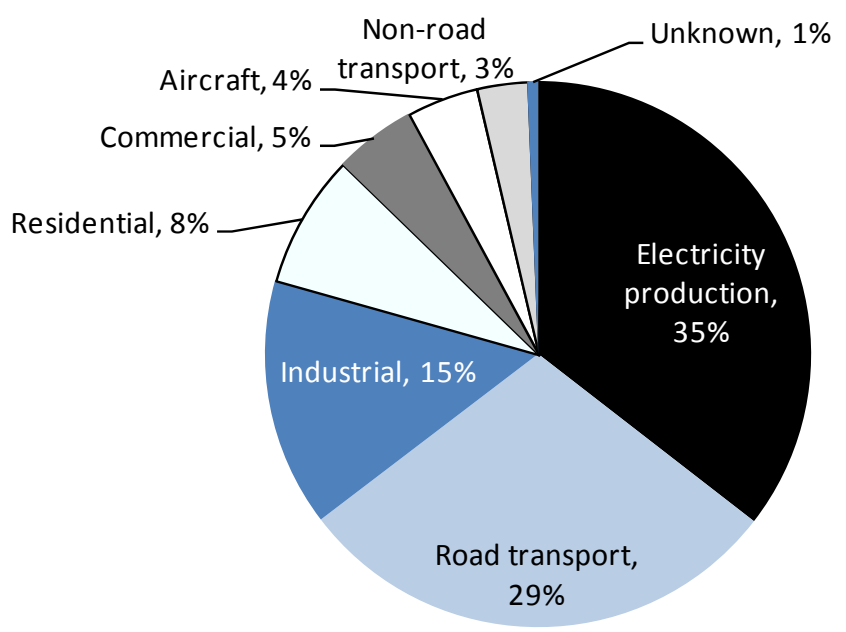

Note: Transport refers to road-related transport. The figure does not include non-road transport.

Source: Own calculations based on data from the Vulcan Project (2009). The Vulcan Project is a NASA/DOE funded effort under the North American Carbon Program (NACP) to quantify North American fossil fuel carbon dioxide (CO2) emissions at space and time scales much finer than has been achieved in the past.

The form of urbanisation matters for energy demand and thus for GHG emissions. Population growth in OECD metropolitan areas has meant an expansion of developed areas through suburbanisation. Suburbanisation and urban sprawl has been important in the OECD, but has recently been more so for the rest of the world. Urban land area in the OECD has doubled in the second half of last century, but has experienced a fivefold increase over the same period in the rest of the world (Figure 1.17). In fact, in the vast majority of OECD metro-regions, the suburban belt grows faster than the core (Figure 1.18). In only $15 \%$ out of 78 metro-regions in the OECD, the core has seen population expansion increase faster than the suburbs. In a number of these cases, the core has benefited from both favourable economic conditions (i.e. lower land prices at the core) and/or intended policies in order to regain population at the core. For example, in Copenhagen, inner-city neighbourhoods have been improved through the 1997 Kvarterloft programme that promoted citizen and private-sector participation and the Urban Renewal act of 1998, with their visions of promoting quality of life in urban areas through densification, regeneration, and traffic and environmental planning (OECD, 2009e). In other cases, such as Tokyo, the process of gentrification coincided with a fall in housing prices in the urban core after the housing bubble burst in the early 1990s (An, 2008). 
Figure 1.17. Urban Sprawl

Trends in urban land expansion in the world and the OECD

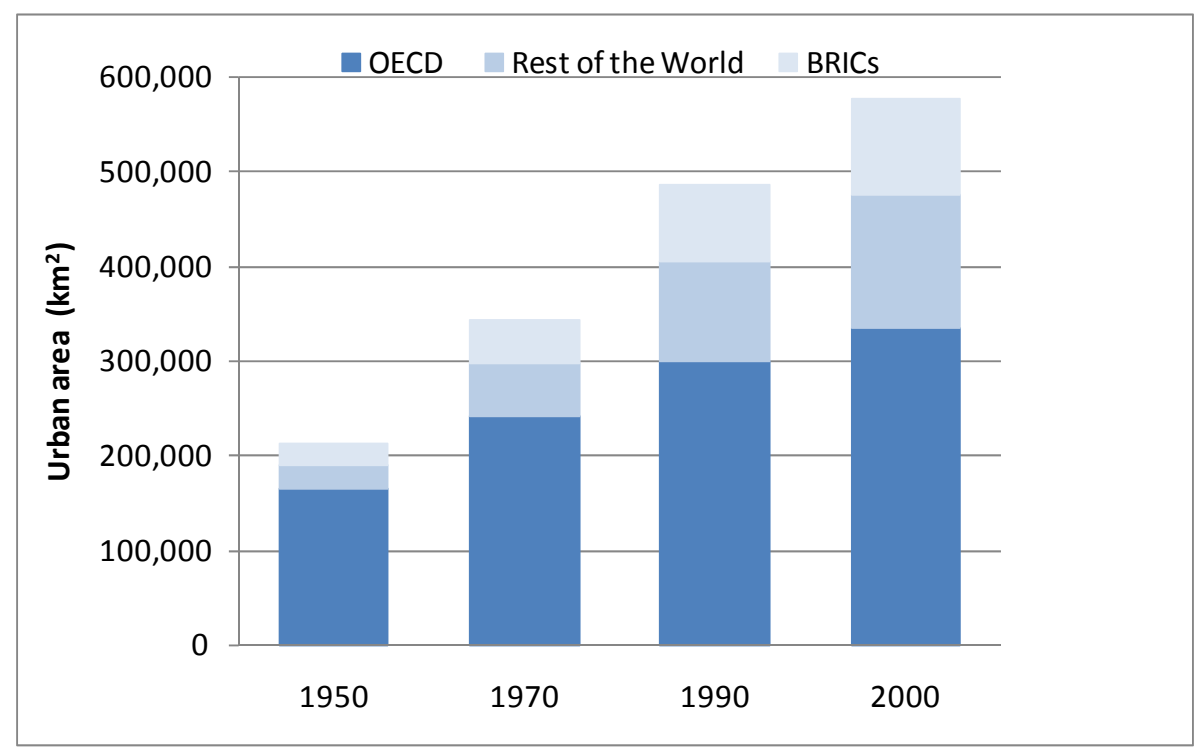

Note: BRIC countries refers to Brazil, Russia, India and China.

Source: OECD (2008b), Environmental Outlook to 2030, OECD Publishing, Paris. 
Figure 1.18. Suburbanisation in OECD Metro-regions

Population growth in metro-region's core and belt compared (1995-2005)

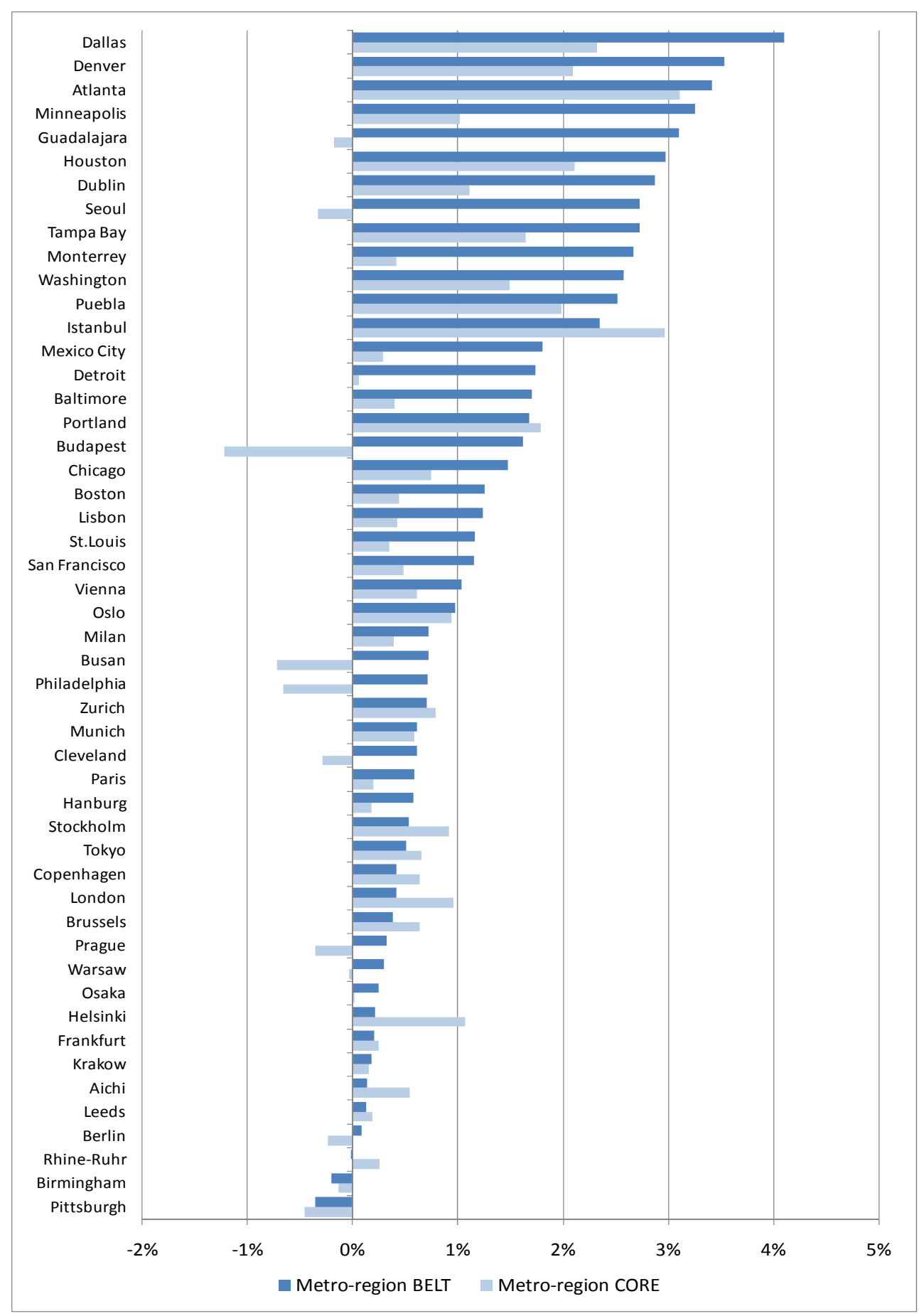

Note: For US metro-regions, core-base counties were used to identify metropolitan statistical areas' cores.

Source: Own calculations based on data from the OECD Metropolitan Database. 
Increasing density could significantly reduce consumption of electricity in urban areas. Where increased urbanisation (estimated in terms of PU areas) has led not only to demographic and economic agglomeration, but also to higher levels of electricity demand, densification tends to decrease electricity demand. In general, the more urbanised a country becomes, the higher the demand for electricity (Figure 1.19). However, not all urban areas demand electricity in the same way and lifestyles in different cities can make a big difference. As density increases in urban areas, per capita electricity demand decreases (Figure 1.20). For instance, Japan's urban areas are around five times denser than Canada's, and the consumption of electricity per person in the former is around $40 \%$ that of the latter. If we take countries in the same geographical context with similar heating needs such as Denmark and Finland, the proportions are quite similar. Denmark's urban areas are denser than Finland's by a factor of four, and people there only consume around $40 \%$ of the electricity consumed by the Finns.

Figure 1.19. Urbanisation and Electricity Consumption

Urban population shares and electricity consumption (PU)

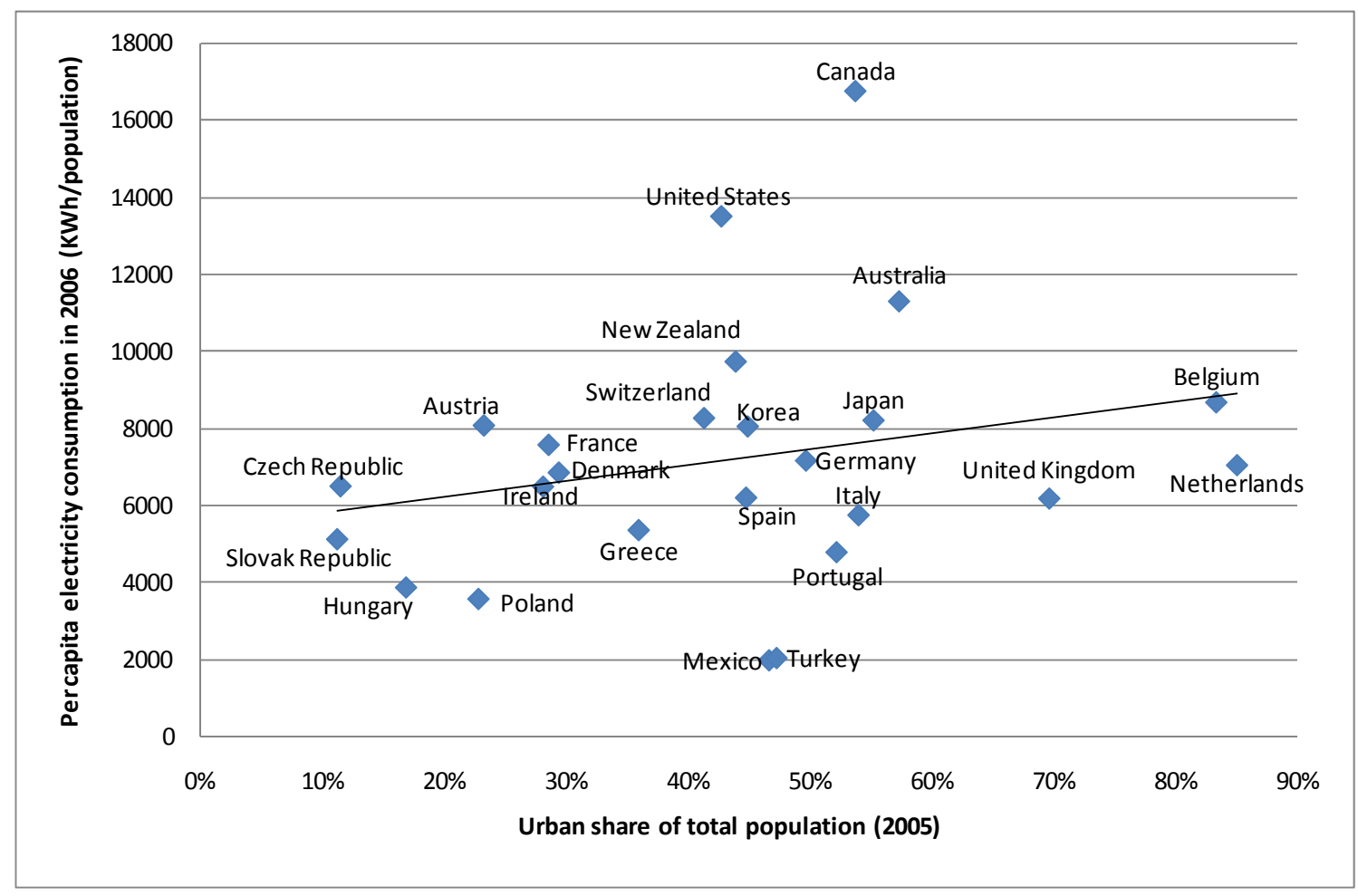

Notes:

Urban shares were calculated on the basis of PU areas.

Finland, Norway and Sweden were taken out of the sample since they were considered to be an outlier.

Iceland and Luxemburg were not included in the sample as the OECD Regional Database identifies no PU areas in those countries.

Source: Own calculations based on data from the OECD Regional Database and IEA (2009) Energy Balances in OECD Countries. 
Figure 1.20. Urban Density and Electricity Consumption

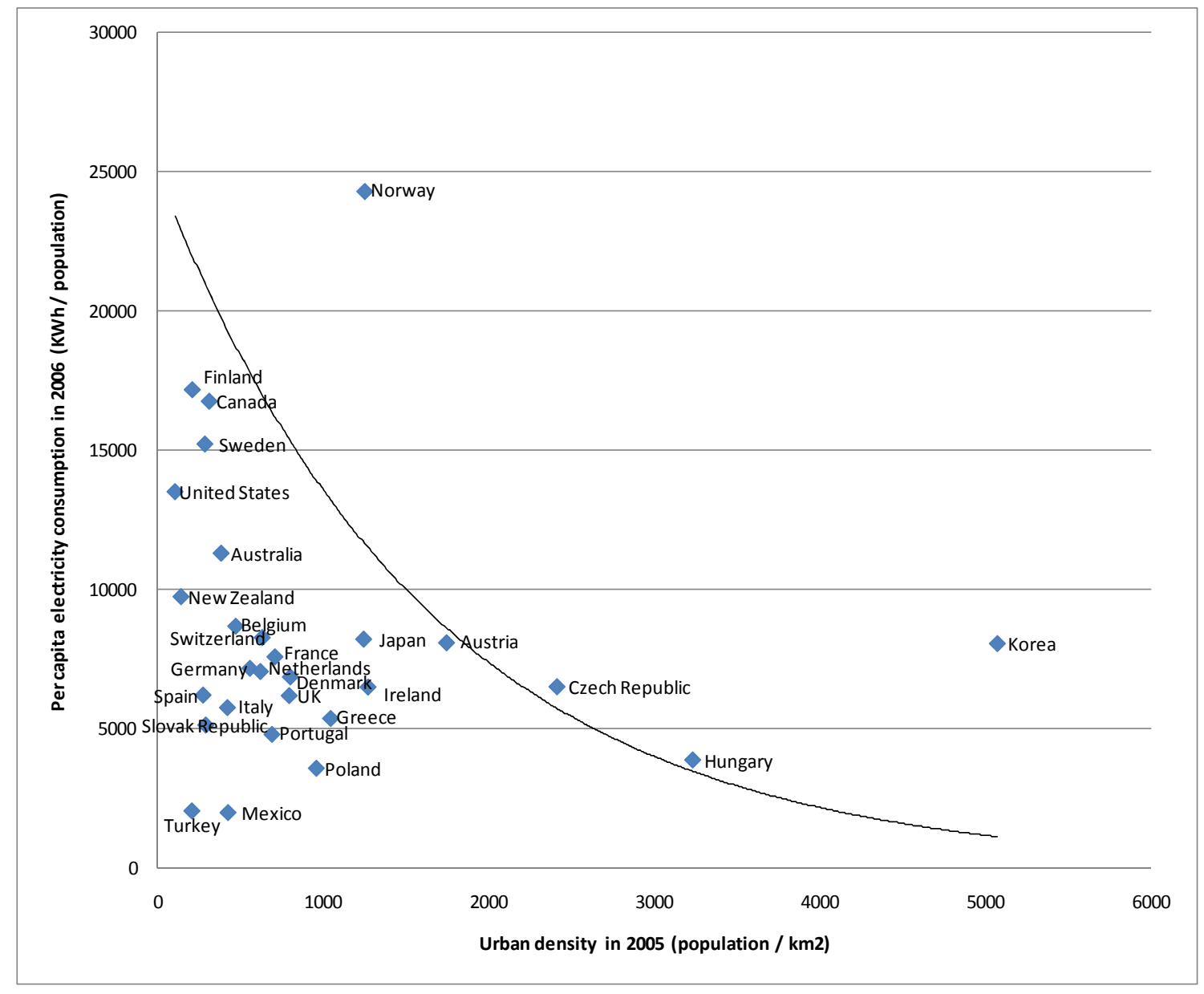

Notes:

Urban density is calculated on the basis of PU areas.

Iceland and Luxemburg were not included in the sample as the OECD Regional Database identifies no predominantly urban (PU) regions in those countries.

Source: Own calculations based on data from the OECD Regional Database and IEA (2009) Energy Balances in OECD Countries.

Not surprisingly, density emerges as a crucial element to reduce carbon emissions. Urbanisation greatly increases carbon emissions (Figure 1.21). Half of Turkish people live in urban areas and produce around $250 \mathrm{mt}$ of $\mathrm{CO}_{2}$ whereas the urban share of population in Britain is $70 \%$, accompanied by nearly double the $\mathrm{CO}_{2}$ emissions of Turkish urban areas. To take another example, Germany has almost twice the urban population of France, and German cities have twice the pollution levels as those in France. However, not all urban areas pollute equally. As density increases, $\mathrm{CO}_{2}$ emissions from transport go down (Figure 1.22). Austria's urban areas are more than four times denser than Australia's, and generate only $60 \%$ of the amount of $\mathrm{CO}_{2}$ emissions that Australia's urban areas generate. Therefore, while urbanisation levels might bring about an expansion in carbon emissions, these are reduced with higher density (Figure 1.23). 
Figure 1.21. Urbanisation and Carbon Emissions

Urban population (according to $\mathrm{PU}$ areas) shares and $\mathrm{CO}_{2}$ emissions

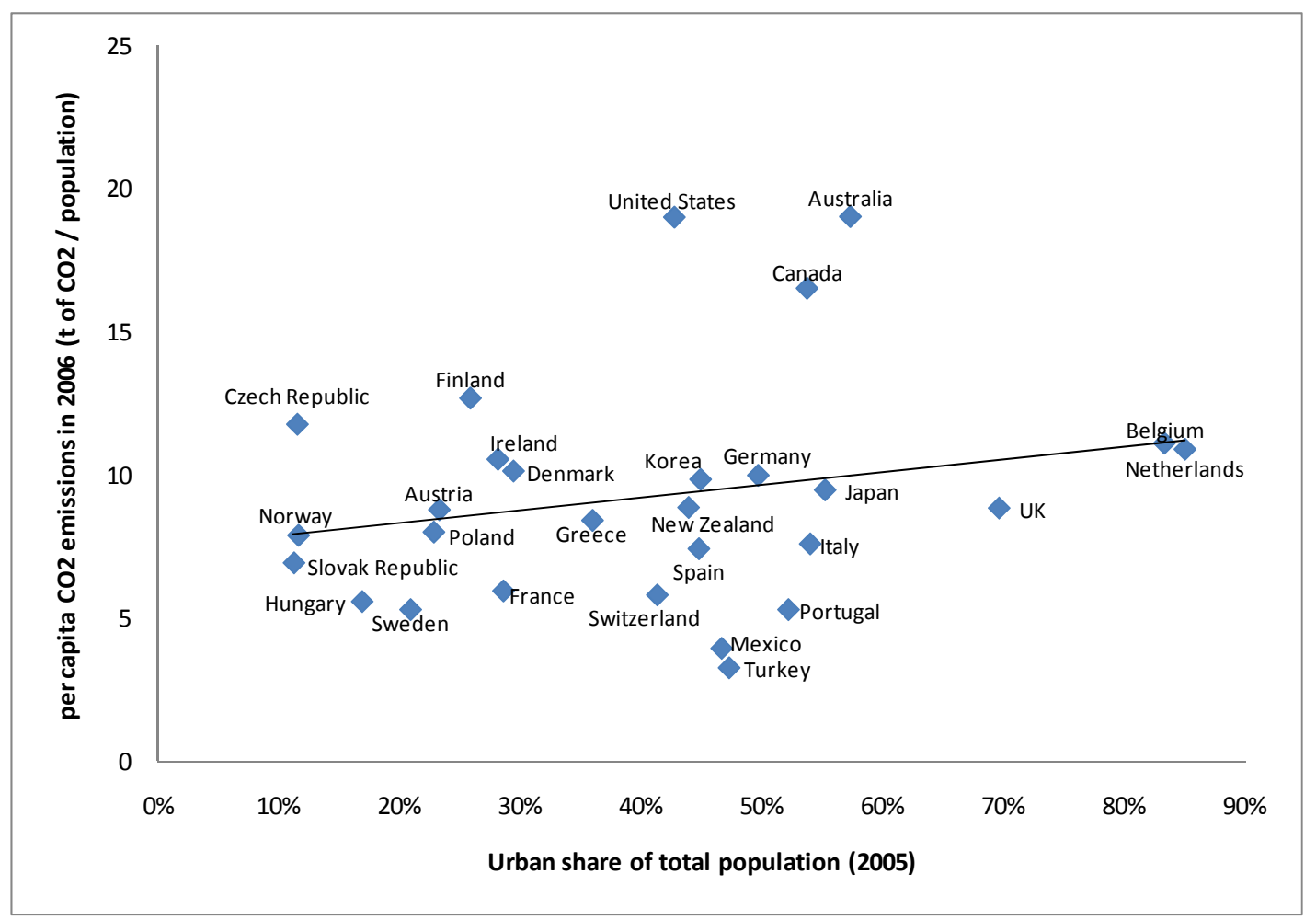

Notes:

Urban shares were calculated on the basis of PU areas.

Finland, Norway and Sweden were taken out of the sample as they were considered outliers.

Iceland and Luxemburg were not included in the sample as the OECD Regional Database identifies no predominantly urban (PU) regions in those countries.

Source: Own calculations based on data from the OECD Regional Database and IEA (2008c), $\mathrm{CO}_{2}$ Emissions from Fuel Combustion, OECD Publishing, Paris. 
Figure 1.22. Urban Density and Carbon Emissions in Transport

Per capita carbon emissions produced by transport activities and urban (PU areas) density

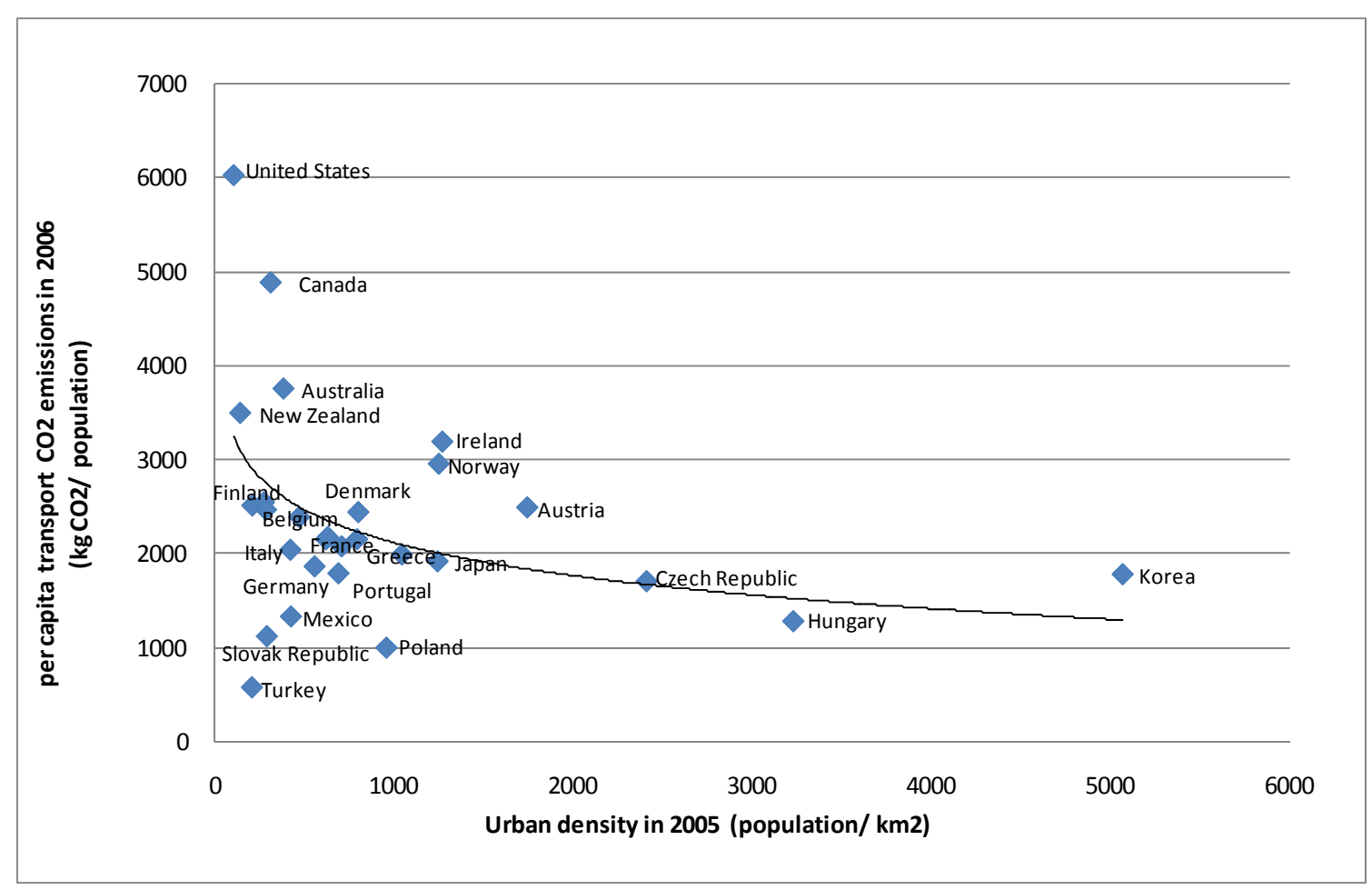

Notes:

Urban density was calculated on the basis of PU areas.

Iceland and Luxemburg were not included in the sample as the OECD Regional Database identifies no predominantly urban (PU) regions in those countries.

Source: Own calculations based on data from the OECD Regional Database and IEA (2008c), $\mathrm{CO}_{2}$ Emissions from Fuel Combustion, OECD Publishing, Paris. 
Figure 1.23. Urbanisation, Density and Carbon Emissions

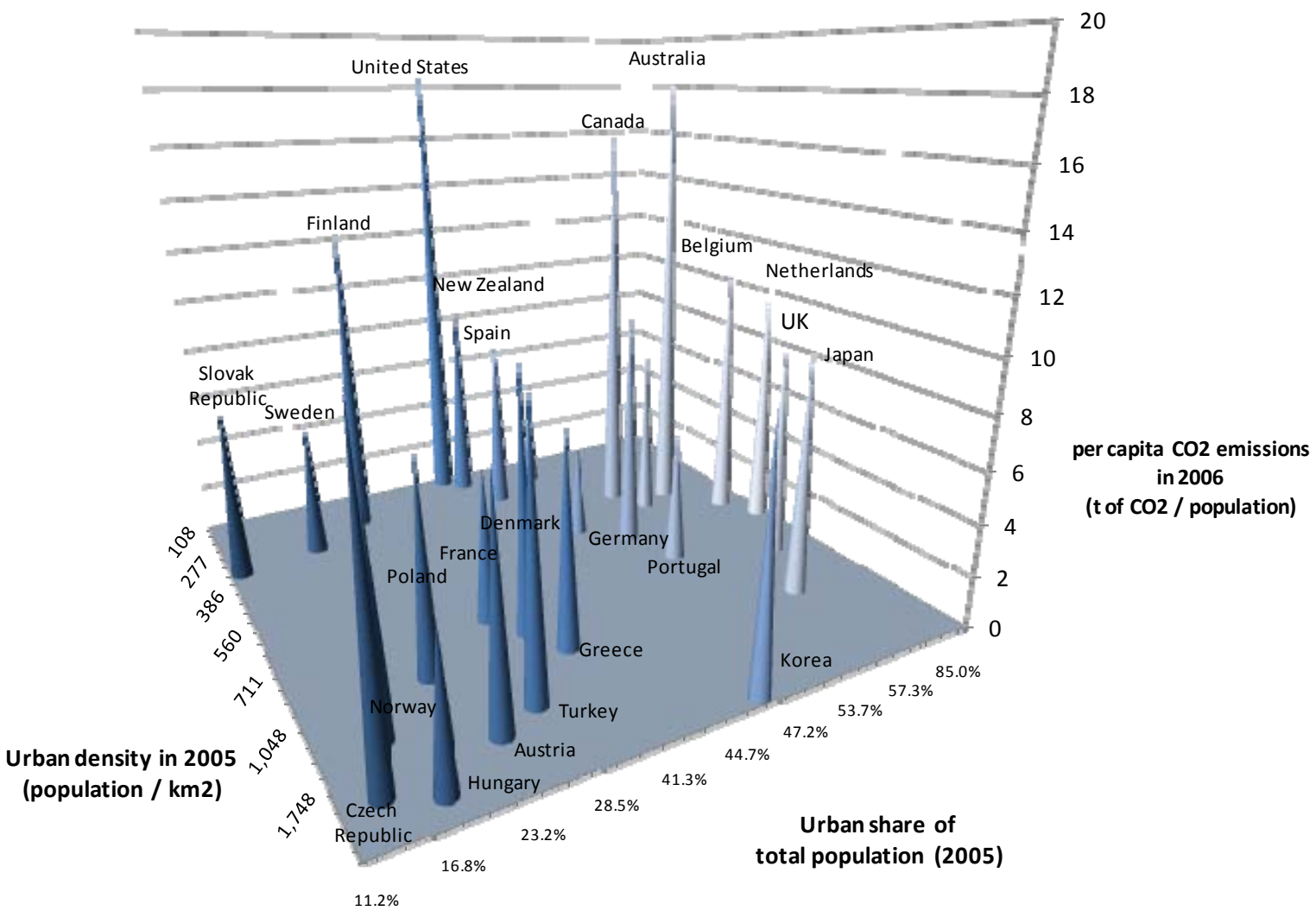

Notes:

Urban density and urban share were calculated on the basis of PU areas.

Iceland and Luxemburg were not included in the sample as the OECD Regional Database identifies no predominantly urban (PU) regions in those countries.

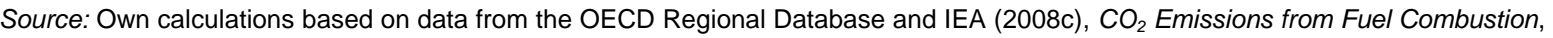
OECD Publishing, Paris.

Lifestyles, in particular the way in which people commute, are also crucial in the generation of $\mathrm{CO}_{2}$. As urban areas become denser and rely more on public transport, carbon emissions are reduced. Not surprisingly, among OECD member countries, North American countries produce $50 \%$ more CO2 emissions than the Europeans; while European countries pollute twice as much as the Asian countries (Figure 1.24). Similarly, not all cities in the same country have the same lifestyles nor do they contribute to carbon emissions in the same way. Although the USA is the OECD country with the most flows of carbon emissions, internally cities like Los Angeles are noticeable for the concentration of $\mathrm{CO}_{2}$ emissions (Figure 1.25). Even smaller cities like Houston produce much more $\mathrm{CO}_{2}$ than New York -the largest city in the country. The Toronto region is one of the metropolitan regions in North America with the highest share of public transit (around 23\% in 2006) only surpassed by New York. The public transit share of the Toronto 
region is comparable to those of many European metropolitan regions, such as London, Munich and Amsterdam, but falls well below public transit shares in Japanese cities like Tokyo. Despite the high use of public transit within the North American context, the Toronto region has one of the highest rates of car use among OECD metro-regions (71\% in 2006) (OECD, 2009f). European metropolitan regions have been able to lower car use through a more extensive use of public transit, as well as development of other transportation modes including walking and cycling.

Figure 1.24. $\mathrm{CO}_{2}$ Emissions in the OECD

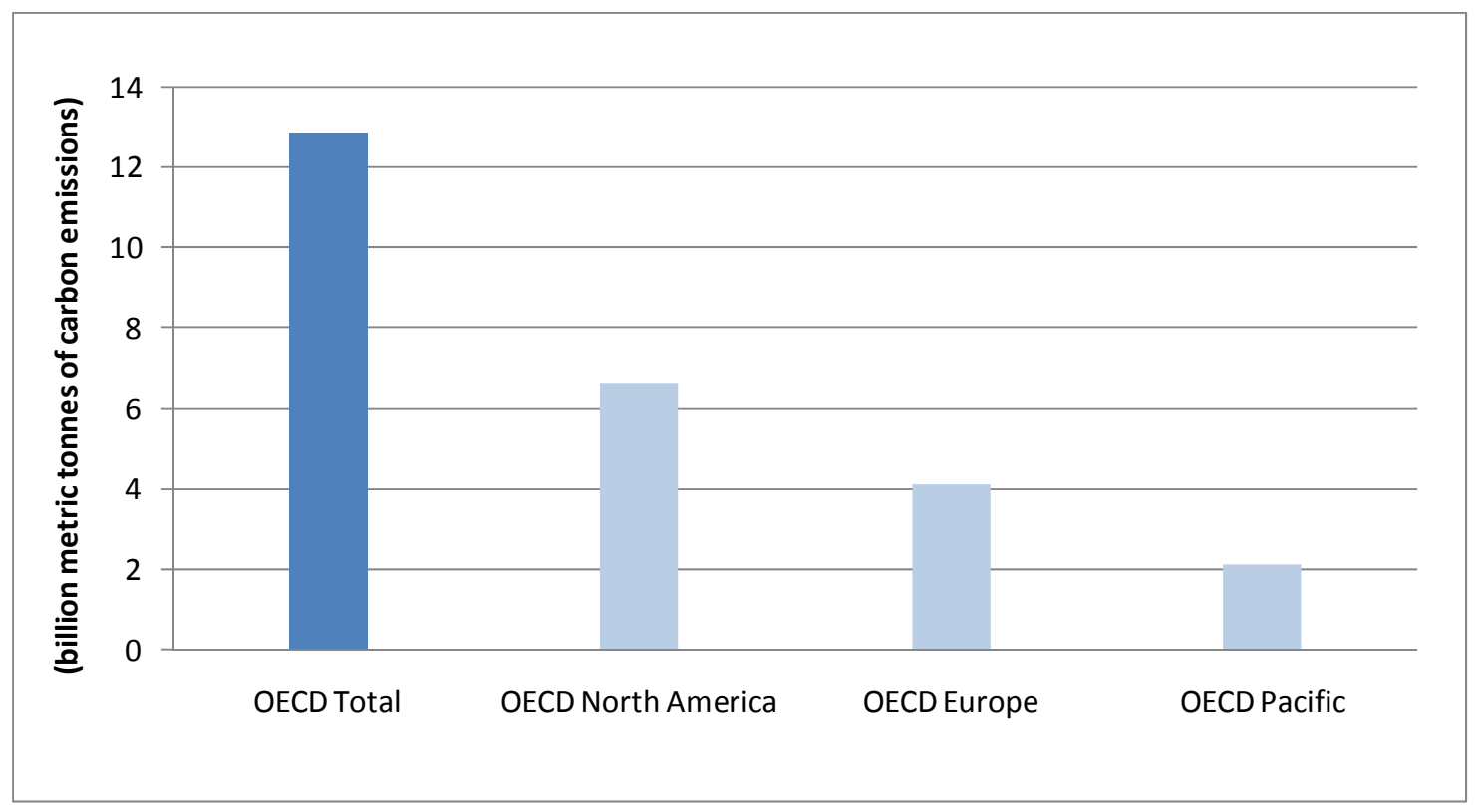

Source: IEA (2008b), $2006 \mathrm{CO}_{2}$ Emissions at National Level,www.iea.org/Textbase/stats/index.asp. 
Figure 1.25. Concentration of Carbon Emissions in the USA

CO2 emissions at county level for 2002

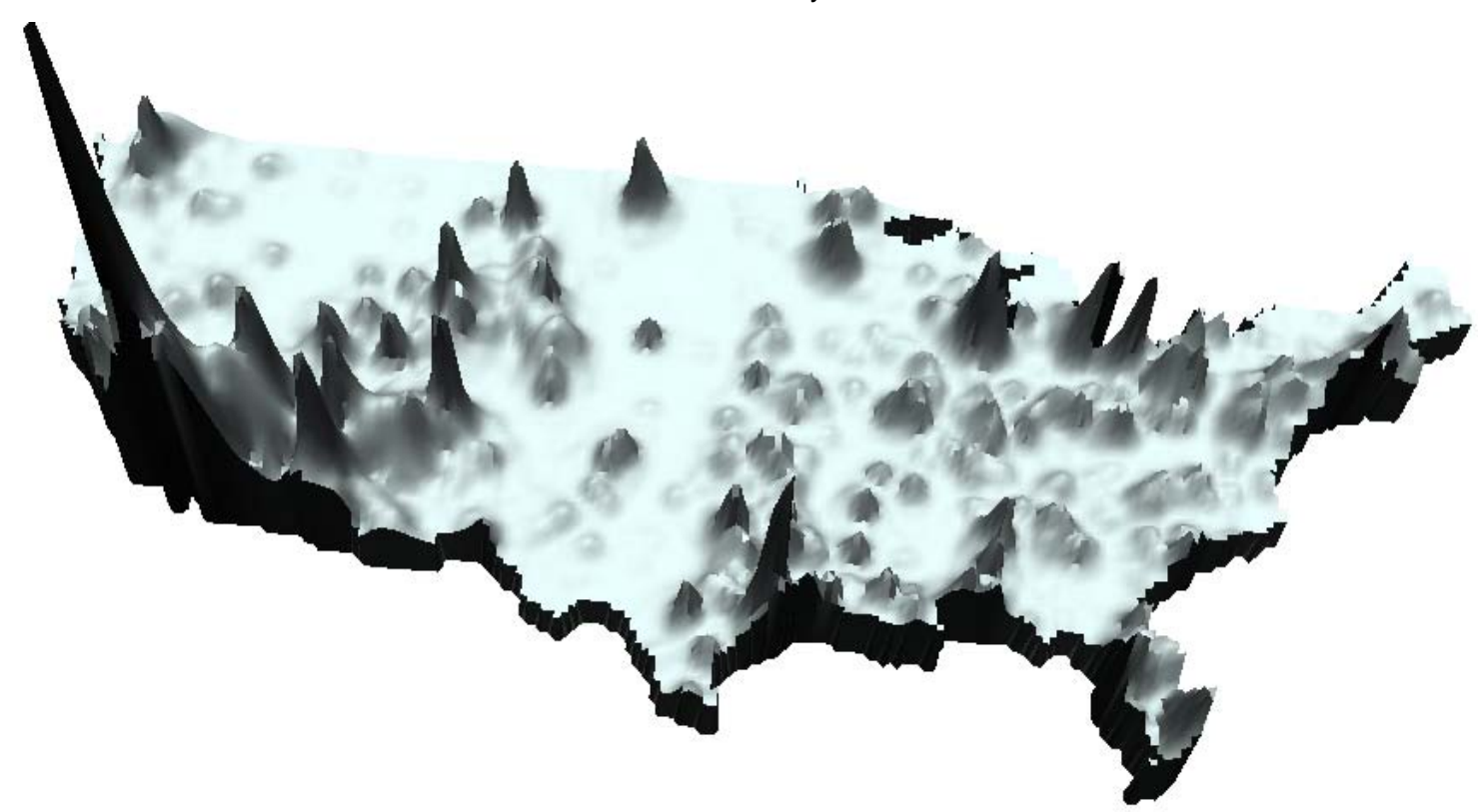

Source: Own calculations based on data from the Vulcan Project (2009) and the OECD typology of regions. The Vulcan Project is a NASA/DOE funded effort under the North American Carbon Program (NACP) to quantify North American fossil fuel carbon dioxide (CO2) emissions at space and time scales much finer than has been achieved in the past. 


\section{REFERENCES}

An, Sang Kyung (2008) "Recentralization of Central Tokyo and Planning Responses”, Journal of Regional Development Studies, Vol., 11, No. 3, pp. 1-20.

Kennedy, Christopher et al. (2009), “Greenhouse Gas Emissions from Global Cities”, Environmental Science \& Technology, Vol. 43, No. 19, American Chemical Society, Washington, US, pp. 72977302.

IEA (International Energy Agency) (2007) Key world energy statistics. OECD/IEA, Paris.

IEA (2008a) World Energy Outlook 2008, OECD/IEA, Paris.

IEA (2008b) $2006 \mathrm{CO}_{2}$ Emissions at National Level,www.iea.org/Textbase/stats/index.asp

IEA (2008c) $\mathrm{CO}_{2}$ Emissions from Fuel Combustion, OECD Publishing, Paris.

IEA (2009) World Energy Outlook 2009, OECD/IEA, Paris.

OECD (2006), Competitive Cities in the Global Economy, OECD, Paris.

OECD (2008a) Competitive Cities and Climate Change: OECD Conference Proceedings, Milan, Italy, October 9-10, 2008, OECD, Paris.

OECD (2008b) Environmental Outlook to 2030, OECD, Paris.

OECD (2009b), “Cities, Climate Change and Multilevel Governance”, Environment Working Papers, OECD, Paris.

OECD (2009c), Regions at Glance 2009, OECD, Paris.

OECD (2009d), Regions Matter: Economic Recovery, Innovation and Sustainable Growth, OECD, Paris.

OECD (2009e), OECD Territorial Review: Copenhagen, Denmark, OECD, Paris.

OECD (2009f), OECD Territorial Review: Toronto, Canada, OECD, Paris, forthcoming.

UN (United Nations) (2008), State of the World's Cities 2008/2009: Harmonious Cities, United Nations Human Settlements Programme, Nairobi, Kenya. 


\section{CLIMATE CHANGE IMPACTS SPECIFIC TO URBAN REGIONS}

Rising sea levels, more extreme storms and flooding, and extreme heat events: just as cities and metropolitan regions contribute to climate change in specific ways, they are also vulnerable to potential climate change impacts in specific ways. Climate impacts will result from worldwide climate change trends, but will affect individual metropolitan regions differently. Some effects of climate change are reasonably predictable (e.g., melting of glaciers, changes in global temperature regimes), while others are not (e.g., frequency and magnitude of extreme weather events). In addition, many impacts, including sea level rise, heat waves, droughts, spread of alien species and disease, vary in their local impact. In general, those that show high regional variation are particularly difficult to predict. Cities are vulnerable because of the complex and fixed nature of urban infrastructure and the potential for higher concentrations of poor residents. This section will assess urban-level impacts caused by coastal flooding, precipitation and storm events, heat extremes and urban heat island effects, and increased drought and water scarcity. Adaptation measures to address these potential impacts are often impeded by the uncertainty of the nature of the impacts and the fact that impacts vary by metropolitan region due to many factors, including geography and physical location (Hunt \& Watkiss, 2007), population size, spatial development pattern, and degree of existing development. However, inaction can increase the costs of climate change damage and as well as those of future adaptation measures.

\subsection{Complex and fixed nature of urban infrastructure}

Urban areas' dependency on complicated and extensive networks for transportation, communication and trade are a key factor in their vulnerability to climate impacts. Functioning urban infrastructure and a healthy environment not only provide the urban population with the necessary structure for carrying out economic and social activities, but are also prerequisites for ensuring the competitiveness of a city. Cities' stability and prosperity rely on vast networks of provisional infrastructure - solid waste disposal; wastewater treatment; transportation; water, energy and sanitary provisional systems. However, environmental impacts are dynamic. Not only do they often exhibit non-linear and cumulative effects, but they have sustainability thresholds and involve irreversibilities (OECD, 2008b). Disruptions in infrastructure systems create inefficiencies and slow down economic progress, imposing costs on the local and national economy.

Physical infrastructure, such as transportation, energy and communications infrastructure, and social infrastructure, such as health, governmental and educational services, are strongly interdependent in urban areas (Hitchcock, 2009), and vulnerable to the non-linear disruptive effects that can result when critical temperature, wind or water exposure thresholds are surpassed. For example, large portions of mass transportation systems and road networks, which are critical to cities' productivity, communication and competitiveness, can be cut off or shut down due to flooding in key locations (Box 2.1). Urban infrastructure is not typically designed to handle extreme events, particularly in developing countries. Temperature extremes and less predictable precipitation cycles will likely require key infrastructure (e.g. for energy production or transport) to be replaced or repaired more frequently and may reduce their operational capacity (e.g. blackouts or service interruptions), if infrastructure design does not take potential climate variations into account (OECD, 2009b). ${ }^{9}$ Many of the dangers of climate change can be mitigated

9. $\quad$ Mansanet-Bataller et al, (2008) Cochran et al., (2009) in OECD (2009b). 
by folding the expectation of a new climate into existing infrastructure development, although this is complicated by the dense interconnections among the infrastructures on which cities rely. It is also made more difficult by the tendency for the information most relevant for climate decision-making (e.g. impact of climate on local rainfall extremes) to be associated with the highest degree of uncertainty. Although urban infrastructure is an essential element in city competitiveness, cities in many parts of the world are struggling to meet the basic needs of their populations, and have limited resources to devote to adapting to climate (Ruth 2006, Ruth \& Kirshen, 2006).

\section{Box 2.1. Climate change, transportation and flood risk}

The City of New York's airports, as well as many of its power plants and waste transfer facilities, are at sea level and/or on waterfront sites. The subway system and subterranean water and sewer systems were designed for current sea levels. A Category III hurricane would flood all the tunnels leading out of New York, as well as the city's airports, requiring the emergency evacuation of up to 3 million people (City of New York, 2007).

The Thames Barrier, which protects London from high seas, was raised only three times in its first six years of operation, but was been raised 56 times between 2001 and 2007. Flash floods caused approximately 600 flooding incidents in the London Underground between 1992 and 2003. A single 2002 flooding incident in the Borough of Camden caused traffic disruptions amounting to losses of at least GBP 100,000 per hour's delay on each main road affected, without counting the costs of infrastructure damage. A recent report concluded that significant changes to current drainage systems would be needed to maintain current service levels in the event of even a small increase in storm rainfall. (Mayor of London, 2007).

Source: OECD (2008a), Competitive Cities and Climate Change: OECD Conference Proceedings, Milan, Italy, 9-10 October 2008, OECD, Paris.

Adaptation is also made difficult by the fact that modifications to urban infrastructure and the built environment are expensive and occur incrementally over long periods of time. For instance, transportation and flood control infrastructure can be built to withstand a wide range of extreme weather events, but such infrastructure generally lasts decades, heightening the need to incorporate extreme climate scenarios into current infrastructure design and planning. Vulnerability to storm and hurricane risks can be reduced through spatial planning and land management, but land-use changes occur over decades and urban buildings typically last 50 to 100 years, if not longer. As a consequence, urban adaptation options often must be anticipated by at least decades to be effective. Current adaptation efforts are challenged by the uncertainty about the nature of future climate change impacts ${ }^{10}$ especially given that adaptation costs are immediate while benefits are delayed and based on present assumptions of climate impacts (Hallegatte et al., 2008). Adaptation to the most catastrophic events would require costly investments while running a strong risk of being unnecessary (Jones, 2004) at the least, and could potentially contribute to greater climate change damage by offering a false sense of security that puts larger population at risks if impacts exceed expectations (Nicholls et al., 2008).

\subsection{Coastal flooding risks}

Cities are highly concentrated in coastal zones, which puts a large portion of the urban population at risk from rising sea levels and intensifying storm surges. ${ }^{11}$ Mean sea level has risen 10-20 centimetres in the $20^{\text {th }}$ century, and while specific predictions are difficult, the IPCC expects sea levels to rise 30-50

10. Citing Hallegatte, 2006 and Hallegatte et al. 2007a

11. The US National Oceanic and Atmospheric Administration estimates that $53 \%$ of United States' population live in coastal regions (Crosset et al. 2004). 
centimetres by 2100 (IPCC, 2001a). ${ }^{12}$ Peak sea levels, which are most relevant for coastal planning as they characterise storm surges, may be rising even faster. Rising sea levels are a critical issue for major cities, particularly in developing countries (Table 2.1). Even in Europe, 70\% of the largest cities have areas that are less than 10 metres above sea level (McGranahan et al., 2007). Projected sea level rise is also associated with significant loss of land in coastal regions. For example, a 0.3 metre sea level rise in the United States, which is on the low end of IPCC projections ( 0.2 to 0.6 meters), would erode approximately 15 to 30 metres of shoreline in New Jersey and 60 to 120 metres in California. ${ }^{13}$ Adaptation measures to combat sea level rise will be necessary because of the lag time between warming and its effects on glaciers. Even under scenarios where emissions are eliminated, sea level rise continues well after temperature has stabilised (Ruth \& Gasper in OECD, 2008a).

Table 2.1. Cities are highly concentrated in coastal zones

\begin{tabular}{|c|c|c|c|c|c|}
\hline \multicolumn{6}{|c|}{ Share of urban settlements whose land area intersects the } \\
\hline \multicolumn{6}{|c|}{ Low Elevation Coastal Zone (LECZ), by urban settlement size, 2000} \\
\hline Region & $<100 \mathrm{~K}(\%)$ & $\begin{array}{c}100-500 \mathrm{~K} \\
(\%)\end{array}$ & $\begin{array}{c}500 \mathrm{~K}-1 \mathrm{M} \\
(\%)\end{array}$ & $1-5 \mathrm{M}(\%)$ & $5 \mathrm{M}+(\%)$ \\
\hline Africa & 9 & 23 & 39 & 50 & 40 \\
\hline Asia & 12 & 24 & 37 & 45 & 70 \\
\hline Europe & 17 & 22 & 37 & 41 & 58 \\
\hline Latin America & 11 & 25 & 43 & 38 & 50 \\
\hline Australia and New Zealand & 44 & 77 & 100 & 100 & N/A \\
\hline North America & 9 & 19 & 29 & 25 & 80 \\
\hline Small island states & 51 & 61 & 67 & 100 & N/A \\
\hline World & 13 & 24 & 38 & 44 & 65 \\
\hline
\end{tabular}

Recent OECD work demonstrates that a $50-\mathrm{cm}$ sea level rise, combined with predicted socioeconomic development patterns, could result by 2070 in a tripling of the population at risk of coastal flooding and a tenfold increase in the amount of assets exposed, or from 5\% of 2008 GDP to 9\% of 2070's GDP (Figure 2.1). About two-thirds of the increase in population exposed to coastal flooding is due to the socio-economic factors that drive coastal settlement, while the remaining third is expected to result from climate change and land subsidence. Port cities most at risk for coastal flooding are located both in rapidly growing developing countries such as India and China (e.g. Kolkata, Shanghai, Guangzhou) and in wealthy countries such as the United States (e.g. Miami, New York City), the Netherlands (e.g. Rotterdam, Amsterdam) and Japan (e.g. Tokyo, Osaka) (Nicholls et al., 2008). Adaptation efforts can also incur costs in the form of negative side effects. For example, coastal infrastructure to protect the city against storm surge, such as sea walls, can damage local landscapes, ecosystems and beaches, which may result in a reduction in tourism. Fisheries industries may also suffer as infrastructure to reduce coastal flooding can damage coastal ecosystems, on which $90 \%$ of fish species depend during at least one stage of their life cycle (Hallegatte et al., 2008).

12. This is the variation between emission scenarios; the range including variation between climate models is 9 to 88 centimetres (IPCC, 2001c).

13. Ruth \& Rong (2006) cited in Ruth \& Gasper in OECD (2008a). 
Figure 2.1. Top 20 port cities' exposed assets (a) and exposed population (b)

Future scenario with socio-economic development, subsidence and climate change

a.

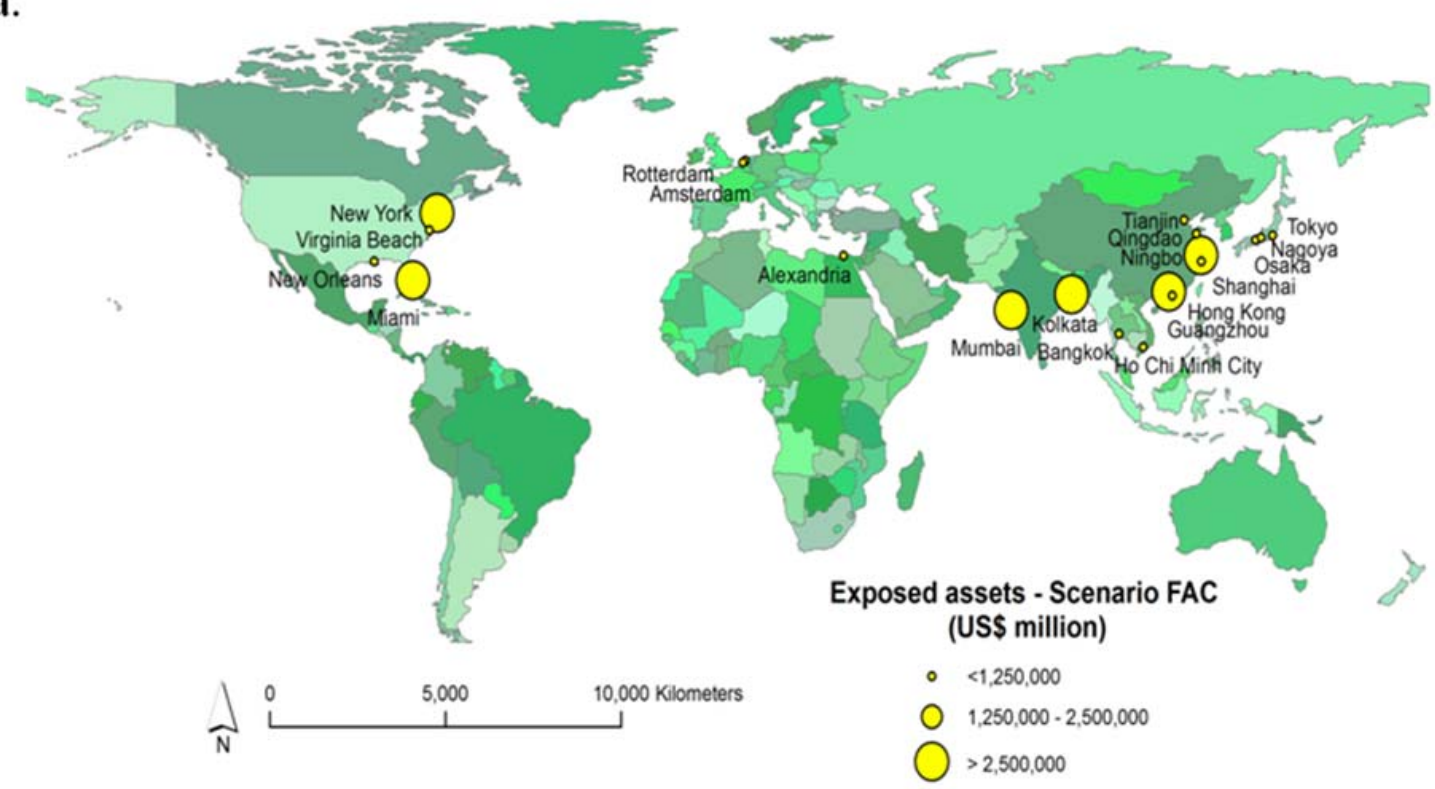

b.

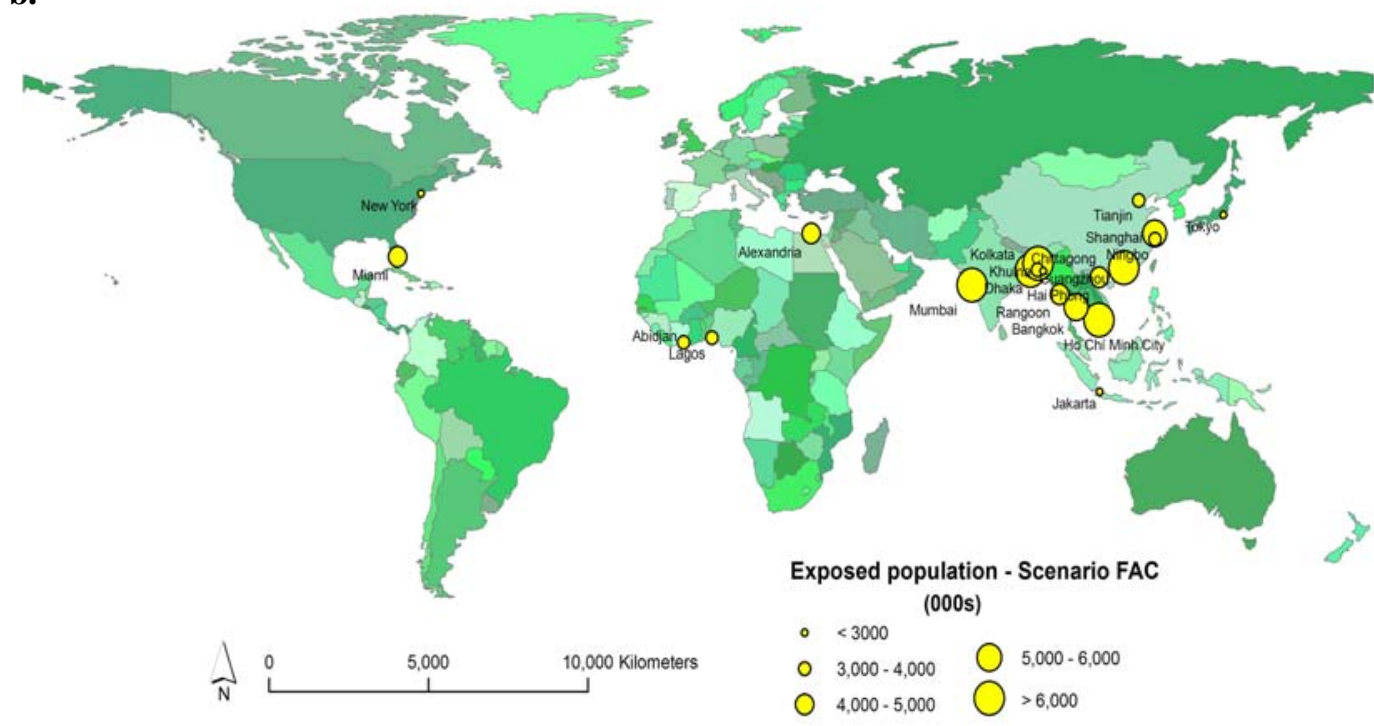

Note: Note the different scales in the key.

Source: Nicholls, R. et al. (2008), "Ranking Port Cities with High Exposure and Vulnerability to Climate Extremes", OECD Environment Working Papers No. 1, OECD Publishing, Paris. 


\subsection{Precipitation and storm impacts}

More frequent storm events caused by climate change can result in hydrological changes that stress the capacity of drainage infrastructures, sewage systems and water treatment facilities in cities (Ruth \& Gasper in OECD 2008a). The increasing frequency of severe weather events, combined with sea-level rise, can cause sanitation problems if urban infrastructure is ill-equipped to accommodate a sudden influx of water (Kamal-Chaoui in OECD 2008a). Heavy precipitation events wash urban pollutants into rivers and lakes, and can reduce water quality in reservoirs by increasing turbidity. ${ }^{14}$ As intense precipitation occurs more often, urban planners will have to confront multi-faceted problems of controlling and managing precipitation inflows and protecting existing water supplies. Urban runoff and failures of combined sewer overflows and municipal sewer plants can all introduce pathogens into water systems that pose a variety of health risks; documented cases globally range from wound infection to kidney failure. ${ }^{15}$ Aside from extreme storms, changes in precipitation patterns will be critical. Scientists expect a general trend of increasing precipitation in middle latitudes and decreasing precipitation near the Equator, but the effects will be highly variable on the local scale, and the technology to predict them accurately does not yet exist. ${ }^{16}$ There is also recent evidence that local precipitation rates may be impacted by urbanisation and that historically arid regions may experience an increase in storms. For example, an analysis of arid regions revealed a statistically significant increase in precipitation in Phoenix, Arizona, and suburbs during its urbanisation period, compared to its pre-urbanisation period. This study also noted increased variability in precipitation for this region and for Riyadh, Saudi Arabia (Ruth \& Gasper in OECD 2008a). ${ }^{17}$

Floods are one of the most costly and damaging disasters, and will pose a critical problem to city planners as they increase in frequency and severity. The frequency and severity of flooding has generally increased in the last decade compared to 1950-1980 flood data, along with the frequency of floods with discharges exceeding 100-year levels. ${ }^{18}$ More frequent severe precipitation events are predicted to cause a greater incidence of flash flooding and urban flooding (Ruth \& Gasper in OECD 2008a). There is a need to evaluate existing infrastructure for treating and transporting water and to better understand how the existing systems can handle excess precipitation or an influx of seawater. The City of London Corporation, for example, has identified "hot spots" vulnerable to flooding, where it plans to install new sustainable drainage system and invest in maintenance to accommodate the expected rise in the volume of precipitation (Kamal-Chaoui in OECD 2008a). In addition to the obvious structural damages and loss of life that they can cause, floods can short-circuit transformers and disrupt energy transmission and distribution, paralyze transportation, compromise clean water supplies and treatment facilities, and accelerate spread of water-borne pathogens. ${ }^{19}$ Socio-economic models of future flood damage in cities (e.g. Boston, Massachusetts; London) independently predict vast increases in spending on damages due to climate change in the absence of adaptive infrastructure changes (Ruth \& Gasper in OECD 2008a). ${ }^{20}$ Cityspecific storm risk assessments are rare. One study of New York City calculated projected damages of approximately $0.1 \%$ of Gross Regional Product, annualised, and a probable maximum loss of $10-25 \%$ of GRP for one event (Hunt \& Watkiss, 2007).

14. Frederick \& Glick (2000) and Miller \& Yates (2006) cited in Ruth \& Gasper in OECD (2008a).

15. Nuzzi \& Waters (1993) and Rose et al., (2001) cited in Ruth \& Gasper in OECD (2008a).

16. IPCC (2001c) cited in Ruth \& Gasper in OECD (2008a).

17. Shepard (2006) cited in Ruth \& Gasper in OECD (2008a).

18. Kron \& Berz (2007) cited in Ruth \& Gasper in OECD (2008a).

19. IPCC (2001) and Ruth \& Rong (2006) cited in Ruth \& Gasper in OECD (2008a).

20. Kirshen et al. (2005), Hall et al. (2005) and Choi \& Fisher (2003) cited in Ruth \& Gasper in OECD (2008a). 


\subsection{Heat impacts and heat-island effects}

Cities will not only face risks from floods and rising sea levels, but also significant increases in temperatures and the frequency of heat waves. According to the IPCC A2 scenario, average annual temperatures projected for the period 2070-2100 indicate that urban population in European cities will feel as if the weather of the city had moved southwards. London will feel more like Bordeaux, Paris much more like Marseilles and Madrid and Rome will be as hot as North African cities (Figure 2.2). However, these changes could be even more acute if action is delayed. With atmospheric GHG stock already at around 430 ppm $\mathrm{CO}_{2}$, delaying action will raise GHG stock levels beyond $500 \mathrm{ppm}$ in less than 25 years (Dietz \& Stern, 2008). The implication is that such levels increase significantly the chances of a three degree increase in temperature.

Figure 2.2. Apparent southward shift of European cities due to climate change, 2070-2100
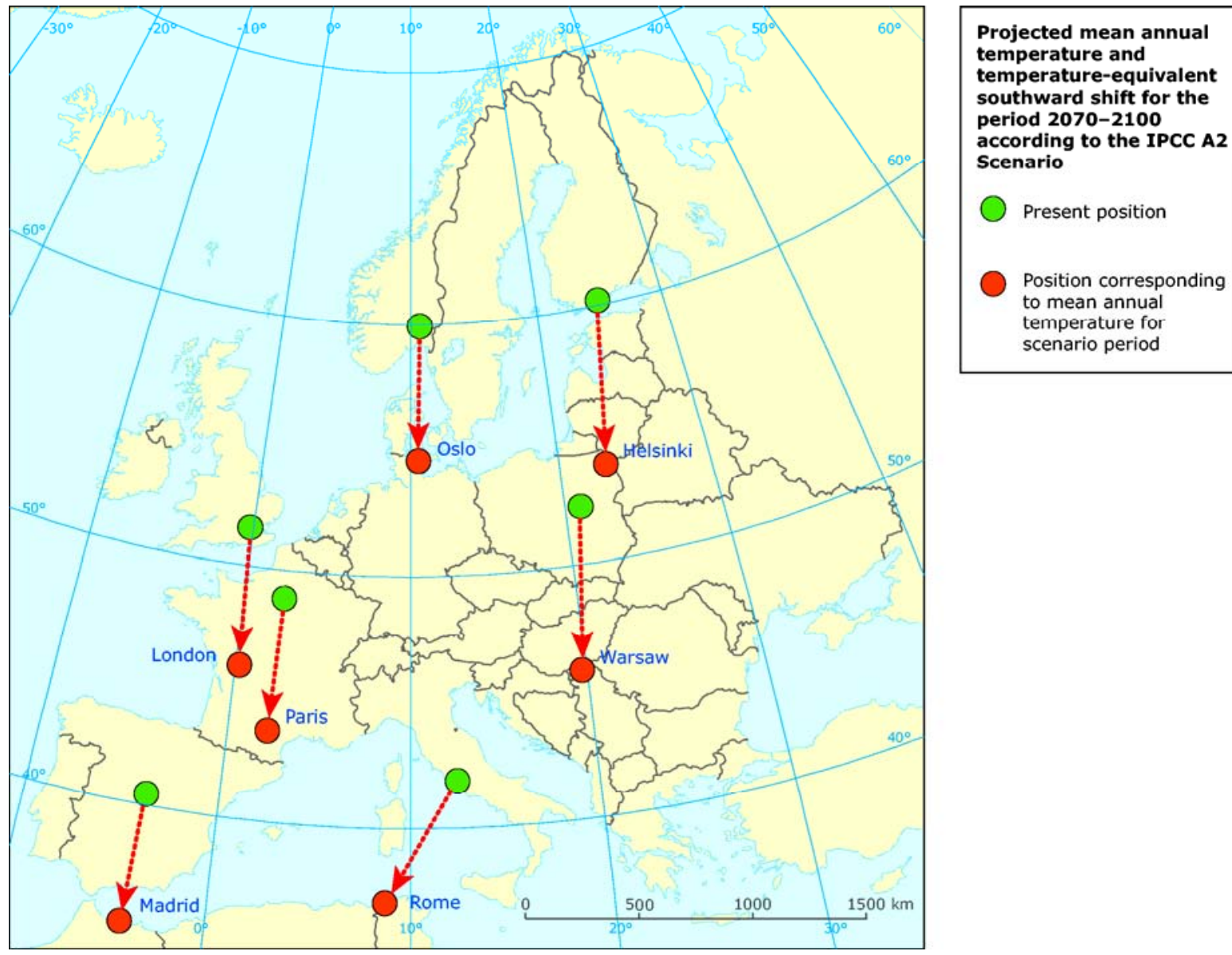

Present position

Position corresponding

to mean annual

temperature for

scenario period

Source: Hiederer et al. (2009a) cited in EEA (2009), Ensuring quality of life in Europe's cities and towns, EEA Report No 5/2009, EEA, Copenhagen.

Heat waves are likely to increase in severity and duration in the future, contributing to heat mortality in both developed and developing countries. These increases will likely be more strongly felt in urban areas, as cities tend to have higher air and surface temperatures compared to rural areas. This is known as the urban heat island (UHI) effect, which is due to combined effects of structural interference with thermal radiation, low albedo of impervious surfaces and reduced transport of water into the atmosphere, known as 
evapotranspiration (Ruth \& Gasper in OECD, 2008a). ${ }^{21}$ The UHI effect is suspected of warming urban areas $3.5-4.5^{\circ} \mathrm{C}$ more than surrounding rural areas and is expected to increase by approximately $1^{\circ} \mathrm{C}$ per decade. $^{22}$ The temperature differences between urban and surrounding rural areas can reach up to $10^{\circ} \mathrm{C}$ for large urban agglomerations. The built environment, including buildings and roadways that absorb sunlight and re-radiate heat, combined with less vegetative cover to provide shade and cooling moisture, all contribute to cities being warmer and susceptible to dangerous heat events (OECD, 2009b).

The UHI effect can have negative public health effects in urban area as the impacts of heat waves can be worse in urban areas. For example, in the 2003 European Heat Wave, a higher percentage of the causalities in France came from urban areas (Hallegatte et al., 2008). Increasing temperatures can affect mortality in a number of ways, including heat-induced mortality, famine, exacerbation of non-infectious health problems and spread of infectious disease (Ruth \& Gasper in 2008a). Climate change can also exacerbate the effects of urban air pollution. UHI effects can generate changes in local atmospheric cycles. Changes in solar influx and chemical composition of near-ground air masses can cause formation of photochemical smog and reduce air circulation, which would otherwise diffuse the concentration of air pollutants (Hallegatte et al., 2008). Warmer temperatures due to climate change and UHI effects, all other things held constant, may increase concentrations of conventional air pollutants, such as ozone and acid aerosols, as well as emissions of particulates and allergens. ${ }^{23}$ Moreover, higher temperatures due to climate change may actually make it more difficult to control the formation of some pollutants, such as ozone, which can exacerbate chronic respiratory diseases and cause short-term reductions in lung function. ${ }^{24}$ One study estimates these effects in the New York metropolitan area to increase mortality rates in the 2050s due to ozone-related acute climate change impacts alone (OECD, 2009b). ${ }^{25}$

By aggravating heat-related climate change impacts, UHI effects are likely to increase future energy demand (Box 2.2). ${ }^{26}$ In the United States, for example, an estimated $3 \%$ to $8 \%$ of annual electricity use is required to offset UHI effects (Ruth \& Gasper in OECD, 2008a). ${ }^{27}$ Adaptation to rising temperatures by increasing air condition can also further increase UHI effects. For instance, massive air conditioning has been shown to increase UHI effects up to $1^{\circ} \mathrm{C}$ (Hallegatte et al., 2008).

21. Oke (1982) cited in Ruth \& Gasper in OECD (2008a).

22. Voogt (2002) cited in OECD (2009b).

23. Aron \& Patz (2001) cited in OECD (2009b).

24. Bernard et al, (2001) cited in OECD (2009b).

25. Knowlton et al., (2004) and Hunt \& Watkiss (2008) cited in OECD (2009b).

26. McPherson (1994) cited in Ruth \& Gasper in OECD (2008a).

27. Grimm et al., (2008) cited in Ruth \& Gasper in OECD (2008a). 


\section{Box 2.2. The urban heat island effect}

The built environment, which is concentrated in cities, reflects less sunlight, absorbs more heat and retains it longer than vegetation does. In addition, the concentration of energy use leads to a concentration of waste heat. Because of this, cities are consistently several degrees warmer than their surroundings, particularly at night. This exacerbates higher temperatures due to global warming, and participates in several feedback cycles with it.

The vicious cycle of business as usual:

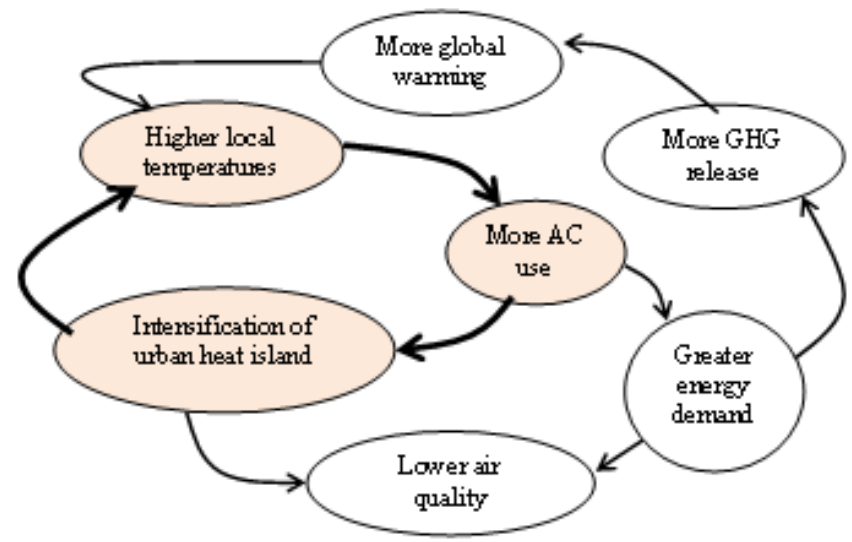

A more virtuous cycle of mitigation and adaptation can be activated by policies that limit the urban heat island effect, such as green roofs, tree cover and permeable and light-coloured surfaces:

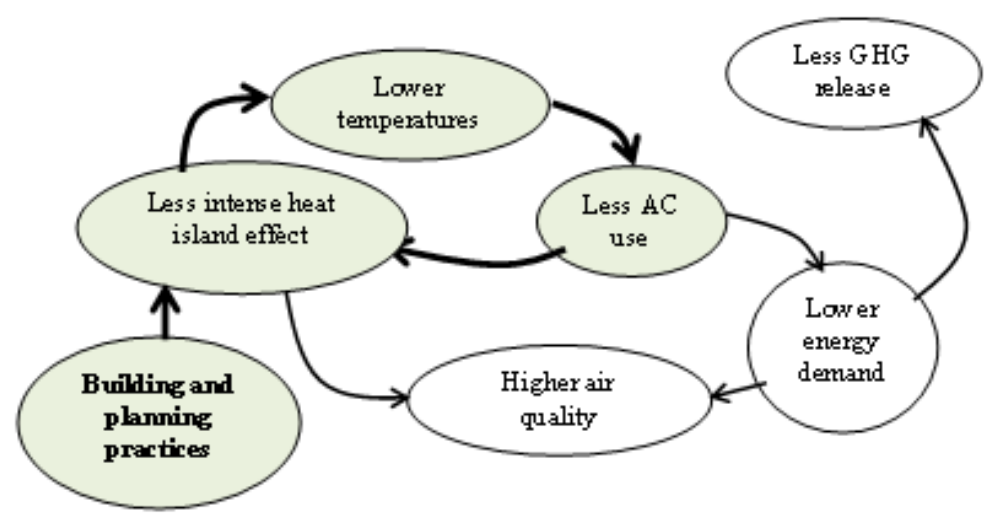

Source: OECD (2008a), Competitive Cities and Climate Change: OECD Conference Proceedings, Milan, Italy, 9-10 October 2008, OECD, Paris.

\subsection{Effects of increased drought and water scarcity}

Climate change may intensify competition for water. Cities generally rely on their immediate surroundings for water. While the effect of climate change on the water resources of a particular city cannot be predicted at present, the competition for water can be expected to intensify in the areas that become dryer than they are now. Since current water management systems are designed for historical 
weather patterns, some adjustment will probably be required in most places (Hitz \& Smith, 2004). Areas most likely to be affected include those that rely on snow melt for water over the course of the summer, since winter snow packs in most places will decline (IPCC, 2001b). This will exacerbate the pressure on water resources caused by rising population and affluence (AAAS, 2006) and require revision of urban water supply strategies (Box 2.3). As much as 50\% of the urban population in Asia and Africa already lacks adequate provision of water and sanitary services (Ruth \& Coelho, 2007). Drinking or recreational water can be contaminated by sewage backup, and microbial/chemical agents and biotoxins can be introduced into the water supply. Urban nitrogen pollution is a common characteristic of cities that further stress hydrological cycles and the clean water available. Salinisation of groundwater and surface water is a critical problem that reduces the availability of potable water and can spread harmful pollutants through urban water systems. Cases of saltwater intrusion are nearly ubiquitous among coastal cities, documented in diverse environments including the eastern United States, the coast of Thailand, as well as both Chinese and Vietnamese deltas. ${ }^{28}$ Costs of desalination are high, at approximately USD 1.00 per square meter to generate potable water from seawater, USD 0.60 per square meter to convert brackish water and 0.02 per square meter for freshwater chlorination (Ruth \& Gasper in OECD, 2008a). ${ }^{29}$

\section{Box 2.3. Barcelona's response to drought}

Barcelona experienced a major drought after two consecutive autumns of insufficient rainfall in 2006 and 2007. The situation was so bad that the city had forecast a possible interruption of the water supply to households and was forced to launch a series of emergency plans to safeguard supplies of drinking water. The city developed a water supply strategy for the period up to 2030 , based on diversification of sources, including targeting consumption savings through publicity campaigns, free distribution of water-saving devices and time restrictions on some ornamental and recreational use; recovery of local aquifers, using new pollution-control technologies, to decrease dependency on river water; water purification of around 290 hectometres of water for the whole metropolitan area; plans for an extension of networks for the transport of purified water; and the opening in 2009 of a desalination plant (although the city recognised this technology entails high energy consumption). Barcelona is also extending its current network of 11 rainwater reservoirs to 17 by 2011 , which will raise the city's collection capacity by $83 \%$.

Source: OECD (2008a), Competitive Cities and Climate Change: OECD Conference Proceedings, Milan, Italy, 9-10 October 2008, OECD, Paris.

Higher air temperatures and more frequent droughts can cause increasing demand for household and industrial use of water in urban areas. ${ }^{30}$ Although modelling evidence has not shown these increases to be dramatic, ${ }^{31}$ effects may be exacerbated, as population growth is concentrated in cities. Increases in temperature vary significantly by region, making it difficult to predict impacts on a given area based on global or broad regional estimates of temperature change. Modelling estimates for the United States have suggested large costs to meet increasing demand as temperature rises through 2060, while studies on Greece have predicted decreasing costs under certain climate change scenarios. ${ }^{32}$ Regional variation has proven significant at the state level in the United States, emphasising the need for understanding not only the potential regional effects of climate change, but also the differences in manifestation of these impacts

28. IPCC (2001) cited in Ruth \& Gasper in OECD (2008a).

29. Z Zhou \& Tol (2005) cited in Ruth \& Gasper in OECD (2008a).

30. IPCC (2007) cited in Ruth \& Gasper in OECD (2008a).

31. Protopapas et al., (2000) cited in Ruth \& Gasper in OECD (2008a).

32. Morrison \& Mendelsohn (1998) and Cartalis et al. (2001) cited in Ruth \& Gasper in OECD (2008a). 
for various urban sectors (e.g. waste management, manufacturing and services) (Ruth \& Gasper in OECD 2008a). ${ }^{33}$

\subsection{More acute impacts on health and the poor}

Urban centres may be particularly vulnerable to some of the distributive impacts of climate change. Poor populations in both rich and poor nations are expected to be the most vulnerable to climate change in part due to the lack of resources and capacity to respond in a timely manner or to adapt or to move to less vulnerable areas. As Hurricane Katrina demonstrated, climate extremes may hit wealthy nations but can still fall the hardest on the poor, ${ }^{34}$ who lack the resources to respond quickly and effectively to protect themselves from extreme weather patterns. The urban poor may also be more exposed to flooding, since they are likely to occupy the cheapest land, sometimes illegally, or reside in floodplain areas such as the Dharavi slums in Mumbai or the New Orleans' $9^{\text {th }}$ Ward. ${ }^{35}$ They are also more vulnerable as they may use cheaper materials to build dwellings, often violating building or safety codes. This may increase vulnerability to storms or natural disasters as was shown by the collapsed structures from Hurricane Mitch (1998) (OECD, 2009b). Where a city's low level of development does not allow for expensive infrastructure investments or institutional capacity to protect the population adequately, a vicious cycle of vulnerability and poverty may result (Ibarrarán et al., 2009). Climate change can also have a disproportionately more severe impact on other more vulnerable members of the urban population, such as on women, the very young, the elderly and people whose health is already compromised (Ruth \& Ibarrarán, 2009).

Local strategies to reduce GHG emissions can also contribute to urban inequality. For example, the swift application of a transportation tax could have redistributive effects in urban areas by placing a larger burden on residents living farther from city centres, including those who have located there because affordable housing is unavailable closer; the impact may be lessened through a more incremental approach. Rising energy costs may incentivize behaviour that reduces GHG emissions, but higher costs leave those with little income to invest in energy efficiency measures exposed to higher energy prices. On the other hand, as the poor spend a greater share of the income on energy costs, they can disproportionately benefit from energy-efficiency programmes (Hallegatte et al., 2008). And, given their disproportionate vulnerability to climate change impacts, mitigation policies' benefits can outweigh their costs to poor residents.

Climate change can also impact cities by increasing rural-urban migration. According to the International Federation of the Red Cross, climate change disasters are now a bigger cause of population displacement than war and persecution. ${ }^{36}$ Estimates of the number of refugees currently displaced for reasons attributable to climate change currently range from 25 million to 50 million, compared to an official global refugee population of 20.8 million (Kamal-Chaoui in OECD, 2008a). ${ }^{37}$ A decrease in income in the agricultural sector due to a climate-related decrease in production could lead agricultural workers to migrate to the city in search of work. Rapid and unmanaged growth in urban populations can strain the availability of housing and basic infrastructures (particularly water and sanitation), increasing the potential for negative health impacts and vulnerability to natural disasters (Hallegatte et al., 2008).

33. Sailor (2001) cited in Ruth \& Gasper in OECD (2008a).

34. Mathew (2007) cited in OECD (2009b).

35. Corfee-Morlot et al. (2009) cited in OECD (2009b).

36. www.ifrc.org/what/disasters/about/factors/climate.asp.

37. These figures exclude environmental refugees. 


\subsection{The costs of urban inaction}

Most of the discussion of climate change impacts in the urban environment has focused on storm and flood-related damages, heat impacts, water use, and human health and welfare; however it is important to consider explicitly how current and potential changes directly and indirectly impact local economies. Economic impacts can determine future capacity to adapt and cope with the aforementioned issues associated with change. Direct costs from climate change impacts can be staggeringly high, especially when related to natural disasters and sea level rise (Box 2.4). Shoreline retreat in the United States costs between USD 270 billion to 475 billion per meter climb in sea level; analogous costs in developing nations can amount to one-third of annual GDP. ${ }^{38}$ Flooding is one of the most expensive disasters, with a single flood causing England, for example, to spend GBP 1 billion to repair damages in $2000 .{ }^{39}$ OECD (2008b) reported a wide range of estimates for the costs of adapting urban water infrastructures from a variety of empirical studies, on the order of hundreds of millions to billions of dollars per year. In sub-Saharan Africa, adaptations in urban wastewater treatment systems (new and existing facilities), could cost USD 2 billion to 5 billion per year, while in Toronto, Canada, similar improvements were valued at around USD 9 billion annually (Ruth \& Gasper in OECD, 2008a).

Indirect impacts can cripple local economic activity as well, when transportation, commercial and industrial activities are interrupted due to severe weather events. Economic impacts can have rebound effects in the job market and reduce tax revenue. These stresses on the local economy may limit investment opportunities and deplete funds for infrastructure innovations, leaving cities more vulnerable to future change (Ruth \& Gasper in OECD, 2008a). Ripple effects from outside the city can also result in costs. Decreases in productivity or income outside the city may lead to a decrease in demand and an increase in import prices that could in turn affect the profitability of many economic sectors in the city and the income of city inhabitants, as well as food security (Hallegatte et al., 2008).

\section{Box 2.4. The high costs of storms}

Storms are currently the costliest weather events in the developed world and some research, particularly from the insurance sector, quantifies the potential future costs of climate change. For example, $\mathrm{ABI}(2005)$ estimated that by the 2080s, there would be a $75 \%$ increase in costs of insured damage in a severe hurricane season in the USA, a $65 \%$ increase in costs of insured damage in a severe hurricane season in Japan, and a $5 \%$ increase in wind-related insured losses from extreme European storms. Swiss Re recently estimated that in Europe the costs of a 100-year storm event could double by the 2080s with climate change (USD50/EUR40 billion in the future compared with USD25/EUR20 billion today), while Nordhaus (2006) assessed the economic impacts of U.S. hurricanes (on the Miami coast and New Orleans) and estimated that the average annual hurricane damage will increase by USD8 billion at 2005 incomes $\left(0.06 \%\right.$ of GDP) due to the intensification effect of a $\mathrm{CO}_{2}$-equivalent doubling. Other estimates indicate that the cumulative contribution of changing climate risk and socio-economic development are likely to double worldwide economic losses due to natural disasters every ten years.

Source: Hunt, Alistair and Paul Watkiss OECD (2007a), "Literature Review on Climate Change Impacts on Urban City Centres: Initial Findings", OECD Environment Directorate Working Paper, 6 December 2007, OECD, Paris.

Most economic loss will come in the form of "hidden" costs, such as the costs of rerouting traffic, lost productivity, provision of emergency and continued aid, relocation and retraining, lost heritage, and urban ecosystem damage. In addition, higher risk and uncertainty stemming from global climate change imposes additional costs on the insurance, banking, financing and investment industries (CIER, 2007). In general,

38. IPCC (2001) cited in Ruther \& Gasper in OECD (2008a).

39. Zoleta-Nantes (2000) cited in Ruther \& Gasper in OECD (2008a). 
these costs will hit cities and their competitiveness. Because of the difficulty of estimating the value of non-market entities and services, costs of lost ecosystems and cultural heritage as well as health-related matters are often ignored in economic studies. However, they may constitute a significant portion of the total damages associated with climate change impacts. Studies also suggest that inaction on climate change will result in major health costs caused by increasing levels of water and air pollution and temperature extremes. For instance, total damages from air pollution emitted by the 10000 largest sources in the United States amount to 0.7 to $2.8 \%$ of the country's GDP. In China, damages from air pollution represent $3.8 \%$ of the GDP, and water pollution can cost nearly 2\% of GDP (OECD, 2008b). Such burdens and other "hidden" costs - increased health care expenses, lost productivity and retrofitted infrastructure - can only compromise cities' competitiveness.

Since emissions and pollution today will have an enduring effect far into the future, the temporal difference in value of money should be considered. It is generally agreed that costs and benefits incurred today have a greater value than those incurred in the future because of the opportunity cost of capital. The difference in the value is measured by the discount rate. Its precise size, however, is uncertain, and researchers may attribute different rates to it depending on their purpose or preference (OECD, 2008b). Putting off adaptation may increase future costs by increasing insurance rates. In reaction to the increased risk, many insurance companies are paying particular attention to their potential exposure to the effects of climate change and are considering raising their premiums. Already Swiss Re, one of the world's largest re-insurers, requires companies to disclose their climate strategy as part of its Directors and Officers Liability insurance application. In 2008, Ernst \& Young identified climate change as the top strategic risk for the industry (Kamal-Chaoui in OECD, 2008a). ${ }^{40}$

40. See: www.ey.com/Global/assets.nsf/International/Industry_Insurance_StrategicBusinessRisk_2008/USD file/Industry_Insurance_StrategicBusinessRisk_2008.pdf. 


\section{REFERENCES}

AAAS (American Association for the Advancement of Science) (2006), AAAS Atlas of Population and Environment, http://atlas.aaas.org.

CIER (Center for Integrative Environmental Research) (2007), “The U.S. Economic Impacts of Climate Change and the Costs of Inaction", www.cier.umd/climateadaption.

The City of New York (2007), "PlaNYC: A Greener, Greater New York”, April, www.nyc.gov/html/planyc2030/downloads/pdf/full_report.pdf

Dietz, Simon and Nicholas Stern (2008) "Why Economic Analysis Supports Strong Action on Climate Change: A Response to the Stern Review's Critics”, Review of Environmental Economics and Policy, Vol. 2, No. 1, pp. 94-113.

EEA (European Environment Agency) (2009) Ensuring quality of life in Europe's cities and towns, EEA Report No 5/2009, EEA, Copenhagen.

Hallegatte, Stéphane, Fanny Henriet and Jan Corfee-Morlot (2008), “The Economics of Climate Change Impacts and Policy Benefits at City Scale: A Conceptual Framework”, Environment Working Paper No. 4, OECD, Paris.

Hitchcock, David, (2009) “Chapter 7: Urban Areas”, in Jurgen Schmandt, Judith Clarkson and Gerald R. North (eds.), The Impact of Global Warming on Texas, 2nd ed., University of Texas Press, Austin, Texas, www.texasclimate.org/Home/ImpactofGlobalWarmingonTexas/tabid/481/Default.aspx

Hitz, S. and J. Smith (2004), "Estimating Global Impacts from Climate Change”, Chapter 2, The Benefits of Climate Change Policies, OECD Publications, Paris.

Hunt, Alistair and Paul Watkiss (2007), "Literature Review on Climate Change Impacts on Urban City Centres: Initial Findings”, OECD Environment Directorate Working Paper, OECD, Paris.

Ibarrarán, M. et al. (2009), "Climate change and natural disasters: macroeconomic performance and distributional impacts”, Environment, Development and Sustainability, Vol. 11, No. 3, Springer Netherlands, pp. 549-569.

IPCC (2001a), “Summary for Policymakers”, in R.T. Watson, and the Core Writing Team (eds.), Climate Change 2001: Synthesis Report, Contribution of Working Groups I, II, and III to the Third Assessment Report of the Intergovernmental Panel on Climate Change, Cambridge University Press, Cambridge and New York, pp. 1-34.

IPCC (2001b), “Hydrology and Water Resources”, in J.J. McCarthy, O.F. Canziani, N.A. Leary, D.J. Dokken and K.S. White (eds.), Climate Change 2001: Impacts, Adaptation, and Vulnerability, Contribution of Working Group II to the Third Assessment Report of the Intergovernmental Panel on Climate Change, Cambridge University Press, Cambridge and New York, pp. 1-17. 
IPCC (2007b), Climate Change 2007: Climate Change Impacts, Adaptation and Vulnerability, Contribution of Working Group II to the Fourth Assessment Report of the Intergovernmental Panel on Climate Change, M.L. Parry, O.F. Canziani, J.P. Palutikof, P.J. van der Linden and C.E. Hanson (eds.), Cambridge University Press, Cambridge.

Jones, Roger (2004), “Managing Climate Change Risks”, The Benefits of Climate Change Policies, OECD Publications, Paris.

Mansanet-Bataller, Maria, Morgan Hervé-Mignucci, Alexia Leseur, (2008) "Energy Infrastructures in France: Climate Change Vulnerabilities and Adaptation Possibilities", Mission Climat de la Caisse des Dépôts, Working Paper 1. www.aprec.fr/documents/08-10-MC-WP1_Energy-Infrastructures-inFrance_Mansanet\&al.pdf.

Mayor of London (2007), Action Today to Protect Tomorrow: The Mayor's Climate Change Action Plan, Greater London Authority, London, February, www.london.gov.uk/mayor/environment/climatechange/docs/ccap_fullreport.pdf

McGranahan, G., D. Balk, and B. Anderson (2007), “The Rising Tide: Assessing the Risks of Climate Change and Human Settlements in Low Elevation Coastal Zones", Environment and Urbanization, Vol. 19, International Institute for Environment and Development, London.

OECD (2007b), Screening Study: Ranking Port Cities with High Exposure and Vulnerability to Climate Extremes, Interim Analysis: Exposure Estimates, 9 November, 2007, OECD, Paris.

Nicholls, R., S. Hanson, C. Herweijer, N. Patmore, J. Corfee-Morlot, J. Chateau, and R. Muir-Wood (2008), "Ranking Port Cities with High Exposure and Vulnerability to Climate Extremes”, OECD Environment Working Papers No. 1, OECD, Paris.

OECD (2008a) Competitive Cities and Climate Change: OECD Conference Proceedings, Milan, Italy, October 9-10, 2008, OECD, Paris.

OECD (2008b), Environmental Outlook to 2030, September, OECD Publications, Paris.

OECD (2009b), “Cities, Climate Change and Multilevel Governance”, Environment Working Papers, OECD, Paris.

Ruth, M. (ed.) (2006), Smart Growth and Climate Change, Edward Elgar Publishers, Cheltenham, England, p. 403.

Ruth, M., K. Donaghy and P.H. Kirshen (eds.) (2006), Regional Climate Change and Variability: Impacts and Responses, Edward Elgar Publishers, Cheltenham, England, p. 260.

Ruth, M. and D. Coelho (2007), "Understanding and Managing the Complexity of Urban Systems under Climate Change”, Climate Policy, Vol. 7, pp. 317-336.

Ruth, M. and M. Ibarrarán (eds.) (2009), Distributional Impacts of Climate Change: Social and Economic Implications, Edward Elgar Publisher, Cheltenham, England. 


\section{ECONOMIC BENEFITS OF CLIMATE ACTION: THE URBAN DIMENSION}

Simultaneously addressing stabilisation of the climate and economic growth has become a challenging task for the international policy community. This apparent trade-off has been so far discussed in two ways. The first is to measure economic growth in a way that integrates the degradation of environmental assets in the calculation of GDP. The second is to take into account the discounted longterm economic benefits of climate stabilisation, by avoiding extreme future adverse events. Both approaches entail significant measurement and valuation problems. However, findings from a regional growth model disaggregated at the metropolitan level, presented in this section, show that the trade-off between economic growth and climate policy can be actually lower when local dimensions are taken into account. Namely, policies to reduce traffic congestion and increase urban density can have a significant effect on national GHG emissions levels while allowing the local economy to grow. Also, adaptation and mitigation policies can provide important benefits in the form of reduced energy costs, increased local energy security and improved urban health. This is particularly important for city and regional governments, which can be sensitive to immediate price increases and investment costs in exchange for the less-tangible and longer-term benefits of addressing global climate change.

\subsection{Impact of urban policies on global energy demand and carbon emissions}

A Computable General Equilibrium (CGE) model has been used to simulate a world economy divided into macro-regions in economic interaction with metropolitan OECD areas. More precisely, this modelling exercise has been carried out by employing the spatialised version of the IMACLIM-R CGE framework (Crassous et al., 2006). IMACLIM-R allows simulating the interactions between changes in energy consumption, carbon emissions and economic growth, given a set of policies and other exogenous factors (Box 3.1). ${ }^{41}$ Two types of urban policies are explicitly explored: i) urban densification ${ }^{42}$; and, ii) congestion charges. The results suggest that densification policies would increase people's propensity to use public transport, from $12.9 \%$ in the baseline scenario to $14 \%$ by 2050 with densification policies. As a consequence, the volume of private transport falls across the OECD, implying a decrease in the demand for oil. If cities were to become denser, total OECD energy demand would decrease from 2020 on, and would reach $0.6 \%$ less compared to the baseline (Figure 3.1). This is in line with previous evidence that urban form affects individuals' travel behaviour and consequently global environmental quality (Grazi et al., 2008). A similar result is obtained if congestion charges only are applied.

41. The baseline scenarios for both the IMACLIM-R and the OECD ENV-Linkages models, were made consistent through comparable exogenous assumptions on demographic trends, labour productivity, GDP trends (as a proxy for the intensity of economic activity), fossil energy prices, energy intensity of the overall economy and carbon tax trajectories.

42. Densification indicates policies that increase the number of people per square kilometre in a given urban area. These include restrictive and enabling policies. The former actively pursue densification through policies such as green belts, whereas the latter are those that allow activity to be drawn to the core such as public transportation systems or the elimination of distortions in the market such as taxes for deconcentration. 


\section{Box 3.1. A CGE Model of Metropolitan Economies}

The impact on climate change of policies at the metro-regional scale can be modelled using a general equilibrium approach that takes into account most of the factors that influence the way in which an economic system works. In particular, computable general equilibrium (CGE) models can be used in order to simulate a world economy divided in countries and groups of countries, multiple sectors, and production and consumption functions. The approach taken in this section involves the use of IMACLIM-R model (Crassous et al., 2006; see Annex A for details). The global CGE model employed in this section has been enriched by a metropolitan module representing the metropolitan economies and their interactions with the macro-level (GRAZI and Waksman, 2009). This module was calibrated on the OECD Metropolitan Database and consistently with the assumptions in the OECD ENV-Linkages model.

The model is based on the comparison of two scenarios: one without policy changes, the so-called baseline scenario (BS), and a climate policy scenario. The comparison of these two scenarios for each period enables quantification of the magnitude of the changes. Two particular local policies have been tested to explore possible impacts on the economy and on carbon emissions: densification policies and congestion charges. The densification policy can be interpreted as an indirect form of intervention whose primary effect is to reduce individuals' dependence on private transport for commuting. Densification is the increase in the number of inhabitants living in a given territorial unit, for instance, the number of inhabitants per square kilometre. In analyzing where an economy chooses to locate and under what determinants it distributes across available agglomerations, the metropolitan module in the IMACLIM$\mathrm{R}$ model draws on the new economic geography approach (Krugman, 1991). The static urban agglomeration structure is described by three main determinants: locally available active population, labour productivity, and urban density. Data are taken from the OECD Metropolitan Database. The long-run mechanism through which firms (and people consequently) agglomerate is driven by an agglomeration-specific attractiveness index that encompasses three main factors: the rate of capital return, the expected volume of production and the change in absolute number of firms. Firms therefore are attracted by cities with higher capital returns (determined by labour productivity), an increase in the size of markets (given by the expected volume of production) and the presence of other firms (so that they can establish backward and forward linkages). The model also allows for migration of people among regions and cities following firms' investment decisions. Higher-productivity cities will be able to offer higher wages and thus attract workers and skills, which completes the agglomeration cycle. Higher wages are assumed to be a compensation for workers as they need to cope with the external costs of the agglomeration, namely commuting, housing costs and local pollution.

Figure 3.1. Energy Demand with a Densification Policy

Percent difference in total OECD demand (densification vis-à-vis baseline scenario)

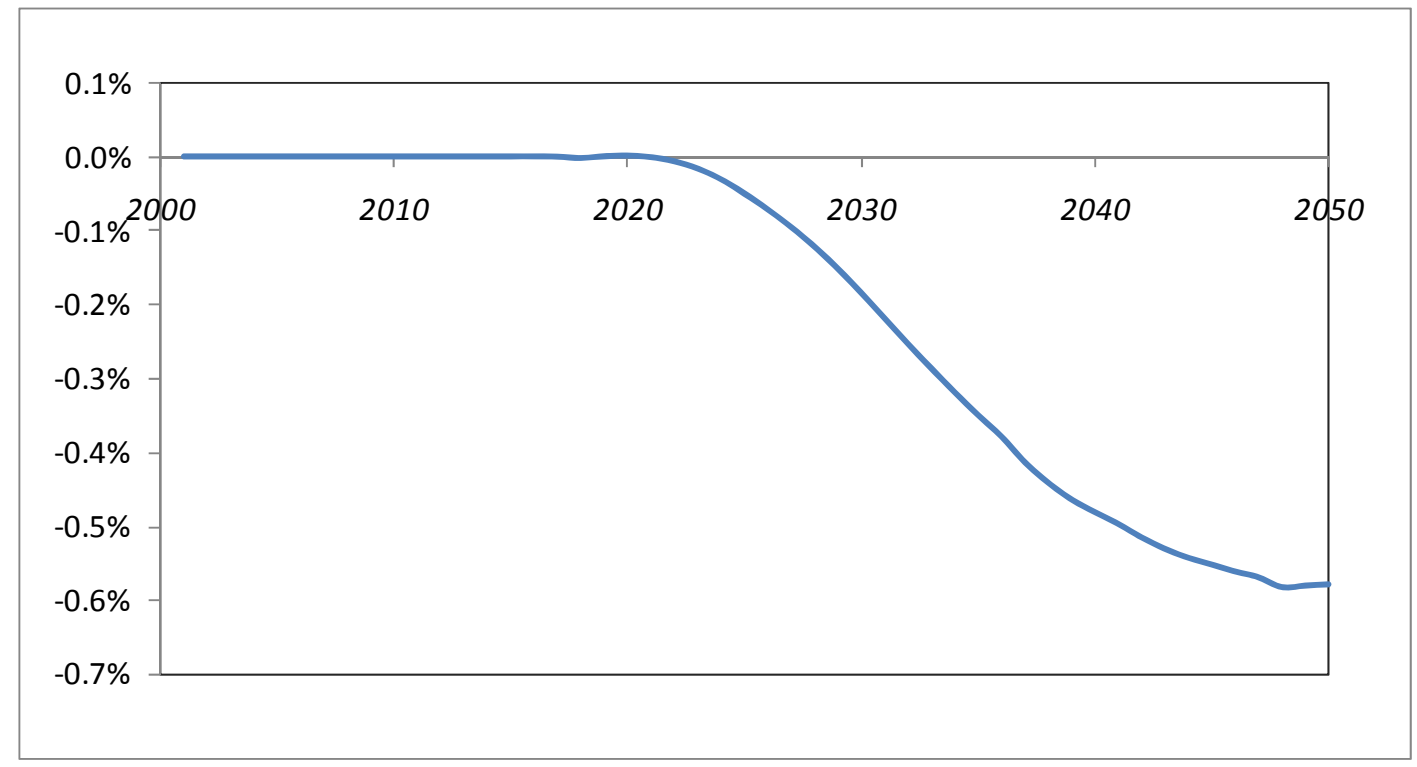

Note: The line shows the difference between demand of energy once cities are denser and the baseline scenario (or business as usual).

Source: Simulations from IMACLIM-R model based on the OECD Metropolitan Database. 
Following the implementation of densification and congestion charges, carbon emissions are reduced relative to the baseline, following a similar pattern to the one of energy demand from 2020 on (Figure 3.2). We consider the introduction of a local tax on the use of private vehicles by individuals for commuting purposes. This takes the form of a toll road of the type already implemented in some metro-regions (London and Stockholm among others). ${ }^{43}$ The toll road tax can be used in second instance to finance metro-region densification plans, thereby lowering the cost of densification.

Figure 3.2. Carbon Emission Reductions with a Densification Policy

Percent difference in total emission reductions in OECD (densification vis-à-vis baseline scenario)

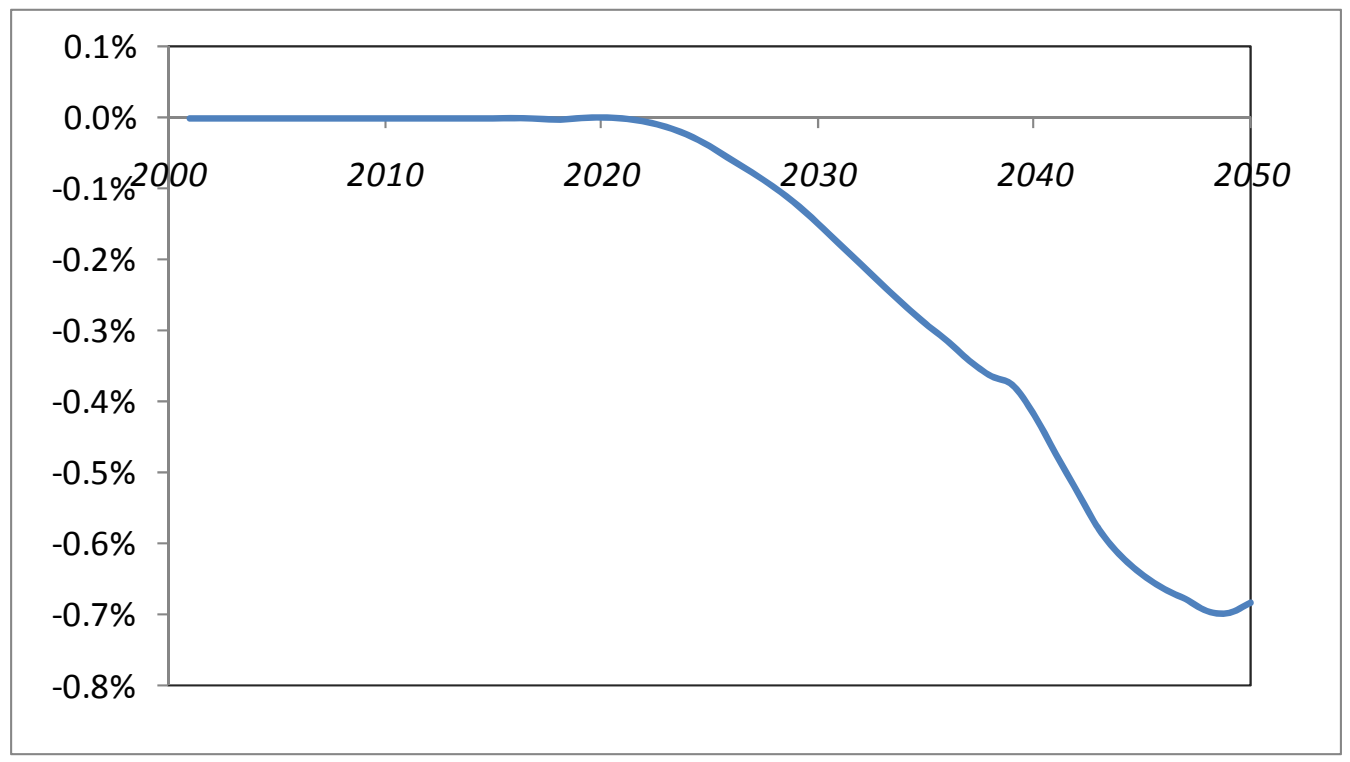

Source: Simulations from IMACLIM-R model based on the OECD Metropolitan Database.

\subsection{Environment and economic growth at the urban scale: from trade-offs to complementarity}

Densification and congestion charges are not the only effective tools to reduce energy demand and carbon emissions, however, they are important as they do not have a detrimental effect on long-term economic growth. ${ }^{44}$ In terms of impact on economic growth, the model generates three adjustment phases over time. First, an initial minor and short-lived economic expansion exists with both policies in an almost the same pattern until 2025, mainly driven by lower fuel prices as demand for oil falls. Second, economic growth becomes mildly negative after 2030 (Figure 3.3). As fuel prices fall, people find it less costly to drive again and so they increase their demand for oil and prices start to rise again, bringing about a shortlived economic contraction. Finally, a more important expansion of economic activity - more so under the

43. Such a road toll reduces average rather than marginal commuting costs by car (see Henderson, 1974 for the underlying economics of road pricing mechanisms).

44. Note that, in the IMACLIM-R model, the explicit representation of technologies through reduced forms of technology-rich bottom-up sub models allows for an explicit description of agents' decisions that drive the pace and direction of technical change. Moreover, consumption and investment choices in IMACLIM-R are driven by agents' imperfect foresight and explicit inertias on the renewal of equipments and technologies. The combination of these two features is the underlying explanation for moderate carbon abatement costs in IMACLIM-R's policy scenarios when compared to those in other general equilibrium models. 
congestion charges scenario - becomes possible around 2038 since the new increase in oil prices tends to accelerate technical change and thus spurs innovation and economic growth.

Figure 3.3. Economic Growth with Local Policies

Changes in GDP comparing densification and congestion charges vis-a-vis baseline scenario)

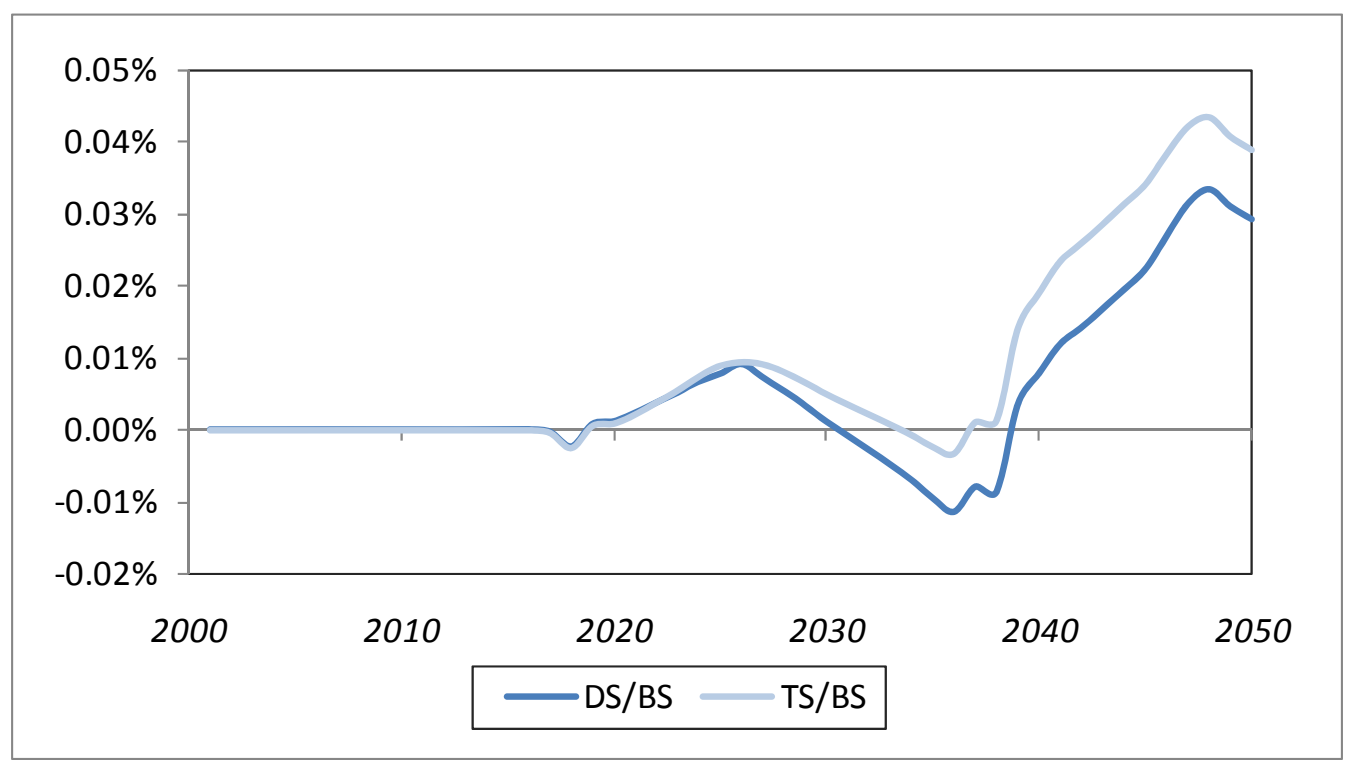

Note: DS refers to Densification Scenario; BS refers to Baseline Scenario; TS refers to Tax Scenario (in turn refer to the application of congestion charges).

Source: Simulations from IMACLIM-R model based on the OECD Metropolitan Database.

Underlying these results is the fact that technology-support policies embodied in the IMACLIM-R model can reduce and even offset the economic cost of curbing carbon emissions. In this regard, the discussion on how to address the climate change problem has mainly focused on the economic impact of carbon abatement. The latter has been evaluated at 1 to 3\% - depending on the discount rate used - of reduction in world GDP (cf. Stern, 2007 and OECD, 2009a). However, the OECD (2009a) acknowledges that the perceived trade-off between economic growth and mitigation policies is lower if technologysupport policies are considered: first because technology-support policies may help address innovation failures and boost economic growth; second because these policies postpone emission cuts until technologies become available and therefore reduce the impact on economic growth (OECD, 2009a).

In other words, the prospects of economic growth can actually be improved by providing incentives to innovation and growth. Emission reduction targets implied by climate policy bring about the need to improve processes and change products in a way that allow firms to comply with such regulations. Firms are then obliged to invest in improving their processes; many will fail to do so and perhaps be driven out of market, but many others may find new ways of doing things and in the long-run such innovation bursts will lead to greater economic progress. OECD (2009a) shows that R\&D policies and technology adoption incentives are better suited than price and command-and-control (CAC) instruments for correcting specific innovation and technology diffusion failures that undermine the creation and diffusion of emissionsreducing technologies.

Assessed at the regional or local level, policies to reduce carbon emissions are less opposed to economic growth than policies designed at the aggregate level. As mentioned previously, cities are major 
contributors to climate change through energy demand and on-road transportation; thus local authorities can play a part in reducing such demand and emissions by inducing changes in the way people live and commute in urban areas. Moreover, policy tools at the disposal of cities' authorities are effective in tackling emissions by avoiding costs that are generally assumed at the macro level. Local policies that change commuting patterns - and there could be other policies to reduce emissions that are not explored with the model, such as building codes - can effectively reduce carbon emissions and, in the long run, boost economic growth through innovation. The reason for this lower trade-off at the urban level lies in the fact that more complementarities among policies and economic activities can be observed at the local than at the aggregate national level.

To illustrate the combined effect of climate and urban policies, an emission reduction scenario was simulated at $450 \mathrm{ppm}$ (IPCC Scenario III, see Box 3.2). ${ }^{45}$ In terms of carbon abatement, this scenario corresponds roughly to more than a three-fold reduction in world carbon emissions by 2050, compared with the baseline (from above 30 to less than 20 GtCO2). Between 2005 and 2050, world GHG emissions are reduced by roughly half. In the OECD, the abatement is even bigger in relative terms (Figure 3.4). The associated GDP losses could represent up to one-third of a percentage point for the OECD (Table 3.1).

\section{Box 3.2. Emission Targets and Modelling of Climate Policy}

When carbon emission targets set to avoid serious climate change (e.g. limiting global warming at $2^{\circ} \mathrm{C}$ ) are compared with those considered in energy economics literature on mitigation scenarios, substantial discrepancies emerge. So far, most model assessments of mitigation costs have considered stabilisation levels of atmospheric greenhouse gas concentrations above $500 \mathrm{ppm} \mathrm{CO} \mathrm{CO}_{2}$ (e.g. Stern (2007) focuses on mitigation scenarios aiming at 500 to $550 \mathrm{ppm} \mathrm{CO} 2 \mathrm{eq}$ ). Although such stabilization levels are likely to be insufficient for keeping warming below $2^{\circ} \mathrm{C}$ (Meinshausen et al., 2006), they are used as a benchmark for climate-energy modelling exercises: out of 177 mitigation scenarios considered in the IPCC AR4, only six were grouped in the lowest stabilization category (corresponding to $445-490 \mathrm{ppm} \mathrm{CO}_{2} \mathrm{eq}$, which is consistent with a medium likelihood of achieving the $2^{\circ} \mathrm{C}$ target).

The rationale behind the limited number of studies considering reduction targets that are consistent with the $2^{\circ} \mathrm{C}$ target is that such low stabilisation can only be attained under a number of restrictive assumptions: $i$ ) a high degree of flexibility of substitution within the energy economic system; ii) a broad portfolio of technology options (including bioenergy, other renewables and carbon capture and storage); iii) a full and immediate participation in a global mitigation effort; and, iv) the necessity of generating negative emissions.

45. Note that a 450 ppm CO2 scenario roughly corresponds to a 530-550 ppm of all GHG scenario. 
Figure 3.4. Trends in carbon emissions under climate policy compared with the baseline World Carbon Emissions (GtCO2) (2005-2050)

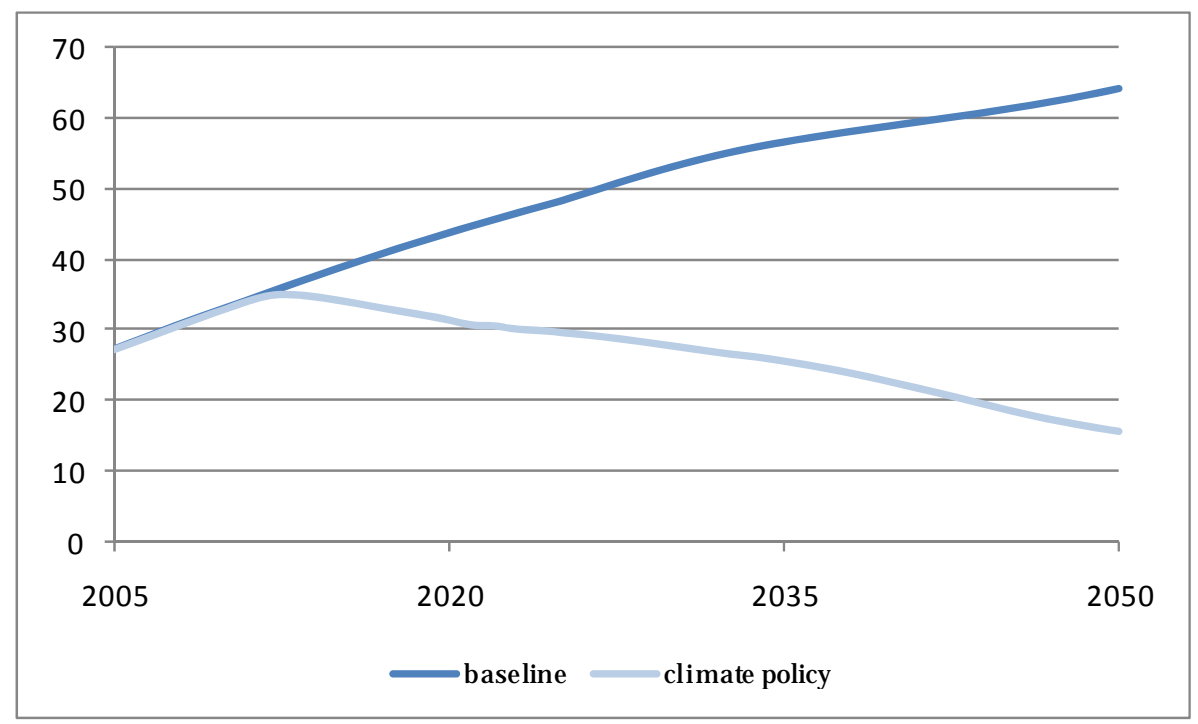

OECD Carbon Emissions (GtCO2) (2005-2050)

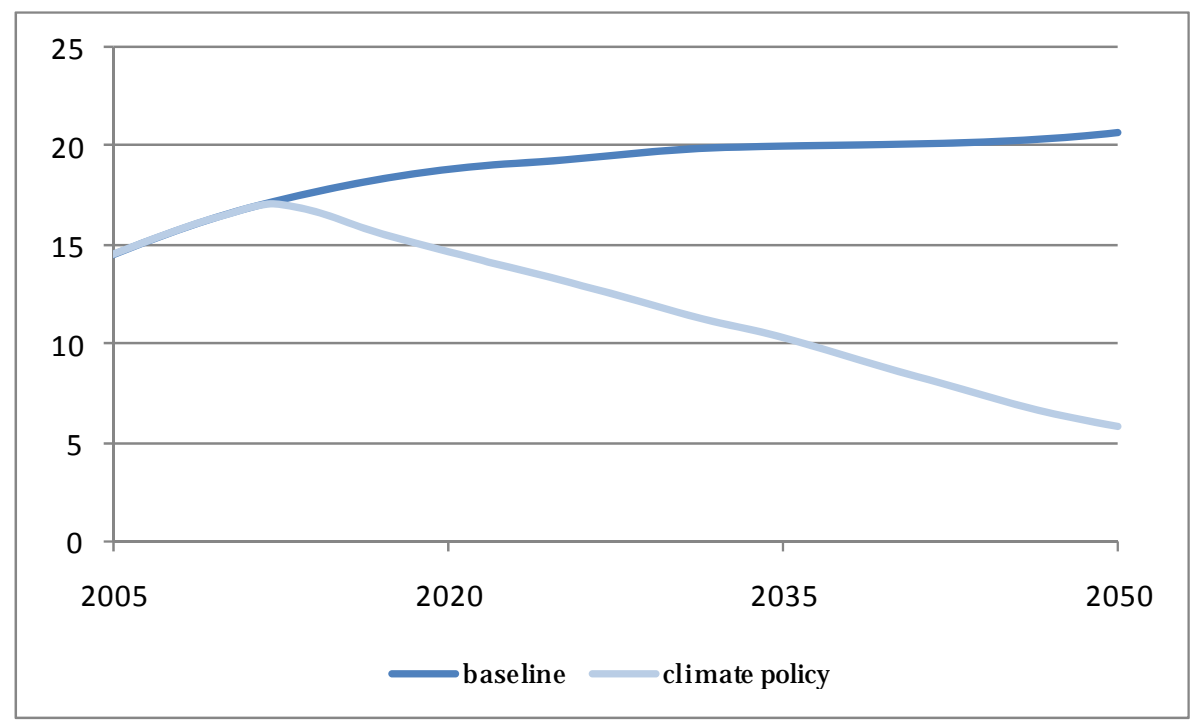

Source: Simulations from the IMACLIM-R model. 
Table 3.1. GDP changes under implementation of alternative climate policy packages

OECD

\begin{tabular}{l|l|l|l|l}
\hline \multirow{2}{*}{ Discount rate } & \multicolumn{2}{l}{$\begin{array}{l}\text { Stabilisation target: 450 ppm } \\
\text { (IPCC scenario III, 2007) }\end{array}$} & \multicolumn{2}{l}{$\begin{array}{l}\text { Stabilisation target: 410 ppm } \\
\text { (IPCC scenario II, 2007) }\end{array}$} \\
\cline { 2 - 5 } & Carbon price & $\begin{array}{l}\text { Carbon price + } \\
\text { Urban spatial policy }\end{array}$ & Carbon price & $\begin{array}{l}\text { Carbon price + } \\
\text { Urban spatial policy }\end{array}$ \\
\hline $1 \%$ & $-0.05 \%$ & $-0.04 \%$ & $-0.91 \%$ & $-0.85 \%$ \\
$7 \%$ & $-0.16 \%$ & $-0.15 \%$ & $-0.84 \%$ & $-0.67 \%$ \\
$7 \%$ & $-0.34 \%$ & $-0.33 \%$ & $-0.72 \%$ & $-0.37 \%$ \\
\hline
\end{tabular}

World

\begin{tabular}{l|c|c}
\hline \multirow{2}{*}{ Discount rate } & $\begin{array}{c}\text { Stabilisation target: } 450 \mathrm{ppm} \\
\text { (IPCC scenario III, 2007) }\end{array}$ & $\begin{array}{c}\text { Stabilisation target: 410 ppm } \\
\text { (IPCC scenario II, 2007) }\end{array}$ \\
\cline { 2 - 3 } & Carbon price & Carbon price \\
\hline $1 \%$ & $-0.88 \%$ & $-4.16 \%$ \\
$3 \%$ & $-1.01 \%$ & $-3.62 \%$ \\
$7 \%$ & $-1.15 \%$ & $-2.95 \%$ \\
\hline
\end{tabular}

Notes:

For a given discount rate r, GDP losses are actualized starting from 2010, year at which the urban densification policy is expected to be set in place;

Actualized GDP losses are computed by making use of the standard formula: $\sum_{t=2010}^{2050} \frac{G D P_{t}}{(1+r)^{t-2010}}$

Note that with high discount rates both, loses and gains, in the long term, yield low discounted values. In a scenario in which loses take place at the beginning of the period and gains at the end (such as in Figure 3.3) then the discounted cumulated losses are higher the discount rate.

Source: Calculations based on the IMACLIM-R model.

For the group of OECD countries, it was possible to simulate the joint effects of implementing both a carbon price and urban spatial policies. Under the $450 \mathrm{ppm}$ target, the gains from urban policies are relatively mild, although positive. If a more demanding target, such as $410 \mathrm{ppm}$, were to ${ }^{46}$ be reached, the complementarity between the two policies would be sizeable (around $0.3 \%$ of OECD GDP, when a strong discounting rate is used. The global GDP losses under the $410 \mathrm{ppm}$ climate policy scenario range from $3 \%$ to greater than $4 \%$ of GDP. Although it could not be simulated at this stage by lack of data, it is likely that urban policies implemented at a global scale could generate much larger benefits.

Going beyond the alleviation of carbon abatement costs, there are complementarities between carbon emission reductions and economic growth that can be found at the urban level. Using the attractiveness

46. This is the result for the OECD using the highest discount rate (7\%) It is the difference between $-0.72 \%$ with carbon prices alone and $-0.37 \%$ with densification added. 
index that is the heart of the agglomeration dynamics in the spatialised version of IMACLIM-R model, it can be seen that a group of highly attractive metro-regions are associated with high levels of carbon emissions stemming from commuting, such as Los Angeles, New York, Seoul, Tokyo or Toronto. In contrast, a number of metro-regions combine relatively low emission levels per automobile and high attractiveness (e.g. Auckland, Madrid, and Sydney, Figure 3.5). Commuting modes could therefore be at the heart of carbon emission patterns, implying that a more intensive use of public transport may contribute significantly to reducing GHG emissions.

Figure 3.5. Attractiveness and Carbon Emissions related to Automobiles across Metro-regions

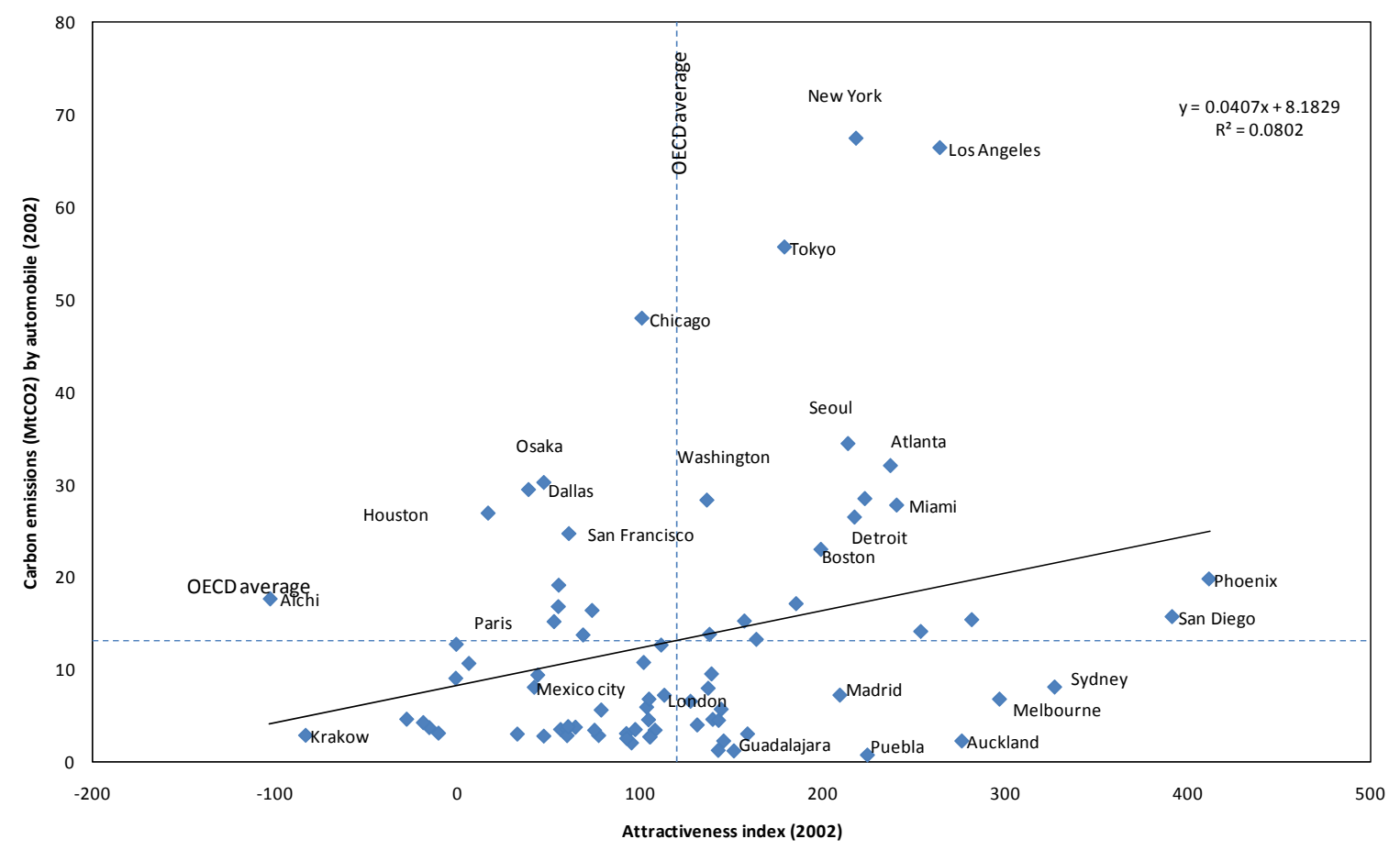

Source: Calculations based on the IMACLIM-R model and OECD Metropolitan Database.

In this context, low pollution levels will increasingly be a factor driving the attractiveness of urban areas. In the next two decades, cities that could become more attractive will do so while also curbing local pollution. According to the results of the CGE model, and if current trends are sustained, cities that could experience improvements in attractiveness by 2030 include Ankara, Auckland, Barcelona, Krakow, Lille, Melbourne, Montreal, Monterrey, and Toronto; they will do so while also trimming down local pollution (Figure 3.6). Conversely, metro-regions could lose attractiveness if they continue to pollute, as in the cases of Chicago, Los Angeles, New York, Osaka, Paris, Philadelphia, Seoul and Tokyo if current trends continue. 
Figure 3.6. Changes in Attractiveness and Local Pollution Emissions across Metro-regions

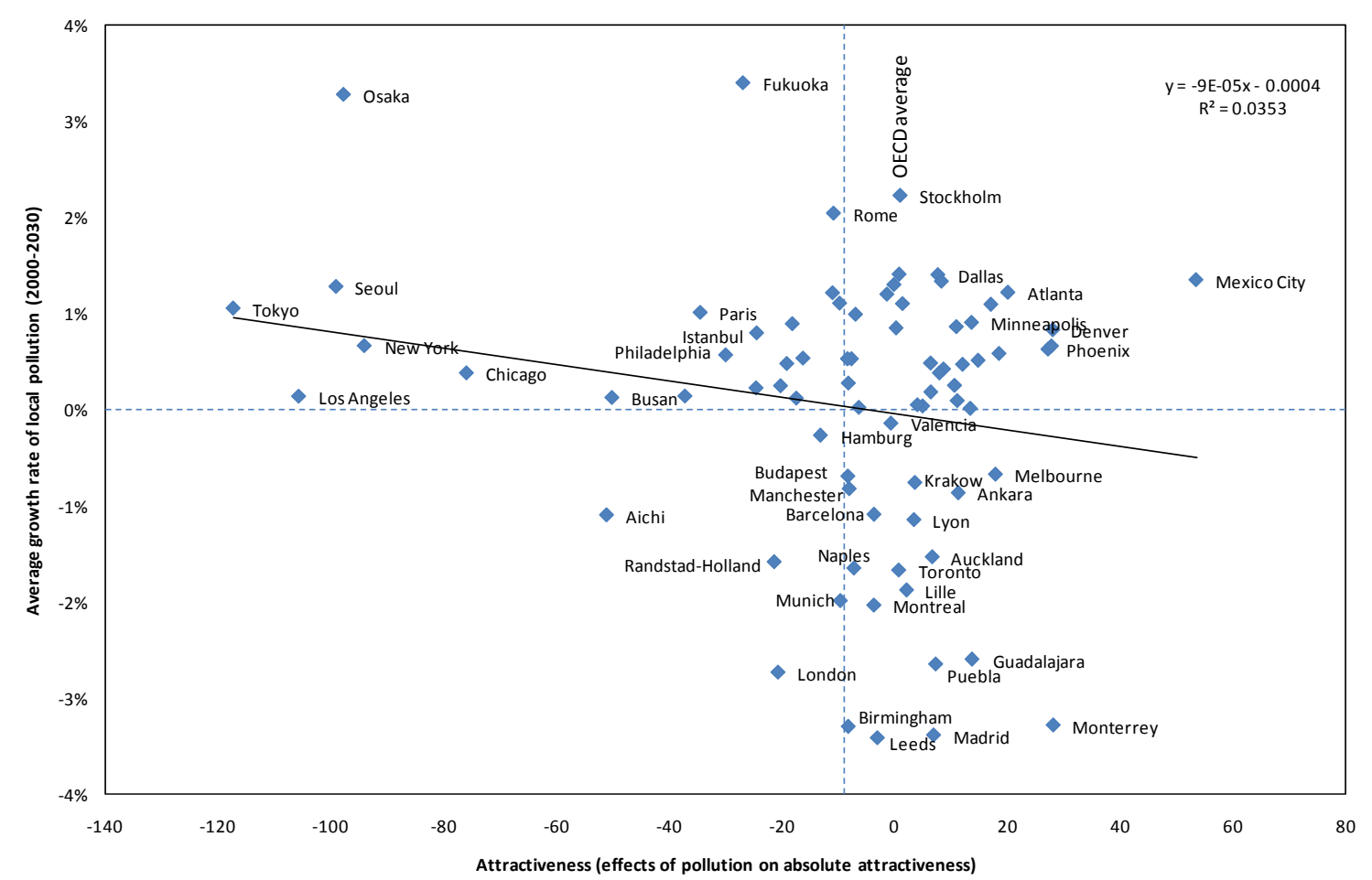

Source: Calculations based on the IMACLIM-R model and the OECD Metropolitan Database.

If local pollution is related to attractiveness, and the latter associated to population and firm creation, higher incomes, productivity and wages, then an environmental policy at the local level could generate economic gains. In particular, changing the urban structure by increasing cities' density and intensifying the use of public transportation may induce both improvements in attractiveness - and therefore economic performance - and in cities' responsiveness to climate change. As will be developed below, densification policies to respond to climate change can take the form of removing tax and development disincentives in the urban core, actively pursuing compact spatial form, and increasing mass transit networks and urban amenities in areas targeted for higher-density growth. These issues should be at the heart of the ongoing debate about a green growth strategy.

\subsection{Benefits for non-climate policies}

Additional local benefits resulting from emissions reductions and climate adaptation policies may also be partly responsible for a potential positive relationship between economic growth and GHG emissions reduction at the metropolitan regional level. These benefits can be grouped into five categories:

i) Public health improvements

ii) Cost savings and increased efficiency

iii) Energy security and infrastructure improvements

iv) Improved quality of life 
Each of these categories of benefits represent gains beyond those directly related to reduced GHG emissions or protection against climate change impacts. Table 3.2 provides an overview of some of the main co-benefits of mitigation policy in urban areas. The non-climate benefits of certain climate change policies are strong enough to warrant their implementation regardless of their impact on mitigating or adapting to climate change. In these cases they are considered "no-regrets" strategies (Hallegatte et al., 2008).

Table 3.2. Related aims and co-benefits of sector policies to reduce GHGs at urban scale

\begin{tabular}{|c|c|c|}
\hline Sector & Climate policy aims and benefits & $\begin{array}{c}\text { Other (non-climate change) } \\
\text { benefits }\end{array}$ \\
\hline $\begin{array}{l}\text { Electricity production and industrial } \\
\text { energy use }\end{array}$ & $\begin{array}{l}\text { Encourage fuel switching from coal } \\
\text { and oil to low or no-emission } \\
\text { energy sources, such as combined } \\
\text { heat \& power, renewable energy } \\
\text { and energy efficiency, to reduce } \\
\mathrm{CO}_{2} \text { emissions }\end{array}$ & $\begin{array}{l}\text { Raises urban air quality and limits } \\
\text { regional } \mathrm{SO}_{x} \text { and } \mathrm{NO}_{x} \text { air pollution, } \\
\text { preserve water quality, increase } \\
\text { energy security, all of which can } \\
\text { deliver local benefits }\end{array}$ \\
\hline $\begin{array}{l}\text { Residential \& commercial energy: } \\
\text { buildings, office equipment \& } \\
\text { appliances }\end{array}$ & $\begin{array}{l}\text { Lower energy use requirements of } \\
\text { housing and household services, } \\
\text { reduce } \mathrm{CO}_{2} \text { emissions }\end{array}$ & $\begin{array}{l}\text { Lower investment costs for energy } \\
\text { suppliers and possibly smooth load; } \\
\text { lower operating costs for } \\
\text { commercial entities \& consumers } \\
\text { and avoids regional air pollution } \\
\text { from (unnecessary) electricity } \\
\text { and/or heat generation; improve } \\
\text { comfort and affordability; raise } \\
\text { energy security }\end{array}$ \\
\hline Transport & $\begin{array}{l}\text { Raise the efficiency and emission } \\
\text { performance of vehicles and } \\
\text { manage demand, reduce } \mathrm{CO}_{2} \text { and } \\
\text { possibly other GHG emissions }\end{array}$ & $\begin{array}{l}\text { Lower congestion in cities and limit } \\
\text { harm to human health from urban } \\
\text { air pollution; lower dependency on } \\
\text { oil imports to raise energy security. } \\
\text { However co-costs may also exist } \\
\text { e.g. increased diesel fuel use } \\
\text { lowers } \mathrm{CO}_{2} \text { but increases } \\
\text { particulates, which have human } \\
\text { health risks; also catalytic } \\
\text { converters lower } \mathrm{NO}_{x} \text { emissions but } \\
\text { raise } \mathrm{N}_{2} \mathrm{O} \text { and } \mathrm{CO}_{2} \text { emissions }\end{array}$ \\
\hline Waste & $\begin{array}{l}\text { Minimise waste, increase recycling } \\
\text { and material efficiency in production } \\
\text { and packaging, reduce } \mathrm{CH}_{4} \\
\text { emissions }\end{array}$ & $\begin{array}{l}\text { Limit needs for costly and unsightly } \\
\text { landfilling; improve economic } \\
\text { performance }\end{array}$ \\
\hline
\end{tabular}

Source: Hallegatte, Stéphane, Fanny Henriet and Jan Corfee-Morlot (2008), "The economics of climate change impacts and policy benefits at city scale: a conceptual framework", Environment Working Papers No. 4, OECD Publishing, Paris.

Mitigating greenhouse gas emissions provides public health benefits by reducing many dangerous air pollutants (OECD, 2008a), making health benefits an important co-benefit of efforts to reduce GHG emissions in metropolitan regions. Indeed, reduction in urban air pollution is an important component of many national estimates of climate change mitigation co-benefits. ${ }^{47} \mathrm{GHG}$ emissions reductions may benefit human health to such a degree as to offset in large part the local costs of emissions reduction (OECD, 2009b). ${ }^{48}$

Policies to reduce GHG emissions through increasing energy efficiency can result in significant reductions in energy costs. Initiatives to improve building energy-efficiency are examples of no-regrets

47. Cifuentes (1999), Davis et al. (2000) and Kunzli et al. (2000) as cited in OECD (2009b).

48. OECD (2001), Davis et al., (2000) and IPCC (2007b) as cited in OECD (2009b). 
strategies because the energy savings achieved can compensate for the initial investment costs in as little as a few years (Hallegate et al., 2008). Policies to reduce the amount of energy already going to waste are cost-neutral if their implementation costs are compensated over time.

Both mitigation and adaptation policies can improve the security of local infrastructure and public services. Policies to mitigate greenhouse gases improve national security through reducing dependency on foreign energy sources and by reducing the risks involved in transporting highly combustible fossil fuels around the world (Schellnhuber et al., 2004). Adaptation measures can also improve the security of an area's energy supply. For example, improving the resilience, efficiency and redundancy of energy supply networks protects against interruptions in electricity service during extreme heat events and also reduces the risk of shortfalls (peak demand outstripping supply) or intentional attacks on the system. Similarly, some infrastructure to protect coastal cities from storm surge and flood risks can be economically justified even at current sea levels (Hallegate et al., 2008).

Many of the measures that mitigate climate change and that help adapt to its effects also make cities more liveable and therefore potentially more competitive. For instance, cities that reclaim land in flood plains as part of adaptation plans can make this land available to the public as parks or recreational land. This provides an amenity to residents, removes buildings and other infrastructure from flood plains, reduces the urban heat island effect, helps control downstream flooding, provides habitat for animals, and limits water pollution by slowing storm water runoff into large bodies of water. Efforts to reduce personal vehicle use and increase use of mass transit can improve public safety and reduce traffic congestion and noise (Hallegate et al., 2008).

Adaptation to climate change and mitigation of climate change can also be complementary strategies. Adaptation focuses on expanding the ability to cope with changes in climate, whereas mitigation focuses on reducing the amount of change through reducing emissions or removing greenhouse gases from the atmosphere through sequestration. In choosing a portfolio of mitigation and adaptation measures, it may be necessary to make investment trade-offs between them. However, adaptation and mitigation can go hand in hand, for example when developing a decentralized energy system based on locally available energy sources. Here, GHG emissions may be lower, as may be the vulnerability to large-area outages from severe weather impacts.

Synergies between policies to reduce GHG emissions and adapt to expected climate change impacts are particularly important at the urban level. For example, efforts to reduce building energy demand for cooling can also reduce urban heat island effects and prevent electricity shortfalls and blackouts during extreme heat events. On the local level, adaptation and mitigation policies are deployed through the same policy sectors, including land-use planning, transportation, and building sectors, as opposed to the global scale, where mitigation and adaptation goals are designed separately. This synergy presents opportunities to design urban mitigation and adaptation policies within a consistent framework (Hallegatte et al., 2008). 


\section{REFERENCES}

Crassous, Renaud, Jean-Charles Hourcade, and Olivier Sassi (2006), "Endogenous Structural Change and Climate Targets: Modeling experiments within IMACLIM-R”, The Energy Journal, Special Issue \#1, International Association for Energy Economics, pp. 259-276.

Fargione, J., J. Hill, D. Tilman, S. Polasky, P. Hawthorne (2008), “Land Clearing and the Biofuel Carbon Debt”, Science, Vol. 319, No. 5867, pp.1235-1237.

Grazi, Fabio and Henri Waksman (2009), "Urban Agglomeration Economies in Climate Policy: A Dynamic CGE Approach”, CIRED Working Paper Series, CIRED (Centre International de Recherche sur l'Environnement et le Développement), Paris.

Grazi, Fabio, Jeroen van den Bergh and Jos van Ommeren (2008), “An Empirical Analysis of Urban Form, Transport, and Global Warming”, The Energy Journal, Vol. 29, No. 4, pp. 97-122.

Hallegatte, Stéphane, Fanny Henriet and Jan Corfee-Morlot (2008), “The Economics of Climate Change Impacts and Policy Benefits at City Scale: A Conceptual Framework”, Environment Working Papers No. 4, OECD, Paris.

Henderson, Vernon (1974), "Road congestion. A reconsideration of pricing theory", Journal of Urban Economics, Vol. 1, No. 3, pp. 346-365.

Krugman, Paul (1991), “Increasing returns and economic geography”, Journal of Political Economy, Vol. 99, No.3, pp. 483-499.

Meinshausen, M. (2006), "What does a $2^{\circ} \mathrm{C}$ target mean for greenhouse gas concentrations? - A brief analysis based on multi-gas emission pathways and several climate sensitivity uncertainty estimates", in: Avoiding Dangerous Climate Change. J. S. Schellnhuber, W. Cramer, N. Nakicenovic, T. M. L. Wigley and G. Yohe (eds.), Cambridge University Press, Cambridge, UK.

Metz, B., O. Davidson, H. de Coninck, M. Loos and L. Meyer (2005), Carbon Dioxide Capture and Storage: Special Report to the IPCC, Cambridge University Press, Cambridge, UK.

OECD (2008a), “Competitive Cities in a Changing Climate: an Issues Paper” in Competitive Cities and Climate Change: OECD Conference Proceedings, Milan, Italy, October 9-10, 2008, OECD, Paris.

OECD (2009a), The Economics of Climate Change Mitigation: Policies and Options for Global Act ion beyond 2012, OECD, Paris.

OECD (2009b), “Cities, Climate Change and Multilevel Governance”, Environment Working Papers, OECD, Paris

Searchinger, T.R. et al. (2008), "Use of U.S. Croplands for Biofuels Increases Greenhouse Gases Through Emissions from Land-Use Change.” Science, Vol.319, No. 5867, pp. 1238-1240. 
Schellnhuber, J. et al. (2004), "Integrated Assessment of Benefits of Climate Policy”, The Benefits of Climate Change Policies, OECD, Paris.

Stern, Nicholas (2007), The Stern Review Report, Cambridge University Press, Cambridge, UK. 


\section{THE URBAN POLICY PACKAGE}

Many cities and metropolitan regions in the OECD are taking action on climate change - even in the absence of national policy or commitments - not only out of recognition of cities' contributions to and risks from climate change, but also of the opportunities to lower the potential tradeoffs between economic growth and environmental priorities. As primary consumers of energy, cities are searching for ways to lessen their impact and prevent damage from climate change while remaining competitive. Cities and regional governments - both small and large - are well positioned to tackle certain types of policies, particularly those relating to spatial development and the built environment, transportation, natural resources management, building and urban utilities. How can urban areas maximise the impact of their climate activities while minimising abatement costs? This section discusses opportunities to most effectively apply urban resources to address climate change by prioritising: $i$ ) policies that are natural extensions of existing modes of urban governance and ii) packages of complementary policies. This is followed by a consideration of the underlying impact of urban spatial development decisions on future energy demand and preparedness for climate impacts. Opportunities to apply long-term strategic planning to future GHG emissions and adaptation scenarios are then presented.

\subsection{Urban governance and policy complementarities}

A key indication of urban areas' increasing interest and sense of responsibility in responding to climate change is the proliferation of climate plans, strategies and policies in recent years. Many cities across OECD have identified opportunities for mitigation and adaptation activities and have implemented them through locally adapted and often innovative programmes. While some local and regional governments have taken action independently, others have benefited from guidance provided by networks of local governments. These include the Nottingham Declaration in the United Kingdom (signed by 300 local authorities ${ }^{49}$ ) and transnational networks such as ICLEI, the METREX EUCO ${ }_{2} 80 / 50$ project, and the Covenant of Mayors. ${ }^{50}$ Urban climate action has also developed in response to national government mandates, such as Japan's Act on Promotion of Global Warming Countermeasures, which requires local governments to formulate climate change action plans. ${ }^{51}$

The context for urban policymaking and programme implementation often involves multiple levels of governance. Cities often need to collabourate with other cities and higher levels of government - as well as private sector and non-governmental stakeholders - to gain the authority, technical expertise and funding needed for their climate policy goals. This can require vertical coordination among local, regional and national governments, and horizontal coordination among the range of agencies engaged in climate policy

49. www.energysavingtrust.org.uk/nottingham, accessed 18 November 2009.

50. ICLEI's Cities for Climate Protection was one of the first networks established, and counts over 680 cities as members from over 30 countries worldwide (www.iclei.org/climate-roadmap). The $\mathrm{EU} \mathrm{CO}_{2}$ 80/50 project, organised by METREX: The Network of European Metropolitan Regions and Areas, targets a reduction in GHG emissions by its member cities of $80 \%$ on 1990 levels by 2050

(www.eurometrex.org/ENT1/EN/Activities/activities.asp?SubCat1=EUCO2). The Covenant of Mayors is a commitment by signatory towns and cities to exceed $\mathrm{EU} \mathrm{CO}_{2}$ emissions reduction targets (www.eumayors.eu/).

51. Response to OECD “National-Local Climate Change Governance Practices Questionnaire” by Naoto Nakagawa, Japanese Ministry of Foreign Affairs, 10 August 2009. 
within a local government, as well as among the local governments within a region. In some cases, the role of local governments is to administer national programmes or apply for and redistribute national funding. In other cases, urban areas act independently of outside programmes and may even innovate policy solutions that get scaled up to the regional or national levels (OECD, 2009b). Urban areas in general engage in at least four modes of governance through which they can design and implement climate change policy responses. These (adapted from Kern \& Alber in OECD, 2008a and OECD, 2009b) are:

i) Self-governing: the municipality as consumer. Sub-national governments can limit their own consumption and ecological footprint through municipal operations management, including such efforts as promoting the energy efficiency of municipal buildings and the greening of public transport vehicles.

ii) Governing by provision: the municipality as provider. Governing by provision is accomplished by influencing infrastructure development, programme administration and service delivery in the provision of urban services (e.g., transportation, water, electricity, public housing, natural resources management, etc.).

iii) Governing by authority: the municipality as regulator. Local governments may enact regulations to curb $\mathrm{CO}_{2}$ emissions or adapt to climate change impacts if they have legal jurisdiction over relevant policy areas such as energy, transport, land use, waste and natural resources.

iv) Governing through enabling: the municipality as a facilitator. The municipality can facilitate coordination with private and community actors, such as by establishing public-private partnerships for the provision of services and infrastructure.

These modes of urban governance point to opportunities for local policy action on climate change in key urban sectors: land-use zoning, natural resources management, transportation, building, and to a lesser extent waste and water services. Self-governance particularly affects the climate impact and vulnerabilities of government-owned or managed infrastructure, buildings, property and natural resources. Governance through service provision shapes GHG emissions generated by mass transit networks, waste collection, water provision, and, in some cities, energy delivery, as well as these services' vulnerability to climaterelated disruptions. City and regional regulations allow urban governments to meet climate policy goals by mandating, prohibiting, or attaching costs to activities related to land use and development, vehicle use, building energy efficiency, generation and use of renewable energy, and waste generation. Their proximity and familiarity with local business and interest groups puts urban governments in a position to inform and enable efforts by the local private sector, civil society organisations and individual residents to reduce GHG emissions and prepare for climate change impacts.

City and regional governments may more easily identify and combine complementary climate policies within and across sectors than higher levels of government, given the interconnectedness of urban policy sectors. The existence of a policy complementarity signals a benefit in the form of the return generated when one policy is enacted along with another (De Macedo \& Oliveira Martins, 2006). Identifying the impact and benefits that policy sectors can have on each other is essential to designing policy packages that enhance the effectiveness of each individual policy. Some urban sectors are particularly interlinked to others, and thus can enhance or undermine the effectiveness of other sectoral policies. As Table 4.1 and Figure 4.1 present, land-use zoning, i.e. the decisions regarding the location and density of residential, commercial, industrial land uses, among others, has the widest influence on other sectors. Transportation policies are also interlinked with land-use zoning, natural resources management and use of renewable energy, as they affect the amount and type of energy required to travel between activities within a metropolitan region as well as the impact and vulnerability of transport infrastructure relative to the surrounding environment. Policy complementarity within each sector is also crucial, and more easily coordinated at smaller scales. For example, transportation polices to limit personal vehicle use are enhanced by policies to increase mass transportation options. 
Table 4.1. Matrix of interdependence of urban policy sectors

\begin{tabular}{|c|c|c|c|c|c|c|}
\hline Impact $\longrightarrow$ & $\begin{array}{l}\text { Land-Use } \\
\text { Zoning }\end{array}$ & Transportation & $\begin{array}{c}\text { Natural } \\
\text { Resources }\end{array}$ & Building & $\begin{array}{c}\text { Renewable } \\
\text { Energy }\end{array}$ & $\begin{array}{c}\text { Waste and } \\
\text { Water }\end{array}$ \\
\hline $\begin{array}{l}\text { Land-use Zoning } \\
\text { Land-use zoning } \\
\text { determines the } \\
\text { density, height of } \\
\text { buildings, and } \\
\text { proportion of } \\
\text { undeveloped land on } \\
\text { each property. }\end{array}$ & -- & $\begin{array}{l}\text { Segregation of } \\
\text { land uses } \\
\text { impacts travel } \\
\text { distances and } \\
\text { frequency; } \\
\text { transit-oriented } \\
\text { development } \\
\text { zones } \\
\text { encourage use } \\
\text { of mass } \\
\text { transportation. }\end{array}$ & $\begin{array}{l}\text { Zoning } \\
\text { designates } \\
\text { natural resource } \\
\text { areas }\end{array}$ & $\begin{array}{l}\text { Zoning impacts } \\
\text { placement and } \\
\text { density of } \\
\text { buildings, which } \\
\text { in turn impacts } \\
\text { building energy } \\
\text { efficiency and } \\
\text { vulnerability to } \\
\text { flooding and } \\
\text { urban heat } \\
\text { effects. }\end{array}$ & $\begin{array}{l}\text { Zoning density } \\
\text { can constrain } \\
\text { on-site } \\
\text { renewable } \\
\text { energy } \\
\text { production but } \\
\text { can also } \\
\text { increase } \\
\text { efficiency of } \\
\text { service delivery. }\end{array}$ & $\begin{array}{l}\text { Zoning density } \\
\text { can determine } \\
\text { the efficacy of } \\
\text { delivery of } \\
\text { waste, recycling } \\
\text { and composting } \\
\text { services; and } \\
\text { the energy } \\
\text { required and } \\
\text { efficacy of } \\
\text { delivery of water } \\
\text { services }\end{array}$ \\
\hline $\begin{array}{l}\text { Transportation } \\
\text { Transportation } \\
\text { policies determine } \\
\text { the development and } \\
\text { extension of road and } \\
\text { mass transportation } \\
\text { networks. }\end{array}$ & $\begin{array}{l}\text { Transportation } \\
\text { infrastructure } \\
\text { policies shape } \\
\text { demand land } \\
\text { and acceptance } \\
\text { of density } \\
\text { increases. }\end{array}$ & -- & $\begin{array}{l}\text { Transportation } \\
\text { systems impact } \\
\text { natural resource } \\
\text { and preserved } \\
\text { zones. }\end{array}$ & & $\begin{array}{l}\text { Transportation } \\
\text { policies can } \\
\text { require } \\
\text { renewable } \\
\text { energy sources } \\
\text { for mass } \\
\text { transportation } \\
\text { systems. }\end{array}$ & \\
\hline $\begin{array}{l}\text { Natural Resources } \\
\text { Natural resource } \\
\text { policies determine } \\
\text { which areas are } \\
\text { preserved from } \\
\text { development and } \\
\text { what uses are } \\
\text { acceptable on them. }\end{array}$ & $\begin{array}{l}\text { Natural } \\
\text { resource } \\
\text { policies } \\
\text { determine the } \\
\text { limits of } \\
\text { developed land- } \\
\text { use zones and } \\
\text { can improve } \\
\text { quality of high- } \\
\text { density zones. }\end{array}$ & $\begin{array}{l}\text { Natural } \\
\text { resource } \\
\text { policies affect } \\
\text { the placement } \\
\text { of road and } \\
\text { mass } \\
\text { transportation } \\
\text { infrastructure. }\end{array}$ & -- & & $\begin{array}{l}\text { Natural } \\
\text { resources } \\
\text { endowment } \\
\text { makes certain } \\
\text { renewable } \\
\text { energies } \\
\text { possible. }\end{array}$ & \\
\hline $\begin{array}{l}\text { Building } \\
\text { Building policies, } \\
\text { including building } \\
\text { codes, affect building } \\
\text { materials, } \\
\text { construction types, } \\
\text { and other physical } \\
\text { conditions }\end{array}$ & $\begin{array}{l}\text { Building codes } \\
\text { can increase } \\
\text { acceptability of } \\
\text { high-density } \\
\text { zones by } \\
\text { requiring design } \\
\text { features to } \\
\text { improve quality } \\
\text { of high-density } \\
\text { structures. }\end{array}$ & & & -- & $\begin{array}{l}\text { Building codes } \\
\text { can require the } \\
\text { on-site } \\
\text { generation of } \\
\text { renewable } \\
\text { energy. }\end{array}$ & $\begin{array}{l}\text { Building codes } \\
\text { can require } \\
\text { design and } \\
\text { building } \\
\text { materials that } \\
\text { produce less } \\
\text { construction } \\
\text { waste. }\end{array}$ \\
\hline $\begin{array}{l}\text { Renewable Energy } \\
\text { Renewable energy } \\
\text { policies can increase } \\
\text { on-site renewable } \\
\text { energy production } \\
\text { and share of energy } \\
\text { produced by } \\
\text { renewable sources. }\end{array}$ & & & & & -- & $\begin{array}{l}\text { Renewable } \\
\text { energy } \\
\text { production can } \\
\text { involve high } \\
\text { water } \\
\text { consumption }\end{array}$ \\
\hline $\begin{array}{l}\text { Waste and Water } \\
\text { Waste policies } \\
\text { determine the means } \\
\text { and extent of waste } \\
\text { disposal. } \\
\text { Water policies } \\
\text { determine service } \\
\text { extent, pricing, and } \\
\text { water sources }\end{array}$ & & & & & & -- \\
\hline
\end{tabular}

Note: Policy sectors with no shading demonstrate highest impact. Policy sectors with shading demonstrate lower impact. Policy sectors with diagonal lines demonstrate negligible or no impact. 
Figure 4.1. Sectoral Complementarities

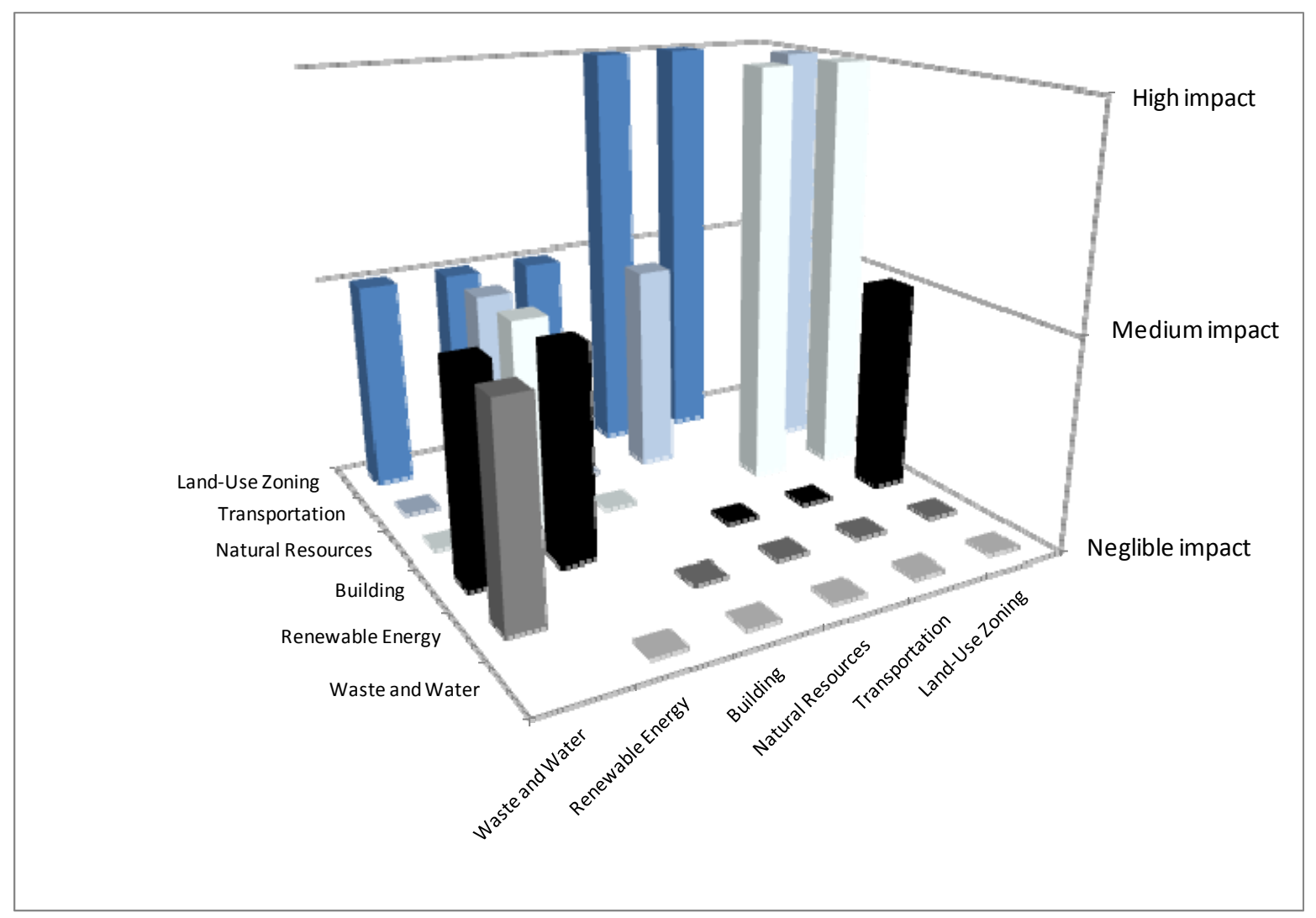

\section{Land-use zoning policies}

Land-use zoning policies have a wide-ranging, long-term and yet underlying effect on sectoral policies to address climate change. Spatial planning affects the placement of the built environment, and therefore the distances required for urban travel, the energy required to heat and cool buildings, and the vulnerability of the built environment. Urban master plans and land-use zoning policies determine the set of land uses that are allowed in a particular zone - at the most basic level these include residential, commercial, industrial, open space and mixed uses - and the degree to which land uses are separated from one another. These decisions shape the built environment and determine long-term travel patterns, building placement, access to amenities and exposure to natural hazards. This subsection presents the impact of land-use zoning policies on other sectoral climate change policies; section 4.2. discusses the impact of density and "compact city" policies.

Land-use zoning policies impact transportation policies that aim to reduce GHG emissions by determining the degree of segregation among land uses and therefore the energy required to travel between home, work, shopping and other activities. The degree to which these uses may be segregated varies with how restrictively zones are defined. For example, German residential zoning is often more flexible than its American counterpart, as it allows for doctor's offices, hostels, small hotels, and multi-story apartment buildings, while most residential zones in the United States are restricted to single-family dwellings (Buehler et al., 2009). The establishment of mixed-use zones, which allow for the development of a combination of business and residential uses, is one way of providing alternatives to segregated zoning. 
However, where mixed use zones are not the norm, they are typically only applied in specially designated districts where their impact is limited (Hirt, 2007).

Land-use zones that allow for transit-oriented development can facilitate increased use of public transportation. While it may not change trip distances or frequencies, it can decrease the distances between mass transit stations and residences, places of work and retail. The City of Toronto has created policies to encourage or require mass-transit oriented development, in addition to policies to facilitate density in the urban core and mixed-use (residential and commercial) development. ${ }^{52}$ The City of Toyoma, Japan, is pursuing transportation-oriented growth by concentrating city functions such as residential, commercial, business, and cultural facilities along a newly established light rail line, built over an underused longdistance rail line (Mori in OECD, 2009g). Arlington County, Virginia, promotes transit-oriented development around the light rail system by providing density credits, increasing parking requirements and improving infrastructure around transit stations. As with mixed-use zones, transit-oriented development zones are often exceptions to traditional land-use zones and therefore can be limited in their reach. Comprehensive reform may require an overhaul of residential zoning codes to systematically allow nonresidential uses rather than the piecemeal designation of mixed-use zones (Hirt, 2007).

Land-use planning tools also have a fundamental impact on natural resource management. They present a primary means for cities to adapt to potential climate change impacts, including reducing vulnerability to flooding and extreme weather events. Local government disaster management plans are being updated to take into account potential impacts and vulnerability assessments. The Municipality Plan for Hedensted, Denmark, focuses on flooding by prohibiting new development areas at risk under 100-year IPCC flood scenarios (Local Government Denmark, 2009). The Finnish cities of Espoo and Helsinki have mandated that new planned areas be 2.6 metres above sea level, and that the lowest floor level of new buildings be 3 metres above sea level. ${ }^{53}$ Planners in the United States have introduced the concept of "rolling easements" to discourage development of coastal areas by granting a public right-of-way to a narrow portion of coastal property, which migrates inland as the shore erodes. This prevents coastal land owners from erecting structures to block sea level rise and transfers the impact of sea level rise to the private land owner (Titus \& Narayanan, 1996). The most immediate impact of the policy would be to discourage new coastal development in areas vulnerable to coastal flooding (U.S. Global Change Research Programme, 2009). In urban areas in developing countries, the process of integrating adaptation into development policies generally involves combining two separate but linked processes : i) understanding the nature of local climate risks and choosing adaptation options; and ii) formulating and implementing development policies that are beneficial to adaptation (OECD, 2009i) (Box 4.1).

52. Response to OECD “Local Climate Change Governance Practices Questionnaire” by Mark Bekkering, City of Toronto, Environment Department, 11 August 2009.

53. Voutilainen, O. (2007), "How do Finnish cities respond to climate change", presented at the OECD Workshop on Competitive Cities and Climate Change: Challenges and Opportunities, Paris, France, 30 November 2007. 


\section{Box 4.1 Integrating adaptation into development planning}

Donors and international agencies can support the development of climate change adaptive capacity within urban settings through the development planning process in a number of ways. They could:

i) Review sectoral priorities in light of climate change, such as drawing the attention of partner governments to the urgent need to increase funding for infrastructure, as the deficits in urban infrastructure provision and maintenance are serious constraints to adaptive capacity.

ii) Explore different options for channelling funds and stakeholder engagement to build local adaptive capacity (e.g. by supporting municipal infrastructure funds).

iii) Support decentralisation processes that transfer authority to elected local governments. Support for decentralisation should be coupled with efforts to enhance local government capacity to take up the responsibilities afforded by decentralisation.

iv) Increase support to civil society organisations. Because these organisations interface most directly with communities, they represent a key constituent in local-level adaptation.

Source: OECD (2009i), Integrating Climate Change Adaptation into Development Co-operation: Policy Guidance, OECD Publishing, Paris.

Land-use policy can also support building policies that increase energy efficiency. Residential zones restricted to single-family dwellings, common for instance in the United States, can greatly restrict the availability of multi-family and row housing, both of which typically are more energy efficient per capita than detached single family dwellings. Land-use policy tools that promote multi-family or compact housing zones can also facilitate the use of district heating and cooling systems by allowing service to a greater number of customers in a given area than would be possible in a single-family residential zone. Land-use policies can also aim to reduce urban heat island effects, as the cities of Stuttgart, Freiburg and Mannheim, Germany have demonstrated. These policies include regional plans that provide minimum standards for open spaces, including a minimum width of 500 metres for "green corridors" and 250 metres for "green breaks". Mannheim is also taking thermal impacts into account when pursuing infill development (Beatley 2000). ${ }^{54}$

Many metropolitan regions have used land-use planning to create "sustainable neighbourhoods" or "eco-neighbourhoods" that combine transportation, natural resource preservation, building, waste and water policies to respond to climate change and reduce the urban environmental footprint. Common principles include increasing energy efficiency, using sustainable building materials, and reducing personal vehicle use. The most notable "eco-neighbourhoods", either completed or currently under development, are located in western and northern Europe, including in Sweden (Bo01 and Augustenborg in Malmö and Hammarby Sjöstad in Stockholm); Finland (Viiki in Helsinki); Germany (Vauban and Rieselfeld in Freiburg; Kronsberg in Hanover); Denmark (Vesterbro in Copenhagen); the Netherlands (Leidsche Rijn in Utrecht); and Great Britain (BedZED in Beddington, zero-carbon communities (Box 4.2)). However, ecocities are also under development in Korea, China and Abu Dhabi. Residential density varies among sustainable neighbourhoods projects, although most could be described as low-rise high density; towers or high-rise apartments are rare. Sustainable neighbourhoods shape development beyond residential density; cars may be restricted or prohibited (such as in Vauban) and waste collection policies that are more restrictive than elsewhere in the city may be imposed.

54. Response to OECD "Local Climate Change Governance Practices Questionnaire” by Klaus Elliger, City of Mannheim, Germany, 12 August 2009. 


\section{Box 4.2. The United Kingdom Eco-Town Programme}

The United Kingdom Government's eco-town programme has been developed as a response to the challenges of climate change, the need for more sustainable living, and an acute shortage of affordable housing. The plans are for five eco-towns by 2016 and up to 10 by 2020, as part of larger plans to build three million homes by 2020. Eco-towns will be new settlements of between 5,000 and 20,000 homes, with good links to existing towns. At least $30 \%$ of the new homes will be affordable housing, and all new buildings across the developments are expected to be zero-carbon and to promote sustainable and healthy living.

In July 2009 the Government announced the locations of the first four new eco-towns. They are Rackheath (Norfolk), north-west Bicester (Oxfordshire), Whitehill Bordon (East Hampshire) and the China Clay Community near St. Austell, Cornwall. Plans at the four confirmed sites are proposed or supported by local authorities. The developments - which will include 4,000 homes on a disused airfield at Rackheath and 5,000 in the Cornwall eco-town - must still go through the planning process. Construction is expected to be underway by 2016. A second wave of at least six eco-towns is planned. The Government is making up to GBP 5 million available for councils to conduct further planning work on these proposals.

Source: Thorpe in OECD (2009g), Green Cities: New Approaches to Confronting Climate Change, OECD Workshop Proceedings, 11 June 2009, Las Palmas de Gran Canaria, Spain.

\section{Transportation policies}

Transportation is a key sector for reducing GHG emissions, while transportation infrastructure is also vulnerable to climate change impacts in key ways. The transport sector is a significant and growing contributor to GHG gas emissions. Transport activity is responsible for $13 \%$ of all anthropogenic emissions of GHG gases and $23 \%$ of world $\mathrm{CO}_{2}$ emissions from fossil fuel combustion - this share rises to $30 \%$ in OECD countries. In most countries, transport $\mathrm{CO}_{2}$ emissions are growing faster than total $\mathrm{CO}_{2}$ emissions: $\mathrm{CO}_{2}$ emissions from fuel combustion in OECD countries grew 17\% from 1990 to 2005, while transport $\mathrm{CO}_{2}$ emissions grew by $30 \%$ over the same period. Transportation infrastructure is also vulnerable to climate change impacts such as flooding and high temperatures. Public transportation systems are at risk for flooding due to storms and rising sea levels, particularly in - but not limited to - coastal areas. Heat extremes can also damage roadways, bridges, and rail lines that were designed for lower maximum temperatures.

The urban transportation sector presents key opportunities for national, regional, and local governments to reduce GHG emissions and adapt to expected climate change impacts. Key transportation policies to reduce GHG emissions or adapt to climate change impacts aim to:

i) increase use of public transportation systems;

ii) decrease personal vehicle use and manage traffic demand;

iii) support non-motorised means of travel;

iv) increase vehicle fuel efficiency and use of alternative fuels;

v) prevent disruptions to transportation system due to flooding; and

vi) prevent disruptions to transportation system due to extreme temperatures.

Local and regional governments deploy policy tools to meet these goals in their capacity as regulatory authorities, managers of public transit systems and road networks, purchasers, and enablers of local non- 
governmental action. National governments may deploy policy tools through local governments by regulatory mandate, funding or incentives. A key distinction should be made between policies that impact accessibility, or the ability for people in urban areas to gain access to employment, retail, services and activities, and policies that impact mobility, or the ability to travel a given distance. Policies to reduce GHG emissions from vehicles may reduce mobility by discouraging personal vehicle use and increasing mass transit use, while land-use policies to increase proximity to urban amenities and a mixture of commercial and residential land uses can improve accessibility.

Local governments can discourage personal vehicle use by using their authority to regulate vehicle circulation, parking and speed limits, but alternatives must be provided to maintain competitiveness. Measures to discourage personal vehicle use include restrictions on personal vehicle use in designated zones or during certain times of day, increased parking fees or reduced parking spaces, and reduced speed limits in certain zones. These restrictions are most likely to be applied in central business districts and regional employment or retail centres (Cambridge Systematics, Inc., 2009). Restrictive policies should target zones that strongly attract employees or consumers and therefore can compete with areas that are more easily accessible by personal vehicles. Policies to discourage personal vehicles should be combined with policies to increase mass transit service, quality and multi-modal linkages to maximise both policies' effectiveness (ECMT, 1995). Local governments can also promote the co-benefits of such restrictions, which include reduced congestion, increased walkability, and increased safety. As a self-governing entity, cities can also encourage or require their employees to restrict their personal vehicle use.

As providers of public transit, local and regional governments can increase the use of public transit systems by focusing on improving quality, increasing linkages with multiple modes and expanding service. There has been a growing focus on better management of existing public transport networks in order to improve their quality and reliability. Public transit agencies can increase quality through measures such as physical improvements to make the system more attractive and feel safer, and improvements to better communicate service times and delays to customers (ECMT, 1995). The City of Beijing aims to achieve a $40 \%$ share of public transport use, which would build on an increase in market share from $30 \%$ to $39 \%$ over 2005-2008, by expanding public transit service, improving quality and providing linkages to other travel modes (Liu et al., in OECD 2009g). Local governments could do more to prioritise demand-side policies to improve management, regulation, information and pricing. Many local transportation agencies, including those in Stuttgart and Paris, have implemented real-time signage systems to communicate expected arrival times to mass transit customers. To improve linkages between multiple modes of travel, multiple local agencies often need to coordinate service delivery, which requires effective regional coordination on transportation planning.

Improvements to the public transit system need to be carefully planned to provide attractive alternatives to personal vehicle travel and to maximize co-benefits while minimizing potentially negative impacts. Increasing the use of public transit systems provides important co-benefits, but does not guarantee a reduction in personal vehicle use. By reducing time and costs spent on travel, an expansion of public transportation systems can make areas of economic or social activities more accessible, thereby increasing the market size for related goods and services; make industrial activities more productive and competitive; and connect previously isolated consumers to the public transportation market. The expansion, operation, and maintenance of transport infrastructure are also regional jobs providers (OECD, 2002). However, actually reducing personal vehicle use requires service expansion and improvements that present viable alternatives to personal vehicle travel. Routes must be carefully planned to target concentrations of employment, retail and social activities and residential neighbourhoods, without increasing demand for undeveloped land. Public transportation system expansion can create winners and losers, both in terms of social classes and economic activities, by making some activities more accessible but not serving others. Expanding services can also result in higher property rents in newly served areas. Noise and other potential 
environmental impacts, such as pollution from buses, may aggravate discrepancies in pollution and other environmental hazards depending on the location and concentration of expanded services (OECD, 2002).

Local governments can use their authority over the design and management of a city's road system to increase the share of non-motorised means of travel, particularly biking and walking. Local governments can eliminate traffic lines lanes or use "traffic calming" strategies, such as replacing intersections with traffic rotaries and enlarging sidewalks, to both discourage driving and encourage foot travel. Local governments can also make structural improvements to encourage travel by bicycle. While city-operated shared bicycle rentals, such as Paris' Vélib', Rio de Janeiro's Samba and Montreal's Bixi have been highly promoted for their potential to reduce GHG emissions, the corresponding efforts to facilitate bicycling, including the creating of protected bicycle lanes and clear signage of bicycle routes, may have a more significant impact on the attractiveness of bike travel.

In their capacity as purchasers and regulators, local governments can increase vehicle fuel efficiency, although their impact may be limited. Many cities have included policies requiring the purchase of hybrid or alternative-fuel vehicles buses and other vehicles in the local government fleet. The City of Toronto, for example, has established the Green Fleet Plan, which has already resulted in an over $10 \%$ reduction in emissions from use of the City's 4,000 vehicles ${ }^{55}$. While it is simpler for local governments to influence their own purchases than those of their residents, governmental fleets seldom constitute more than $1 \%$ of GHG emissions within most jurisdictions. Climate policies that focus on reducing government-owned vehicle emissions are therefore not a substitute for comprehensive approaches to emission reduction. By contrast, measures to regulate vehicle emissions standards and lowering speed limits can allow local governments to affect the efficiency of all local vehicles. Regulations to lower and strictly enforce speed limits and prevent engine idling, both of which increase fuel efficiency, may be more effective in reducing GHG emissions reductions than other regulatory policies such as those that discourage personal vehicle use through parking and driving restrictions. (Cambridge Systematics, Inc., 2009, Ewing et al 2007). However, the average optimal speed for fuel efficiency in most cars may be higher than typical city speed limits, making it difficult for urban areas to realise GHG emissions reductions through speed restrictions. Local governments may have greater opportunities to enact policies to restrict engine idling, because these regulations are most easily incorporated into existing enforcement of parking restrictions.

Local governments can also decrease personal vehicle use by enabling alternatives through programme coordination and technical assistance. Cities can facilitate the use of alternatives to personal vehicle use through programmes such as the City of Toronto's Smart Commute Programme, in which the city works with large employers to develop plans that encourage their employees to utilize alternate forms of transportation. ${ }^{56}$ Some cities have also begun to provide shared-car services through concessionaries, including the City of Hanover. While cities influence individuals indirectly when they work with employers to create employee travel plans, Cambridge Systematics, Inc. (2009) estimated that employerbased commute strategies (including vanpools, employee parking pricing and tele-work policies) can result in an up to $1.7 \%$ reduction in baseline GHG emissions, similar to their estimates for congestion pricing. The actual impact of employer-based strategies on GHG emissions depends of course on the scale at which they are implemented (Cambridge Systematics, Inc., 2009).

Cities can also take the lead on promoting use of renewable fuels for transportation and discouraging fossil fuel use by increasing the share of renewable energy used for mass transit systems (Box 4.3) and supporting the development of new technologies. Some local or regional governments directly fund

55. From response to OECD “Local Climate Change Governance Practices Questionnaire” by Mark Bekkering, City of Toronto, Environment Department, 11 August 2009.

56. From response to OECD “Local Climate Change Governance Practices Questionnaire” by Mark Bekkering, City of Toronto, Environment Department, 11 August 2009. 
development. For example, the Eindhoven metropolitan region, in the Netherlands, was at the centre of the development of a low-emission public transport vehicle, the Philias-an advanced, guided bus that is controlled by a magnetic system built into the road—and that connects various communities within and around Eindhoven to major regional facilities, including the airport ${ }^{57}$ (OECD, 2009b; Broaddus, 2007). Others provide funding, such as the City of Paris’ programme providing EUR 400 to purchasers of electric motorcycles (City of Paris, 2009b).

\section{Box 4.3. Calgary's electric light rail powered by wind}

The City of Calgary's light rail transit system, the C-train, with electric drive motors powered by overhead electric wires, transports around 200000 passengers daily. Strong westerly winds coming from the Rocky Mountains led to the development of a twelve $650 \mathrm{~kW}$ turbine wind farm to the south of Calgary. Changes in the regulations that govern the sale of electricity in Alberta now allow anyone to buy electricity from companies producing wind power. A partnership between the city, the local energy supply company ENMAX Power Corporation and Vision Quest Windelectric Inc. resulted in the City of Calgary announcing the Ride the Wind!TM programme in September 2001. The council took the decision to buy commercial wind power as the primary source of the C-train's electricity at an additional cost of around CAN 0.005 per passenger trip. The greenhouse gas emissions from operating the train are now effectively zero. This was the first light rail system in North America to, in effect, run on wind power. A high speed train between Calgary and Edmonton is now under evaluation and could theoretically also be powered by renewable electricity.

Source: IEA (2009a), Cities and Towns and Renewable Energy -YIMFY: Yes In My Front Yard, OECD/IEA, Paris.

Reducing infrastructure vulnerability to climate change impacts poses a key challenge for local and regional transportation authorities. Preventing disruptions due to flooding is chief among these concerns. It is vital for cities to clearly assess and plan for sea-level rise, storm-surge and other storm impacts that exceed existing 100-200 year plans. Below-ground transportations systems are particularly susceptible to water damage. Effects from extreme temperatures can also disrupt mass transit systems if they exceed the heat thresholds for which roadways and public transportation systems have been designed. Currently, most transit system agencies have not yet started making improvements to infrastructure, although some cities have developed plans for protecting underground transit systems from coastal flooding. Concern about climate change impacts is also beginning to shape future infrastructure development. For this reason, nationally funded local infrastructure projects in Switzerland have to submit to climate change standards mandated by the Swiss Federal Department of the Environment, Transport, Energy and Communications. ${ }^{58}$ While adaptation plans and taking climate change impacts into account in new infrastructure are important steps, system-wide vulnerability assessments and large-scale retrofitting are needed to respond to impacts that are expected to exceed existing worst-case infrastructure planning scenarios.

An assessment of local initiatives that aim to reduce personal vehicle use, increase use of nonmotorized travel, and adapt to anticipated climate change impacts should take into consideration policy complementarity, the scale of policy impact and the opportunities for co-benefits. Policies to lower speed limits, prohibit idling and enable employer-based commute plans are easily implementable on a wide-scale on the local level and have demonstrated significant results on GHG emissions. Policies to increase demand for public transportation through improvements to quality, communication and linkages, and physical improvements to calm traffic and ease bike and foot travel may require additional investment but

57. Philias Bus Rapid Transport Eindhoven, Part I, Video. http://www.youtube.com/watch?v=StN-4xdzhz4.

58. From response to OECD “Local Climate Change Governance Practices Questionnaire” by Barbara Jeanneret, Swiss Federal Statistical Office, 17 August, 2009. 
can provide important co-benefits in the form of reduced congestion, decreased pollution, increased health, and reduced time and cost associated with local or regional travel.

Transportation policies have an impact on land-use zoning policies and natural resource policies as transportation networks can increase the value of the properties they serve and can improve the perceived quality of high density developments. On the flip side, expansions in road and rail services can also lead to demand for suburban land. These measures can provide co-benefits in the form of a wider set of sustainability objectives, such as congestion mitigation, improved air quality and better accessibility.

Transportation policies can enhance policies in other sectors as well as within the transportation sector. Transportation policies can be designed to support strategic territorial plans by prioritising service in compact and high density Policies to reduce personal vehicle use such as through restrictions on travel and parking are most effective when combined with policies to increase transportation quality and options for bicycle or foot travel. Taking advantage of policy complementarity requires transportation decision making to become more multi-sectoral and to coordinate with other local and regional, and in some case national, policy makers.

\section{Natural resources and environmental management}

Local governments can accomplish climate goals in their roles as land owners and land managers of a range of infrastructure and environmental services. These include planning and managing parks and other outdoor spaces, and providing other protective infrastructure. Natural resource policies can be applied to reduce energy demand, absorb $\mathrm{CO}_{2}$, and protect against climate impacts. Natural resource policies can also enhance the effectiveness of land-use zoning policies by improving the quality of high-density areas through provisions of green space. Natural resource policies can also play an important role in adaptation, as well as in providing opportunities for GHG emissions absorption and offsets.

Local governments are making use of their jurisdiction over environmental features within their boundaries to protect developed land from potential climate change impacts. For coastal cities, public investment for flooding protection is a primary adaptation tool. Examples include Venice (Box 4.4), New Orleans, Helsinki and Rotterdam. These investments are not without controversy, however, as they can lead to the destruction of ecological resources in order to protect the built environment. Parks and natural spaces can also be used as an adaptation measure, by planning new parks in areas that are most vulnerable to flooding. A number of cities and regions including the City of Dresden, Germany and the Dolnoslaskie Region, Poland are implementing adaptation programmes to prevent flooding, minimise and manage rain water and storm water. ${ }^{59}$ Through national hydraulic engineering and forestry legislations, the Swiss federal government is providing funding at the canton level for protective measures against natural hazards, which is matched by funding from cantons, municipalities, and infrastructure owners. ${ }^{60}$ Other cities are increasing their capacity to assess potential impacts. The coastal city of Shenzhen, China, has developed a network of 2,000 automatic meteorological data collection stations, to provide a monitoring range of 250 $\mathrm{km}$ (OECD, 2010 forthcoming). Because environmental zones do not often fall within city boundaries, adaptation planning and management often requires horizontal coordination with multiple local governments within the same region as well as vertical coordination with regional and national governments.

59. From response to OECD “Local Climate Change Governance Practices Questionnaire” by Wolfgang Socher, City of Dresden, Department of Urban Ecology, 26 August, 2009; and by Maciej Zathej, Dolnoslaskie Region, Poland, Regional Bureau of Spatial Planning, 28 August 2009.

60. From response to OECD “National-Local Climate Change Governance Practices Questionnaire” by Barbara Jeanneret, Swiss Federal Statistical Office, 17 August, 2009. 


\section{Box 4.4. Venice's MOSE flood protection system}

The City of Venice has undertaken massive infrastructure improvements to protect the city from rising sea levels and more extreme storm impacts, at a cost of EUR 4.272 billion. The main aim of this complex system of mobile dams and permanent works is to protect the cities of Venice and Chioggia, the lagoon's historical centres, and the broader lagoon basin from the detrimental effects of medium-to-high tides and the devastating effects of exceptional tides. MOSE is a series of projects under the broader General Work Plan for the Safeguard of Venice and the Lagoon, started by the Italian Ministry for Infrastructure in 1987 together with Venice's Magistrato alle Acque (the operational branch of the Ministry for the lagoon), which exemplifies the largest plan ever for the defense, recovery and requalification of the environment carried out by the Italian State. The MOSE includes several complementary public works to safeguard Venice, such as:

- 1400 hectares of tidal mudflats and salt marshes and sandbars have been reinstated and protected;

- $\quad 35 \mathrm{~km}$ of industrial channels and 5 former landfills have been protected;

- $100 \mathrm{~km}$ of embankments have been raised;

- $45 \mathrm{~km}$ of beaches have been rebuilt and $10 \mathrm{~km}$ of wharfs have been restructured.

The MOSE's mobile dams will protect Venice and its lagoon from tides up to 3 metres high and from the expected increase in the sea level of at least $60 \mathrm{~cm}$ in the next 100 years. Even when the dams are up, the port's operations will still be ensured, thanks to the construction of a large shipping lock at the mouth of the lagoon.

Source: OECD (2009h), OECD Territorial Reviews: Venice, Italy, OECD Publishing, Paris, forthcoming; Paruzzolo in OECD (2009g), Green Cities: New Approaches to Confronting Climate Change, OECD Workshop Proceedings, 11 June 2009, Las Palmas de Gran Canaria, Spain.

The natural environment of the urban landscape is also often included in climate plans as a means of absorbing $\mathrm{CO}_{2}$ and reducing overall urban GHG emissions, as well as reducing potential urban heat island effects. The City of New York's PlaNYC Climate Plan includes a goal of planting an additional one million trees by 2030, and filling all available spaces for trees. The plan sets a goal of planting 23,000 additional trees annually (City of New York, 2007). Sejong City, a new city in Korea that will be completed by 2014 with an expected population of a half million by 2030, plans to reduce average city temperatures by $2.5^{\circ} \mathrm{C}$ by devoting over half of its total surface area to parks, greenbelts and waterfronts and operating a water circulation system that draws on natural water resources (Sejong City, 2009). Tokyo has initiated policies for Greening Projects that include tree-lined streets and rooftop greening. In São Paulo, the development of Linear Parks along waterways has served to minimize flooding effects, reduce water pollution, and contribute to the planting of more than half a million trees in over four years (Sobrinho in OECD, 2009g). Improvements to the urban environment to reduce $\mathrm{CO}_{2}$ can provide an opportunity to capitalise on carbon offsets through cap and trade systems. As service and information providers, cities can provide alerts in advance of extreme climate events. For example, the City of Tatabánya, Hungary, designed an action plan detailing city agencies' responsibilities in responding to heat and UV-alerts and providing related information to local residents. ${ }^{61}$

\section{Building policies}

Energy demand from buildings represents a significant share of cities' energy emissions in OECD countries; at the same time, the built environment is vulnerable to climate change impacts. The share of energy demand from residential and commercial buildings can be much higher in cities than in worldwide figures. For example, GHG emission from buildings in the City of New York accounted for $79 \%$ of the

61. From response to OECD “Local Climate Change Governance Practices Questionnaire” by Dr. Barbara Botos, Strategic and Environmental Manager, City of Tatabánya, Hungary, 28 August, 2009. 
city's total emissions in 2005 (City of New York, 2007). While contributing to climate change, the built environment is also vulnerable to anticipated climate impacts, including urban heat-island effects, flooding, and related extreme weather events. Building location and design can add to the negative outcomes of urban heat-islands. The increased frequency and severity of flooding will threaten buildings that were located in areas previously believed to be at lower risk of flooding. Urban planners, architects, engineers and urban policymakers are now in the position of dealing with the dual challenges of designing and constructing urban zones that both curb energy consumption and can cope with future climate change impacts.

National, regional, and local governments can deploy a range of building policies to assist local authorities, reduce GHG emissions and adapt to climate change impacts. Building policies that regularly demonstrate GHG emissions reductions aim to:

i) increase building energy efficiency through design, placement and retrofitting with energy-saving devices; and

ii) increase local share of renewable and captured energy generation

These measures all have the potential to reduce $\mathrm{CO}_{2}$ emissions from building heating and cooling while simultaneously providing co-benefits in the form of reduced energy prices for energy consumers, reduced risk of blackouts during extreme heat events, and health benefits associated with reducing air pollution from unnecessary electricity and heat generation. In addition to this, building policies for adaptation aim to:

iii) adapt to flooding and extreme storm events by requiring minimum ground clearances; and

iv) reduce urban heat island effects by requiring or encouraging "green roofs".

Regional and local governments often implement these tools in their capacity as regulators of building codes, providers of building services, fiscal authorities, building and property owners, and enablers of local non-governmental action. National governments deploy these tools through local governments by regulatory mandate, subsidies, incentives, unilateral action and technical assistance.

As illustrated in Table 4.1, building policies impact or benefit other sectoral policies to a lesser extent than, for example, land-use zoning policies. However, they can enhance other sectoral policies in a few key ways. Design requirements, such as minimum setbacks from the street, can increase quality of residential development and therefore the acceptability of increased multi-family zones and higher residential density in land-use zoning plans. Building policies can require or encourage on-site generation of renewable energy in new developments, which can enhance renewable energy policies. Building policies can also contribute to the waste policies by requiring or encouraging design and building materials that produce less construction waste.

Building codes are the primary means for increasing building energy efficiency. Through building design and placement criteria, they can require reducing the demand for energy to light, heat and cool buildings. Their regulatory approach can be seen as an effective way for achieving a given goal of energy efficiency of new buildings (OECD, 2003). For example, because they are applied equally to owneroccupied and rented buildings, they can pre-empt the disincentive that owners and renters of rented buildings face in making energy efficiency investments ${ }^{62}$. They can also facilitate the meeting of specific

62. Known as a "principal-agent” problem, owners of rented buildings have little incentive to make investment because they usually do not have to pay the energy bills, and renters do not have incentive, either, because they are not likely to benefit from the investment over the long term. Under such circumstance, economic instruments and information tools may not function effectively (OECD, 2003). 
targets. For example, the city of Shenzhen became in 2006 the first Chinese city to establish building energy efficiency regulations, and has since set targets of $20 \%$ energy reductions for retrofitting existing buildings and 50\% reductions for new construction (OECD, 2010 forthcoming). On the other hand, the effectiveness of building codes is often constrained in several ways. First, as building codes typically apply only to new construction and renovations, their benefits are only felt over the long-term (IEA, 2005). Second, while most of the OECD countries now include national energy efficiency requirements in their building codes for all new buildings, city or regional building regulations to apply more stringent efficiency standards often apply only to projects over a certain size. ${ }^{63}$ Third, due to strong opposition of stakeholders, it is often difficult to set energy efficiency requirements strict enough to effect significant reductions in GHG emissions or real protections against climate change impacts (OECD, 2003). Fourth, building codes may discourage innovation because developers rarely have an incentive to exceed efficiency standards (IEA, 2008c). Performance-based codes, which set a total requirement for the building based on the supply of energy or the resulting environmental impact, may provide more incentives for innovation, but require a comprehensive and reliable method for calculating the energy performance of a building (IEA, 2008c). Finally, and perhaps most importantly, the effectiveness of building codes can vary significantly due to difficulties and resulting differences in compliance and enforcement (UNEP, 2007).

While some local authorities have added their own energy efficiency standards to their building codes, these can often be limited in their scale, impact and implementability, and therefore may be well suited to a package of national building codes and programmes. Because local building codes are typically stricter than national codes, local stakeholders' opposition tends to be stronger. Second, local building codes are often limited to projects over a certain size. Third, local building codes can also reduce a city's or region's competitiveness if they lead builders to seek locations in adjacent areas with more favourable building regulations. National building energy efficiency standards can reduce the risk of regional competition based on building codes and could potentially result in more uniformly strict standards across cities. National regulations can even take the lead in place of local policy, if ambitious goals are set. In Germany, it is now national policy for new construction of commercial buildings to attain a minimum performance of $110 \mathrm{kWh}$ per square metre.

Supporting building retrofitting or the installation of energy-efficient technologies can be an effective instrument for local governments to reduce the GHG emissions from existing buildings. The City of Berlin has pioneered a model for improving energy efficiency in buildings in which the city project-manages the retrofit of public and private buildings by contracting with energy service companies to implement efficiency retrofits to achieve an average of $26 \%$ reduction of $\mathrm{CO}_{2}$ emissions (C40 Cities, 2009); the City of Toronto has provided technical support for owners of large buildings to retrofit their buildings for energy efficiency through its Better Buildings Partnership and Sustainable Energy Funds. ${ }^{64}$ The benefits of such projects are greatest where heating and cooling loads are high. While retrofit programmes present an opportunity to have an impact on the energy demand of the built environment, governance of such programmes can be more complicated. They are less well suited to implementation through building codes, given that uniform performance requirement by building codes could be too much burden for some existing buildings, but rather are more appropriate for policy instruments such as public private partnerships and grant programmes. They also require a good monitoring system and a competitive energy

63. For example, the City of Boston approved a green building zoning code in January 2007 that requires all construction projects exceeding 50000 square feet to be designed and planned to meet the U.S. Green Building Council’s (USGBC) LEED “certified” level standards (City of Boston Redevelopment Authority). the Flemish Climate Policy Plan for 2006-2012 sets out comprehensive requirements for new or significant additions to dwellings, schools and offices, as well as major renovations of schools and offices exceeding 3,000 m3 (Flemish Ministry of Public Works, Energy, Environment and Nature, 2006).

64. From response to OECD “Local Climate Change Governance Practices Questionnaire” by Mark Bekkering, City of Toronto, Environment Department, 11 August 2009. 
performance contracting industry (IEA, 2008c). Energy efficiency technical assistance programmes are a key vehicle for national assistance on the local level. Public private partnerships can also result in the construction of buildings that are energy efficient by design, such as in the case of the Kronsberg Passive House Estate in Hannover, Germany. ${ }^{65}$

\section{Box 4.5. Multilevel governance building efficiency programmes}

- The Crown Energy Efficiency Loan, in New Zealand, is a financial instrument to assist central and local government agencies to implement energy efficiency projects. It complements the 2007 National Energy Efficiency and Conservation Strategy, which required 10\% improvement in in-house energy efficiency in central and local government over five years. Local authorities and other publicly agencies borrow funds from the government and repaid over 5 years; ideally, loan repayments are structured such that the energy cost savings exceed the cost of the loan repayments. The Crown Energy Efficiency Loans finance energy efficiency measures previously recommended by audits carried out by independent energy experts, and are allocated based on the project's cost effectiveness, projected $\mathrm{CO}_{2}$ emission reductions, contribution to renewable energy, potential for replication by public and private sectors, and co-benefits. As of June 2008, loans exceeding USD 23 million have been granted to 230 projects to achieve estimated cost savings of USD 60 million and reductions in $\mathrm{CO}_{2}$ emissions of nearly 23000 tonnes per year - the equivalent of taking 6500 cars off New Zealand roads.

- The Low Income Retrofitting Project, in Greece, is an initiative of the national government in cooperation with municipalities to improve energy efficiency in homes built before the 1980s for families with incomes of less than EUR 60,000 a year. The national government works with national associations of private businesses and the local community (municipalities and private business) to identify and inform low- income households about this project. The project focuses on increasing energy and cost savings through projects to increase the energy efficiency of insulation, windows, and heating, and to install solar collectors and cool roofs. The Ministry of Development created an agreement with national business associations to freeze the costs of these services for two years. The programme is evaluated through an "auto-verification" scheme in which the associations must evaluate whether their industry members are implementing technologies that meet the national standards - which can result in a conflict of interest.

- Upper Austria's Regional Market for Third-Party Financing (TPF) links municipal and private energy efficiency projects with financing in order to remove the barrier of high upfront investment costs. This programme originally linked municipalities with investors interested in financing energy efficiency renovations in public buildings, and was later expanded to link building, lighting and renewable energy projects in the public and private sectors with energy financing. TPF projects look to Energy Service Companies (ESCOs) to provide pre-financing energy-conservation schemes. ESCO guarantee that energy costs will be reduced by a certain percentage after energy improvements are made. Subsequent energy savings are then used to cover investment costs over an agreed pay-back period (typically 10 to 15 years). Out of eleven participating ESCOs, two are publicly owned; the rest are private. ESCOs are responsible for financing energy-saving measures as well as implementation, operation and maintenance. Municipalities enter TPF projects on a voluntary basis and are responsible for collecting all relevant data prior to setting up the project. Depending on the status of the owner, the regional government may fund the upfront investment costs for energy performance contracts up to $12 \%$ in the case of private owners, and up to $20 \%$ for municipalities. The upper limit in both cases set at EUR 100,000 per project. Funding comes on top of other State (Upper-Austria) subsidies. The budget comes from the broader climate change programme of Upper Austria.

Source: IEA (2009b), Innovations in Multi-Level Governance for Energy Efficiency: Sharing experience with multi-level governance to enhance energy efficiency, IEA, Paris.

65. From response to OECD "Local Climate Change Governance Practices Questionnaire” by Astrid Hoffmann-Kallen, Ute Heda and Rainer Konerding, City of Hannover, Climate Protection Unit, 1 September 2009. See also www.passivhaustagung.de/zehnte/englisch/texte/PEPInfo1_Passive_Houses_Kronsberg.pdf 
Building retrofitting, or the installation of energy-efficient technologies in local government-owned properties have become widely adopted into local climate action plans (Wheeler, 2008), and are often easier to implement than policies for private buildings. Depending on the scale of the intervention, selfgoverning and purchasing policies can have a wide impact on city building efficiencies; they can also serve as a model for privately funded energy efficiency projects. These projects can require coordination among multiple local government agencies. For example, cities in Japan provide matching funds to public schools that have made energy efficiency improvements, in the amount of half of the projected annual cost savings (Sugiyama \& Takeuchi, 2008). Many governments have undertaken retrofitting local street lighting, including Graz, Austria, Gwalior, India and Stockholm, Sweden. While not typically subject to building policies, efficient street lighting programmes reflect the focus on improving the energy efficiency of government-owned properties. In the case of Graz, investments were pre-financed and refinanced from the energy cost savings, which are paid off over 15 years, while in Stockholm an investment in light-emitting diode (LED) traffic signals is expected to pay off within 10 years (IEA, 2008d).

Programmes to require or enable use of renewable or captured energy sources can have a large-scale effect on demand for low-emissions energy sources. Barcelona's "Solar Thermal Ordinance", which requires all new buildings and major renovations to use solar thermal collectors to supply at least $60 \%$ of the energy used to heat water, led to similar ordinances in over 60 other Spanish municipalities. In the Greater London area, building codes requiring renewable energy generation have expanded to communities across the UK (Box 4.6). District heating and cooling systems, which capture heat produced in energy generation to heat or cool water for all buildings connected to the systems, have the added benefit of being able to be applied incrementally at appropriate scales. Moreover, given that district energy systems connect to both new and existing buildings, they are an effective way of altering the energy demand of existing building stock. One of the earliest district heating systems, in Copenhagen, provides $97 \%$ of the city's total heating needs. The Cities of Stockholm, Sweden and Mannheim, Germany provide other examples of district heat generation, including through the use of biofuels. The City of Toronto, Canada, has enabled the creation of a district cooling system by establishing a corporation that has connected most of the major downtown office buildings to a deep lake water cooling system and which has resulted in a significant decrease in electricity demand for air conditioning. ${ }^{66}$ Regulatory changes requiring buildings within a designated zone to connect to the system allow district heating and cooling projects to realise energy efficiency gains for a large number of energy consumers. For example, MVV Energie in Mannheim, Germany, makes more money selling hot water than it does electricity, due to the efficiencies of its system. However, potential price inefficiencies may exist if the projects receive significant government subsidies (Agrell \& Bogetoft, 2005).

66. From response to OECD “Local Climate Change Governance Practices Questionnaire” by Mark Bekkering, City of Toronto, Environment Department, 11 August 2009. 


\section{Box 4.6. The Merton Borough initiative ${ }^{67}$}

Known as the "Merton Rule" after being first introduced by the London Borough of Merton in 2003, it is a prescriptive planning policy regulation that requires developers of all new buildings in the district to plan to generate at least $10 \%$ of their predicted future total annual energy demand (for heating, cooling and electrical appliances) using renewable energy equipment that is integrated into the building design or located on-site. Acceptable systems include solar PV panels, solar water heaters, ground source heat pumps (for heating and cooling space and heating water), and biomass from residues and energy crops. Energy arising from direct combustion or fermentation of domestic or industrial organic wastes is not permitted due to the possible problems of local pollution, odours etc.

The concept was deemed to be successful and has since been taken up by the Greater London Council and many other municipalities across the United Kingdom. Each municipality can vary the details and thresholds outlined in the regulations to suit their local conditions. For example, variations in the original $10 \%$ demand level have ranged between $5 \%$ and $20 \%$. The most commonly accepted threshold for implementation of the regulation is a development of more than 10 dwellings or non-residential developments with floor areas greater than $1000 \mathrm{~m}^{2}$, but other thresholds exist. The regulation also serves to encourage the energy efficient design of buildings, and to give consideration to their layout and orientation on site, since having to provide $10 \%$ energy demand from renewables is more costeffective at lower levels of demand. In cases where the incorporation of renewable energy equipment could make a new building development unviable, for example it is not possible to mount solar panels or wind turbines on a roof, a waiver can be sought by the developer. When given sufficient grounds, the regulation may not be enforced. The energy use of the buildings is subsequently monitored to ensure the target is being met.

Source: IEA (2009a), Cities and Towns and Renewable Energy -YIMFY: Yes In My Front Yard, OECD/IEA, Paris.

Local governments face the challenge of revising local building regulations to address potential climate change scenarios, particularly those that expose the built environment to flooding and extreme storm events. Building codes that require minimum floor height requirements in new developments located in areas at risk for flooding and extreme storms represent an underutilised adaptation opportunity. The challenge for local governments is assessing the nature of the threat compared to existing metrics such as the commonly used 100-200 year flood measurement. In the Netherlands, for example, 1,000-year flood metrics are now being used for development planning. Building codes are however not sufficient to address flood vulnerabilities because they typically only affect new construction and major renovations. They therefore must be combined with additional flood mitigation measures, such as retrofitting and infrastructure investments.

Local governments can also address the threat of increased urban heat island impacts by implementing building codes that require "green roofs". Green roofs may take the form of roofs planted with vegetation, which can both increase building insulation from heat and cold as well as reduce storm water runoff into local waterways. Green roofs planted with vegetation do consume additional water and therefore are not suited to areas facing the risk of increased drought or water shortages. Other types of green roofs may be painted white or composed of materials that allow them to reflect sunlight and minimize the amount of heat they absorb, which makes them well suited to warm climates but could work against efforts to reduce heating energy consumption in colder climates. Toronto has made it mandatory for almost all new buildings to include a green roof. ${ }^{68}$ Stuttgart currently subsidizes $50 \%$ of all costs to retrofit existing roofs to become "green" roofs, and Chicago provides grants of USD 5000 to residential and smaller commercial building owners to help with the planning and installation of a green roof (Velasquez, 2003; City of Chicago, 2005). Building codes that mitigate urban heat islands provide co-

67. www.merton.gov.uk/living/planning/planningpolicy/mertonrule.htm

68. From response to OECD “Local Climate Change Governance Practices Questionnaire” by Mark Bekkering, City of Toronto, Environment Department, 11 August 2009. 
benefits by reducing the demand for energy to cool buildings. As green roofs reduce cooling bills, they provide an economic incentive; however, like other energy efficiency measures, the upfront investment may need to be surmounted by local governments.

\section{Renewable energy policies}

Some cities and regions have undertaken the provision and production of renewable energy, in addition to pursuing goals of increasing renewable energy consumption through land-use zoning, transportation, natural resource and building policies. Local governments can develop their own sources of renewable energy by capturing and converting energy from one or more renewable energy sources that exist in many cities and towns (IEA, 2009a). A distinction can be made between distributed energy options (e.g. rooftop solar or solar water heaters) and centralized power production. Cities are generally better placed to incentivise distributed energy technologies, in part through zoning laws such as Barcelona's Solar Thermal Ordinance, as discussed earlier, Cities can also use their self-governing authority to purchase renewable energy for city or regional operations (IEA, 2009a).

Some cities in the OECD own and operate power generating facilities, which provides them with more options for increasing local use of renewable energies. Local governments that do generate energy or electricity through public power utilities, such as the City of Los Angeles, United States, can increase their share of renewable energy they produce. The city's GreenLA Climate Action Plan sets targets for the Los Angeles Department of Water and Power (LADWP) to increase its renewable fuel sources to $20 \%$ by the end of 2010 and to 35\% by 2020, in part by developing four new renewable energy projects. These new projects build on $\mathrm{CO}_{2}$ reductions of $3 \%$ achieved over 2004-2008, which resulted in an estimated reduction of 524000 metric tons of $\mathrm{CO}_{2}$ (City of Los Angeles, 2008). The City of Seoul, Korea, aims in its new climate change master plan to expand its renewable energy share from $1.5 \%$ in 2007 to $20 \%$ by 2030, with nearly half of this share to come from hydrogen energy (Seoul City Government, 2009). Cities and regions that are not municipal power producers can still use their regulatory authority to remove obstacles to local renewable energy production and their self-governing authority to purchase renewable energy for city or regional operations (IEA, 2009).

Renewable energy policies can be enhanced or undermined by other sectoral policies, particularly land-use zoning, transportation and building. Renewable energy production can also have a negative impact on adaptation activities by increasing demand for water: a range of renewable energy producers, including solar farms, biofuel refineries and cleaner coal plants, consume significant amounts of water to produce energy. For example, some local water authorities in California have denied permits for potential renewable energy developments based on their high projected water demand (Woody, 2009).

\section{Urban utilities}

\section{Waste policies}

While urban waste contributes to climate change through methane $\left(\mathrm{CH}_{4}\right)$ and to a lesser extent $\mathrm{CO}_{2}$ released by landfills and emitted by waste incinerators, heat and energy capture from waste incineration can provide an efficient energy source. Methane, which represents the largest share of GHG emissions produced by the waste sector (IPCC, 2007c), presents a key concern for local GHG emissions reduction because $\mathrm{CH}_{4}$ has a significantly greater impact on climate change than $\mathrm{CO}_{2}$ emissions and continues to be released for decades after waste disposal. Outdoor burning of waste, more common in cities in developing countries, contributes to air pollution and poses significant health risks (IPCC, 2007c). Waste processing and transfer facilities in coastal areas are also at risk from rising sea levels and more severe storm events. 
Local governments can reduce GHG emissions from the waste sector through policies that aim to reduce waste quantities and increase the net energy efficiency of incinerators. Local governments can deploy these policy tools in their roles as regulators, waste service providers, and enablers of efforts to reduce waste consumption. National governments can provide technical and financial assistance for energy generation programmes and set standards for incinerators. Co-benefits to reducing waste and improving incineration technologies include reduced air pollution and reduced landfill impacts on water quality.

Local governments can reduce the quantity of waste that ends up in landfills by providing recycling and composting services and setting fees to discourage waste. Many cities divert waste from landfills through recycling and composting programmes. The City of San Francisco's recycling and food composting efforts have allowed it to divert from landfills $70 \%$ of all waste consumed (Kamal-Chaoui in OECD, 2008a). ${ }^{69}$ The actual amount of non-recyclable and non-compostable waste provided to collectors can be reduced through incentives in the waste collection rate structure. The City of Zurich restricts the amount of waste that residents can generate, and sets fees for additional amounts. Local governments also have opportunities to reduce waste by improving waste management systems. To meet its target of recycling 35\% of the waste stream in 2009 and 51\% in 2011, the province of Rome, with financial support from the Lazio region, provides economic grants to municipalities in its jurisdiction to establish waste collection systems that enable them to quantify individual household waste and thereby create fiscal incentives for waste reduction recycling (Kamal-Chaoui in OECD, 2008a). Waste quantities can also be reduced through education campaigns, which are already common in many urban areas in OECD countries. In order for efforts to reduce the amount of non-recyclable and non-compostable waste through fees or information to be effective, they need to be coupled with collection services that offer recycling and composting for a wide range of consumer waste products. The EU Landfill Directive requires reductions in the volume of biodegradable municipal waste it sends to landfills.

Local government agencies that use waste as an energy source can increase the net energy efficiency of incinerators and reap economic benefits from energy savings. Even when incinerators do not generate energy, they emit a significantly smaller amount of GHG emissions than landfills. The amount of other pollutants they emit depends greatly on their cost and design; many European countries have adopted stringent emission standards for incinerators (IPCC, 2007c). Cities are also capturing methane gas from landfills to be used as a source of energy. The city of Monterrey, Mexico, which has been active in generating electricity by harvesting methane, constructed using public and private funds a 7-megawatt energy plant that captures and converts enough landfill gas into electricity to power the city's light-rail transit system and its streetlights (Kamal-Chaoui in OECD, 2008a). In China, the City of Guangzhou in Guangdong province has undertaken one of the largest landfill energy capture projects, which is expected to generate more than $50 \mathrm{Gwh}$ of electricity, or enough for 30,000 households (OECD, 2010 forthcoming). Other cities investing in landfill methane gas capture include Amman, Jordan (Freire in OECD, 2009g), Christchurch, New Zealand and Nelson, New Zealand. ${ }^{70}$

69. The South Waikato Region, New Zealand; Christchurch, New Zealand; Dolnoslaskie Region, Poland; Darmstadt, Germany; and Toronto, Canada also provide examples of composting (Response to OECD "Local Climate Change Governance Practices Questionnaire” by James Piddock, South Waikato District Council, New Zealand, 29 July 2009; Response to OECD "Local Climate Change Governance Practices Questionnaire” by Tony Moore, Christchurch City Council, New Zealand, 3 September 2009; Response to OECD “Local Climate Change Governance Practices Questionnaire” by Maciej Zathej, Dolnoslaskie Region, Regional Bureau of Spatial Planning, 28 August 2009; Response to OECD "Local Climate Change Governance Practices Questionnaire” by Günther Bachmann, City of Darmstadt, Department of Economy and Urban Development, 21 August 2009; Response to OECD "Local Climate Change Governance Practices Questionnaire” by Mark Bekkering, City of Toronto, Environment Department, 11 August 2009).

70. Response to OECD “Local Climate Change Governance Practices Questionnaire” by Tony Moore, Christchurch City Council, New Zealand, 3 September 2009; Response to OECD "Local Climate Change 
The waste services sector provides an opportunity for local government to reduce GHG emissions economically because they can build on services they already provide and capitalize on economic benefits. Policies to reduce waste through expanding recycling and composting services and raising the price of nonrecyclable waste recycling programmes have been shown to consume less energy than disposing of the waste in landfills or by incineration, even when taking into account the potential energy that may be captured at either landfills or incinerators (Morris, 2005). It is therefore important that policies to support waste-to-energy capture do not compete with recycling programmes. Policies that support waste incineration and landfill gas capture complement recycling and composting policies by increasing the energy efficiency of disposal of non-recyclable or non-compostable waste. Incineration or landfill programmes that capture heat and energy can reduce net GHG emissions while offering economic benefits.

\section{Water policies}

While many cities' do not prioritise urban water policies as part of their climate policy goals, they deserve attention because water service provision both consumes energy and is also vulnerable to climate change impacts such as increased droughts and rising sea levels. Water services provision contributes to GHG emission because of the energy demanded by water treatment, pumping and other water provision activities. For example, approximately $5 \%$ of all the electricity used in California is related to water provision, while an additional $15 \%$ is related to end uses of water, such as heating and pressurizing (California Natural Resources Agency, 2008). Local governments respond to a variety of climate change impacts scenarios with four key water policy goals that aim to:

i) reduce water consumption;

ii) reduce energy demand of water delivery systems;

iii) prevent water system infiltration due to flooding; and

iv) prevent water system disruption due to drought.

Technological improvements and other policies can reduce the amount of energy required to provide water and reduce water consumption to better adapt to the risk of less available water due to climate change impacts.

Climate change requires changes in local water management to anticipate shifts in demand, and to confront the potential reduction of water availability and quality. Smart water policies that help achieve water conservation and efficiency goals include proper pricing of water to encourage waste reduction, financial incentives for low-flow appliances, proper design of subsidy and rebate programmes, new state and national efficiency standards for appliances, education and information outreach, water metering programmes, and more aggressive local efforts to promote conservation. Local and regional governments can enact regulations to increase the use of recycled water. For example, more than 40000 homes in Melbourne, Australia, are required to use Class A recycled water, metered and delivered separately in a distinctive purple pipe, rather than potable water for toilet flushing, washing cars and watering outdoor landscaping. More could be done to drive better environmental performance in new housing through demand management. Best practices involve developing policy tools that give water efficiency equal priority to energy efficiency. This raises issues of funding and whether it is appropriate for customers to finance widespread improvements to the housing stock through water charges.

Governance Practices Questionnaire” by Debra Bradley, Nelson City Council, New Zealand, 3 September 2009. 
Empirical evidence emphasizes that using prices to manage water demand is more cost-effective than implementing non-price conservation programmes, and they also have advantages in terms of monitoring and enforcement. Water supply managers are often reluctant to use price increases as a water conservation tool, however, and often rely instead on non-price demand management techniques, such as the adoption of specific technologies (e.g. low-flow fixtures) and restrictions on particular uses (e.g. lawn watering). On average, in the United States, a ten percent increase in the marginal price of water can be expected to diminish demand in the urban residential sector by about 3-4\%. A recent study of 12 cities in the United States and Canada suggests that replacing two-day per week outdoor watering restrictions with drought pricing could achieve the same level of aggregate water savings, along with welfare gains of approximately USD 81 per household per summer drought (Mansur \& Olmstead, 2006). Toronto's WaterSaver Program helps businesses that use a lot water to identify areas that may be 'wasting' water and offers solutions and cash incentives. Industrial, commercial and institutional facilities that successfully reduce water use can receive a rebate (CAD 0.03 per litre of water saved). The programme allows Toronto to buy back water or sewer capacity that has been freed up by participants who have reduced water use in their operations (Raissis in OECD, 2009g).

Cities have also begun incorporating adaptation strategies into their water supply planning processes. New York City has started to adapt its water supply, drainage, and waste water systems to account for climate change and sea level rise. The City of Crisfield, USA has incorporated sea level rise and storm surge into its comprehensive plan and is using land elevation to guide future land use planning. Many other cities are assessing vulnerabilities of water supplies. In the East of England plan (one of nine Regional Spatial Strategies in England), clear policy guidance on water planning is incorporated at the regional level to inform the next stage of the spatial planning hierarchy (Hickey in OECD, 2009g).

Adaptation and mitigation policies in the water sector are interconnected, as increased water shortages increase the energy required to provide water. Water scarcity can require greater pumping and greater travel distances from water source to consumer. Desalinisation, a possible solution for water scarce areas, requires a significant amount of energy. Policies to reduce consumption complement adaptation policies by reducing vulnerability to fluctuations in water availability and the need for energy intensive delivery methods.

\section{Key urban policy packages}

As national, regional, and local governments seek climate change policy packages that maximise their impact on GHG emissions and reduce their vulnerability to climate change impacts, a focus on policies that fit best with urban modes of governance and that enhance other climate policies is warranted (Table 4.2). City and regional regulatory authority is an important governance mode for implementing mitigation and adaptation policy tools across urban sectors, particularly as relates to the goals of reducing travel distances, discouraging personal vehicle use, increasing building energy efficiency and reducing vulnerability to storm, flooding and extreme heat impacts. Many cities display however a reluctance to make full use of their regulatory authority in the face of potential political, private sector and public opposition. Notable exceptions include Barcelona's Solar Thermal Ordinance and San Francisco's recent introduction of mandatory recycling (Kern \& Alber in OECD, 2008a; Partin, 2009). Services provision is another key means of implementing climate change policy goals, particularly those related to increasing mass transit use; providing renewable energy, district heating/cooling, and waste-to-heat initiatives; administering funding, incentives and partnerships with the private sector; and managing the urban environment to reduce the risk of flooding and other climate impacts. The impact of policies implemented through selfgovernance tend to be more limited in scope, but environmental management policy tools for adaptation and installation of energy efficiency technologies in city-owned buildings can have a large impact when applied widely. Public information campaigns can enhance number of other policy tools, including those 
that can benefit most from targeted climate-related information. However, as the impact of urban facilitative activities is diffuse, it is hard to measure.

Policies that enhance each other when applied concurrently should also be considered as top priority policies. Land-use zoning policies that allow for higher densities and greater mixing of residential and commercial uses can enhance transportation climate goals by reducing trip distances and frequency, protect natural areas that act as buffer zones against climate impacts, decrease building energy demand, and increase efficiency of urban services delivery. Other sectors, in turn, can enhance the quality of densification policies and lessen their potentially negative impact on adaptation measures. The expansion of mass transportation and non-motorised travel options can provide benefits that outweigh the disadvantages of high residential density, while natural resource policies can enhance the quality and availability of open spaces within densely developed areas. Building design policies can enhance the quality of the densely built environment while reducing climate vulnerability through minimum ground clearances and design features to reduce urban heat island impacts.

Policy complementary within sectors is also important for enhancing policy effectiveness. Transportation policies to increase the quality and availability of public transportation, bicycle, and foot travel make policies to discourage or restrict vehicle travel and circulation more politically feasible. For example, congestion fees for driving during peak hours worked well in London because they were combined with improvements in management of the road network and substantial enhancements in bus service. In the building sector, local government coordination of public-private partnerships to provide energy efficiency retrofitting programmes complement energy efficiency codes that affect only new development and major renovations. Waste policies to promote both waste-to-energy incineration and the collection of recyclables can enhance rather than undermine the economic viability of recycling programmes while diverting waste from landfills. Policies to reduce water consumption can increase local resilience to drought while lowering energy demand for water services provision and the development of energy-intensive water sources in response to water scarcity.

Table 4.2. Policy tools for local-level action on climate change

\begin{tabular}{|c|c|c|c|c|c|}
\hline Policy Goals & Policy Tools & Policy Sector & Purpose & \begin{tabular}{|c|} 
Mode of \\
Governance
\end{tabular} & $\begin{array}{l}\text { Complementary with } \\
\text { Policy Tools That: }\end{array}$ \\
\hline \multirow{2}{*}{$\begin{array}{l}\text { Reduce trip } \\
\text { lengths }\end{array}$} & $\begin{array}{l}\text { Restructure land value } \\
\text { tax to increase value of } \\
\text { land closer to urban } \\
\text { core, jobs, or services }\end{array}$ & $\begin{array}{l}\text { Land-use } \\
\text { zoning }\end{array}$ & Mitigation & Regulatory & Increase mass transit use ${ }^{\star}$ \\
\hline & $\begin{array}{l}\text { Mixed-use zoning to } \\
\text { shorten trip distances }\end{array}$ & $\begin{array}{l}\text { Land-use } \\
\text { zoning }\end{array}$ & Mitigation & Regulatory & $\begin{array}{l}\text { Discourage vehicle use* } \\
\text { Support non-motorized } \\
\text { means of travel }\end{array}$ \\
\hline \multirow{5}{*}{$\begin{array}{l}\text { Increase mass } \\
\text { transit use }\end{array}$} & $\begin{array}{l}\text { Transit-oriented } \\
\text { development zones }\end{array}$ & $\begin{array}{l}\text { Land-use } \\
\text { zoning }\end{array}$ & Mitigation & Regulatory & $\begin{array}{l}\text { Increase mass transit use* } \\
\text { Discourage vehicle use }\end{array}$ \\
\hline & $\begin{array}{l}\text { Restructure land value } \\
\text { tax to increase value of } \\
\text { land served by public } \\
\text { transportation }\end{array}$ & $\begin{array}{l}\text { Land-use } \\
\text { zoning }\end{array}$ & Mitigation & Regulatory & Increase mass transit use \\
\hline & $\begin{array}{l}\text { Tax-incentives to } \\
\text { developers near public } \\
\text { transportation }\end{array}$ & $\begin{array}{l}\text { Land-use } \\
\text { zoning }\end{array}$ & Mitigation & Regulatory & Increase mass transit use* \\
\hline & $\begin{array}{l}\text { Improve quality of public } \\
\text { transportation }\end{array}$ & Transportation & Mitigation & $\begin{array}{l}\text { Service } \\
\text { provision }\end{array}$ & Discourage vehicle use* \\
\hline & $\begin{array}{l}\text { Provide linkages with } \\
\text { multiple modes of travel }\end{array}$ & Transportation & Mitigation & $\begin{array}{l}\text { Service } \\
\text { provision }\end{array}$ & $\begin{array}{l}\text { Discourage vehicle use* } \\
\text { Support non-motorized } \\
\text { means of travel* }\end{array}$ \\
\hline
\end{tabular}




\begin{tabular}{|c|c|c|c|c|c|}
\hline Policy Goals & Policy Tools & Policy Sector & Purpose & \begin{tabular}{|c|} 
Mode of \\
Governance
\end{tabular} & $\begin{array}{l}\text { Complementary with } \\
\text { Policy Tools That: }\end{array}$ \\
\hline & $\begin{array}{l}\text { Expand mass transit } \\
\text { service }\end{array}$ & Transportation & Mitigation & $\begin{array}{l}\text { Service } \\
\text { provision }\end{array}$ & Discourage vehicle use* \\
\hline & $\begin{array}{l}\text { Employee transport } \\
\text { plans }\end{array}$ & Transportation & Mitigation & Facilitative & $\begin{array}{l}\text { Improve quality of public } \\
\text { transportation } \\
\text { Provide linkages with } \\
\text { multiple modes of travel } \\
\text { Expand mass transit service }\end{array}$ \\
\hline \multirow{2}{*}{$\begin{array}{l}\text { Discourage } \\
\text { vehicle use }\end{array}$} & $\begin{array}{l}\text { Traffic calming to } \\
\text { discourage driving }\end{array}$ & $\begin{array}{l}\text { Land-use } \\
\text { zoning }\end{array}$ & Mitigation & $\begin{array}{l}\text { Regulatory/ } \\
\text { Service } \\
\text { provision }\end{array}$ & $\begin{array}{l}\text { Improve quality of public } \\
\text { transportation } \\
\text { Provide linkages with } \\
\text { multiple modes of travel } \\
\text { Expand mass transit service }\end{array}$ \\
\hline & $\begin{array}{l}\text { Driving and parking } \\
\text { restrictions in certain } \\
\text { zones }\end{array}$ & Transportation & Mitigation & Regulatory & $\begin{array}{l}\text { Improve quality of public } \\
\text { transportation } \\
\text { Provide linkages with } \\
\text { multiple modes of travel } \\
\text { Expand mass transit service }\end{array}$ \\
\hline $\begin{array}{l}\text { Support non- } \\
\text { motorized } \\
\text { means of travel }\end{array}$ & $\begin{array}{l}\text { Traffic calming and } \\
\text { increasing bike lanes }\end{array}$ & Transportation & Mitigation & $\begin{array}{l}\text { Regulatory/ } \\
\text { Service } \\
\text { provision } \\
\end{array}$ & Discourage vehicle use* \\
\hline \multirow{2}{*}{$\begin{array}{l}\text { Increase } \\
\text { vehicle } \\
\text { efficiency and } \\
\text { alternative } \\
\text { fuels use }\end{array}$} & $\begin{array}{l}\text { Special parking } \\
\text { privileges for alternative } \\
\text { fuel or hybrid vehicles }\end{array}$ & Transportation & Mitigation & Regulatory & $\begin{array}{l}\text { Driving and parking } \\
\text { restrictions in certain zones }\end{array}$ \\
\hline & $\begin{array}{l}\text { Purchase of fuel- } \\
\text { efficient, hybrid, or } \\
\text { alternative fuel vehicles } \\
\text { for city fleet }\end{array}$ & Transportation & Mitigation & $\begin{array}{l}\text { Self- } \\
\text { governance }\end{array}$ & -- \\
\hline \multirow{3}{*}{$\begin{array}{l}\text { Increase } \\
\text { building energy } \\
\text { efficiency }\end{array}$} & $\begin{array}{l}\text { Zoning regulation to } \\
\text { promote multi-family and } \\
\text { connected residential } \\
\text { housing }\end{array}$ & $\begin{array}{l}\text { Land-use } \\
\text { zoning }\end{array}$ & Mitigation & Regulatory & $\begin{array}{l}\text { Increase attractiveness of } \\
\text { higher density developments } \\
\text { through policies tools that: } \\
\text { Increase neighbourhood } \\
\text { open space } \\
\text { Improve quality of public } \\
\text { transportation } \\
\text { Provide linkages with } \\
\text { multiple modes of travel } \\
\text { Expand mass transit service } \\
\text { Tree-planting programmes }\end{array}$ \\
\hline & $\begin{array}{l}\text { Energy efficiency } \\
\text { requirements in building } \\
\text { codes }\end{array}$ & Building & Mitigation & Regulatory & $\begin{array}{l}\text { Coordination of public- } \\
\text { private retrofitting } \\
\text { programmes } \\
\text { Stringent enforcement } \\
\text { policies } \\
\text { National building codes }\end{array}$ \\
\hline & $\begin{array}{l}\text { Coordination of public- } \\
\text { private retrofitting } \\
\text { programmes }\end{array}$ & Building & Mitigation & $\begin{array}{l}\text { Service } \\
\text { provision }\end{array}$ & $\begin{array}{l}\text { Energy efficiency } \\
\text { requirements in building } \\
\text { codes }\end{array}$ \\
\hline \multirow{2}{*}{$\begin{array}{l}\text { Increase local } \\
\text { share of } \\
\text { renewable and } \\
\text { captured } \\
\text { energy } \\
\text { generation }\end{array}$} & $\begin{array}{l}\text { Building codes requiring } \\
\text { a minimum share of } \\
\text { renewable energy }\end{array}$ & Building & Mitigation & Regulatory & $\begin{array}{l}\text { Technical support to } \\
\text { developers and property } \\
\text { owners }\end{array}$ \\
\hline & $\begin{array}{l}\text { District heating and } \\
\text { cooling projects }\end{array}$ & Building & Mitigation & $\begin{array}{l}\text { Regulatory/ } \\
\text { Service } \\
\text { provision }\end{array}$ & $\begin{array}{l}\text { Remove regulatory barriers } \\
\text { to requiring connection to } \\
\text { district heating/cooling } \\
\text { system }\end{array}$ \\
\hline
\end{tabular}




\begin{tabular}{|c|c|c|c|c|c|}
\hline Policy Goals & Policy Tools & Policy Sector & Purpose & $\begin{array}{c}\text { Mode of } \\
\text { Governance }\end{array}$ & $\begin{array}{l}\text { Complementary with } \\
\text { Policy Tools That: }\end{array}$ \\
\hline & $\begin{array}{l}\text { Waste-to-energy } \\
\text { programmes }\end{array}$ & Waste & Mitigation & $\begin{array}{l}\text { Service } \\
\text { provision }\end{array}$ & $\begin{array}{l}\text { Strictly regulate incinerator } \\
\text { emissions } \\
\text { Remove recyclables from } \\
\text { waste stream }\end{array}$ \\
\hline \multirow{4}{*}{$\begin{array}{l}\text { Reduce } \\
\text { vulnerability to } \\
\text { flooding and } \\
\text { increased } \\
\text { storm events }\end{array}$} & $\begin{array}{l}\text { Zoning regulation to } \\
\text { create more open space }\end{array}$ & $\begin{array}{l}\text { Land-use } \\
\text { zoning }\end{array}$ & Adaptation & Regulatory & $\begin{array}{l}\text { Zoning regulation to promote } \\
\text { multi-family and connected } \\
\text { residential housing }\end{array}$ \\
\hline & $\begin{array}{l}\text { Retrofitting and } \\
\text { improvements to mass } \\
\text { transit systems to } \\
\text { reduce potential } \\
\text { damage from flooding }\end{array}$ & Transportation & Adaptation & $\begin{array}{l}\text { Service } \\
\text { provision }\end{array}$ & $\begin{array}{l}\text { Improve quality of public } \\
\text { transportation } \\
\text { Provide linkages with } \\
\text { multiple modes of travel } \\
\text { Expand mass transit service }\end{array}$ \\
\hline & $\begin{array}{l}\text { Designation of open } \\
\text { space as buffer zones } \\
\text { for flooding }\end{array}$ & $\begin{array}{l}\text { Natural } \\
\text { Resources }\end{array}$ & Adaptation & Regulatory & $\begin{array}{l}\text { Zoning regulation to create } \\
\text { more open space } \\
\text { Zoning regulation to promote } \\
\text { multi-family and connected } \\
\text { residential housing }\end{array}$ \\
\hline & $\begin{array}{l}\text { Building codes requiring } \\
\text { minimum ground } \\
\text { clearance }\end{array}$ & Building & Adaptation & Regulatory & $\begin{array}{l}\text { Designation of open space } \\
\text { as buffer zones for flooding }\end{array}$ \\
\hline \multirow{4}{*}{$\begin{array}{l}\text { Reduce urban } \\
\text { heat-island } \\
\text { effects and } \\
\text { vulnerability to } \\
\text { extreme heat }\end{array}$} & $\begin{array}{l}\text { Retrofitting and } \\
\text { improvements to mass } \\
\text { transit systems to } \\
\text { reduce potential } \\
\text { damage from extreme } \\
\text { temperatures }\end{array}$ & Transportation & Adaptation & $\begin{array}{l}\text { Service } \\
\text { provision }\end{array}$ & $\begin{array}{l}\text { Improve quality of public } \\
\text { transportation } \\
\text { Provide linkages with } \\
\text { multiple modes of travel } \\
\text { Expand mass transit service }\end{array}$ \\
\hline & $\begin{array}{l}\text { Tree-planting } \\
\text { programmes }\end{array}$ & $\begin{array}{l}\text { Natural } \\
\text { Resources }\end{array}$ & $\begin{array}{l}\text { Mitigation } \\
\text { and } \\
\text { Adaptation }\end{array}$ & \begin{tabular}{|l|} 
Self- \\
governance
\end{tabular} & $\begin{array}{l}\text { Increase attractiveness of } \\
\text { higher density developments } \\
\text { through policies tools that: }\end{array}$ \\
\hline & $\begin{array}{l}\text { Building codes requiring } \\
\text { design materials that } \\
\text { reduce heat-island } \\
\text { effects }\end{array}$ & Building & Adaptation & Regulatory & $\begin{array}{l}\text { Energy efficiency } \\
\text { requirements in building } \\
\text { codes }\end{array}$ \\
\hline & $\begin{array}{l}\text { Building codes requiring } \\
\text { "green roofs" with } \\
\text { vegetation or white } \\
\text { surfaces }\end{array}$ & Building & $\begin{array}{l}\text { Mitigation } \\
\text { and } \\
\text { Adaptation }\end{array}$ & Regulatory & $\begin{array}{l}\text { Energy efficiency } \\
\text { requirements in building } \\
\text { codes }\end{array}$ \\
\hline
\end{tabular}

Note: * Denotes all policy tools listed under a policy goal.

\subsection{Density and spatial urban form in combating climate change}

The urban policies discussed above intersect with the question of urban density. Many cities have begun pursuing policies to increase the density of residential neighbourhoods and favour concentration at the centre of the urban agglomeration as a means to facilitate the mitigation and adaptation measures discussed above. The questions of whether to densify development and which spatial development patterns to pursue have come to the forefront of local long-term planning concerns. Compact cities and sustainable neighbourhoods have been presented as models of development patterns that can address climate challenges and long-term resource, economic, and social sustainability. However, questions remain about the effectiveness of these spatial urban forms in meeting environmental goals and in attracting residents over the long term.

In determining whether and how to incorporate climate policies into spatial urban form and density decisions, city and metropolitan governments face a number of questions: 
i) How to define density in order to set priorities for compact development?

ii) Which spatial development patterns best contribute to GHG emissions reductions, climate change adaptation, and efficient resource use?

iii) How can spatial planning reduce the energy required to travel between home, jobs, and activities?

iv) What impact does compact development have on economic growth?

v) How can challenges to urban quality of life, housing affordability, and urban attractiveness be overcome?

These questions require consideration of the potential impact on GHG emissions and climate change vulnerability, but also on economic growth, long-term resource sustainability, affordability, and urban quality of life.

The concept of the "compact city" as a spatial development strategy has become popular in many OECD countries, particularly in Europe and Japan. The European Commission (Commission of the European Communities, 1990, 1992) encourages European cities to move towards more compactness, on the basis of environmental and quality of life objectives. The British government has made urban compactness a central element of its sustainable development policy (Department of the Environment, 1993) and the Dutch government has taken similar action (National Physical Planning Agency, 1991). Most recently, the Japanese government has introduced the concept of "Eco-Compact City" as one of its top-priority urban policies (Ministry of Land, Infrastructure, Transport and Tourism, 2009). The compact city strategy aims to intensify urban land use through a combination of higher residential densities and centralisation, mixed land uses, and development limits outside of a designated area (Churchman, 1999). Compact cities also typically involve concentrations of urban services and transportation options and high degrees of land-use planning controls (Table 4.3) (Neuman, 2005).

Table 4.3. Compact city characteristics

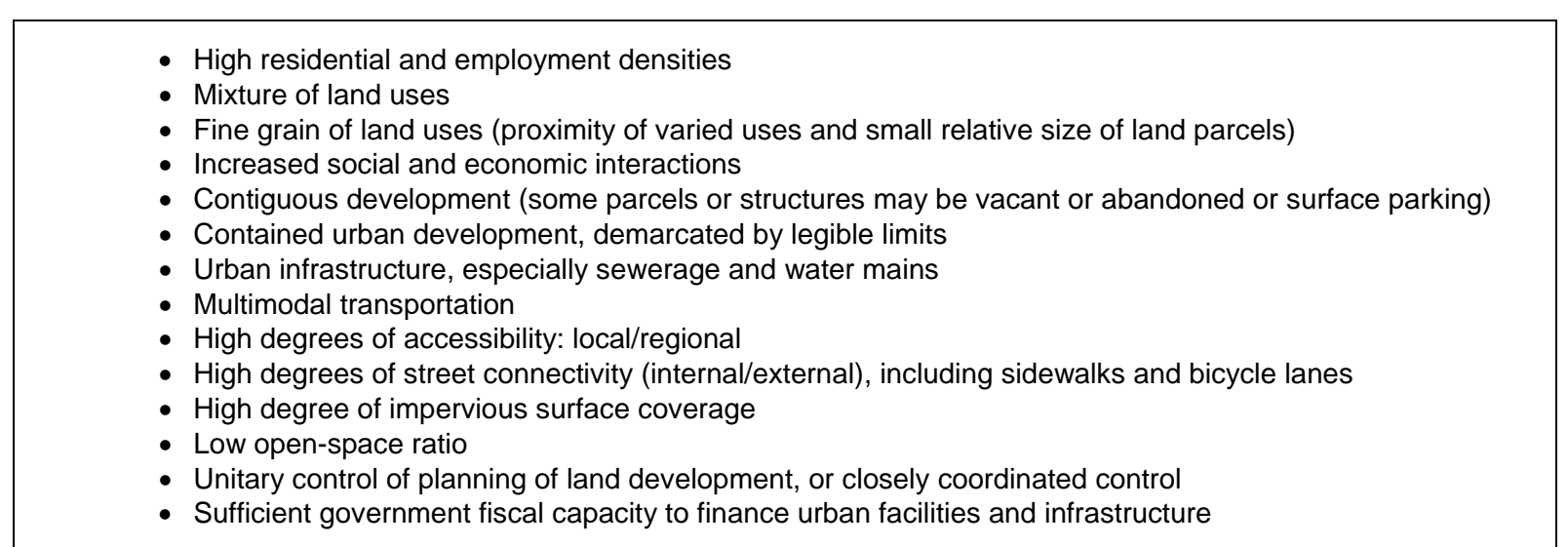

Source: Neuman, Michael (2005), "The Compact City Fallacy", Journal of Planning Education and Research, Vol. 25, No. 1, Sage Publications, pp. 11-26.

While some associate compact cities with high-density development, the concepts are distinct. Compact development prioritises development close to and radiating from an urban core, where the definition of high-density development is based primarily on the concentration of dwelling units, regardless of proximity to an urban core or urban amenities. In some metropolitan regions, compact development may apply to polycentric development, where two or more cities in a region share 
complementary functions (Nordregio, 2005), in which case compact development strategies radiate from each urban core.

\section{Impact on urban amenities and services}

As illustrated in the Chapter 1, dense and compact development emerges as a crucial strategy to reduce GHG emissions. Policies to increase residential density in urban areas, whether or not they are part of a compact cities or sustainable neighbourhoods strategy, have been credited with providing benefits such as reduced GHG emissions from travel, increased efficiency and reduced costs of public services provision, and increased protection of agricultural land and open spaces (Churchman, 1999). Higher residential densities may also facilitate many of the urban policies to reduce GHG emissions and adapt to climate change impacts. For example, dwellings that are adjacent rather than stand alone are more insulated and therefore require less energy for heating and cooling. Mass transport networks and public utilities benefit from economies of scale in more-dense areas, which can facilitate expansion of mass transit and reduction of personal vehicle use. Compact development can provide the economies of scale required to make district heating and cooling projects economically viable, and reduce the energy required to provide water, wastewater, and waste services. Higher-density development can also result in the preservation of key open spaces critical for climate change adaptation, such as flood plains or buffer zones for coastal flooding. Estimates of the effect of compact growth scenarios on U.S. national GHG levels range from 1\% (U.S. National Research Council, 2009) to 10\% (Ewing et al., 2008), but further research is needed to understand the impact of a range of spatial development scenarios on future greenhouse gas emissions.

The impact of density on urban economic and social priorities is even more diverse and complex. On one hand, high-density residential areas have been associated with a more economically efficient use of high-priced land and a greater mix of housing types, which may facilitate a more diverse mix of residents than areas dominated by single-family housing (Churchman, 1999). On the other hand, policies to promote high-density residential development have also attracted criticism, in particular for their potential impact on residents' quality of life, access to open space, housing prices, and responsiveness to market demand. High residential densities can lead to increased traffic congestion and pollution, which can be exacerbated by a lack of trees or vegetation. The value of land may also rise significantly as a result of high-density developments, which can discourage the preservation of open space and limit residents' access to in highdensity areas (Churchman, 2009). The increase in land values also can result in the exodus of low-income and even middle-class residents from high-density areas with valuable amenities such as proximity to the urban core, open space, and mass transit. If increases in urban density are accompanied by efforts to reduce pollution or otherwise improve the urban environment, wealthier households may move in, driving up rents and benefiting landlords at the expense of existing tenants, as demonstrated in a study of California cities (Banzar \& Walsh, 2006). Higher housing prices and smaller dwelling sizes, both associated with highdensity areas, may lead families with children to leave for areas with lower prices, larger dwellings, or opportunities for outdoor space. This can lead in turn to economically and socially heterogeneous highdensity areas.

Building design and availability of neighbourhood amenities affect residents' perceptions of highdensity developments' advantages and disadvantages. In determining urban quality of life, residents' perceptions of density, or perceived density, may be as important as real measures of residential density (Churchman, 1999). For example, in the Netherlands, 10 dwelling units per net hectare is considered low density and 100 units per hectare high density, while in Israel, 20 to 40 dwelling units per net hectare is considered low density, and 290 units per hectare is considered high density. While high-density developments are often associated with high-rise towers, low-rise buildings can also achieve relatively high densities. For example, a study of Toronto, Canada, identified net densities of 120-230 dwelling units per hectare in areas of buildings up to five stories (Churchman, 2009). Urban amenities, such as open space, 
mass transit service, shopping areas and cultural activities, can all serve to lessen the potential impacts of high-density developments on quality of life. For example, a study of neighbourhood satisfaction in central Dublin found that density itself was less important to perceived quality of life than management of the physical environment (e.g. litter, pollution, greenery), noise and traffic congestion, and access to open space, children's facilities, quality food stores and secure parking (Howley et al., 2009). However, while building design and amenities may increase high-density areas' attractiveness, they do not address the issue of potentially rising housing prices.

\section{Spatial policy tools for low-carbon development}

A focus on spatial compactness or density to increase urban growth's responsiveness to climate change and sustainability may be limiting if it does not take into account the impact of the activities within the city (Neuman, 2005). Metropolitan regions must be able to respond to rapid growth and demand for undeveloped land. To effectively reduce GHG emissions, it is critical for spatial policy tools to reduce distances between residential, employment, shopping, and leisure activities, which is not necessarily achieved increasing residential densities alone. Transportation and resource efficiency, and open space preservation can be facilitated by spatial development that is planned to maximise transportation linkages, prioritise areas adjacent to public utilities services, and preserve open space. The Ile-de-France region provides a key example of combining these elements in a long-term master plan (Box 4.7).

A number of policy tools exist to facilitate compact development, through mixing land-uses, improving mass transit services and providing urban amenities. These include reducing existing regulatory barriers to more compact development, including barriers to mixed-use, transit-oriented and brownfields development, accompanied by fiscal reform that internalises environmental and public services costs incurred by new development and concentrates urban amenities and services in priority growth areas. A primary strategy for promoting more compact urban development is to reform land-use policies that restrict opportunities for high-density development. Zoning and other land-use controls impose an "implied zoning tax" that discourages new housing construction (Glaeser \& Gyourko, 2003). Floor-area-ratio restrictions, restrictions on units per acre, and height restrictions all can restrict compactness policies. Zoning reform and incentives to increase mixed-use developments, which combine residential and non-residential land uses, can reduce the length and frequency of personal vehicle trips. Mass transit use is facilitated not only by increasing density but also by ensuring service to key employment centres, even those located away from residential neighbourhoods or on the urban periphery. Transit-oriented developments, which often include mixed-use elements, and mass transit connections to key employment and residential areas are needed to reduce personal vehicle use and can function even in the absence of high-density policies. 


\section{Box 4.7. Ile-de-France's Regional Master Plan to become first "Eco-Region"}

Where and at what density future construction should take place in Paris and the surrounding île-de-France Region, and how this will impact climate change goals, are key questions for the revision of the Île-de-France Regional Master Plan.

The new SDRIF (Master Plan for the Île-de-France Region) continues past practices of targeting polycentric development in the region, but also emphasizes the importance of a compact region and places new attention on the historically dense urban core of the agglomeration. With the goals of limiting traffic and curbing urban sprawl, the SDRIF encourages higher density in existing urban spaces and prioritises development in areas served by public transportation. As a prescriptive land-use document in particular, it reworks the map of constructible land, seeks minimum densities for new urbanisation, and places conditions on the urbanisation of certain areas.

As density is only sustainable if it translates into urban spaces with a high quality of life, the revision of the SDRIF aims for urban "intensity", or the linking of dense neighbourhoods to quality public transportation, parks and open spaces, services, and jobs. To maximize opportunities for quality densification:

- $\quad$ The general map of the SDRIF, which must be respected by local plans, identifies preferential sites for densification, often to optimize planned public transport links.

- $\quad$ The rules expressed in the SDRIF's text make it compulsory for all municipalities to increase their local average densities.

- $\quad$ Other elements of the SDRIF set expectations for densification of districts around existing and planned public transport stations (express railway, metro, tram).

- To balance plans to reduce the expansion of urbanized land, the SDRIF requires new districts to meet higher minimal housing densities than currently in practice.

The counterpart of this "ville compacte" is the plan's strong effort to preserve and mobilize the region's open spaces, whose various economic, environmental, and public uses are now better acknowledged. This includes the strengthening of a network of green spaces that runs through the central agglomeration and the creation of "biological corridors" in the outer areas of the region.

Finally, the new SDRIF continues longstanding efforts to develop the metropolitan area around a network of strong, structured urban centres. The plan's transportation programme plays a key role in this effort as it will help structure the region's urban core and give a boost to the new dense neighbourhoods called for in the SDRIF. In addition to reinforcing the region's historically "radial" transportation system, which spans outward from Paris, the new SDRIF calls for a number of new high-capacity lines running around the Parisian centre.

Source: Fouchier in OECD (2009g), Green Cities: New Approaches to Confronting Climate Change, OECD Workshop Proceedings, 11 June 2009, Las Palmas de Gran Canaria, Spain.

Many policy instruments to reduce urban sprawl, which is characterised by low density, segregated land uses whose outward expansion is unchecked and may "leap" over undeveloped land (Burchell et al., 2002) may result in higher residential densities within the urban area, but also achieve goals related to increasing the use of mass transit, improving accessibility of the urban environment, and increasing urban amenities such as nearby open space (Table 4.4). Land-use policies such as urban growth boundaries and development incentives can actively promote more-dense urban development. However, while more compact development is achieved, negative impacts on property values can have perverse effects on the value of land outside urban growth boundaries. Less restrictive approaches also exist. In Germany, for example, new development is restricted to land immediately adjacent to already developed land (Buehler et al., 2009). Local governments can also promote densification by allowing developers to exceed zoning regulations if they meet other climate policy goals. Given the tendency for higher housing prices closer to urban cores, it can often be relevant to keep some land for future infrastructure, including through tools such as land banks for affordable housing, urban amenities, and infrastructure. 
Table 4.4. Policy instruments to manage urban sprawl

\begin{tabular}{l|l}
\hline \multicolumn{1}{c|}{ Policies for managing urban growth } & \multicolumn{1}{c}{ Policies for protecting open space } \\
\hline $\begin{array}{l}\text { Public Acquisition } \\
\text { Fee simple public ownership of parks, recreation areas, } \\
\text { forests, environmentally sensitive areas etc. }\end{array}$ & $\begin{array}{l}\text { Public Acquisition } \\
\text { Fee simple public ownership of parks, recreation areas, } \\
\text { forests, environmentally sensitive areas etc. }\end{array}$ \\
\hline Regulation & $\begin{array}{l}\text { Regulation } \\
\text { Subdivision exactions }\end{array}$ \\
Development moratoria, interim development & Cluster zoning (incentives often provided) \\
regulations & Down-zoning or large-lot zoning \\
Rate of growth controls (such as building permit caps), & Exclusive agricultural or forestry zoning \\
growth-phasing regulations & Mitigation ordinances and banking \\
Adequate public facility ordinances & Non-transitional zoning \\
Up-zoning or small-lot zoning, minimum density zoning & Concentrating rural development \\
Mixed-use zoning & \\
Transportation-oriented zoning & \\
Greenbelts & \\
Urban growth boundaries & \\
Urban service boundaries & \\
Comprehensive planning mandates (master plans) & \\
\hline Incentives and Fiscal Policies & Incentives and Fiscal Policies \\
Development impact fees & Right-to-farm laws \\
Real estate transfer tax & Agricultural districts \\
Split-rate property tax & Transfer of development rights \\
Infill and redevelopment incentives & Purchase of development rights, conservation \\
Brownfield redevelopment & easements \\
Historic rehabilitation tax credits & Use-value tax assessment \\
Location efficient mortgages & Circuit breaker tax relief credits \\
Priority funding for infrastructure in city centre & Capital gains tax on land sales \\
\hline Source: OECD adaptation based on Bengston, D.N. et al.(2004), "Public Policies for Managing Urban Growth and Protecting Open \\
Space: Policy Instruments and Lessons Learned in the United States", Landscape and Urban Planning, Vol. 69, pp.271-286. \\
\hline
\end{tabular}

\subsection{Strategic urban planning for climate change}

Long-term strategic planning needs to take into account urban areas' contributions and vulnerabilities to climate change. As urban areas have shifted towards the concept of urban governance, which involves managing and coordinating public and private interests, future growth and development decisions are no longer made solely by a central authority. Strategic planning - determining future action, identifying implementing roles, and monitoring and evaluating the outcomes ${ }^{71}$ - has been increasingly used to coordinate diverse priorities and contributions from multiple levels of government, non-governmental stakeholders and the private sector. The basic principles of strategic urban planning are to observe urban dynamics, land and house prices and understand the reasons why key stakeholders intervene in urban development processes; establish a consensual long-term vision and translate it into specific goals, define and prioritise required actions to achieve those goals given local capacity to act and power structures; and manage linkages among sectoral policies and uncertainty. The tools for flexible and strategic public intervention that can be used to incorporate climate change responses into long-term growth plans typically:

i) analyse urban emissions drivers and urban vulnerabilities

ii) identify local capacity to act;

iii) model long-term implications of policy options; and

iv) assess costs and benefits and cost-effectiveness.

71. See Steiss, Alan W. (1986), Strategic Management and Organizational Decision-Making. Rowman \& Littlefield, Lanham, MD, USA. 
To plan long-term reductions of urban areas' contributions to climate change, it is critical to inventory sources of GHG emissions. Scenarios to predict future GHG emissions are needed to identify policy priorities and choose among policy options. Analysing the drivers of GHG emissions involves identifying energy-consuming activities, the modes through which those activities take place, the energy intensity of the activities and the GHG emissions intensity of the energy sources consumed. Many cities have begun to inventory their emissions sources, however, the need exists for harmonisation of tools.

Climate change impacts are often localised, thus effective responses require region-specific assessments of local vulnerabilities. Vulnerability assessments model potential local damage in scenarios of flooding, rising sea levels, heat extremes, and other expected climate change impacts. Many urban areas are beginning to undertake these assessments, including the Washington, DC/Northern Virginia region (Box 4.8). However, they are costly and require scientific expertise that may not be relatively available to urban governments. This points to a role for national governments to foster science-policy capacity building and information to improve local understanding about how climate change will affect cities (OECD, 2009b).

\section{Box 4.8. The Sustainable Shoreline Community Management in Northern Virginia project}

To support the development of a regional climate change adaptation plan for Northern Virginia, USA, the Northern Virginia Regional Commission embarked on a three-year effort to develop a plan for sustainable shoreline and near-shore restoration, protection, revitalization and community development along the region's tidal waters. Through the Sustainable Shoreline Community Management in Northern Virginia project, the local governments in Northern Virginia are able to addresses coastal hazards and sea level rise preparation in a collabourative manner.

This plan focuses specifically on impacts due to sea level rise and storm surge and is funded in part by the Virginia Coastal Zone Management Programme through a grant sponsored by the National Oceanic and Atmospheric Administration. Phase I, of this three-year, three-phase project, includes an inventory of existing data resources and policies to determine the natural and man-made resources at risk, identify data gaps, and understand current local shoreline management regulations. A workgroup consisting of representatives from local, state, and federal governments, colleges and universities, and other stakeholders assists in highlighting and collecting relevant data including policies, land use, and natural resource information. Phase II will focus on filling data gaps, identified through Phase I of this project, and producing a report and maps of areas at risk of sea level rise and other climate change impacts.

Source: Grape in OECD (2009g), Green Cities: New Approaches to Confronting Climate Change, OECD Workshop Proceedings, 11 June 2009, Las Palmas de Gran Canaria, Spain.

An assessment of local capacity to respond to urban contributions and vulnerabilities to climate change is critical to planning future responses. Understanding local capacity allows local authorities to identify what they are capable of accomplishing alone and what may require the involvement of other levels of government or of non-governmental stakeholders. For instance, a city may have direct control of the local electric or gas utility, and therefore a say in pricing policies or the fuels used to generate power, but may have much more limited control over another sector such as public transport planning. Assessing capacity to act can be challenging, but some cities are forging ahead. Wedge analysis and stakeholder mapping are two types of tools to assess local capacity to act. For instance, the Greater London Authority has assigned responsibility for different initiatives proposed in its climate action plan (Figure 4.2), noting that city policies are capable of delivering no more than $15 \%$ of the necessary reductions, while the remaining reductions will come from actions by other London boroughs (5-10\% of the requirement), London's companies and public sector organizations (35-40\%), London residents (5-10\%) and the UK government (30\%) (GLA Climate Change Plan). To understand GLA's ability to influence the emissions associated with buildings around London, the Mayor's team developed an influence 'hierarchy' examining 
different factors that could potentially affect buildings' related emissions, and the mayor's influence over these factors (Lefèvre \& Wemaere, 2009).

Figure 4.2. Wedge Analysis

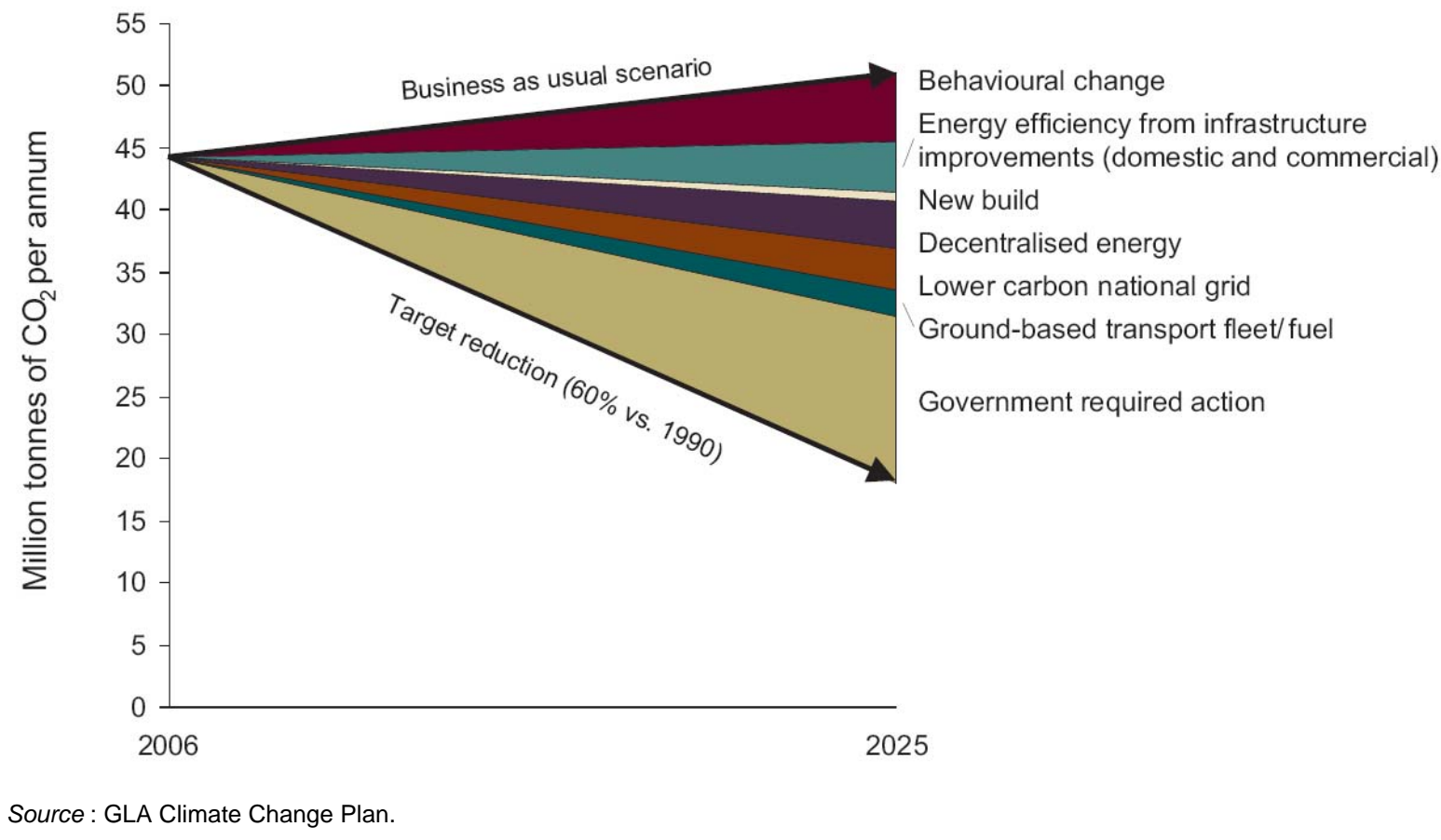

Modelling the impact of policy options on future GHG emission and climate vulnerabilities is a key step in understanding policy opportunities and tradeoffs. Because of the complexity of the interrelations between the drivers of spatial organization processes within a city, the empirical prediction of the multiple impacts of various combinations of urban policies is a difficult task. Given the various trade-offs that sustainability requires, it is necessary to also find a way to quantitatively assess the impacts of policy on the welfare of different population categories, productivity, energy consumption, and GHG emissions. Strategic planning processes can be significantly facilitated by long-term prospective methods that are able to forecast the effects of urban policy alternatives on urban spatial organization. Current models are driven mainly by transport scenarios and estimate through quantitative assessment their consequences on various sustainable parameters, such as the utility of different population categories, congestion, energy consumption, GHG emissions, etc. One example, the TRANUS model, which integrates transport and land-use scenarios, has been implemented both in northern cities (Baltimore, Sacramento, Osaka, Brussels, etc.) and southern cities (São Paulo, Mexico, Caracas, Bogotá, etc.). Models that go beyond transportationbased scenarios, and which also take climate change impacts into account, are needed to better inform policy options.

Tools to assess costs and benefits and inform cost-effectiveness planning also play a key role in strategic planning. Policies, plans, and projects tend to be assessed on short-term financial returns, or on an economic valuation based narrowly on a structured cost-benefit analysis, from the perspective of a limited range of stakeholders or project objectives. Few cities worldwide have a real knowledge of the impact of new development on their long-term fiscal condition. Decisions are dominated by immediate capital costs, 
despite the fact that often over $90 \%$ of lifecycle costs for typical infrastructure are expended during operational maintenance and rehabilitation. At the same time, most government budgets do not account for ecological assets, the services they provide, and the economic and social consequences of their depletion and destruction. Introducing qualitative assessment in cost-benefit analyses can be challenging; one example is the performance-based planning approach in use in the San Francisco Bay Area, USA, to help the Metropolitan Transportation Commission focus on sustainable measurable outcomes of potential investments and the degree to which they support stated policies (Box 4.9).

\section{Box 4.9. The San Francisco Bay Area Metropolitan Transportation Commission Transportation 2035 Plan}

The San Francisco Bay Area Metropolitan Transportation Commission (MTC) developed a vision for its Transportation 2035 Plan, based on the principles of economy, environment and equity, to support a prosperous and globally competitive economy, provide for environmental health and safety, and produce equitable opportunities for all Bay Area residents to benefit from a well-maintained, efficient, regional transportation system. The MTC then performed a detailed assessment of some 700 projects proposed for consideration in the financially constrained Transportation 2035 Plan. The two-part project assessments included a quantitative appraisal to measure benefits and costs with respect to performance objectives, and a qualitative policy assessment to reflect the somewhat broader considerations embodied in the goals of the Plan and the Three Es.

The results of the performance assessment guided the Commission in making tradeoffs among competing priorities that vied for funding and inclusion in the financially constrained plan. Performance results, however, were not the only factor. The Commission also considered input from transportation partners and stakeholders and took into account local priorities and the regional need for specialized programs that focused on lifeline transportation, bicycle use, climate protection and other policy considerations. In some cases, these policy considerations outweighed poor performance results. Ultimately, the Commission found that using a performance-based approach to defining the investment priorities not only made good analytic and policy sense, but also framed the policy discussion and decisionmaking process.

Source: MTC (2008), Change in Motion, Transportation 2035 Plan for the San Francisco Bay Area.

While the requirement for cost-effectiveness should probably be proportional to the environmental ambitions (similarly for social initiatives), the economic dimension of the problem is rarely seriously considered. For instance, few local climate action plans are currently based on a serious economic analysis of the possibilities and constraints. The cities of London and New York are exceptions. Energy-economy or sectoral energy models have made it possible to simulate different policies and especially to build sets of Marginal Abatement Cost Curves (MACCs). ${ }^{72}$ These mechanisms are highly efficient tools for analysing different aspects of climate policies, particularly by seeking to reduce the global cost through levelling, to a certain degree, the marginal costs of sectoral initiatives. These mechanisms can provide the required support to develop a methodology for defining and prioritising actions to be initiated, based on technicaleconomic criteria. The different actions required can then be organised to build a cost-effective programme (Lefèvre \& Wemaere, 2009).

72. "Marginal Abatement Cost Curves (MACCs) provide an assessment of the level of emissions reduction which a range of measures could deliver at a given point in time, against a projected baseline level of emissions. They show how much $\mathrm{CO}_{2}$ each measure could save (the level of abatement potential) and the associated cost per tonne of $\mathrm{CO}_{2}$ ” (Committee on Climate Change, 2009). 


\section{REFERENCES}

Agrell, Per J. and Peter Bogetoft (2005), “Economic and Environmental Efficiency of District Heating Plants”, Energy Policy, Vol. 33, No.10, Elsevier, pp. 1351-1362

Banzar, H. Spencer and Randall P. Walsh (2006), "Do People Vote with Their Feet: An Empirical Test of Environmental Gentrification”, Resources for the Future, Washington, DC, www.rff.org/Documents/RFF-DP-06-10.pdf.

Bengston, D.N. et al. (2004), "Public Policies for Managing Urban Growth and Protecting Open Space: Policy Instruments and Lessons Learned in the United States", Landscape and Urban Planning, Vol. 69, pp.271-286

Brouillard, Carolyn and Sarah Van Pelt (2007), “A Community Takes Charge: Boulder’s Carbon Tax”, City of Boulder, Boulder, February 2007, www.bouldercolorado.gov/files/Environmental\%20Affairs/climate\%20and\%20energy/boulders_car bon_tax.pdf.

Buchanan, Wyatt (2008), “Newsom signs strict green building codes into law," The San Francisco Chronicle, 5 August 2008, page B-1, www.sfgate.com/cgibin/article.cgi?f=/c/a/2008/08/04/BADQ1250K9.DTL\#ixzzOPNILRyFP.

Buehler, R., J. Pucher and U. Kunert (2009), “Making Transportation Sustainable: Insights from Germany”, The Brookings Institution Metropolitan Policy Programme, Washington, DC.

Bulkeley, H. and K. Kern (2006), "Local Government and the Governing of Climate Change in Germany and the UK”, Urban Studies, Vol. 43, No. 12, Routledge, London, pp. 2237-2259.

Burchell, R.W., G. Lowenstein, W. R. Dolphin, C.C. Galley, A. Downs, S. Seskin, K.G.Still and T. Moore, (2002), TCRP Report 74: Costs of Sprawl - 2000, Transportation Research Board, National Research Council, Washington, D.C.

C40 Cities (2009), “Energy Saving Partnership Berlin (ESP), - An effective and innovative model to reduce CO2 and energy costs without expenses for building owners", www.c40cities.org/bestpractices/buildings/berlin_efficiency.jsp, accessed 28 August 2009.

California Natural Resources Agency (2008), Managing an Uncertain Future: Climate Change Adaptation Strategies for California's Water, State of California, October 2008, www.water.ca.gov/climatechange/docs/ClimateChangeWhitePaper.pdf.

Cambridge Systematics, Inc. (2009), Moving Cooler: An Analysis of Transportation Strategies for Reducing Greenhouse Gas Emissions. Urban Land Institute, Washington, DC.

Carmin, JoAnn, Debra Roberts and Isabelle Anguelovski (2009), "Planning Climate Resilient Cities: Early Lessons from Early Adapters”, paper prepared for the World Bank, $5{ }^{\text {th }}$ Urban Research Symposium, Cities and Climate Change, Marseille France, June 2009. 
Chen, Cynthia, Hongmian Gong and Robert Paaswell (2008), "Role of the built environment on mode choice decisions: additional evidence on the impact of density", Transportation, Vol. 35, No. 3, Springer Netherlands, pp. 285-299.

Churchman, Arza (1999), “Disentangling the Concept of Density”, Journal of Planning Literature, Vol. 13, No. 4, Sage, London, pp. 389-411.

City of Boston Redevelopment Authority (2009), Green Building Task Force website, City of Boston, United States, www.bostonredevelopmentauthority.org/gbtf/GBTFhome.asp, accessed 25 August 2009.

City of Chicago (2005), “City Launches Green Roof Grants Program” City of Chicago website, http://egov.cityofchicago.org/city/webportal/portalContentItemAction.do?BV_SessionID=@@@@@0 628823192.1260183006@@@@BV_EngineID=ccccadejdekkhihcefecelldffhdfhk.0\&contentOID= $536932287 \&$ contenTypeName $=$ COC_EDITORIAL\&topChannelName $=$ Dept\&blockName $=$ Environ ment $\% 2$ FGreen + Roof $+\% 26+\mathrm{Cool}+$ Roof + Grants + Programs $\% 2 F I+$ Want + To\&context $=$ dept\&chan nelId=0\&programId=0\&entityName $=$ Environment\&deptMainCategoryOID $=-536887205$.

City of Los Angeles (2008), Climate LA, Municipal Program Implementing the GreenLA Climate Action Plan, Executive Summary, Los Angeles, United States, www.environmentLA.org.

City of New York (2007), PlaNYC - a Greener, Greater New York, City of New York, United States.

City of Paris (2009a), “Autolib’ est né”, 27 July 2009,

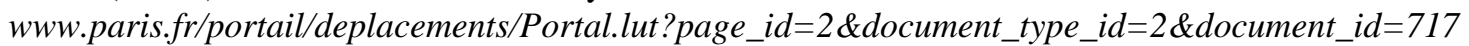
72\&portlet_id=21994.

City of Paris (2009b), “Jusqu'à $400 €$ de subvention pour l'achat d'un scooter électrique”, 9 June 2009, City of Paris, France, www.paris.fr/portail/deplacements/Portal.lut?page_id=2\&document_type_id=2\&document_id=655 82\&portlet_id=21994.

City of San Francisco (2008), San Francisco Municipal Green Building Report 2004-2007, City of San Francisco, United States, www.sfenvironment.org/downloads/library/nicipalgreenbuildingreport.pdf.

City of Santa Cruz (2009), General Plan 2030 Administrative Draft, February 27, 2009, City of Santa Cruz, United States.

City of Toronto (2008), “Mayor's Tower Renewal Executive Report”, City of Toronto, 19 August 2008, City of Toronto, Canada, www.towerrenewal.ca/MTR_execReport.pdf.

Committee on Climate Change (2009), "Marginal Abatement Cost Curves (MACCs)", The Committee on Climate Change, UK Government,www.theccc.org.uk/reports/building-a-low-carbon-economy/maccurves, accessed 7 December 2009.

De Macedo, Jorge Braga and Joaquim Oliveira Martins (2006), "Growth, reform indicators and policy complementarities” Economics of Transition, Vol. 16, No. 2, Blackwell Publishing, Oxford, UK, pp.141-164.

Durnbaugh, Arlon N. (2008), “Urban Ecology and regional partnerships,” presented in The Mayors Conference - Local Action for Biodiversity, Bonn, Germany, May 26-28, 2008, 
www.iclei.org/fileadmin/template/project_templates/LAB-

bonn2008/user_upload/Presentations/Durnbaugh_Chicago.pdf.

ECMT (European Conference of Ministers of Transport), (1995), Urban travel and sustainable development, OECD, Paris.

ECMT (2002), Implementing Sustainable Urban Travel Policies, Final Report, OECD, Paris.

Flemish Ministry of Public Works, Energy, Environment and Nature (2006), The Flemish Climate Policy Plan 2006 - 2012, Flanders, Belgium, October 2006.

Glaeser, Edward L. and Joseph Gyourko (2003), "The Impact of Building Restrictions on Housing Affordability”, Federal Reserve Bank of New York Economic Policy Review, June.

Hacker, Jacob N. and Michael J. Holmes (2007), “Thermal Comfort: Climate Change and the Environmental Design of Buildings in the United Kingdom”, Built Environment, Vol. 33, No. 1, Oxon, UK, pp. 97-114.

Hirt, S. (2007), "The Devil Is in the Definitions: Contrasting American and German Approaches to Zoning”, Journal of the American Planning Association, Vol. 73, No. 4, Routledge, London, pp. 436- 450.

Howley, Peter, Mark Scott and Declan Redmond (2009), "Sustainability versus liveability: an investigation of neighbourhood satisfaction” Journal of Environmental Planning and Management, Vol. 52, No. 6, Routledge, London, pp. 847-864.

ICLEI (ICLEI-Local Governments for Sustainability), (2007), ICLEI Oceania, unpublished data.

IEA (International Energy Agency), (2005), Evaluating Energy Efficiency Policy Measures \& DSM Programmes, Volume I Evaluation Guidebook. OECD/IEA, Paris.

IEA (2008c), Energy Efficiency Requirements in Building Codes, Energy Efficiency Policies for New Buildings, IEA information Paper March 2008, OECD/IEA, Paris.

IEA (2008d), Promoting Energy Efficiency, Best Practice in Cities, September 2008, OECD/IEA, Paris.

IEA (2009a), Cities and Towns and Renewable Energy -YIMFY: Yes In My Front Yard, 4 August, 2009, OECD/IEA, Paris.

IEA (2009b), Innovations in Multi-Level Governance for Energy Efficiency: Sharing experience with multi-level governance to enhance energy efficiency, IEA, Paris.

International Association for Public Transport (UITP), (2009), Car-Sharing in Small Cities, Car-Sharing Fact Sheet No.9, www.uitp.org/knowledge/pdf/factsheet9esmallcities.pdf.

IPCC (Intergovernmental Panel on Climate Change), (2007c), Climate Change 2007: Mitigation, Contribution of Working Group III to the Fourth Assessment Report of the Intergovernmental Panel on Climate Change, B. Metz, O.R. Davidson, P.R. Bosch, R. Dave and L.A. Meyer (eds), Cambridge University Press, Cambridge and New York.

Lefèvre, B. and M. Wemaere (2009), Fitting Commitments by Cities into a Post-2012 Climate Change Agreement, Ideas IDDRI, IDDRI, Paris. 
Local Government Denmark (2009), “Municipality Plan with climate adaptation”, 25 June 2009, www.kl.dk/Dokumenter/Artikler/BEM/2009/06/Municipality-Plan-with-climate-adaptation.

Morris, Jeffrey (2005), “Comparative LCAs for Curbside Recycling Versus Either Landfilling or Incineration with Energy Recovery” International Journal of Life Cycle Assessment, vol. 10, no. 4, ecomed publishers, Landsberg, Germany, pp. 273-284.

Neuman, Michael (2005), “The Compact City Fallacy”, Journal of Planning Education and Research Vol. 25, No. 1, Sage Publications, pp. 11-26.

New York City Climate Summit (2007a), "Barcelona's Solar Hot Water Ordinance”, www.nycclimatesummit.com/casestudies/energy/energy_barcelona.html, accessed 25 August 2009.

New York City Climate Summit (2007b), “97\% of Copenhagen City Heating Supplied by Waste Heat” www.nycclimatesummit.com/casestudies/energy/energy_heating_copen.html, accessed 26 August, 2009.

Nishida, Yuko (2009), “From Tokyo: Climate Change Policy of Tokyo Metropolitan Government”, City Planning Review (Toshi keikaku), Vol.58, No.3, the City Planning Institute of Japan, Tokyo, pp. 4144.

Nordregio (2005), ESPON 1.1.1 Potentials for polycentric development in Europe, Nordregio, Stockholm.

OECD (Organisation for Economic Co-operation and Development), (2002), Impact of Transport Infrastructure Investment on Regional Development, OECD, Paris.

OECD (2003), Environmentally Sustainable Buildings: Challenges and Policies, OECD, Paris.

OECD (2008a), Competitive Cities and Climate Change: OECD Conference Proceedings, Milan, Italy, October 9-10, 2008, OECD, Paris.

OECD (2009b), “Cities, Climate Change and Multilevel Governance”, Environment Working Papers, OECD, Paris.

OECD (2009g), Green Cities: New Approaches to Confronting Climate Change, OECD Workshop Proceedings, 11 June 2009, Las Palmas de Gran Canaria, Spain.

OECD (2009h), OECD Territorial Review: Venice, Italy, OECD, Paris, forthcoming.

OECD (2009i) Integrating Climate Change Adaptation into Development Co-operation: Policy Guidance, OECD, Paris.

OECD (2010), “Climate Change and Chinese Cities”, Working Paper, OECD, Paris, forthcoming.

Partin, Joahnna G. (2009) Presentation by Director of Climate Protection Initiatives, City of San Francisco, at "Les plans climat, un levier pour les autorités locales? (Climate plans - a tool for local authorities?)”, Institut Pour la Ville en Mouvement, 28 October 2009.

Pierre, J. (1999), "Models of urban governance: the institutional dimension of urban politics”, Urban Affairs Review, Vol. 34, No. 3, Sage Publications, 372-396. 
Pinjari, Abdul Rawoof, et al. (2007), "Modeling residential sorting effects to understand the impact of the built environment on commute mode choice”, Transportation, Vol. 34, No. 5, Springer Netherlands, pp. 557-573.

Renewable Energy Policy Network for the 21st Century (REN21), (2009), Renewables Global Status Report: 2009 Update, REN21, Paris.

Seoul City Government (2009), “2030 Low-carbon Green Development Masterplan”, proposed July 2, 2009, Seoul City Government, Korea.

Sejong (Korea) (2009), Green City Sejong, Multifunctional Administration City Construction Agency, Yeongi-gun, Korea.

Sugiyama, N. and T. Takeuchi (2008), “Local Policies for Climate Change in Japan,” The Journal of Environment and Development, Vol. 17, No. 4, Sage, London, pp. 424-41.

Titus, James G. and Vijay Narayanan (1996), “The Risk of Sea Level Rise: A Delphic Monte Carlo Analysis in which Twenty Researchers Specify Subjective Probability Distributions for Model Coefficients within their Respective Areas of Expertise”, Climatic Change, Vol. 33, No. 2, Springer Netherlands, pp. 151-212.

Tokyo Metropolitan Government (2008), “Tokyo Green Building Programme and Green Labelling System of Condominiums”, The Environment of Tokyo 2008, www.kankyo.metro.tokyo.jp/kouhou/english/2008/warming/cu06_07.html\#cu06, accessed 25 August, 2009.

Wheeler, S. M. (2008), “State and Municipal Climate Change Plans: The First Generation”, Journal of the American Planning Association, Vol. 74, No. 4, Routledge, London, pp. 481-496.

Xcel Energy Inc. (2008a), Xcel Energy Smart Grid - A White Paper, www.bouldercolorado.gov/files/City\%20Council/Study\%20Sessions/2008/10-28-08/xcel-8smart_grid_white_paper.pdf.

Xcel Energy Inc. (2008b), SmartGridCity Design Plan for Boulder, Colo., www.bouldercolorado.gov/files/City\%20Council/Study\%20Sessions/2008/10-28-08/xcel-9smart_grid_city_design_and_scope_plan.pdf.

UNEP (United Nations Environment Programme), (2007), Assessment of Policy Instruments for Reducing Greenhouse Gas Emissions from Buildings, UNEP Sustainable Buildings \& Construction Initiative and Central European University, Paris.

Ewing, Reid et al. (2008), Growing Cooler: The Evidence on Urban Development and Climate Change, Urban Land Institute, Washington, US.

U.S. Department of Energy, Energy Information Administration (2009), "Electric Sales, Revenue, and Average Price 2007,” January 2009, www.eia.doe.gov/cneaf/electricity/esr/esr_sum.html.

U.S. Global Change Research Programme, (2009), Global Climate Change Impacts in the United States, Cambridge University Press, Cambridge, UK 
U.S. National Research Council (2009), Driving and the Built Environment: The Effects of Compact Development on Motorized Travel, Energy Use, and CO2 Emissions, Special Report 298, National Academy of Sciences, Washington, DC., www.nap.edu/catalog/12747.html.

Woody, Todd (2009), “Alternative Energy Projects Stumble on a Need for Water”, New York Times, New York, US, September 30, 2009. 


\section{FINANCIAL INSTRUMENTS AND FUNDING NEW EXPENDITURE NEEDS}

Climate change creates new challenges for urban finance: it necessitates a greening of existing financial instruments, and put additional pressure on city budgets, which creates the need for additional resources. Existing financial instruments that could be made more sustainable are taxes, fees and grants; they could be 'greened' by providing more incentives for compact development and reduction of activities leading to GHG emissions. Additional pressure on city budgets could result from adaptation and mitigation policies, as well as rises in the price of fossil-fuel energy sources. Carbon finance mechanisms and increased access to capital markets are potential additional sources of financing for cities.

\subsection{Financial instruments and incentives}

Fiscal instruments and incentives already at cities' disposal could be considered complementary instruments for achieving urban sustainability goals, including climate change targets. Local revenue sources are not neutral: revenue sources, rates, exemptions and composition all impact the price of certain goods and services for citizens and firms, such as urban transportation options, land development and housing. As citizens and firms are in most cases price elastic (at least to a certain extent), these pricerelated mechanism will be able to influence the behaviour of citizens and firms. A key challenge for sustainable urban finance is thus to combine revenue-raising capacity with the introduction of fiscal incentives that stimulate sustainable development. In addition to the access to revenue sources needed to implement adaptation and mitigation measures, an important part of the behavioural changes needed for sustainable urban development could be stimulated by incentives mechanisms that internalise externalities and put a price on behaviours that contribute to GHG emissions and unsustainable resource use. The financial instruments that form part of cities' climate change plans express this search for revenue sources that stimulate sustainable development (Table 5.1). These incentive mechanisms could be introduced in the three main city's revenue sources: taxes, fees and grants. 
Table 5.1. Financial instruments in selected city's climate change plans

\begin{tabular}{|c|c|}
\hline City & Financial/fiscal instruments \\
\hline Paris & 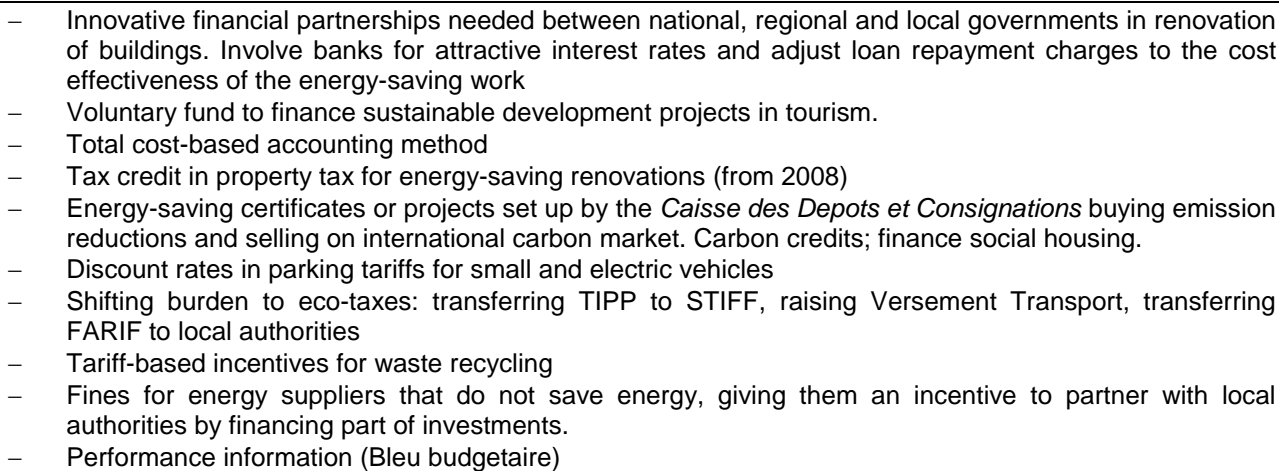 \\
\hline Mexico City & - $\quad$ Additional resources from sale of GHG emission reduction credits \\
\hline London & $\begin{array}{l}\text { - } \begin{array}{l}\text { Introduce carbon pricing; host carbon-trading markets } \\
\text { - }\end{array} \text { Carbon pricing for transport: charge cars to enter in the central business area on the basis of their } \\
\text { carbon emission levels. } \\
\text { - } \quad \text { Become world leader in financial development on climate change: carbon emission trading, green funds, } \\
\text { pricing climate change risks, financing climate change research } \\
\text { - } \quad \text { Lobby the national government to change vehicle charges in different Vehicle Excise Duty bands } \\
\text { - } \quad \text { Support borough-based carbon pricing initiatives: permit-parking charges on the basis of CO2-emissions }\end{array}$ \\
\hline Tokyo & $\begin{array}{ll}- & \text { Climate Change Fund } \\
- & \text { Examine the introduction of Energy Efficiency Promotion Tax System }\end{array}$ \\
\hline Philadelphia & $\begin{array}{ll}- & \text { Systems benefit charge for demand side management programmes by local utilities } \\
- & \text { Update pricing of parking }\end{array}$ \\
\hline Austin & - $\quad$ Development of carbon offset credits \\
\hline Toronto & $\begin{array}{ll}- & \text { Investigate road pricing in the Greater Toronto Area } \\
- & \text { Financial incentives to use public transit }\end{array}$ \\
\hline Portland & $\begin{array}{ll}- & \text { Public utility charges funding energy conservation programmes } \\
- & \text { Support extension of the State Business Energy Tax Credit } \\
\end{array}$ \\
\hline Los Angeles & - $\quad$ Increase of LA Department of Water and Power rebates for energy efficient investment by customers \\
\hline San Francisco & $\begin{array}{ll}- & \text { Expand transportation impact fee assessment to all the downtown commercial space } \\
- & \text { Increase Gas Tax } \\
- & \text { Investigate congestion pricing and cordon tolls } \\
- & \text { Consider charging market rates for parking permits; differentiate parking rates based on vehicle size } \\
- & \text { Collecting parking lot taxes from hotels } \\
- & \text { Differentiate vehicle registration fees based on vehicle size or emissions } \\
- & \text { Promote bridge toll waivers for alternative fuel vehicles } \\
- & \text { Commuter tax benefit programmes for city and county employees } \\
- & \text { Reduce city permit fees for solar energy } \\
- & \text { Provide differentiated rates for waste recycling }\end{array}$ \\
\hline Seattle & $\begin{array}{ll}- & \text { Road pricing } \\
- & \text { Parking tax: implementation and increase } \\
- & \text { Consider open-space impact fee }\end{array}$ \\
\hline Stockholm & - $\quad$ Congestion charge \\
\hline
\end{tabular}

Note: the elements in the table have the common characteristic of being mentioned in the city's climate change plan, but express a large heterogeneity, as they refer to measures already implemented as well as projected plans and principles.

There is a huge variety of urban finance practices available from which cities could learn. The composition of revenues varies across OECD cities: for example, in a selection of 18 OECD cities, revenues from grants from national or regional governments range from 5\% to almost 70\%, and a similar range applies to tax revenues (Figure 5.1). The introduction of incentives for sustainable urban development could be considered for these traditional city revenue sources: grants, taxes and fees. At the same time, this variety means that there are few universal recipes that could apply to all metropolitan regions. Particular fiscal instruments and incentive mechanisms will be more or less effective in cities according to their specific revenue composition and local conditions. 
Figure 5.1. Main revenue sources of selected cities within the OECD

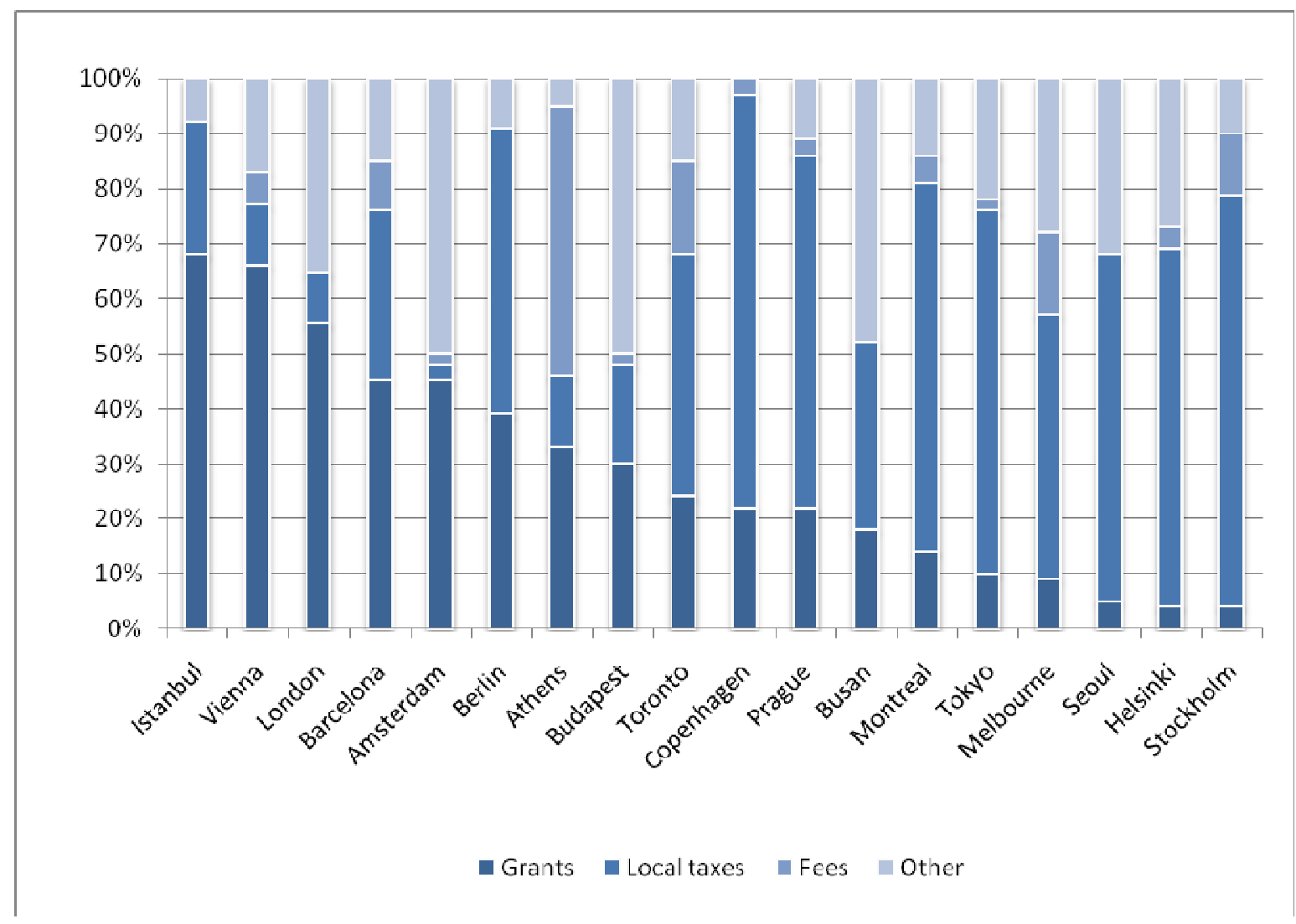

Note: Demarcation of the cities refers to municipal boundaries (except for Melbourne, which refers to the city centre). Financial year: Tokyo, Seoul, Budapest (2003), Istanbul, Toronto, Prague, Barcelona, Copenhagen (2004), Athens, Berlin, Helsinki, Melbourne, Stockholm (2005), Amsterdam, Vienna (2006).

Source: OECD (2006), Competitive Cities in a Global Economy, OECD Publishing, Paris.

\section{Taxes}

Urban taxation is a potentially powerful tool for stimulating sustainability for two reasons. First, tax revenues provide more than half of the revenues for many OECD cities and could thus be considered the most important revenue source for cities. Second, the urban tax most often used in OECD countries is the property tax, which has a direct relation with land use and the built environment, which is responsible for a large part of cities' GHG emissions (Figure 5.2). Income tax, another large local tax resource - although less frequently used - is less directly related to the environment.

Over the last decades, several OECD countries have 'greened' their taxation system, but this has taken place mostly at the national level rather than sub-nationally. In order to improve environmental conditions, many OECD countries have introduced environmental taxes, such as carbon taxes (e.g. Sweden since 1991), climate change levies (e.g. United Kingdom since 2001) and other similar fiscal instruments aimed at stimulating environmental sustainability. Some countries, such as the Netherlands, have made greening of their tax system an explicit policy goal, and introduced comprehensive reform of the tax system. Attention by policy-makers and researchers has been mostly focused on greening taxation at the national rather than the sub-national level. There is however room for greening sub-national taxes, especially those 
that have an impact on the city's built environment, transport and energy, such as property taxes and transportation taxes, as will be discussed below.

Figure 5.2. Main taxes of selected cities within the OECD

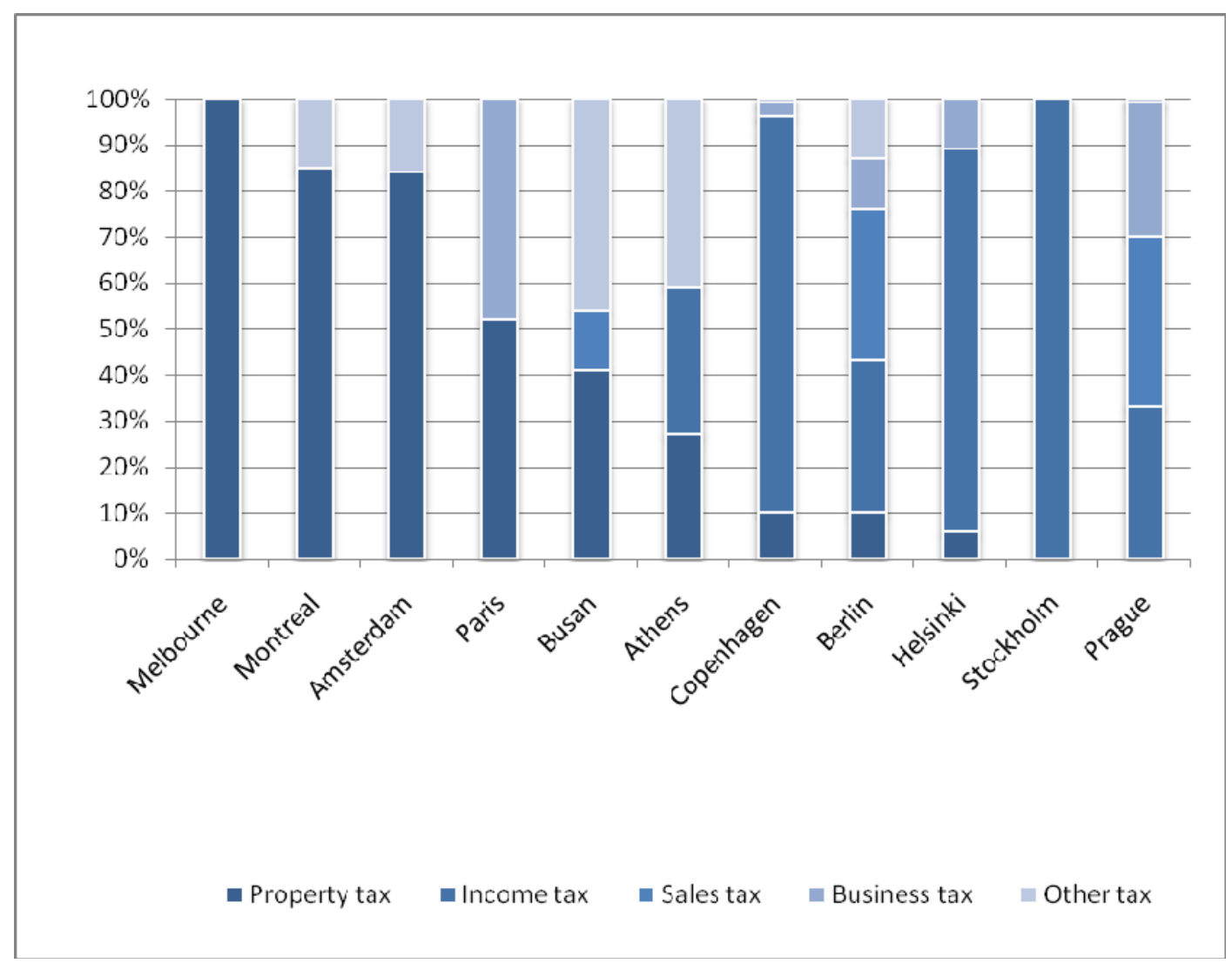

Source: OECD (2006), Competitive Cities in a Global Economy, OECD Publishing, Paris.

Carbon taxes, and climate change levies, are almost always introduced at the national level, as they would distort competition between regions. One of the exceptions is the carbon tax introduced in the City of Boulder (Colorado, USA) which is low enough not to have a negative impact on the city's attractiveness for citizens and companies, but arguably not high enough to have a substantial impact on reducing carbon emissions (Box 5.1). In order for the carbon tax to have a real impact on reduction of carbon emissions, it would in many countries have to increase the price of carbon significantly, especially since price elasticity is relatively low in the short term. To avoid distortions to competitiveness, supra-national co-ordination might be necessary. 


\section{Box 5.1. Carbon tax in the City of Boulder, USA}

In order to finance its Climate Change Action plan, the City of Boulder introduced a local carbon tax in 2006, thereby becoming the first local government in the United States to introduce such a tax. The tax base for the tax is residential and commercial electricity consumption, and the tax generates up to USD 1.6 million annually through 2012 - when the tax is set to expire. The tax was approved by referendum in 2006 . The budget estimates were broken down by sector expenditures, such that the residential sector contributes $58 \%$, the commercial sector contributes $39 \%$ and the industrial sector contributes 3\%. The City Council set the first year tax at a maximum rate of USD 0.0022 per $\mathrm{kWh}$ for residential customers; USD 0.0004 per kWh for commercial customers; USD 0.0002 per kWh for industrial customers. The average household will pay USD 1.33 per month and an average business will pay USD 3.80 per month. In subsequent years, the City Council has the authority to increase the rates as needed to fund the Plan, as it may be amended, to a maximum rate of USD 0.0049 per kWh for residential customers; USD 0.0009 per kWh for commercial customers; and USD 0.0003 per kWh for industrial customers.

Source: Koehn in OECD (2009g), Green Cities: New Approaches to Confronting Climate Change, OECD Workshop Proceedings, 11 June 2009, Las Palmas de Gran Canaria, Spain.

\section{Taxes impacting land use and the built environment}

The property tax, the primary source of local tax revenue in many OECD cities, is sometimes skewed in favour of single family houses, discouraging compact city development. Multifamily rental housing in the United States, for example, bears an effective tax rate (tax divided by property value) that is considerably higher than the rate for single-family owner-occupied housing: at least $18 \%$ in 2001 (Goodman, 2006). The higher tax rate for apartments observed in the national totals holds for 10 of the 12 states that are identified in the Residential Finance Survey data. One of the explanations is the explicit policy of sub-national jurisdictions to tax apartments more heavily than single family houses: apartments are often classified as commercial real estate rather than as housing and many local governments tax commercial property at a higher rate than residential real estate. In other instances, such as in Illinois since 2004, jurisdictions have capped taxes or tax increases for single-family houses without setting corresponding caps for apartments. Another explanation is that some jurisdictions value owner-occupied houses by sales prices and apartments by rental revenue or net operating income (Almy, 2000). Implemented like this, the residential property tax promotes low-density development and disproportionally burdens lower-value properties. A similar bias in the property tax system towards single family homes exists in other OECD cities (e.g. Toronto), but the inverse also occurs. For example, housing cooperatives, offering housing options in multi-apartment buildings representing around one eight of the dwellings in Greater Copenhagen, are not subject to the municipal property tax, in contrast to other less compact dwelling types, such as single family houses (Skatteministeriet, 2008; Andersen, 2007). Other provisions related to the property tax can also have an impact when they provide more incentives for dwelling types that are denser, such as rental housing or social housing: e.g. the property tax rate for owner-occupied housing in Sweden is twice as high as for rented properties (Birgersson \& Turner, 2006).

In addition, as most property tax systems tax land and structures on the land at the same rate, they provide limited incentives to develop undeveloped land within cities. Distortions created by the property tax may result in the inefficient spatial expansion of cities, which makes the tax one possible cause of urban sprawl (Brueckner \& Kim, 2003). Sprawl is stimulated when it is more beneficial for developers or other actors to develop on undeveloped land outside of cities rather than within cities. Placing proportionally higher taxes on land than on built structures would make it more costly to hold on to vacant or underutilized, centrally located sites. Reducing the tax burdens on development and redevelopment of urban land could facilitate revitalization and the replacement of obsolete buildings in older central cities. More compact development can be stimulated by introducing a form of land taxation such as a split-rate property tax. The key characteristics of such a tax, applied in Sydney, Hong Kong, the U.S. cities of Pittsburgh and Harrisburg and other cities within OECD countries such as Denmark and Finland, is that 
land value is taxed more heavily than the buildings on the land, thereby providing an incentive to develop it. This is in contrast to the conventional equal-rate system that applies the same tax rate to land and to build structures on it.

Some cities have introduced property tax reform to favour compact development. Through differential taxation, a special area tax could be applied on suburban properties or use a set of cascading taxes that gradually increase as one moves away from the city centre towards the periphery. A relatively simple form of such a tax might be a higher standard property rate for suburban inhabitants or preferential rates for multiple dwellings. Although the introduction of such a tax could be politically difficult to implement, there are cities that have introduced a tax along these lines. The City of Austin, USA has for example introduced a special transportation levy on all city utility bills, based on the estimated average number of daily trips made by individuals residing in different types of property. The levy averages USD 30-40 per year for a typical household, but differentiation takes place according to housing type (Litman, 2009). Depending on local circumstances, such a tax could have social consequences if lower-income groups have difficulties finding affordable housing in city centres and are dependent on car use, which might already be taxed in other ways.

\section{Taxes impacting transportation}

Cities in the OECD have overall limited fiscal incentives in place for reducing car use. Car users are in many cases not charged for their use of the road network, non-residential parking is free in many cities, and personal income tax regulation often favours automobile use over transit, as the costs of owning, operating and parking a car are in many cases deductible for firms and individuals, whereas transit benefits for employees are not. Companies in OECD countries often provide subsidies (frequently stimulated by fiscal arrangements) to their employees for their individual motorised transport and free company parking, rather than for public transportation. In many non-OECD countries, such as India, Indonesia and Egypt, fuel subsidies provide further disincentives for the reduction of car use. They are usually provided by central governments, but mostly benefit the urban population in these countries. Some cities and regions have introduced motor vehicle or fuel taxes, although this remains a predominantly national tax in most OECD countries (Figure 5.3 and 5.4). In Canada, for example, excise taxes on gasoline and diesel are collected by both federal and provincial governments, as well as by some select metropolitan regions (Montreal and Vancouver), with combined excise taxes up to $30.5 \mathrm{c} / \mathrm{L}$ in Vancouver. Similar effects on fuel consumption could be attained by a pay-as-you drive insurance, although such schemes have not been introduced yet (Parry, 2005). 
Figure 5.3. National, state and local motor vehicle taxes in unitary OECD countries (2006)

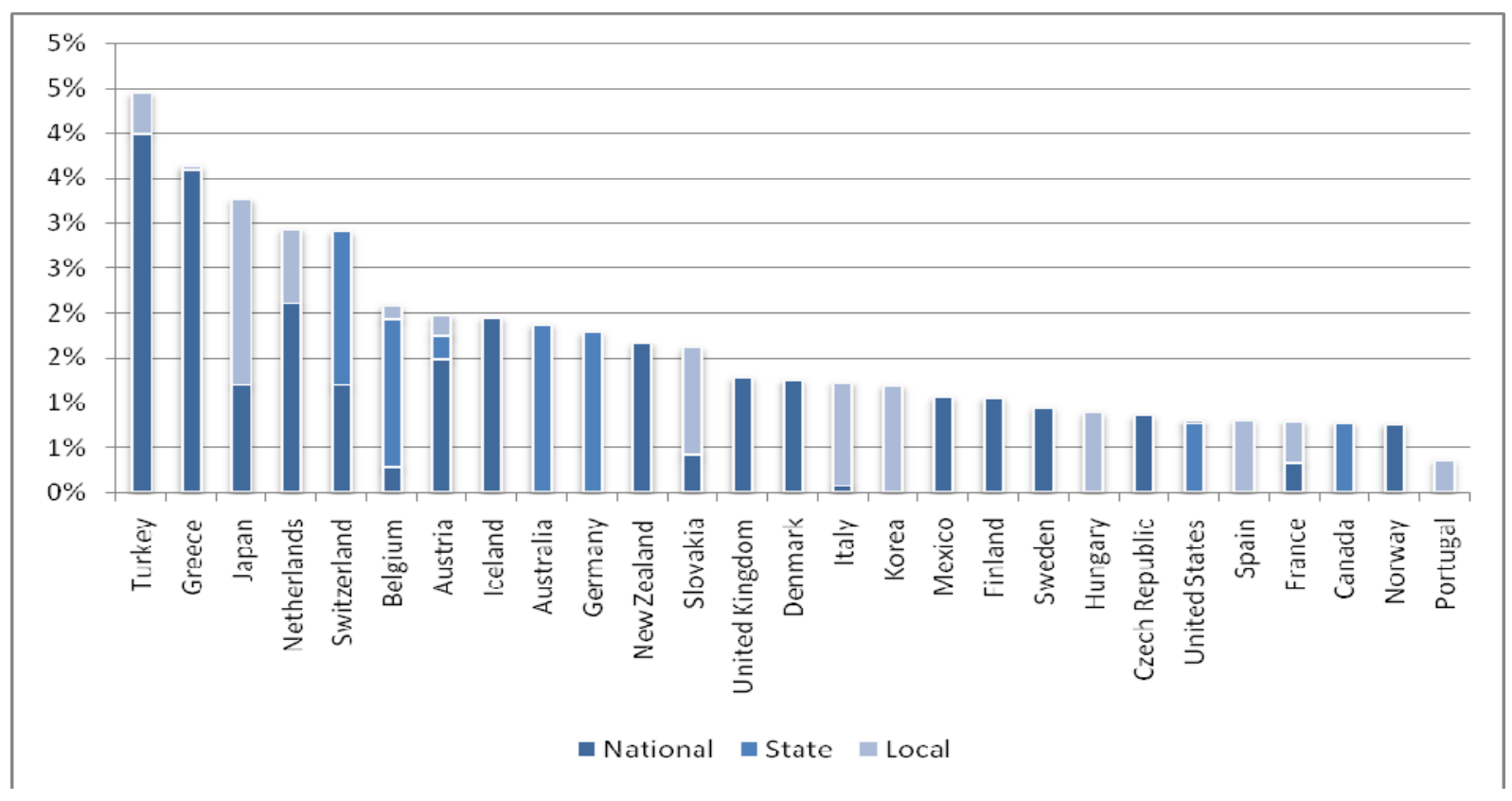

Note: Tax revenues as share of total government revenues (central and local)

Source: OECD Revenue Statistics Database.

Figure 5.4 National, state and local fuel taxes in unitary OECD countries (2006)

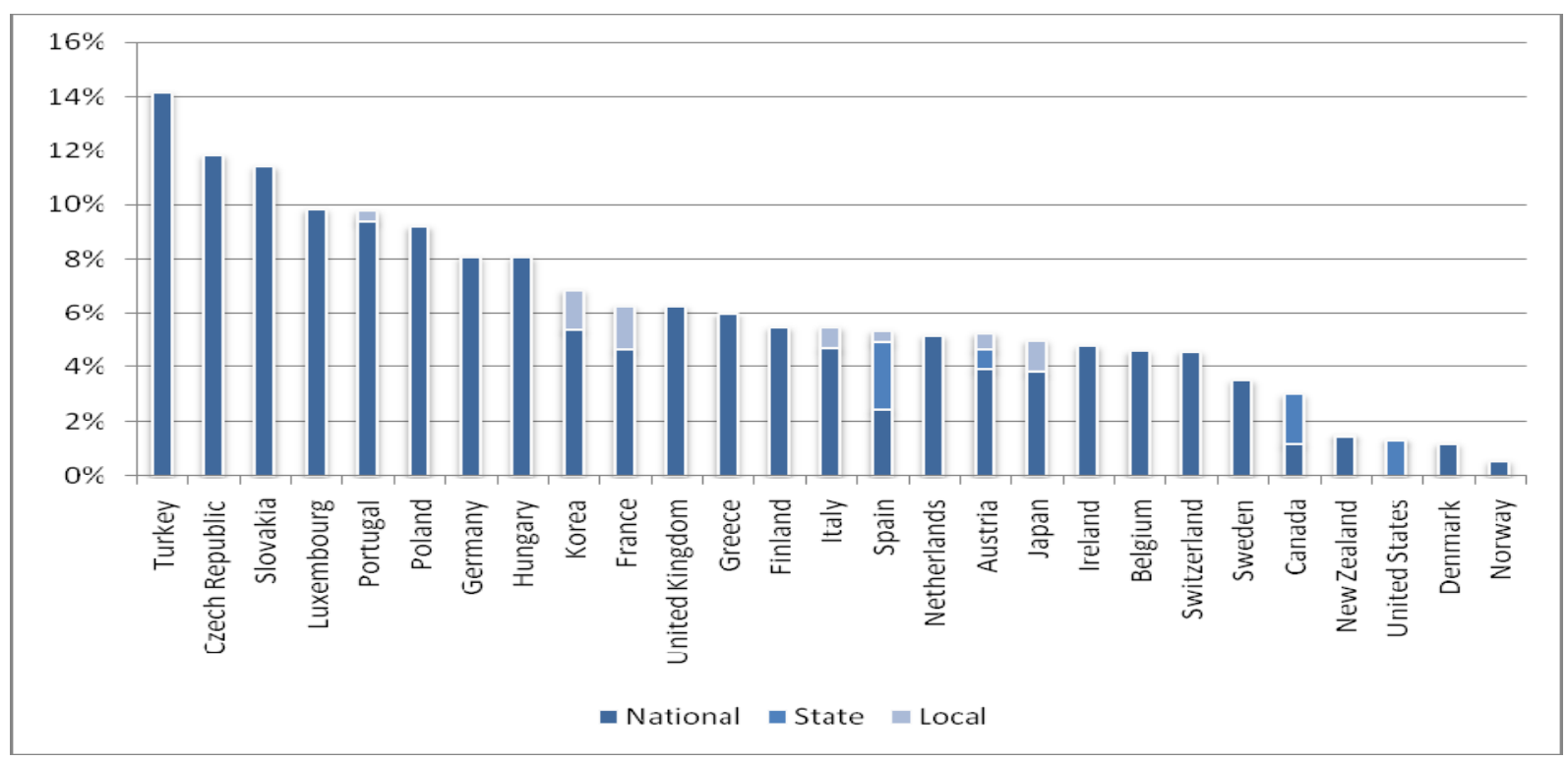

Note: Tax revenues as share of total government revenues (central and local), including petroleum excise taxes.

Source: OECD Revenue Statistics Database. 
In some metropolitan regions, transportation-related taxes are used to fund metropolitan transit. A local tax that is frequently used to finance public transportation is the value capture tax. The base for a value capture tax is an increase in property values arising from public infrastructure development. This increased value results from the increased desirability of the location, better access, and the potential for higher rents, increased resale value and higher-density development. Value capture taxes can be imposed or can take the form of a negotiated agreement; they may be levied as an ongoing annual charge or as a one-time tax. Value capture taxes have been used to finance transport infrastructure in cities as different as Hong Kong, Miami, Milan and Bogotá. A value capture tax can only be applied when the property value increase can be unambiguously attributed to infrastructure investment. Value capture taxes are less useful when property taxes are assessed on a yearly or regular basis, since the annual assessment captures any increases in the property value that might result from public infrastructure investment; this does however not take place in most OECD countries. In addition, some metropolitan transit authorities dispose of tax income, an example of which is the "versement transport" to finance metropolitan public transport in France. This tax is collected from companies employing nine or more people, as a surcharge on salaries at a rate that may vary between $1 \%$ and $2.2 \%$, and is earmarked for public transport at the discretion of the metropolitan transit authority. These revenue sources, although not uncontroversial, complement other public transportation fees and provide a substantial part of revenues for metropolitan public transport (around 70\% of the income for STIF, the metropolitan transport authority of the region Paris Ile-de-France).

\section{Fees and charges}

Fees and charges could be effective instruments in a variety of areas to signal the higher cost of internalising environmental externalities, including in the sectors of transport, land development, waste and water. Fees and charges are ideal for funding local services where specific beneficiaries can be identified and non-payers excluded. Fees are particularly effective when they recover full costs and when fees are paid according to individual or household use, as these give residents incentives for more efficient use of resources. Fees have been applied to land use and the built environment, transport, urban water provision and waste disposal.

\section{Fees and charges impacting land development and the built environment}

Development charges could be used to cover the costs of urban sprawl, but much depends on their design. Development charges are levied on developers to provide funding for the infrastructure needed to provide services to the developed area. They are in principle good instruments for compensating for the costs of sprawl, as long as they take into account real costs and as long as charges for single detached homes are considerably larger than those for apartments. This, however, is not always the case. In Toronto, for example, area-specific charges could give developers incentives to develop compactly, but municipalities in the Toronto metropolitan area have not widely used them: most development charges are applied using a uniform rate for the whole municipality (OECD, 2009f). This means that the costs for the municipalities are equalised over the various development projects being undertaken in the municipality. Although this minimises the risk of conflicts with developers, the disadvantage is that the development charge does not have a direct relation to the costs of providing services to new developments, and therefore does not provide an incentive to developers to develop compactly. Other impediments to internalising the costs of sprawl could be the limited amount of cost categories than can be recovered via development charges. More efficient use of the development charges would imply charging a fee to developers that closely resembles the real and full costs for building and providing the infrastructure to a particular area. The effects of development charges on social equity appear ambiguous. On the one hand, low-income families might try to find affordable housing far from the city centre; internalising the costs of sprawl could raise the price of this housing so that it becomes unaffordable to these groups. On the other hand, development charges can include a partial subsidy to finance social housing inside the development area; countries like France and the UK impose a percentage of social housing in new developments. 
Several cities depend on land sales for a large part of their revenues, which also can create incentives for urban sprawl. This is the case with the metropolitan cities in Guangdong province in China. The contribution of land sales to local revenue has been estimated to be 55\% in the City of Guangzhou in 2006 and around 80\% in the City of Shenzhen throughout the 1990s (Tian \& Ma, 2009; Peterson, 2006; OECD, 2010 forthcoming). Although these could be valuable instruments to capture land value increases and to finance infrastructure, in practice local governments in China have been so motivated to generate revenues from land sale and leasing that they have generated an oversupply of land for construction. This has stimulated sprawled development and loss of cultivated land in the whole of China. Similar dynamics, although less extreme, are at work around other metropolitan regions in the OECD. Municipalities in the peri-urban fringe of many German agglomerations compete with each other by developing new land to attract inhabitants and companies, thereby bringing in gains that are used to finance public services. This dynamic is made possible by municipal autonomy in land-use planning and large demand for undeveloped land; the result is an undermining of sustainable planning principles.

Brownfield or infill development in many OECD metropolitan regions usually offers fewer benefits to developers. It also takes more time to complete, and so occurs less frequently unless specifically stipulated by local governments. Suburban municipalities have thus actively pursued the development of previously undeveloped land, or greenfields. Because suburban municipalities typically have a greater supply of greenfields, they can be more attractive to developers and can benefit from the revenues and revenue bases brought in by greenfield development. However, greenfield development does not take into account the costs of sprawl, given that other actors are responsible for much of the transport infrastructure to connect newly developed land and bear the brunt of the resulting vehicle congestion and travel-related air pollution.

\section{Fees and charges impacting transportation}

The congestion charge has in some OECD metropolitan areas contributed to the reduction of GHGemissions. This instrument is similar to toll roads in that it charges for road use, but differs in that it charges exclusively or more intensely during peak traffic periods. Some congestion charges have to be paid when entering a certain delineated area within the city (cordon-based charges), whilst others charge according to kilometres travelled within an area. Examples of the first type of congestion charge are functioning in London and Stockholm, whereas an area-based charge is in operation in Singapore. The congestion charges also vary according to technology, tariffs and design, including differentiation to time of the day and other criteria (Table 5.2). Some of these initiatives (Singapore, Milan) are designed to tax higher-polluting vehicles more heavily, whereas other systems do not differentiate according to vehicle type. Congestion charges have been observed to reduce $\mathrm{CO}_{2}$ emissions from transport up to $19.5 \%$ (in London), as well as emissions of other air pollutants (Beevers \& Carslaw, 2005). These beneficial effects on emission reductions could lead to the reduction of traffic volumes, shifts in transit modal shares and reduction of congestion responsible for a considerable part of GHG-emissions. In some cases, the receipts from the congestion charge are used to finance urban public transport; this is the case in London. Congestion-charge technology can be costly and charges could be subject to the risk of "rebound effects" (with more people willing to take the car if congestion charges manage to actually de-congest traffic) if not accompanied by other policies, such as parking fees. 
Table 5.2. Main urban congestion charges in operation and their environmental outcomes

\begin{tabular}{|c|c|c|c|c|c|}
\hline & London & Stockholm & Singapore & Milan & Durham (UK) \\
\hline Introduced & 2003 & 2006 & $\begin{array}{l}1975 \\
1998\left(2^{\text {nd }} \text { generation }\right)\end{array}$ & 2008 & 2002 \\
\hline $\begin{array}{l}\text { Maximum } \\
\text { tariff }\end{array}$ & $\begin{array}{l}\text { GBP } 5 \\
\text { GBP } 8 \text { from July } \\
2005\end{array}$ & $\begin{array}{l}20 \text { SEK highest } \\
\text { tariff }\end{array}$ & USD 3, later USD 5 & EUR 10 & GBP 2 \\
\hline $\begin{array}{l}\text { Differentiat } \\
\text { ion by }\end{array}$ & $\begin{array}{l}\text { single rate for } \\
\text { vehicles entering } \\
\text { central London } \\
\text { between } 7-18.30\end{array}$ & - time of day & $\begin{array}{l}\text { 1975-1998: single } \\
\text { rate entering the } \\
\text { Central Business } \\
\text { District during } 7.30- \\
10.15 \text { am } \\
\text { 1998: differentiation } \\
\text { by vehicle type, time } \\
\text { of day and location }\end{array}$ & $\begin{array}{l}\text { - vehicle emission } \\
\text { standards } \\
\text { - type of vehicles } \\
\text { - resident or not }\end{array}$ & $\begin{array}{l}\text { Single rate } \\
\text { between } 10 \\
\text { am and } 4 \text { pm } \\
\text { Monday- } \\
\text { Saturday }\end{array}$ \\
\hline Area & $21 \mathrm{~km} 2$ & $36 \mathrm{~km} 2$ & $7 \mathrm{~km} 2$ & $8 \mathrm{~km} 2$ & \\
\hline $\begin{array}{l}\mathrm{CO}_{2} \\
\text { emission } \\
\text { reduction }\end{array}$ & $\begin{array}{l}\text { 19.5\% reduction } \\
2.3-2.5 \text { million } \\
\text { UK pounds in } \\
\text { CO2-emissions } \\
\text { saved }\end{array}$ & $\begin{array}{l}36,000 \text { tonnes a } \\
\text { year ( } 13 \% \\
\text { reduction) }\end{array}$ & & $\begin{array}{l}9 \% \text { reduction } \\
\text { (150,000 tonnes) }\end{array}$ & \\
\hline $\begin{array}{l}\text { Other } \\
\text { environme } \\
\text { ntal effects }\end{array}$ & $\begin{array}{l}12 \% \text { reduction of } \\
\text { NOx-emissions in } \\
\text { charging zone } \\
12 \% \text { reduction of } \\
\text { PM10 emissions } \\
\text { in charging zone } \\
15 \% \text { reduction in } \\
\text { vehicle kms } \\
12 \% \text { traffic } \\
\text { reduction } \\
\text { Reduction of } 211- \\
237 \text { million vehicle } \\
\text { distance } \\
\text { Reduction of } 35 \% \\
\text { in pollution } \\
\text { Total } \\
\text { environmental } \\
\text { benefits: } € 4.9 \\
\text { million per year }\end{array}$ & $\begin{array}{l}8.5 \% \text { reduction of } \\
\text { NOx } \\
14 \% \text { reduction CO } \\
13 \% \text { reduction of } \\
\text { PM10 } \\
\text { Avoidance of } 27 \\
\text { premature deaths } \\
22 \% \text { reduction of } \\
\text { vehicle passages } \\
\text { in charging area }\end{array}$ & $\begin{array}{l}75 \% \text { reduction of car } \\
\text { traffic in the morning } \\
\text { peak; in } 1992 \text { car } \\
\text { volume was still at } \\
54 \% \text { of the pre-1975 } \\
\text { level } \\
\text { Drop of car share in } \\
\text { modal split from } 48 \% \\
\text { to } 29 \% \text { immediately } \\
\text { after introduction } \\
1998 \text { model: } \\
\text { Elasticity of } \\
\text { passenger cars - } \\
0.106 \text { in their } \\
\text { restricted zone } \\
-0.21 \text { in the short run, } \\
-0.30 \text { in the long run } \\
\text { Reduction of } 15 \% \text { of } \\
\text { daily traffic volumes }\end{array}$ & $\begin{array}{l}\text { 19\% reduction of } \\
\text { PM10-emissions } \\
\text { (EUR } 3.3 \mathrm{mn} \text { ) } \\
37 \% \text { reduction of } \\
\mathrm{NH}_{3} \text {-emissions } \\
11 \% \text { reduction of } \\
\mathrm{NO}_{x} \text {-emissions } \\
\text { Traffic reduction: } \\
14.4 \%\end{array}$ & $\begin{array}{l}\text { Reduction of } \\
50-80 \% \text { of } \\
\text { number of } \\
\text { vehicles }\end{array}$ \\
\hline Period & $2002-2003$ & January-July 2006 & & $\begin{array}{l}\text { January-December } \\
2008\end{array}$ & \\
\hline
\end{tabular}

Alternative effective measures are high occupancy toll (HOT) lanes. HOT lanes make use of the infrastructure provided by high occupancy vehicle (HOV) lanes introduced in many OECD countries. HOV lanes are highway lanes on which only vehicles with a minimum number of occupants (usually two or three) are allowed to drive, in order to promote car pools. In the United States, several of these HOV lanes have been found to be ineffective, because car pooling did not have a wide appeal. In order to use their excess capacity, several HOV lanes instituted in the United States are being transformed into HOT lanes on which vehicles with less than the minimum number of occupants are permitted if they pay a toll. Assessments of the effectiveness of these HOV-lanes are mixed, considering the relatively high costs for collecting tolls. 
Other similar options include parking fees and taxes. Parking fees and taxes are price-elastic, and there is ample evidence that they are effective in reducing car trips and decreasing the car share in the modal split. Parking charges have led to a $12 \%$ decrease of vehicle miles of commuters in US cities, a $13 \%$ point reduction of car shares in modal splits in British cities, a 20\% reduction in single car trips in Ottawa and a 38\% increase of car pooling in Portland (Shoup, 1997; Bianco, 2000; Dasgupta et al., 1994, Wilson and Shoup, 1990). Parking fees could be differentiated in order to make them more effective. A parking surcharge might be levied on drivers who arrived at parking garages during the morning peak hours, and spatially differentiated parking fees could rival time-differentiated congestion fees (Arnott et al, 1991). The cost per minute associated with meter parking is however nominal in most cities. Some cities make use of congestion pricing for parking. For the most part, however, this takes the form of making parking cheaper in spaces further away from the high-demand areas. There are also other arrangements in place. Los Angeles has an area (Venice Beach) where the rates on the metres charge depending on the time of day. New York City has a congestion pricing programme for commercial parking that involves a graduated fee depending on how long the vehicle remains parked (Cerreno, 2002) These kinds of arrangements allow the price of parking to better reflect demand; as such they can reduce parking congestion and thus vehicle use.

\section{Grants}

Ecological goods and services are often public goods with important spillover effects, which might necessitate intergovernmental grants in order to internalise externalities. Non-excludability and positive spillover effects frequently lead to under-supply and scarcity of environmental goods and services, and thus to misallocation. This misallocation can to a limited degree be avoided by planning and law, as these mechanisms are less able to ensure an environmentally sound allocation of resources. In addition, ecological endowment and fiscal capacities for nature conservation are often distributed unequally among regions, requiring some form of fiscal transfers to prevent certain regions from being responsible for nature preservation without having the means to finance it.

The need for intergovernmental grants is linked to the expenditure assignments in specific countries or regions. Discovery and dissemination of basic knowledge about environmental harm and the effectiveness of various policy instruments, as well as policies tackling trans-boundary environmental problems and pollutants, such as sulphur dioxide, carbon dioxide and ozone, are in many instances assigned to central government levels, as their spatial externalities would lead to under-provision at the local level. In contrast, environmental policy associated with more localised characteristics, such as land use, soil contamination, water resources and nature conservation, have lower probabilities of crossboundary spatial externalities, and would thus be better suited for assignment to lower levels of government. In cases where environmental policies with large spillovers are assigned to local governments, intergovernmental grants could make sense in order to compensate local governments for the external benefits of its expenditures.

Specific grants are in many cases used to internalise positive externalities. A large variety of Länder in Germany provide conditional grants for ecological functions, ranging from sewage disposal, water supply, waste disposal and remediation of contaminated sites to landscape maintenance and water conservation schemes (Ring, 2002). Although the allocation of some of these environmental grants is criteria-based, many specific grants for environmental goals are allocated to a limited set of projects on the basis of a competitive process. A different category of grants is formed by payment schemes for environmental services provided by farmers and other landowners, as they are usually directly paid to the service provider by the national and supranational (EU) governments - and in some cases (e.g. Austria) even local governments.

General grants, however, rarely use ecological indicators, although there are some exceptions. In Germany, a few states (e.g. Saarland) have included ecological functions, such as those related to natural 
hot springs and damage from mining, as a basis for calculating the fiscal need in determining fiscal transfers from Länder to local governments (Ring, 2002). The Portuguese fiscal transfer scheme rewards municipalities for designated Natura 2000 sites and other protected areas within their territories, as these represent $5 \%$ of the allocation criteria of general grants to municipalities (Prates, 2007). In Brazil, a variety of states have introduced environmental criteria to allocate state tax shares to local governments via the green ICMS (Box 5.2).

\section{Box 5.2. Environmental indicators in tax shares to local governments in Brazil}

The tax on the circulation of goods and services (ICMS) is a value-added tax collected by state governments, and part of these revenues must be redistributed among municipalities. Three-quarters of this redistribution is defined by the federal constitution, but the remaining $25 \%$ is allocated to each state's legislation. The state of Paraná was the first Brazilian state to introduce the ecological ICMS (ICMS-E) in 1992, followed by the states of Minas Gerais in 1996, and several other states including São Paulo in 1996 and Rio de Janeiro in 2009. The ICMS-E was introduced against the background of state-induced land-use restrictions (protected areas) for several municipalities, which prevented them from developing land and generating value added, without being compensated for these restrictions: in the municipality of Piraquara, for example, $90 \%$ of the municipal territory was a designated protected area for conserving a major watershed to supply the Curitiba metropolitan region with drinking water (May et al., 2002).

Depending on the different states, the share of the ICMS allocated on the basis of ecological indicators ranges from $0.5 \%$ in São Paulo to $13 \%$ in Tocantins. Rio de Janeiro started with $1 \%$ in 2009 , which will be gradually increased to $2.5 \%$ in 2011 . Although the states have different systems in place, there are many commonalities in the allocation mechanism. The revenues are allocated according to the ecological index of a municipality, which is based on the total area set aside for protection, in relation to the total area of the municipality. The protected areas are weighted according to the different categories of conservation management, with weights ranging from 1.0 (for ecological research centres and biological reserves) to 0.1 (for special local areas of tourist interest, and buffer zones). Some states, such as Paraná, have included an evaluation of the quality of the protected areas in the calculation of the ecological index. The quality of the protected area is assessed by regional officers of the state environmental agency on the basis of physical quality, biological quality (fauna and flora), quality of water resources, physical representativeness, and quality of planning, implementation and maintenance.

Evaluations of in Paraná and Minas Gerais show that the introduction of the ICMS-E has been associated with the creation of new protected areas and have improved environmental management and quality of these areas. In Paraná, the total area measured in conservation units increased with 165\% between 1992 and 2000; the increase in Minas Gerais was 62\% over 1995-2000 (May et al., 2002). The ICMS-E has also improved relations between protected areas and the surrounding inhabitants, as they start to see them as an opportunity to generate revenue, rather than an obstacle to development. The ICMS-E has built on existing institutions and administrative procedures, and thus has had very low transaction costs (Ring, 2008).

Introduction of ecological indicators in general grants is considered in several countries. The German Advisory Council on the Environment has since 1996 called for the integration of ecological indicators into intergovernmental fiscal transfers, which has resulted in a number of detailed studies for implementation, for example financing on the basis of improvements for local nature and wildlife, or on the basis of 'nature points' valuating activities to improve nature protection (Perner \& Thöne, 2005). The incorporation of biodiversity per standardised area has been suggested for the general grant system in Switzerland, providing more biodiverse cantons with relatively more fiscal transfers (Köllner et al., 2002). In India, the $13^{\text {th }}$ Finance Commission advised that $7.5 \%$ of fiscal transfers to states and territories be based on the criterion of forest cover; in this proposed formula the states and territories with lesser forest cover area would receive fewer lump-sum transfers, while the others would gain according to their forest cover area (Kumar \& Managi, 2008).

Introduction of ecological indicators in general grants might entail a shift of transfers from urban to rural areas. Model calculations of a fiscal transfer system in which biodiversity indicators would be 
incorporated show that fiscal transfers would change relatively in favour of non-urban cantons, although the changes would be limited compared to the actual situation in 1999, due to small regional differences in biodiversity status and low transfer sums use in the model in order to provide realistic scenarios (Köllner et al. 2002). Model calculations show that incorporation of protected areas within the fiscal transfer system in Saxony (Germany), along the lines of the ICMS-E in Brazil, would lead to higher transfers to rural communities, as they would be compensated for the ecological functions they perform for urban areas and the rest of the country (Ring, 2008).

As general grants in many cases compensate for cost differentials between localities, there would be a need to develop indicators that reflect costs for ecological public functions. There are different methodologies that could be used in developing these criteria. A grant for environmental management in Queensland (Australia) has been allocated according to a environmental needs index, constructed through a multi analysis criteria analysis (MCA) approach, using 29 different criteria that were selected and weighed by a group of decision makers (Hajkowicz, 2007). Although it provided a structured approach for achieving equalisation of environmental funds, it could create problems related to objectivity and transparency. An alternative approach to inform the allocation of fiscal resources for the environment across regions is environmental valuation, e.g. in the form of damage cost assessment, hedonic pricing and contingent valuation. Although valuation could provide a powerful tool to inform fiscal equalisation of environmental funds, it is rarely used, perhaps because they are relatively costly.

\subsection{New urban expenditures and new funding sources}

Measures to reduce GHG emission and adapt to expected climate change impacts will put additional pressure on city budgets and increase the need for additional resources. Three forms of upward pressures on city budgets can be anticipated: costs related to adaptation, costs related to mitigation and costs related to price rises in carbon-related energy sources. The costs of adaptation are uncertain, but could be substantial. Many cities are exposed to the risks connected to climate change; these risks could entail huge casualty rates and damages. Some cities have set out adaptation strategies that require additional investments, for example to increase shock resistance of buildings and to facilitate evacuation of water in case of flooding. In addition, cities might try to insure some of their key assets, but insurers will provide climate change insurance only with a high mark-up rate due to considerable uncertainties about possible impacts of climate change. Mitigation also often requires public investments; a considerable extent of these would appear to be necessary in order to realise the GHG reductions announced by several cities in their climate change plans. Although investment in climate change and urban sustainability policies can produce co-benefits, such as increased accessibility and greater attractiveness of the city, these investments will present an additional burden on most cities' budgets. A third source of pressures on city budgets are costs related to carbon-related energy sources. Several city expenditure items are energy-intensive, in particular basic services such as garbage collection and disposal, street lighting, water supply and bus transportation. This might become problematic when energy prices rise, as anticipated in energy forecasts. ${ }^{73}$

Cities are responsible for large parts of government expenditure, including expenditures for the environment, transport and buildings. This is the result of decades of fiscal decentralisation, which have increased the average share of sub-national expenditures in OECD countries to 33\% in 2005 and have

73. The ability to substitute away from using energy in providing these services is limited. For example, garbage cannot be hauled in public transport, but must instead rely upon conventional trucks until alternative technologies are available. This means that cities will have difficulties reducing their energy bills in the short term. As local government revenues are not highly sensitive to the price of energy, so there are limited fiscal gains for local governments when energy prices increase. As a result, raising energy prices that might result from climate change agreements will create an adverse fiscal shock for most local governments (Clarke Annez and Zuelgaray, 2009). This is particularly the case for cities that are mainly responsible for providing basic local services. 
made sub-national governments responsible for almost $70 \%$ of total investment spending, which is particularly important for climate change. Following this decentralisation tendency, cities are now responsible for a range of sectors that impact environmental sustainability and GHG emissions, sometimes as the sole authority, but more often in partnership with other levels of government. For example, local governments in many OECD countries are responsible for amounts of public spending on environmental protection (which includes waste management, waste water management, pollution abatement, protection of biodiversity and landscapes, and R\&D on environmental protection) that are almost similar to that of their respective national governments (Figure 5.5). Transportation is in many OECD countries a shared responsibility, with local governments taking care of local infrastructure, regional governments for regional infrastructure and national governments for national infrastructure. Similar shared responsibilities can also be found with respect to the built environment and land use. Debates on environmental federalism have showed that local governments can play an important role in environmental policies, especially when they are able to internalise externalities.

Figure 5.5. National and sub-national expenditures on environmental protection in OECD countries (2005)

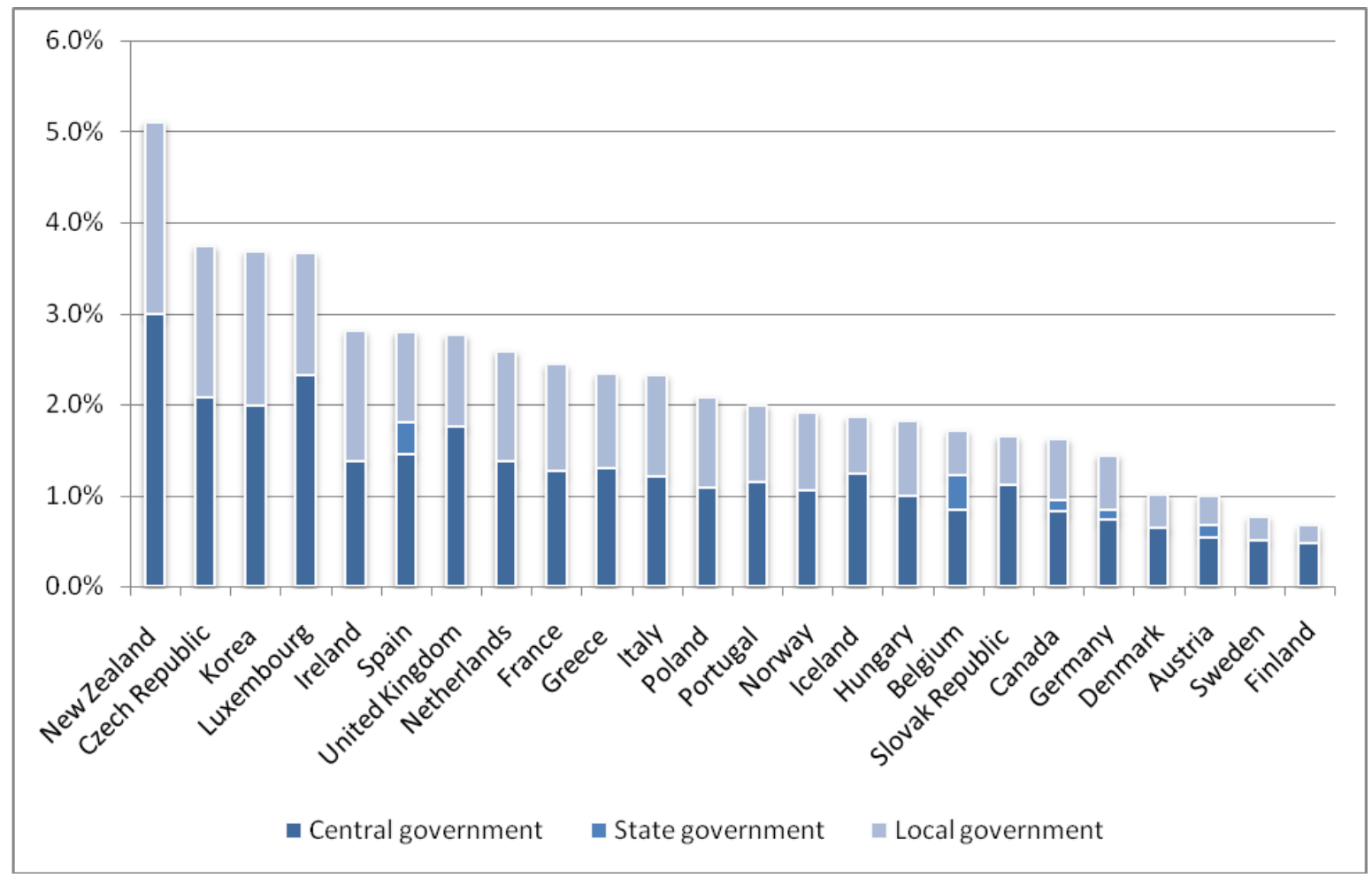

Source: OECD National Accounts Statistics Database.

Through these responsibilities for spending, cities have in many instances the capacity to influence local circumstances. Although local governments act sometimes as agencies for higher governments, which does not give them much leeway to adapt programmes to local circumstances, fiscal decentralisation has in most cases gone hand-in-hand with the transfer of responsibility for policy instruments to local governments. Cities have over the last decades seen increased budgets and discretion in how to use these instruments. In order to fund new expenditures connected to climate change, cities would benefit from increased access to carbon finance and capital markets. 


\section{Carbon finance}

A variety of financial instruments have been developed to create a market for carbon emissions and carbon offsets, which cities can use as a revenue source. Cap-and-trade mechanisms have been put in place in different countries (Australia, New Zealand, parts of the United States), at the European level (EU Emissions Trading Scheme) and at the global level, following the Kyoto Treaty. Cities are part of some of these mechanisms (such as the Chicago Climate Change Exchange), and have in some cases (Los Angeles, Chicago, Santiago) set up some cap-and-trade mechanisms themselves (Box 5.3), or are planning to do so (metropolitan Tokyo in 2010). Certain cities, such as London, have explicitly defined emissions trading as a business opportunity that would increase their metropolitan competitiveness (City of London, 2006). Cities could earn revenues from the two mechanisms that the Kyoto protocol put in place to create carbon offsets, the Clean Development Mechanism (CDM) for developing countries (non-Annex 1 countries) and Joint Implementation (JI) for developed countries (Annex 1 countries), both certified and issued by the UNFCCC. ${ }^{74} \mathrm{CDM}$ allows developed countries to purchase carbon credits from emission reduction projects in developing countries, and JI from emission projects in other developed countries. In addition to this, voluntary carbon markets have been created that are unconnected to an emissions cap. In these voluntary markets, carbon offsets are verified by another carbon market standard, twelve of which are currently operational. Carbon offset markets have been promoted as an important part of the solution to the climate crisis because of their economic and environmental efficiency. Their cost-effectiveness allows for lower caps or voluntary commitments and the potential to deliver sustainable co-benefits as a by-product through technology transfer and capacity building.

\section{Box 5.3. Metropolitan emission trading programmes}

Since the 1990s, a limited number of cities and metropolitan regions have introduced emissions trading programmes: Los Angeles in 1994, Santiago (Chile) in 1994 and Chicago in 2000. In these programmes a variety of objectives are targeted. The Regional Clean Air Incentives Market (RECLAIM) programme in Los Angeles targets reductions of $\mathrm{NO}_{x}$ and $\mathrm{SO}_{x}$ emissions, and the Emissions Reduction Market System (ERMS) in Chicago aims to reduce volatile organic materials (VOMs) emissions, whereas the emissions trading programme in Santiago focuses on total suspended particulates (TSP). At the introduction of these programmes, ambitious objectives were formulated: e.g., the RECLAIM programme calls for reductions of about $75 \%$ for nitrogen and $60 \%$ for sulfur oxides.

These programmes have in common the presence of an explicit or implicit cap and the possibility to trade emission credits. In the RECLAIM programme, pollution credits are allocated to each major source facility in the region, based on their historic level of emissions. Facilities are free to buy and sell these pollution credits. Each year the number of credits allocated by the programme is decreased, forcing facilities either to decrease their pollution or purchase credits from other facilities. The TSP programme in Santiago does not impose an explicit cap on emissions, but rather an implicit cap equal to the sum of the capacity permits to be distributed. The total number of permits to be distributed was estimated to be $64 \%$ of the aggregate emissions capacity prior to the programme. Sources registered and operating by March 1992 were designated as existing sources and received permits. New sources, on the other hand, received no permits, so they must cover all their emissions with permits bought from existing sources.

74. Annex 1 countries are Australia, Austria, Belarus, Belgium, Bulgaria, Canada, Croatia, Czech Republic, Denmark, Estonia, European Community, Finland, France, Germany, Greece, Hungary, Iceland, Ireland, Italy, Japan, Latvia, Liechtenstein, Lithuania, Luxembourg, Monaco, Netherlands, New Zealand, Norway, Poland, Portugal, Romania, Russian Federation, Slovakia, Slovenia, Spain, Sweden, Switzerland, Turkey, Ukraine, United Kingdom, and United States of America.

(http://unfccc.int/parties_and_observers/parties/annex_i/items/2774.php) 


\section{Box 5.3. Metropolitan emission trading programmes (cont.)}

An important part of regional emitters are covered by these programmes. In the case of RECLAIM, this concerns a wide range of small and medium-sized stationary sources as well a few large ones, with participating facilities operating in industries as diverse as ceramics, food, furniture, glass and tiles. The number of market participants is 390 RECLAIM nitrogen-emitting facilities and 41 sulfur-emitting facilities (Schwarze \& Zapfel, 2000). Public facilities (such as police and fire fighting facilities) were categorically excluded. The TSP emissions programme in Santiago covers the largest 600 stationary sources, including industrial boilers, industrial ovens and large residential and commercial heaters. These programmes are mostly implemented at the level of the metropolitan region: e.g. the jurisdiction of the RECLAIM programme includes the South Coast Air Quality Management District (Greater Los Angeles). The TSP emissions programme in Santiago covers however only the territory of the city.

Metropolitan emissions trade programmes have achieved most of their goals, although their effectiveness has been contested. Emissions in Los Angeles region fell with approximately $24 \%$ on average at RECLAIM facilities relative to counterfactual facilities (Fowlie et al, 2009). In Chicago, market-wide VOC emissions were reduced by three times more than the policy goal of a $12 \%$ cap reduction. The environmental objective of the TSP-programme in Santiago, to reduce PM10 emissions from stationary sources by $50 \%$, was met by 1998 . Because industrial emissions are influenced by numerous factors, attributing changes in emissions patterns to specific policy interventions is difficult. Not surprisingly, the emissions impacts of RECLAIM vis-à-vis the subsumed command and control rules remain controversial (Fowlie et al. 2009). Part of this controversy is connected to the design of the programmes: under RECLAIM, allowable emissions have declined each year as required by regulation, but emission reduction credits were found to be initially allocated in an amount significantly inflated above actual emissions: in the first three years of the RECLAIM programme, actual industrial $\mathrm{NO}_{x}$ emissions have declined by at most three percent, while allowable emissions have been reduced on paper by about thirty percent (Drury et al. 1999). A similar pattern (allocation of emission rights higher than actual emissions) was found in Chicago. The fact that emissions are below the cap in Chicago has been found to be primarily due to continuing and ever more comprehensive command-and-control regulation (Kosobud et al. 2008).

Although the different programmes did not always manage to install completely functioning markets, the programme incentives have enabled further introduction of markets. In Chicago, there are several indications of incomplete markets: there are large volumes of permit banks, a significant number of permit expirations, and a sixyear-long decline of the emission permit costs, to USD 17 per permit in 2006. This was far below estimates of the marginal control costs of reducing emissions cited in academic literature (Kosobud et al. 2008). Observed prices and trading volumes in Santiago differ significantly from those predicted by numerical models of a frictionless market, with some firms relying on autarkic compliance, paying less attention to the permits market. In addition, the market has not fully developed because of transaction costs, regulatory uncertainty, and incomplete enforcement (Montero et al. 2002). In the Santiago system, grandfathering the permits has created economic incentives for the incumbent sources to more readily declare their (historic) emissions in order to claim any permits. This has proved effective in helping the authority complete its inventory of sources and emissions during the early stages of the programme.

There are concerns that metropolitan emissions trading could lead to environmental "hot spots", but these claims have so far not been substantiated. Spatially sensitive pollutants like $\mathrm{NO}_{\mathrm{x}}$, which are prone to excessive local concentration problems ("hot spots"), call for some kind of trade restrictions. The issue of constraining the market was dealt with in the Los Angeles region by dividing the local cap and trade market into two zones, an inland and a coastal zone, and preventing trades from the former to the latter because of prevailing winds (Kosobud et al., 2004). There are no indications of such "hotspots" in the case of Chicago: 89 out of 95 sub-areas covered by the programme revealed a decrease and only six an increase in emissions over pre-trading levels, with the sub-areas with the largest initial emissions revealing the most significant reductions after trading (Kosobud et al., 2004).

Urban usage of these instruments has been marginal so far. Of the 1224 CDM projects currently registered, only a limited number have been urban projects. There have been two urban transportation projects: the Bogotá bus rapid transit, TransMilenio, and the Delhi subway regenerative breaking system. A similar marginal number of CDM projects $(0.57 \%)$ and generated certified emission reductions (CERs) by $2012(0.16 \%)$ deal with energy efficiency in the urban building sector (Fenhann, 2009), such as in Khayelitsha (South Africa). In addition, some projects are implemented in other urban sectors, such as electricity and solid waste (Chandigargh, India and Urimqi, China). JI projects have also been applied in a 
limited number of metropolitan regions (North Rhine-Westphalia in Germany and Rhône-Alpes in France). Carbon offsets realised by urban projects in the voluntary market are equally marginal: projects have been implemented or prepared in Sao Paolo, Timisoara, Lille and Newcastle.

Marginal urban use of carbon markets to raise revenue for GHG emissions-reduction projects can largely be explained by high costs to prove the additionality of projects. This additionality criterion is part of the Kyoto protocol to ensure that the mechanisms result in additional carbon reductions and are not used to finance activities that would otherwise also have taken place. Several mitigation efforts in cities are however notably difficult to measure, because emissions are diffuse, costly to identify and to aggregate into calculations of total emissions. CDM challenges that are particularly problematic for the urban transport sector are the definition of project boundaries, complex up-stream and down-stream leakages, the establishment of a reliable baseline, and the implementation of a reliable monitoring methodology. There are similar challenges for using CDM in the urban building sector: fragmentation and complexity of construction projects, as well as small scale and disperse emission points making the registry and the "measurable, reportable and verifiable" procedures (MRV) costly and time-consuming under the current CDM framework. Some "soft" measures taken in cities, such as optimised architecture design for passive heating or cooling, are not quantifiable in terms of GHG mitigation and thus not recognised and credited in the project provision (Cheng et al., 2008).

As a result, carbon finance has not been integrated in urban finance practice. Transport and CDM projects are generally conducted in parallel, without much interaction (Lefèvre, 2009). Cities outsource CDM projects to international experts and organizations without much involvement, and the effects of CDM are rather limited on urban transportation policies or other carbon emitting sources. CDM projectbased design misses large GHG reduction opportunities, as few projects deal with modal shift and none involve a reduction of total transportation activities. In contrast, the majority of the accepted or proposed CDM transportation projects claim their emission reductions through fuel switch, and some entail improvements of vehicle efficiency through a change in engine type or by better vehicle utilization.

The possibilities for cities to use existing carbon finance instruments could be increased. If international climate negotiations were to mention transport and buildings as key areas to reduce GHG emissions, this would provide a rationale to involve urban areas. In order to keep transaction costs down and to take systems dimensions of urban problems into account, these actions should take the form of broad programmes rather than specific projects. Funding from CDM, as it is currently designed, could help to reduce public transport fares, thus increasing transit usage, and also help to finance inter-modality infrastructures, thereby facilitating modal shifts. Other CDM opportunities for the urban sector would be to explore the easily attainable targets on GHG sources related to urban transportation planning, such as urban forestry, street lighting, waste energy used for transportation purposes, etc. City involvement in CDM might require broadening the project-based approach of CDM, for instance to include a sectoral crediting mechanism beyond 2012. In addition, there is a need to develop carbon emission inventories that are harmonized across cities (OECD, 2009b).

New carbon finance instruments are currently being discussed in which the role of both OECD and non-OECD cities could be strengthened. One set of these instruments relates to the national appropriate mitigation actions (NAMA) that were proposed in the Bali Action Plan. NAMA is based on the observations that countries are not in the same situation; therefore differentiation may be one of the keys for a successful agreement. NAMAs could be designed as policies, legal requirements and measures that integrate climate consideration within specific national sustainable development policies. A citywide NAMA that would incorporate building and transport policies could be envisaged, provided that appropriate institutions were put in place. Translating NAMA into the development strategies of cities will require local governments to define suitable guidelines or directions in the context of sustainable urban 
development, which are supported and enabled by technology, financing and capacity building in a measurable, reportable and verifiable manner.

\section{Access to capital markets}

Cities have, to a varied extent, access to capital markets, but this access to capital markets might have to be increased in order to accommodate long-term climate change challenges. Larger cities especially have increasing access to international capital markets, although this aspect of their funding is still a modest proportion of the total funding and not open to all OECD cities. It occurs mostly by intermediation of a specialized body and, in all cases, the issuing community must have been subject to a credit rating carried out by a rating agency, such as Moody's or Standard and Poor's. There is a striking difference that separates Europe and North America: in Europe, investments are made largely by specialized financial institutions, such as Dexia in France and Belgium, while in the United States, a large part is provided by the bond market. This can be explained both by the absence in the US of a financial institution specialized in financing local authorities and also the reluctance of banks to finance them. Overall, the use of the bond market is very important in the United States, and is estimated to finance between $70 \%$ and $80 \%$ of local authorities' investments.

\subsection{An optimal mix of revenue sources}

There is no optimal mix of revenue sources that applies to all metropolitan areas. Not only do conditions in different metropolitan areas vary hugely, but expenditure and revenue assignments differ across metropolitan areas. This implies different financing needs and different possibilities to introduce fiscal incentives. The challenge is to identify which mix of revenue sources suits which set of conditions in cities. In general, metropolitan areas can most easily influence fees and grants; have some influence over tax rates, but less on tax design; and have hardly any influence on grants from higher levels of government.

Metropolitan areas could make more use of fees and charges as instruments to influence behaviour. As they confront users with the real costs of their choices, they could reduce inefficient use of resources and limit sprawl. Fees and charges will be most effective when they cover all costs of the service provided to individual users, and less effective when costs are equalised among all users. Development charges and value capture taxes could finance the construction of new infrastructure needed to serve new suburban developments, whereas transport-related revenue sources (fuel taxes, congestion charges, parking fees) could charge for the use of the infrastructure. Fees and charges could be considered appropriate fiscal instruments regardless of specific conditions, although they are not always easy to introduce, with total or area-specific cost coverage often politically sensitive.

Transport-related revenue sources, such as parking charges and congestion charges, are inter-related and would need coherent planning. Local fuel taxes or parking charges have effects that are somewhat similar to a congestion charge, taxing car use rather than car ownership, but they are less refined instruments because they cannot be used to regulate congestion or be adjusted to vehicle emissions. Elasticities of parking charges are in many cases similar to those found for congestion charges, especially when parking charges are smartly designed. Taxes of this kind are however easier to implement than a congestion charge, because they require no investment in a charging system. Congestion charges will arguably be more appropriate for those cities whose parking fees are already high. Fiscal disincentives for car use will be more effective when alternative traffic solutions, such as public transport, are in place, which is why some metropolitan areas use these types of revenues to finance public transit.

National governments could play a role in greening urban finance, by re-designing sub-national taxes and grants to sub-national governments. Re-design of sub-national taxation could include property tax reform, in order to correct for biases towards unsustainable behaviour. In addition, governments could 
design grants that take environmental indicators into account in case of jurisdictional spillovers. A comprehensive greening of urban finance would also increase the coherence between urban finance and urban planning frameworks to enhance urban sustainability and to contain unlimited urban growth.

New revenue sources such as carbon offsets have so far been unconnected from more traditional revenue sources. These revenue sources, currently marginally used by cities due to a variety of constraints, provide an interesting potential revenue source for cities. These constraints should be dealt with, and the possibility of city involvement in current climate change negotiations could also be secured. There is a need to make sure that future use of these instruments by cities will be integrated within urban planning and financial frameworks, in order to avoid a situation in which these instruments finance isolated projects without connection to the larger urban sustainability agenda. 


\section{REFERENCES}

Almy, R. (2000), "Property Tax Policies and Administrative Practices in Canada and the United States: Executive Summary”, Assessment Journal, July/August 2000, pp. 41-57

Andersen, H., (2007), “Housing market and Housing Policy in Copenhagen”, in: Andersson, Petersson and Stömquist, European Metropolitan Housing Markets, Springer, New York

Arnott, R., A. de Palma and R. Lindsey, (1991), "Does providing information to drivers reduce traffic congestion?”, Transportation Research 25A, 309-318.

Beevers, S. and Carslaw, D. (2005), “The impact of congestion charging on vehicle emissions in London”, Atmospheric Environment, Vol. 39, pp. 1-5

Bianco, M. (2000), “Effective Transportation Demand Management: Combining Parking Pricing, Transit Incentives, and Transportation Management in a Commercial District of Portland, Oregon”, Journal of the Transportation Research Board, Vol. 1711, pp. 46-54

Birgersson, B., and Turner, B. (2006), The future of mainstream public housing in Europe - a Swedish perspective, Paper presented at ENHR conference "Housing in an expanding Europe", Ljubljana, Slovenia, 2-5 July 2006

Brueckner, J. and Kim, H. (2003), “Urban sprawl and the property tax”, International Tax and Public Finance, Vol. 10, pp. 5-23

Cerreno, A. de (2004), “The Dynamics of On-Street Parking in Large Central Cities”, Transportation Research Record, vol. 1898, pp. 130-137

Cheng, C. et al. (2008), The Kyoto Protocol, Clean Development Mechanism, the building and construction sector. UNEP SBCI, Paris, 2008.

City of London (2006), Emissions Trading and the City of London, London

Dasgupta, M. el al., (1994), Impact of Transport Policies in Five Cities, Project Report 107, Transport Research Laboratory. Crowthome, Berkshire.

Drury, R. et al. (1999), "Pollution trading and environmental injustice: Los Angeles’ failed experiment in air quality policy”, Duke Environmental Law \& Policy Forum, Vol. 9: pp. 232-289

Evans, D. and Kruger, J. (2006), Taking up the Slack: Lessons from a Cap and Trade Program in Chicago, Discussion Paper 06-36, Resources for the Future, Washington DC

Fenhann, F., (2009), CDM pipeline, UNEP Risø, Centre cd4cdm 
Fowlie, M., Holland, S and Mansur, E. (2009), What do Emission Markets Deliver and to Whom? Evidence from Southern California's NOx Trading Program, Working Paper 186, Center for the Study of Energy Markets, University of California Energy Institute, Berkeley

Gangadharan, L., (2004), “Analysis of prices in tradable emission markets: an empirical study of the regional clean air incentives market in Los Angeles”, Applied Economics, Vol. 36, pp. 1569-1582

Goodman, J., (2006), “Houses, Apartments and the Incidence of Property Taxes”, Housing Policy Debate, Vol. 17, pp. 1-26

Hajkowicz, S. (2007), “Allocating scarce financial resources across regions for environmental management in Queensland, Australia”, Ecological Economics, Vol. 61, pp. 208-216

Johansson, C. Burman, L. and Forsberg, B. (2008), “The effects of congestions tax on air quality and health”, Atmosperic Environment, Vol. 42, pp. 1-12

Köllner, T., Schelske, O. and Seidl, I., (2002), “Integrating biodiversity into intergovernmental fiscal transfers based on cantonal benchmarking: a Swiss case study”, Basic and Applied Ecology, Vol. 3, pp. 381-391

Kosobud, R., Stokes, H. and C. Tallarico, (2004), “Does emissions trading lead to air pollution hot spots? Evidence from an urban ozone control programme”, International Journal of Environmental Technology and Management, Vol. 4, pp. 137-156

Kosobud, R. et al., (2008), "Regulatory conflict in the Chicago VOC control program”, Journal of Environmental Planning and Management, Vol. 51, pp. 561-579

Kumar, S. and Managi, S. (2008), Compensation for Environmental Services and Intergovernmental Fiscal Transfers in India, TERI Working paper, University of New Delhi

Lefèvre, B., (2009), Assessment of integrated “Transport - Land Use” policies potential to reduce long term energy consumption of urban transportation. A prospective simulation in Bangalore, India., ECEEE

Litman, T. (2009), Smart Growth Reforms: Changing Planning, Regulatory and Fiscal Practices to Support More Efficient Land Use, Victoria Transport Policy Institute

Lundqvist (2008) Can congestion charging support sustainable development of metropolitan areas? - The Case of the Stockholm trial on congestion charging, Paper presented at $47^{\text {th }}$ Annual Meeting of the Western Regional Science Association, Hawaii.

May, P. et al. (2002) "Using fiscal instruments to encourage conservation: municipal responses to the 'ecological’ value added tax in Paraná and Minas Gerais, Brazil”, in: Pagiola,S., Bishop, J., LandellMills, N. (Eds.), Selling Forest Environmental Services: Market-based Mechanisms for Conservation and Development, Earthscan, London.

Menon, A. (2000) “ERP in Singapore - A perspective one year on”, Traffic Engineering and Control, Vol. 41, pp. 40-45.

Milan Municipality (2009) Monitoraggio Ecopass, Gennaio - Dicembre 2008, Agenzia Milanee Mobilità Ambiente. 
Montero, J., Sanchez, J. and R. Katz, (2002), “A market-based environmental policy experiment in Chile”, Journal of Law and Economics, Vol. XLV, pp. 267-287

OECD (2006) Competitive Cities in a Global Economy, OECD, Paris

OECD (2009f), OECD Territorial Review: Toronto, Canada, OECD, Paris, forthcoming.

OECD (2009g), Green Cities: New Approaches to Confronting Climate Change, OECD Workshop Proceedings, 11 June 2009, Las Palmas de Gran Canaria, Spain.

Olszewski, P. and Xie, L., (2005), “Modelling the effects of road pricing on traffic in Singapore”, Transportation Research, Vol. 39A, pp. 755-772

Olszewski, P., (2007), "Singapore motorisation restraint and its implications on travel behaviour and urban sustainability”, Transportation, Vol. 34, pp. 319-335

Parry, I. (2005), “Is Pay-as-You-Drive Insurance a Better Way to Reduce Gasoline than Gasoline Taxes?”, AEA Papers and Prooceedings, Vol. 95, pp. 288-293

Perner, A. Thöne, M., (2005), Naturschutz im Finanzausgleich; Erweiterung des naturschutzpolitischen Instrumentariums um finanzielle Anreize für Gebietskörperschaften, FiFo-Reports, No.3, University of Köln

Prates, J., (2007), EcoTerra Model - application of environmental fiscal reform in local government financing in Portugal, Presentation at $8^{\text {th }}$ Global Conference on Environmental Taxation, 18-20 October 2007, Munich

Prud'homme, R and Bocarejo, J., (2005), “The London Congestion Charge : A Tentative Economic Appraisal”, Transport Policy, Vol. 12, pp. 279-288

Ring, I., (2002), "Ecological public functions and fiscal equalisation at the local level in Germany”, Ecological Economics, Vol. 42, Vol. 415-427

Ring, I., (2008), "Integrating local ecological services into intergovernmental fiscal transfers: The case of the ecological ICMS in Brazil”, Land Use Policy, Vol. 25, pp. 485-497

Santos, G. and Fraser, G. (2006), “Road pricing: lessons from London”, Economic Policy, Vol. 21, pp. 263-310

Schwarze, R. and Zapfel, P., (2000), "Sulfur Allowance Trading and the Regional Clean Air Incentives Market: A Comparative Design Analysis of Two Major Cap and Trade Permit Programs?”, Environmental and Resource Economics, Vol. 17: pp. 279-298

Shoup, D., (1997), “The High Cost of Free Parking”, Journal of Planning Research, Vol. 17, pp. 3-20

Skatteministeriet, (2008), Tax in Denmark, Copenhagen, Denmark

Transport for London (2004), Congestion Charging - Update on Scheme Impacts and Operations, February 2004

Willoughby, C. (2000), Singapore's experience in managing motorization and its relevance to other countries, Discussion Paper TWU-43, TWU Series, The World Bank, Washington DC

Willson, R. and Shoup, D. (1990) The effects of employer-paid parking in downtown Los Angeles: a study of office workers and their employers. Prepared for the Southern California Association 


\section{CONTRIBUTION OF CITIES TO A GREEN GROWTH MODEL}

A fundamental question that metropolitan regions face is how to address climate change while pursuing economic growth and job creation. The challenge for cities and regions is to identify the mechanisms for increasing economic growth through policies addressing climate change and urban sustainability - in other words, how to achieve green growth. In this report, we define green growth as a "growth strategy that accounts for increases in public and private investments and consumption leading to sustainable resource use, lower greenhouse gas emissions, and reduced vulnerability to climate change". Green growth involves a paradigm shift in the way public policy for economic growth is conceived at all levels of governance, and calls for a better integration of national, regional, and local policies and stronger links with non-public actors, including the business sector and civic organisations.

City and regional governments will play an essential role in fostering the green growth agenda. In fact, while the main financial inputs to green growth strategies in the 2008-2009 global economic crisis have come from the national stimulus packages, city and regional governments will have great responsibilities for implementation. This requires a better understanding by local policy makers of what the green economy is and which policies are more likely to support the growth of the new green industries as well as the greening of production in general. City and regional governments can exert a direct impact on lowcarbon, resilient economic development by

i) facilitating job creation in the green economy, through:

- investments in greener infrastructure and greener service provision,

- integrated urban energy management strategies, including technical support to start-ups in the renewable sector and energy conservation measures in the industry,

- information and incentive programmes targeting private demand for green products and services; and

ii) fostering systemic changes in the medium-long term through eco-innovation, co-operation in green research and development (R\&D), and green clusters.

Shifting away from carbon-intensive industries through public investments and by enhancing economic support to the low-carbon economy has the potential of creating thousands of jobs worldwide. This has been acknowledged in the recent OECD Declaration on Green Growth (Box 1), which forcefully argues that growth policies and environmental policies can go hand-in-hand. An integrated strategy at the city or regional level requires supporting the growth of the new green sectors, through incentives and regulatory changes, while managing possible adjustment costs due to environmental regulations defined at the national or international level. Raising the environmental awareness of urban residents will be critical to generate sufficient demand for green products and services. Cities can also raise the growth potential of the clean-energy economy in the longer term through innovation. This will primarily require the development of local networking platforms for eco-innovation, in partnership with private sector researchers and universities. 


\section{Box 6.1. The new green wave in economic policy}

The environmental goods and services sector is increasingly seen as a promising business opportunity. "Greening the economy" is becoming a pressing issue in many countries, mainly in the context of the implementation of international commitments such as the Kyoto Protocol or the Millennium Development Goals. In the midst of the global crisis, the growing policy consensus on the opportunity of combining economic recovery with economic greening is leading to the development of green growth strategies both at the global and national levels. The OECD Declaration on green growth was signed by all 30 OECD countries plus Chile, Estonia, Israel and Slovenia, at the Meeting of the Council at Ministerial Level, 24-25 June 2009. It invites OECD to develop a Green Growth Strategy that brings together economic, environmental, technological, financial and development aspects into a comprehensive framework. According to recent estimates (HSBC, 2009), South Korea has invested the highest portion - 81\% of its total recovery package - in clean energy (renewable energy, energy efficiency, and public transport). China, France, Germany and the US also rank high with $38 \%, 21 \%, 13 \%$ and $12 \%$, respectively, of their total packages focused on clean energy. The Korean green growth strategy also includes three action plans for "greening" industrial production: $i$ ) expand the green industrial complex, such as resource recycling and IT-based industries (green industrial complexes with circulation facilities for energy recycling expanded from 5 in 2009 to 10 in 2013 and 20 in 2020); ii) enhance green partnerships (1500 firms expected to participate in the partnerships by 2013), iii) disseminate green business structures for enhancing exports of green products (green product share in export value expected to rise to $15 \%$ by 2013) (PCGG, 2009).

The role of regions and cities in green stimulus plans has been acknowledged in different stimulus packages. The American Recovery and Reinvestment Act includes USD3.2 billion to fund the Energy Efficiency and the Conservation Block Grants (EECBG), a programme conceived by the Conference of Mayors to implement climate change mitigation strategies in cities. The European Commission announced in March 2009 an investment of EUR 105 million in projects under the EU's Cohesion policy, representing about a third of the overall regional policy budget. A large part of this package (EUR 54 billion) is designed to help Member States comply with EU environmental legislation. Improvement of water and waste management alone accounts for EUR 28 billion of the total.

Source: HSBC (2009), "A Climate for Recovery, The colour of stimulus goes green", HSBC Global research www.globaldashboard.org/wp-content/uploads/2009/HSBC_Green_New_Deal.pdf; UNESCAP (2008), "The Green Growth approach for climate action" background paper for The 3rd Policy Consultation Forum of the Seoul Initiative Network on Green Growth, 18-20 September 2008 Cebu, Philippines; OECD (2009j), "Policy Responses to the Economic Crisis: Stimulus Packages, Innovation and Long-Term Growth". OECD, Paris.

\subsection{Facilitating job creation in the green economy: the role of cities and regions}

City and regional economies function as catalysts for the green economy by helping create stronger markets for new renewable and efficient energy products and services. Green industries are activities which improve sustainability by producing goods and services to measure, prevent, limit environmental risk and minimize pollution and resource use (ECOTEC, 2002). The European Commission's Environmental Policy Review of 2004 concluded that eco-industries are an engine for growth, expanding at around 5\% per year, with the expanded world market for environmental goods and services estimated at over 500 billion Euros (European Commission, 2004). They are characterized by their relative novelty and by their close link with environmental policy and regulation. We can distinguish five main categories of green industries relevant to cities and metropolitan regions:

i) Renewable energy and energy efficiency;

ii) Transportation efficiency, new modes of transport and substituting transport;

iii) Green manufacturing, construction and product design;

iv) Waste and pollution control and recycling;

v) Environmental analysis, training and consulting. 
For each of the five categories, several sub-sectors can be identified. In urban areas, this translates into a wide array of traditional and new jobs (Table 6.1). As discussed in detail below, cities can catalyze green markets through investments in greener infrastructures and buildings, policy interventions in the domains of renewable energy and energy efficiency, and awareness programs for green consumers, as discussed below. Comprehensive job-creation programs at the city and regional level can rely on a variety of instruments, ranging from purchasing and pricing policies, to financial incentives and tax exemptions, to one-stop-shop services for green businesses and training programmes for the labour force.

Table 6.1. Green firms and green jobs

\begin{tabular}{|c|c|c|}
\hline Category & Sectors & Examples of Jobs \\
\hline $\begin{array}{l}\text { Renewable Energy and } \\
\text { Energy Efficiency }\end{array}$ & $\begin{array}{l}\text { - Hydroelectric } \\
\text { - Solar PV } \\
\text { - Solar thermal } \\
\text { - Geothermal } \\
\text { - Wind } \\
\text { - Bio-energy } \\
\text { - Combined Heat and Power (CHP) }\end{array}$ & $\begin{array}{l}\text { - Energy Engineers } \\
\text { - Electrician and plumbers installing the } \\
\text { systems } \\
\text { - Mechanics building the infrastructure } \\
\text { - Renewable energy plant operators }\end{array}$ \\
\hline Transportation Efficiency & $\begin{array}{l}\text { - Urban Public transport } \\
\text { - Railways }\end{array}$ & $\begin{array}{l}\text { - Public transport drivers and employees } \\
\text { - Bus retrofitters } \\
\text { - Builders of rail networks }\end{array}$ \\
\hline $\begin{array}{l}\text { Green Manufacturing, } \\
\text { Construction and Product } \\
\text { Design }\end{array}$ & $\begin{array}{l}\text { - Retrofitting } \\
\text { - Energy efficient buildings' materials } \\
\text { - Domestic and office equipment and } \\
\text { appliances } \\
\text { - LED (light emitting diodes) } \\
\text { - Cleaner coal technologies } \\
\text { - Biodegradable products } \\
\text { - Hybrid vehicles }\end{array}$ & $\begin{array}{l}\text { - Engineers and scientists working on } \\
\text { energy efficiency improvements } \\
\text { (efficient lighting, smart metering, low } \\
\text { energy monitors...) } \\
\text { - Chemists developing environmentally } \\
\text { friendly packaging, cleaning products } \\
\text { and sprays } \\
\text { - Employees of firms producing green } \\
\text { building materials (alternative cement, } \\
\text { recycled wood...) }\end{array}$ \\
\hline $\begin{array}{l}\text { Waste and Pollution Control } \\
\text { and Recycling }\end{array}$ & $\begin{array}{l}\text { - Mobile and stationary air pollution } \\
\text { source controls } \\
\text { - Water conservation and reuse } \\
\text { - Pulp and paper recycling } \\
\text { - Aluminium recycling } \\
\text {-Electronic recycling }\end{array}$ & $\begin{array}{l}\text { - Workers employed for renewing water } \\
\text { infrastructure } \\
\text { - Hazardous material removal workers }\end{array}$ \\
\hline $\begin{array}{l}\text { Environmental Analysis, } \\
\text { Training and Consulting }\end{array}$ & $\begin{array}{l}\text { - Landscape } \\
\text { - Building maintenance and contracting } \\
\text { - Public administration } \\
\text { - Specialized consulting and marketing } \\
\text { - Green Venture capital and other } \\
\text { financial services }\end{array}$ & $\begin{array}{l}\text { - Energy contractors } \\
\text { - Specialized consultants } \\
\text { - Trainers } \\
\text { - Marketing } \\
\text { - Green-civil engineers } \\
\text { - NGOs }\end{array}$ \\
\hline
\end{tabular}

\section{Investments in greener infrastructure and greener service provision}

In their self-governing role, city and regional governments can directly increase demand for green products and services through their purchasing choices and their management of existing and new infrastructure. The economic crisis of 2008-2009 should be seen as an opportunity for a dramatic shift towards better integrated national and regional investments in sustainable infrastructure, speeding the transition to low carbon economies while pursuing employment recovery. Thanks to the fiscal stimulus packages enacted by many governments, major long-term infrastructure investments are expected over the coming years in buildings, transport and power generation both in developed and in developing countries (Box 6.2). There is considerable room to improve the environmental sustainability of the urban infrastructure through these investments, by replacing dwindling raw materials with suitable waste products, by using improved materials to extend infrastructure service life and energy efficiency, and by 
introducing performance-based design and specifications or sustainable structural shapes, including reusable building components.

\section{Box 6.2. Fiscal stimulus for investments in infrastructure, examples from OECD countries}

Most OECD and non-OECD economic stimulus packages contain a focus on improving national infrastructure mostly through public works. The government of Australia launched an USD 800 million Community Infrastructure Programme that will fund local governments to build infrastructure such as town halls, local libraries and sporting facilities. Only in Australia, USD 8.4 billion will be spent on regional highways and country roads, and USD 3.2 billion in regional rail networks over six years. Japan has offered a subsidy to municipalities of JPY 4 billion to repair and earthquake-proof public facilities. Canada has assigned CAD 6.4 billion to renew infrastructure in partnership with provinces and municipalities. At the regional level, Ontario announced an investment of USD 622 million in housing in the 2009 Provincial Budget. The investment is expected to rehabilitate 50,000 social housing units, build 4,500 new affordable housing units and is estimated to create 23,000 jobs province-wide over the course of the program. Moreover, the Federation of Canadian Municipalities (FCM) is endowed with CAD 515 million to accelerate projects such as construction of schools, water and waste-water projects and critical community services infrastructure.

Source: OECD (2009j), "Policy Responses to the Economic Crisis: Stimulus Packages, Innovation and Long-Term Growth". OECD, Paris.

Despite the new funding stream provided by stimulus packages, it is still not clear whether local governments will be able to rely on larger budgets for their own investments in infrastructure in the midst of the global downturn. The crisis is putting serious pressures on local budgets, by raising the demand for welfare and reducing revenues from taxes. Public investment is often the first expenditure that is cut by city and regional governments in financial stress (OECD, 2009k). It is important to address these liquidity constraints, through direct transfers or through the establishment of public funds encouraging applications by sub-national governments, so that profitable investments in greener infrastructure are not delayed. Green infrastructure funds can be particularly effective in raising the environmental value of infrastructure investments, as financing can be made conditional on transparent criteria or scores (use of improved materials, energy efficient design), and because they create incentives for the creation of public-private partnerships. Enhancing the local ownership of the stimulus measures can be instrumental for ensuring that these new investments are conceived of and implemented as policies for green growth, and for improving the quality of public spending. The main reason for this efficiency gain is that local governments usually know best what the most urgent needs are and can therefore target the provision of public infrastructure to these needs. Larger projects might require greater coordination among interested cities, as joint production of neighbouring jurisdictions can ensure economies of scale in the delivery of infrastructure services and reduce free-riding problems.

Purchasing policies of cities and regional governments in the infrastructure domain can strongly boost the market for climate friendly products and services. Having the capacity to plan and responsibility over infrastructure, transport, water, energy, waste and public buildings, city and regional governments authorities are uniquely placed with procurement to implement effective climate mitigation and adaptation actions. City governments can use their large market power and market engagement to bring new technologies on the market. Several experiences show that sustainability concerns can be successfully integrated in urban procurement practices through innovative tools (e.g. life cycle costing ${ }^{75}$ ), and institutional solutions. As discussed earlier, Berlin has a pioneering program whereby public retrofitting tenders include a requirement for average $\mathrm{CO}_{2}$ reductions of $26 \%$ : within this program 1,400 buildings

75. Life cycle costing (LCC) is a structured approach that can be used to produce a spend profile of the product or service over its anticipated life-span. The results of an LCC analysis can be used to assist management in the decision-making process where there is a choice of options. See http://www.ogc.gov.uk/implementing_plans_introduction_life_cycle_costing_.asp 
have already been upgraded (Hidson, 2009). The city of Helsinki established a Procurement Centre, charged with developing operational models for managing markets through systematic dialogue with businesses. The centre is defining environmental criteria for different product groups and coordinating training programs to raise awareness among procurers. Coordination in procurement among cities is important, both from a cost-efficiency and from a market-stimulus perspective. On the cost efficiency side, joint procurement can effectively bring down the costs through economies of scale in purchasing. On the market stimulus side, coordinated action can magnify the signal sent to the market.

While there is no clear consensus on what actually is a good green investment, experts have drawn up sets of criteria to assess the effectiveness of the green investment measures and have come up with similar results that apply equally well to national and local projects. Edenhofer and Stern (2009) and Bowen et al. (2009), for instance, suggest that investments should meet the following criteria:

- Timeliness in decision and implementation,

- Potential long-term social returns (with respect to climate change objectives),

- Positive ‘lock-in’ effects from investment in long-lived low-carbon capital stock,

- Likely extent of job creation and size of the domestic fiscal multiplier,

- Use of under-utilised resources,

- Time-limitedness: the extent to which spending is likely to be shifted forward in time, reducing necessary spending later on.

Among the pre-conditions for effectiveness, participatory processes and stakeholder involvement, as well as an engaged local leadership, are particularly important for investments undertaken at a regional or urban scale.

The most obvious option for a shovel-ready, local green investment to re-employ displaced workers or create new jobs is a large-scale building retrofit programme. Jobs can be created immediately, with no new plans, environmental impact statements, or land acquisition, to repair or replace deteriorated assets. Further, the technology to reduce energy consumption in buildings already exists and simply needs to be deployed. Regional and city governments must resist the temptation of focusing on new construction projects as the primary means for reducing energy demand from buildings, as retrofitting the existing stock is generally a more efficient and a more labour-intensive activity. Current practice in retrofit programs makes possible a considerable reduction in building maintenance costs and investments in the repair and replacement of worn-out elements. Finally, retrofitting public-owned residential complexes has the important complementary benefit of increasing the market value of dwellings, making residential areas more attractive. The city of Freiburg, Germany, has pursued this strategy by allocating a budget of EUR 2M to the renovation of the city's old and historical buildings. This has included the non-intrusive, strategic installation of 180 solar PV panels on the tiled roof of the old City Hall.

In recent years, several local governments in OECD and non-OECD countries have already opted to invest in renewable energy, resource-saving, recycling activities and green area management in order to spur job creation (IEA, 2009). These activities include projects linked with waste treatment systems (Oslo), brownfield redevelopment (Toronto) water supplies (Amman), care of green areas and landscape (Sao Paulo), development of products and energy efficient technologies for use in their own buildings (Hamburg), as well as in public transport (Calgary) and local schools (Bristol). Many examples exist of community owned solar photovoltaic installations (Toronto Solar Neighbourhoods), wind farms (Samsǿ), biodiesel vehicles (Halifax), hydrogen vehicles and related infrastructure (Reykjavik, Fukuoka, Seoul), or biogas-fuelled buses (Stockholm). These public projects have the common characteristics of seeking the participation of private business partners. Recycling is one of the most dynamic drivers of environmental- 
friendly employment creation. In the recycling sector, private companies are taking the lead in launching new investments and up-scaling existing ones, the role of city governments being more one of improving the business environment (through initial grants for factory facilities, land-use regulations and one-stop services to reduce unnecessary red tape). The example of Kitakyushu City is illustrative of the tremendous employment opportunities that strategic waste management and recycling can open in a globalized economy (Box 6.3).

\section{Box 6.3. Strategic urban economic policy in the recycling sector, Kitakyushu City's example}

The recycling sector yields great potentials of employment creation and re-employment of displaced workers, in particular in cities with an industrial history. Kitakyushu City, Japan, once the capital of steel and chemical industries, overcame severe pollution and sought out the growth potential in the recycling sector. Kitakyushu City has now many recycling companies, which handle sludge and waste materials produced as by-products of industrial production processes. Kitakyushu City launched the Eco-Town project in 1997. In attracting recycling companies, local government emphasized the cheap and vast land available away from residential districts, abundant industrial water from the ocean, subsidies for factory facilities, accumulated human capitals and manufacturing sectors, and clustering of related recycling companies. Local government also facilitated companies' establishment in Eco-town through onestop support services. As of 2008, 26 companies and 17 research institutions were in operation, and employing 1352 people (see the graph for Japan below).

\section{Percentage share of recycling sector employees among total employees in 2001 and 2006}

(Top 10 ranking)

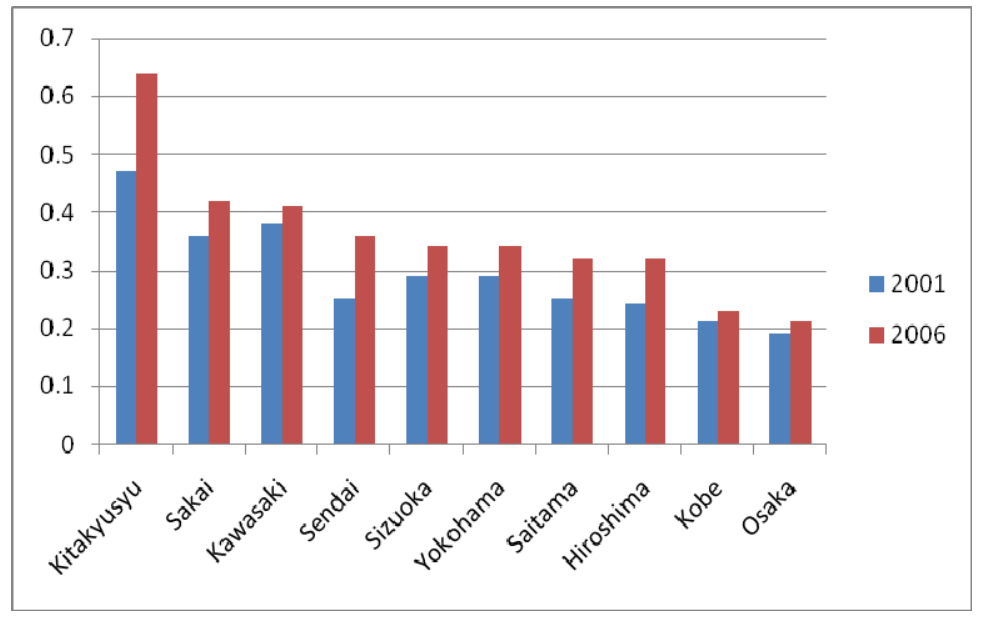

Source: Ministry of Internal Affairs and Communications, enterprise statistics.

According to the public opinion survey of 2007 ,an increasing number of citizens at Kitakyushu city recognise the recycling sector as one that contributes to environment, partly due to the government's effort for public involvement. Residents' support of the recycling industry is a big attraction for a sector that is often exposed to an attitude of "not in my back yard".

Globalisation is opening new windows of opportunity for Kitakyushu City. For example, China has gradually increased the need for recycling due to serious water contamination and inappropriate waste disposal. Kitakyushu City has begun environmental co-operation with Chinese cities, including Dalian City since the 1990s, Quingtao City since 2007 and Tianjin City since 2008. Kitakyushu International Technology Cooperation Association (KITA), a public training institution for environment policies and technologies, has taught over 5000 people from 130 countries from 1980-2008. The City aims to link environmental co-operation with development of environmental business. In this way, Kitakyushu city's environment strategy is deeply embedded in the economic growth strategy.

Source: Bank of Japan, Kiatkyushu subsidiary (2008), "Recycling Industry in Kitakyushu City", http://www3.boj.or.jp/kitakyushu/sonota/kitarecycle.pdf, accessed 2 October, 2009; OECD (2009l), OECD Territorial Reviews: Transborder Urban Cooperation in the Pan Yellow Sea Region, OECD, Paris. 
Intra-urban mobility is crucial for agglomeration economies to produce their effect. More compact, connected cities can improve their environmental effectiveness through combined investments in transportation networks and ICT. There are important complementarities between these two investments. Both respond to the need of improving connections between people and businesses, reducing costs of commuting and information transfers. Besides their productivity, quality of life and ecological footprint benefits (saving time, money and energy), investments aimed at reducing mobility costs within the cities can have important benefits in terms of spatial equity, breaking the physical disconnection from jobs that exacerbate unemployment in poorest neighbourhoods. For what concerns transportation networks, the "New Mobility" models experimented in both developed (e.g. Toronto, San Francisco, London) and developing countries (e.g. Cape Town, Chennai, Bangalore) search for better integration of different transport modes around hubs: these hubs are dynamic centres for service provision, generating new employment opportunities in entertainment, recreation, dining, banking, commerce, and community services. Integrated urban strategies for sustainable transportation can serve as incubators for important innovations, providing the necessary framework for evaluating cost-benefits of new technologies with wide industrial applications, like hybrid engines, hydrogen fuels and sensor networks.

Several countries are investing to generate rapid shifts in the composition of physical capital towards information and communication technology (ICT) equipment. There is increasing evidence of the positive effects of ICT on productivity growth in OECD countries (OECD, 2003, Crandall et al., 2006) ${ }^{76}$. ICT is a significant contributor to energy efficiency through the innovation process, or the substitution of a new technology for an old one, which brings with it a lower level of energy consumption. Given the significant environmental benefits (energy savings from transportation substitution, "dematerialization" and smart building) and the employment effects in the short-term (new construction sites for broadband deployment) and medium-to-long term (creation of new business, higher productivity and better market access for the existing ones), it makes sense for cities to invest more resources in green ICT infrastructure. Regulatory reforms, reducing barriers to entry and investment by new service providers, are critical to sustain private investment in broad-band networks. First-movers in ICT network investments seem to enjoy significant benefits. The Paris suburb of Issy-les-Moulineaux, by providing superior broadband infrastructure, a business-friendly climate and innovative e-services, has managed in less than a decade to radically change its industrial structure, reducing local unemployment to virtually zero ${ }^{77}$. Korean municipalities are particularly active in the deployment of ITC technologies as a mean of enhancing energy efficiency of urban infrastructure. The Gangnam-gu district of Seoul, home to corporate headquarters, multinationals and IT venture firms, had adopted a carbon mileage system and is now pioneering innovative service provision via wireless.

Increasing the environmental sustainability of public infrastructures generally implies higher fixed costs. However, the range of economic benefits that must be accounted for in cost-benefit analysis is wide. First of all, there are important multiplier effects generated along the value chain ${ }^{78}$. For example, the US

76. ICT is a general purpose technology that changes the way firms produce goods and services - for example, through just-in-time manufacturing, supply-chain management, and electronic commerce - thereby enhancing the quality of other factor inputs such as labour and non-ICT capital. Crandall, Lehr and Litan (2006) find that employment in both manufacturing and services industries (especially finance, education and health care) is positively related to broadband penetration. One percentage point increase - equal to roughly 3 million lines - is associated with nearly 300,000 more jobs, assuming that the economy is not already at full employment.

77. Today, more than half of the $\mathbf{1 5 0 0}$ companies in Issy are in the ICT sector, including Cisco Systems' European headquarters, Hewlett Packard, Orange Internet, Sybase, Canal+, and Microsoft Europe.

78. For example, the US Department of Commerce's Bureau of Economic Analysis (BEA) estimates that across the United States as a whole, for each additional dollar's worth of output of the water and sewer 
Department of Commerce's Bureau of Economic Analysis (BEA) estimates that across the United States, for each additional dollar's worth of output of the water and sewer industry in a year, the dollar value of the increase in output that occurs in all industries is USD 2.62 in the same year. Moreover, raising energy efficiency and investing in new energy infrastructure and smart grids can also raise regional energy security, by reducing exposure to highly volatile fossil fuel prices. ${ }^{79}$ Rightly accounting for these complementary benefits in urban investment strategies requires new tools and dedicated investments in training and human capacity. The introduction of enabling technologies (ICT and nanotechnologies) can significantly increase the cost and environmental efficiency of the new infrastructure and network investments (OECD, 2009m). Moreover, contracting issues and corruption must be addressed. Public sector wages would need to be closer to private sector wages to avoid cost over-runs and maximize efficiency in output delivery.

\section{Urban energy management strategies for employment creation}

In the wide spectrum of urban green growth policies, particular attention should be paid to Renewable Energy (RE) generation and Energy Efficiency (EE) for local energy provision. In fact, these are areas with relevant synergies between environmental impacts and employment generation, requiring capacity to act at the local level. Renewable energy initiatives in city and regional climate action plans are often focused around distributed energy technologies, such as rooftop solar photovoltaics (PV) and solar water heaters, which cities are more able to influence directly ${ }^{80}$ Energy efficiency initiatives are "no-regret measures", as in addition to climate change-related impacts they generate additional benefits in the form of cost savings. The substantial local-level investments that adapting to climate change will require in the energy sector, such as increasing the heat-resistance of transformers and wiring, will produce sustained public demand for specialized and semi-skilled jobs. ${ }^{81}$ The private sector will receive a boost from investments in the energy sector as they are increasingly realised through public-private partnerships. However, the net employment effect of investments in the energy sector, and in renewable energy in particular, are difficult to assess in the short-medium term, as some jobs will be lost in carbon-intensive sectors as others are created in lowcarbon sectors (Figure 6.1).

industry in a year, the dollar value of the increase in output that occurs in all industries is USD 2.62 in the same year.

79. Following the energy crisis in 2000-2001, the Energy Action of the California State government, optimizing energy conservation and building new generation facilities, was effective in eliminating outages and excessive price spikes (Roland-Holst, 2008).

80. Distributed resources are those located near the point of use (e.g. energy efficiency, rooftop solar water heaters, or municipal transportation plans), and centralized resources are those generally located far from the point of use (e.g. large-scale wind farms, gasoline and other transportation fuels, or regional development plans).

81. As discussed above, these strategies emphasize the 'hardening' of system assets such as power generation facilities or transmission and distribution grids. They include the use of higher temperature-rated transformers and wiring, and the construction of flood-prevention berms around power plants (MansanetBataller et al. 2008). They also involve more "soft" approaches, focused on managing risk and specific climate change impacts without making extensive (or expensive) capital improvements. Soft strategies include adjusting reservoir release policies to ensure sufficient summer hydropower capacity, shading buildings and windows, or using high-albedo roof paints and surfaces (Hill and Goldberg 2001). 


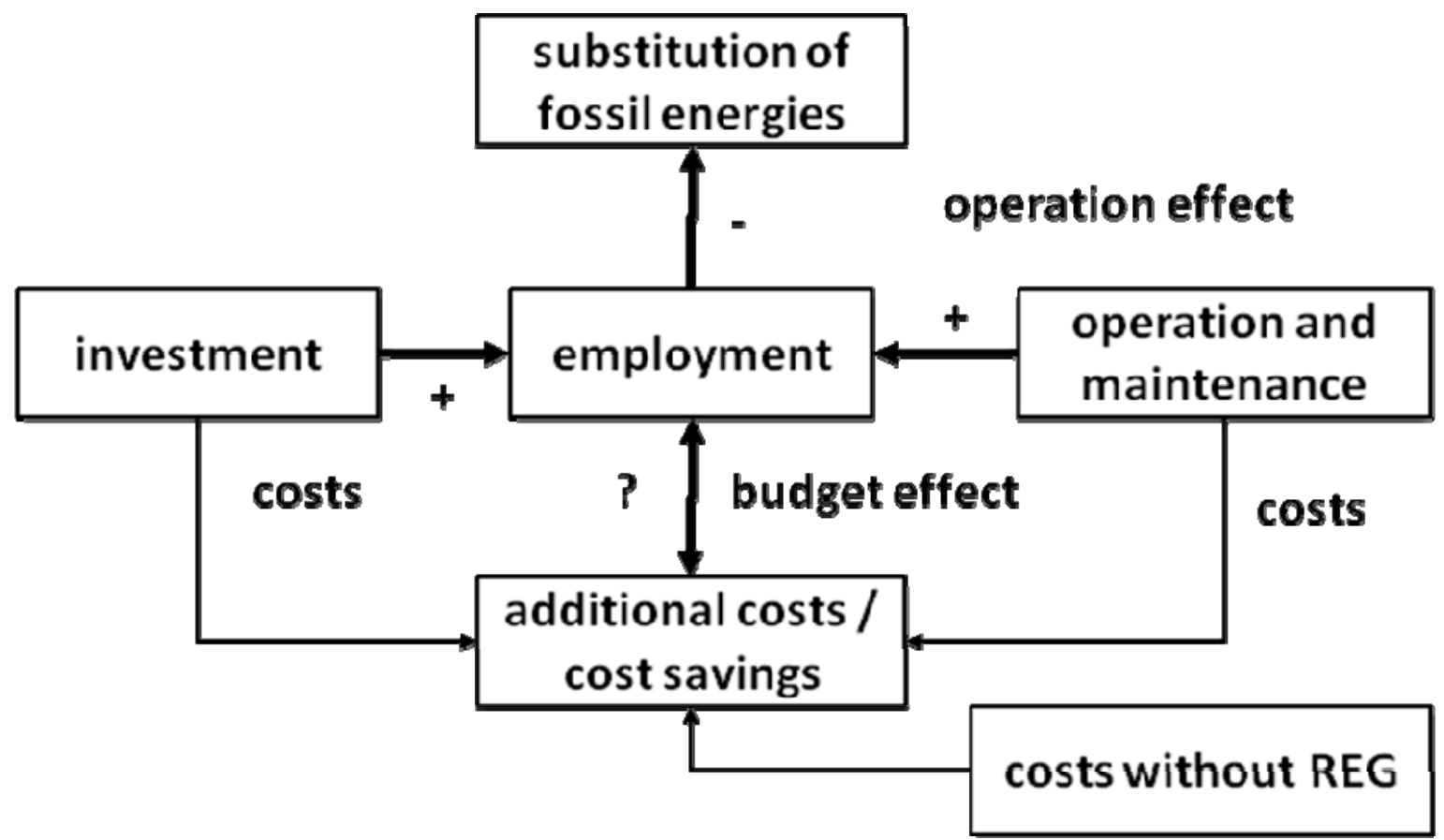

Source: Bremer Energy Institute (2006), "Renewable energies - environmental benefits, economic growth and job creation", http://www.estif.org/fileadmin/estif/content/press/downloads/060506_Bremer_insitute_impact_jobs_renewable_energies.pdf.

Raising the share of renewable energy can be attractive from the perspective of generating employment because new investments in renewable technologies are generally more labour-intensive than investments to expand fossil fuel-based energy generation. A distinction here is needed between large scale, centralized renewable energy utilities, and small scale, decentralized utilities. The latter, distributed solar PV in particular, have higher labour intensity as a result of the fragmentation (number of systems required to achieve the needed capacity) and of the labour-intensive installations. Installing a large 100 MW solar PV array in the desert requires significantly less labour than installing $100 \mathrm{MW}$ of $4 \mathrm{~kW}$ residential rooftop PV systems (i.e., 25000 systems). There are also significant differences across renewable technologies, in particular concerning labour demands for maintenance and operation of the facilities. Kammen et al. (2006) estimate that installing $1 \mathrm{MW}_{\mathrm{a}}$ of wind turbine capacity creates an estimated 0.7-2.9 times as much permanent employment vis-à-vis a comparable natural gas combined cycle (NGCC) power plant; installing $1 \mathrm{MW}_{\mathrm{a}}$ of rooftop solar PV creates an estimated 7.8 times more employment than a NGCC power plant. ${ }^{82}$

The numbers from different sources show that the renewable energy industry has already reached a noteworthy size, with about 200000 jobs in the EU in 2003 (European Commission 2004). While the majority of jobs in the fossil fuel industry are in fuel processing, a relatively capital intensive activity, the

82. $\quad \mathrm{MW}_{\mathrm{a}}$ refers to "average installed megawatts de-rated by the capacity factor of the technology" (Kammen et al., 2006). In this analysis, the authors control for both the different capacity factors and lifetimes among different generating technologies. 
majority of jobs created in the renewable energy industry are in manufacturing and construction. ${ }^{83}$ In all renewable energy sectors, costs have fallen dramatically due to improved technologies. ${ }^{84}$ However, renewables are not yet cost-effective compared to conventional energy sources, as they require more inputs - both in terms of capital and labour - for a given amount of output. Renewable installations are in fact more short-lived (on average 25 years versus 40 years for coal and gas), and have a lower capacity factor (operating on average $25 \%$ of the time, with respect to about $80 \%$ of fossil fuel plants). Again, there are large differences in costs across technologies. To summarise: $i$ ) distributed generation is currently more expensive than centralized generation, ii) residential PV is more expensive than commercial PV, iii) PV is more expensive than solar thermal, iv) solar is more expensive than wind, $v$ ) onshore wind can be cheaper than natural gas (Figure 6.2).

Figure 6.2. Estimated Levelised Cost of Generation, Various Technologies

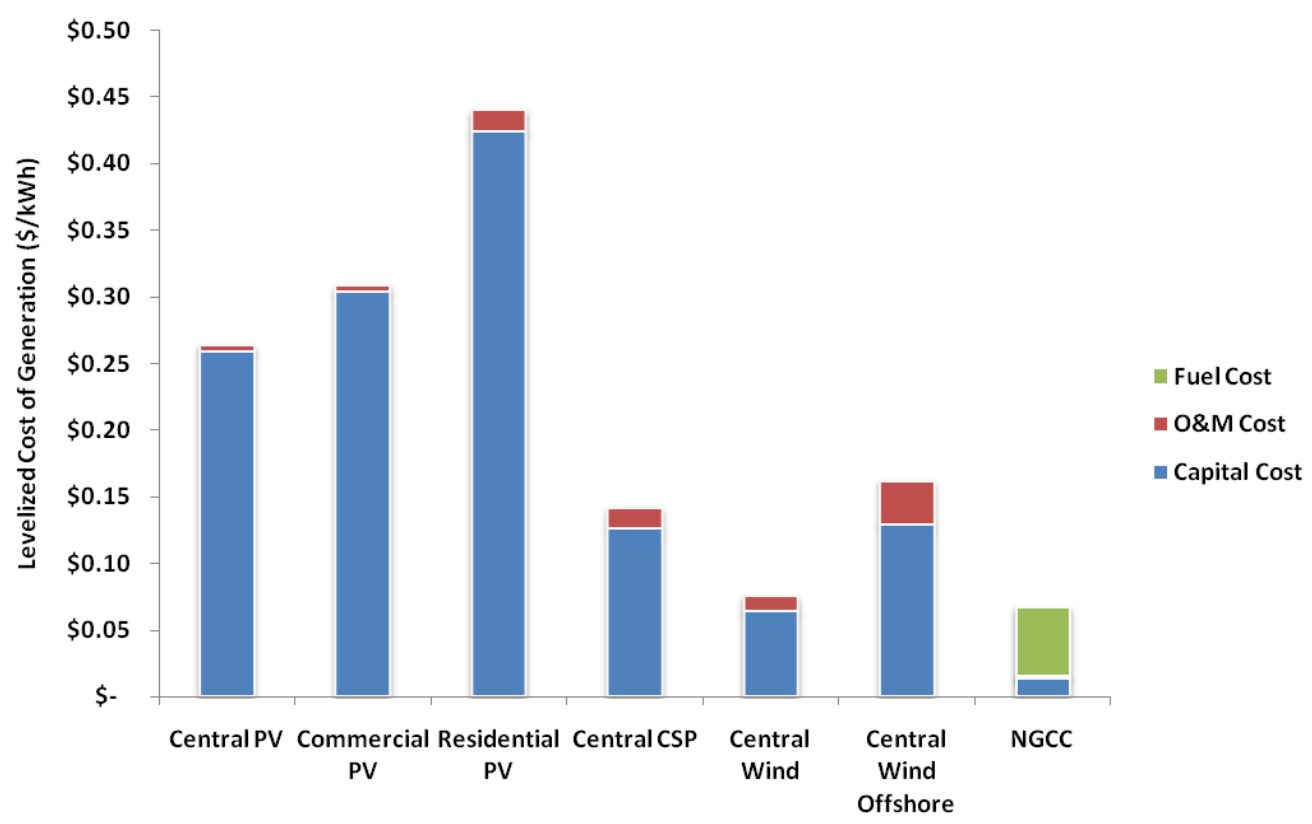

Note: NGCC is combined cycle natural gas and central CSP is concentrating solar power. Levelised costs are early 2009 estimates based on Kahrl,F., W. Tao, and D. Roland-Holst (2009), "Municipal Climate Policies: Scope, Economics, and Institutions", Center for Energy, Resources, and Economic Sustainability, University of California at Berkeley.

Whereas renewable energies' higher current cost relative to fossil fuels may increase city and regional governments' net expenditures, energy efficiency can be cost-effective now. For instance, recent empirical analysis for California suggests that, at USD $0.027-0.034 / \mathrm{kWh}$, the average resource costs of energy efficiency are still well below the cost of generation and are significantly below the cost of distributed

83. Estimates for the share of installation jobs in total PV employment ranges from 15\% (Singh and Fehrs, 2001) to 70\% (Solar Technologies FZE website, http://www.solartechnologies.net/sg_part5.html), although lack of specificity in these estimates makes them difficult to compare. See also Grover (2007) and NCI (2008) for other estimates.

84. Investment costs for wind power have declined by approximately $3 \%$ each year over the last 15 years. For solar photovoltaic cells, unit costs have fallen by a factor of 10 over the past 15 years. The price of solar photovoltaic continues to decline 20\% for every doubling of capacity (Van der Zwaan and Rabel, 2004). 
renewable energy (Shin, 2009). In addition to direct savings, energy efficiency allows households and businesses to shift expenditures from a low value-added, capital-intensive sector (energy) to higher valueadded, labour-intensive sectors (e.g. energy efficiency services). For cities, expenditure shifting has the added benefit of redirecting expenditures from energy, whose revenues are likely to be re-invested outside the city, to sectors that are more likely to be local (e.g. services). Income that remains local is more likely to be reinvested in the local economy, producing local multiplier effects that have a positive impact on growth. $^{85}$

Tax incentives to encourage residents and corporations to use renewable energy or adopt energy efficiency systems and equipment can be effective in raising the demand for clean energy and achieving the critical market size to support local or regional investments. Market access in the energy sector is still severely constrained, especially for small and medium entrepreneurs (SMEs). Direct purchasing of renewable electricity, bio-fuels and of renewable equipment, possibly jointly by several municipalities, can be useful to support the growth of energy efficiency or renewable energy SMEs. Regulations imposed by cities can complement national and regional standard setting (e.g. Renewable Portfolio Standards and Energy Efficiency Resource Standards), encouraging the local generation and deployment of renewable energy. Access to funds for new projects in renewable energies often proves difficult due to the lack of available and adapted financing resources. Soft loans and guarantees provided by city or regional governments can be thus highly attractive for renewable energy project developers.

Fixed price systems ("feed-in tariffs") have played a decisive role in attracting wind energy investment in European regions. Through feed-in tariffs systems, producers of renewable energy feed solar electricity into the public grid and receive a premium tariff per generated $\mathrm{kWh}$, reflecting the benefits of renewable electricity compared to electricity generated from fossil fuels or nuclear power. While the first programmes were financed through government budgets, it is more and more the case that utilities pay a premium tariff for renewable electricity, and then pass on this extra cost, spread equally, to all electricity consumers through their regular electricity bill. Feed-in-tariffs operate over a fixed period of time, reducing uncertainty in anticipated revenues. The first two cities to adopt a local feed-in tariff in the United States were Gainesville, Florida, and Los Angeles, both in 2008. Feed-in tariffs to promote solar energy have been implemented in several German cities, following the positive experience of the "solar city" of Freiburg (Fitzgerald, 2009). The conditions for feed-in tariffs need to be set through a coordinated effort of national and local governments, as feed-in tariffs can turn out to be a competitive disadvantage for some cities or regions. Cities and regions can also consider the implementation of least-cost-planning (LCP) and integrated resource planning (ICP) in order to support energy saving technologies. These mechanisms oblige the utilities to verify whether investment in renewable energy (or reduction of consumption) is feasible when they intend to substitute or extend their existing production capacities.

When considering the employment effects of energy policies, possible adjustment costs should not be ignored. As a result of climate policies, jobs will be lost in carbon-intensive sectors directly affected by regulations and standards (for example, in decommissioned fuel and coal power plants). Further jobs will be lost along the value chain: for example, contraction in demands for coal-fired power generation will lead to upstream job losses in the mining industry. Regional economies face two main dangers when exposed to aggressive price measures and environmental regulations for business: $i$ ) industry downsizing due to adjustment costs, and ii) relocation of foot-loose industries. First, manufacturing firms might be unable to adjust in the short term to a rise in input prices caused by greater reliance on renewable energies or compliance with new environmental regulations. Difficulties in adjusting can result in sizable losses in

85. See O’Sullivan (2000) and Shaffer et al. (2004) for lucid descriptions of multiplier processes at the substate level. 
employment. ${ }^{86}$ Secondly, national or regional differentials ${ }^{87}$ in effective price of power and regulation might induce relocation of industries, and multinationals in particular, towards localities with looser environmental regulation (pollution haven hypothesis). Industries most likely to locate in pollution havens are not necessarily those labelled "the dirtiest" industries but rather more "footloose" industries such as electronic and appliance manufacturers. ${ }^{88}$

The possible employment costs of climate policies for regional economies mentioned above, either in the form of profit losses for business or leakage effects, should be weighed against potential productivity gains achievable in the longer run. Innovative firms capable of investing in and adopting clean energy technology are likely to see their input costs decrease in time relative to those businesses not adjusting, as coal and oil are likely to become relatively more expensive in the incoming years. While it is still early to draw conclusions, anti-carbon regulations might spur a process of creative destruction that could be ultimately beneficial to regional productivity and innovation. The argument is that the need to adopt energy-saving technologies with wide-ranging applications will trigger in the longer term a process of technology diffusion, adaptation and experimentation, with significant spillovers on regional productivity growth (Fankhauser et al. 2008). In the short-medium term, there is scope for regional economic policies aimed at minimizing potential employment losses. These will take the form of services reducing the costs of energy conservation and pollution reduction measures, and local labour market policies facilitating the absorption of laid-off workers in the expanding green industries.

City and regional capacity building programmes for management can lead to wider and less costly adoption of conservation measures. Increasing evidence shows that establishments in better managed firms are significantly less energy intensive (Bloom et al. (2008)). ${ }^{89}$ Local or regional one-stop-shop agencies for business support should acquire specialized skills in order to advise firms on the most cost-effective ways of reducing emissions. Their role would consist mainly in enabling businesses to reach conservation goals at lower costs, for example through sustainability audits. They might also engage in demonstration projects for new equipment, in partnerships with manufacturers and academia (OECD 2009n). ${ }^{90}$ In Canada, programmes such as the Eco-Efficiency Partnership in British Columbia, the Eco-Efficiency Centre in Nova Scotia and the EnviroClub of Quebec are good examples of approaches to improving simultaneously the environmental performance and the competitiveness of local SMEs. The "Chicago Industrial Rebuild

86. Firms can take two measures to mitigate the environmental burden of production: cleaner production and end-of-pipe technologies. Cleaner production reduces resource use and/or pollution at the source by using cleaner production methods, whereas end-of-pipe technologies curb pollution emissions by implementing add-on measures.

87. There are important within-country differences in the price of energy. In 2006, the average price of electricity in 106 US cities was USD 0.073 per kWh. In the same year, however, it varied from USD 0.036 per kWh in Omaha, Nebraska, to USD 0.195 per kWh in New York City (Bae, 2008).

88. Recent research on a cross section of countries (Kellenberg, 2009) shows that the enforcement of environmental policy is more of a deterrent to inward investments than the level of the regulation itself. This might indicate that even if political coordination leads countries or regions to agree on common level of regulations, the playing field might still not be level due to strategic local enforcement behaviour.

89. According to the OECD programme on "Firms, Innovation and the Environment" (Johnstone, 2007), the frequency of inspections (regulatory oversight) is found to have a positive effect on the designation of an individual as being responsible for environmental matters and on the comprehensiveness of environmental management.

90. The provision of technical assistance should be carefully designed to build capacity within the firm, rather than substitute for it. Indeed, OECD studies (Johnstone, 2007) show that technical assistance has a consistently negative impact on the implementation of environmental management. This might be explained by publicly provided technical assistance crowding out internal management practices. 
Program" assists facilities in securing financing to implement recommended improvements. An interestfree loan is available to participants who purchase "green" or renewable power. Nearly half of the metal casting industry in Chicago participated in the city-funded assessments. If all recommendations are implemented, it is estimated to generate over USD 5 million in cost savings, 10-25\% in energy savings and reduce air pollution by 1000 US tons per year.

Finally, greater eco-efficiency can be a source of business opportunities for firms, which can realise profits by exchanging waste and energy. Recently, eco-industrial parks and regional eco-industrial clusters are being integrated in several regional and national economic development plans. At the heart of these initiatives is the argument that industry can mimic natural ecosystems, shifting from the current wasteful linear model of production to a circular model, where wastes are converted into new inputs and energy cascaded through the local industrial network (Gibbs, 2008). Kalundborg in Denmark is the most well known example of the economic gains that can be achieved by connecting waste and energy exchanges in an eco-industrial park. The diverse firms in the eco-park of Kalundborg utilise each other's surplus heat and waste products, with annual estimated savings of USD 12-15 million (Tudor et al, 2006). Several other eco-industrial parks have followed this successful model and provide examples of how efficiency and sustainable use of resources can be integrated in business development programs (e.g. Styrian recycling network in Austria, Rotterdam Harbour and Industrial Complex in the Netherlands, Londonderry industrial park in New Hampshire, and Guigang Eco-Industrial Park in China). It is difficult to plan effective ecoindustrial systems from scratch. However, local governments can facilitate their development. Japan's EcoTown program is an example of a large-scale public program to seeking to maximize business and resource-savings opportunities generated by the proximity of industrial and urban areas. It launched 61 innovative recycling projects, which successfully contributed to raising industrial productivity and generating employment, both to improve environmental amenities (Van Berkel et al, 2008).

\section{Greening preferences to raise the size of green markets}

While public investment can sustain the development of the green economy in the actual earlier phase, the healthiness of the sector will crucially rely on the dynamism of demand from private consumers. Private customers' willingness to pay a premium for products and technologies that reduce GHG emissions and resource use (i.e. "green products") will impact the extent to which newer and better products will be offered for sale. Identifying policy instruments able to affect preferences for green goods in a cost-efficient manner is a crucial challenge of urban green policy. There is significant heterogeneity in the willingness to pay for green products, and individual and community characteristics can explain why we observe a high concentration of demand in particular cities or regions (Kahn \& Vaughn, 2009) ${ }^{91}$. Lack of customer education on renewable energy is one of the most serious barriers for retail green power products (Wiser et al., 1998). Cities in OECD and in some non-OECD countries are increasingly raising local awareness through consumer education programmes, eco-standards and eco-labelling, and best-practice demonstration sites. It makes sense to develop and implement these programs locally, as research has shown that mass information (e.g. international labels) are easily ignored, while local and targeted information seems more effective to raise demand (OECD, 2008c). While these initiatives have yet to be rigorously assessed, it is increasingly clear that systemic changes in consumption habits are critical for raising market penetration of green goods and services.

91. Individuals look at their local environment when making consumption choices. The spatial clustering of purchases of hybrid vehicles and of LEED registered buildings in US provides insight into the role of imitation in preferences. Kahn and Vaughn (2009) find that initial hybrid penetration in California occurred predominantly in census tracks with greater than average environmental preference, as measured by the percentage of registered green party voters. 
Relying on voluntary contributions from customers, through utility green pricing programs, can be highly effective to support higher levels of local investment in renewable energy. Participating customers in green pricing programs typically agree to pay a premium on their electric bill to cover the incremental cost, for the utility, of providing additional renewable energy. The number of these programs has increased steadily in recent years: to date, more than 750 utilities in the US offer a green pricing option.$^{92}$ Green pricing programs involving voluntary contributions from private citizens and from corporations are proliferating in many other OECD countries ${ }^{93}$. A review of the experience of green pricing programs in the US until 2000 concludes that success, in terms of consumers' participation and increases in supply capacities, is determined by: product design (e.g. multiple products to appeal to different market segments), value creation (e.g. participation raises personal recognition and civic pride), product pricing (e.g. premiums are cost-based and transparently invested in new renewable energy development), and program implementation (e.g. how the product is marketed) (Swezey \& Bird, 2001). The development of marketing capacity at the city level, in particular, seems to be a crucial element behind impressive capacity developments, such as the City of Palo Alto's 100\% renewable energy optional program ${ }^{94}$.

Local and regional government can go a long way to increasing local green consumption by financing arrangements reducing the upfront cost hurdles and unit costs of distributed energy technologies. For example, the City of Berkeley's Financing Initiative for Renewable and Solar Technology (FIRST) programme reduces these hurdles by providing loans to homeowners to purchase and install solar photovoltaic systems at interest rates and payback periods similar to those for home mortgages. Borrowers repay the city through an additional, transferrable tax added to their annual property taxes. ${ }^{95}$ Berkeley FIRST also illustrates the limitations of funding mass residential PV system at the city level, as the city's first round of funding provided 1.5 million for only 40 homes; expanding the programme to reach $1 \%$ of the city's housing stock would require USD17.5 million in capital, equivalent to $5.4 \%$ of the city's total budget for fiscal year 2009. ${ }^{96}$ For solar water heaters, low interest, long-term finance can make them cash flow positive in year 1 . These financing arrangements primarily concern new homes, as solar water heaters are integrated into the mortgage. Incentives programs are also being developed to retrofit existing houses with solar water heaters. The California Public Utilities Commission (CPUC) developed a state-wide Solar

92. See US Department of Energy's website for an overview of green power markets, at http://apps3.eere.energy.gov/greenpower/markets/index.shtml.

93. In Europe, green power purchasing and utility green pricing have existed since the late 1990s, and have achieved good results in particular in the Netherlands, Finland, Germany, Switzerland, and the United Kingdom. In Japan, there were an estimated 60000 green power consumer-participants by early 2005. Green power in Japan initially developed through voluntary community organizations, like the Seikatsu Club Hokkaido.

94. Palo Alto Green (PAG) is the City of Palo Alto's 100\% renewable energy optional program open to all residential and commercial customers. The program has about $20 \%$ of the customers involved, with residential customers making up on average $95 \%$ of the mix and the commercial customers at $5 \%$. The residential sales account for roughly $60 \%$ of the program sales with commercial and governmental making up the rest. However, starting with July 2008, both the City of Palo Alto (CPA) and the Regional Water Quality Plant (RWQCP) are increasing their commitment to buy renewable energy equal to 30\% of their total usage, a ten-fold leap from the previous $3 \%$ of total usage purchases (source http://www.cityofpaloalto.org/environment/default.asp).

95. To raise funds for the project, the city of Berkeley created a special tax district and issued bonds on future tax revenue from the special tax district. For further details on the Berkeley FIRST programme, see http://www.ci.berkeley.ca.us/ContentDisplay.aspx?id=26580

96. In 2000, Berkeley's housing stock was 46,875 houses (http://quickfacts.census.gov/qfd/states/06/0606000.html). The city’s budget was USD 321 million in FY09 (see http://www.ci.berkeley.ca.us/ContentDisplay.aspx?id=31028). 
Hot Water incentive program. The proposed incentive amount for residential SWH systems is expected to be about USD 1500 per system on average.

City and regional programs to raise awareness of the value of green products aim to overcome information failures. Information on the quality and character of green services and goods can be quite technical and difficult to obtain, leading individuals to inadequately perceive the risks implied by climate change and unsustainable resource use. Local programmes investing in information and communication technologies (ICT) can significantly lower the information asymmetries that often lead to non-economic behaviours in energy consumption. An example is the provision of new smart metres that display and record real-time energy consumption data and analyse electricity demand patterns to encourage changes in energy usage. Recent research at the MIT Portugal Program has shown that smart metres produced energy savings of up to $20 \%$ for households in Lisbon. ${ }^{97}$ City-level demonstration projects, even of a limited scale, have been very effective. A multi-year survey in the city of Blacktown, Australia, shows that awareness of the Blacktown Solar City project grew to $44 \%$ two years after its initiation. Of the people surveyed, $91 \%$ had switched to energy-saving light bulbs, 73\% had chosen an appliance because of its energy rating, 42\% had installed insulation to reduce energy use, $30 \%$ had signed up for green electricity and $5 \%$ had installed solar panels during the two years of the project's implementation. ${ }^{98}$ This demonstrates the potential impact of government information campaigns, coupled with wide technology deployment (e.g. roll-out of smart metres), on local and regional green spending and energy efficiency.

\subsection{Systemic changes through regional eco-innovation}

As argued by Schellenber et al (2008) there is a "dilemma - a "Gordian Knot"-at the heart of any effort to deal with global warming. If policymakers limit greenhouse gases too quickly, the price of electricity and gasoline will rise abruptly, triggering a political backlash from both consumers and industry. But if policymakers limit greenhouse gases too slowly, clean energy alternatives will not become cost-competitive with fossil fuels in time to prevent catastrophic global warming." Innovation, by cutting down the costs of green product and technologies, can be the stroke that will cut the knot. Green innovation can be defined as innovations in environmentally responsible products and services that are both sustainable and contribute to reducing the impact of GHG emissions upon the environment.

Large cities and metropolitan areas have a very important role as centres of innovation (OECD 2008c). The size and compactness of urban centres generate opportunities for enhanced information flows: as Glaeser et al. (1992) put it, "intellectual breakthroughs must cross hallways and streets more easily than continents and oceans". The mobility of workers through sectors, firms and space may be an additional way of spreading innovation that is facilitated by proximity. Most importantly, the availability of a large and diverse pool of labour is a crucial competitive advantage of cities in attracting innovation activities. The processes by which innovation unfolds in cities are self-reinforcing. The concentration of knowledge creation in the cities attracts skilled, entrepreneurial and creative individuals, whose location choices in turn contributes to producing innovation (OECD 2009o).

The importance of size and density as "pull factors" for knowledge industries and creative individuals does not mean that green innovation will only happen in large urban centres. The green economy is in fact a vast mosaic of differentiated products and services, requiring very diverse labour and capital inputs. There are many latent opportunities for small and medium-sized cities to raise their competitive position in

97. See http://www.mitportugal.org/ses/research-projects.html and the OECD research on ICT and climate change at $h t t p: / / w w w . o e c d . o r g / s t i / i c t / g r e e n-i c t$.

98. For details on the Australian Solar City Program, see http://www.environment.gov.au/settlements/solarcities/index.html. See also OECD Green ICTs publication: http://oecd.org/dataoecd/3/7/44001912.pdf. 
the green markets. These opportunities need to be fed by dedicated investments in knowledge creation. A notable example comes from Århus, Denmark's principal port city, which has been successful in linking university research with both spin-off firms and larger, indigenously established firms involved in "green innovation” (Cooke, 2008).

Most innovation activities seem however to take place in urban areas (OECD, 2009o). Innovative activities are not distributed evenly within countries; some areas are highly innovative while others produce little or no technical and organizational innovations (OECD, 2009o). Innovation tends to be "spiky" among cities as well: some cities have a lot of it, some have very little. The analysis of patterns of concentration and specialization of innovative activities is important for understanding the regional dimension of green growth. While predominantly urban (PU) regions, as defined by the OECD regional typology, have produced between 2004 and 2006 an average of 106 patents in the green technology classes above, intermediate urban regions (IR) have produced on average only 30 patents, and predominantly rural (PR) areas only $10{ }^{99}$ This evidence is in line with the findings of Bettencourt et al. (2007), who show that new patents are granted disproportionately in larger urban centres and argue for the presence of increasing returns in innovation activity with respect to population size.

99. This result is only descriptive and must not be interpreted as causal evidence of a link between urbanisation and green innovation. For recent evidence arguing for the existence of a causal relation between urban size and innovation activities, see Bettencourt et al. (2007). 
Table 6.2. Top innovators in renewable energy, counts of patents by region from 2004 to 2007

\begin{tabular}{|c|c|c|c|c|c|c|c|c|c|c|}
\hline & \multicolumn{2}{|l|}{ Wind } & \multicolumn{2}{|l|}{ Solar } & \multicolumn{2}{|l|}{ Hydropower } & \multicolumn{2}{|l|}{ Geothermal } & \multicolumn{2}{|l|}{ Biomass } \\
\hline & & $\begin{array}{l}\text { Pat } \\
\text { ents }\end{array}$ & & $\begin{array}{l}\text { Pat } \\
\text { ents }\end{array}$ & & $\begin{array}{l}\text { Pat } \\
\text { ents }\end{array}$ & & $\begin{array}{l}\text { Pat } \\
\text { ents }\end{array}$ & & $\begin{array}{l}\text { Pat } \\
\text { ents }\end{array}$ \\
\hline 1 & Ost-Friesland (DE) & 340 & $\begin{array}{l}\text { San Jose-San } \\
\text { Francisco-Oakland } \\
\text { (US) }\end{array}$ & 323 & Ostwurttemberg (DE) & 28 & Aichi (JP) & 21 & Oxfordshire (UK) & 148 \\
\hline 2 & $\begin{array}{l}\text { Los Angeles-Long } \\
\text { Beach-Riverside (US) }\end{array}$ & 129 & $\begin{array}{l}\text { Los Angeles-Long } \\
\text { Beach-Riverside (US) }\end{array}$ & 191 & $\begin{array}{l}\text { New York-Newark- } \\
\text { Bridgeport (US) }\end{array}$ & 28 & $\begin{array}{l}\text { Los Angeles-Long } \\
\text { Beach-Riverside (US) }\end{array}$ & 19 & $\begin{array}{l}\text { New York-Newark- } \\
\text { Bridgeport (US) }\end{array}$ & 142 \\
\hline 3 & Tokyo (JP) & 81 & Tokyo (JP) & 151 & Isère (FR) & 22 & Stuttgart (GE) & 14 & $\begin{array}{l}\text { Cleveland-Akron- } \\
\text { Elyria (US) }\end{array}$ & 135 \\
\hline 5 & Berlin (DE) & 64 & $\begin{array}{l}\text { Detroit-Warren-Flint } \\
\text { (US) }\end{array}$ & 141 & Sydney (AU) & 19 & $\begin{array}{l}\text { Atlanta-Sandy } \\
\text { Springs-Gainesville } \\
\text { (US) }\end{array}$ & 13 & Cheshire (UK) & 62 \\
\hline 6 & $\begin{array}{l}\text { Schleswig-Holstein } \\
\text { Mitte (DE) }\end{array}$ & 58 & Sydney (AU) & 139 & Linz-Wels (AT) & 18 & Aachen (DE) & 13 & Rheinpfalz (DE) & 53 \\
\hline 7 & Osaka (JP) & 58 & Munchen (DE) & 137 & Rogaland (NO) & 18 & Zug $(\mathrm{CH})$ & 12 & $\begin{array}{l}\text { Houston-Baytown- } \\
\text { Huntsville (US) }\end{array}$ & 50 \\
\hline 9 & Fyns amt (DE) & 47 & Melbourne (AU) & 94 & $\begin{array}{l}\text { Philadelphia-Camden- } \\
\text { Vineland (US) }\end{array}$ & 16 & $\begin{array}{l}\text { Industrieregion } \\
\text { Mittelfranken (DE) }\end{array}$ & 10 & Unterer Neckar (DE) & 30 \\
\hline $\begin{array}{l}1 \\
0\end{array}$ & $\begin{array}{l}\text { San Jose-San } \\
\text { Francisco-Oakland } \\
\text { (US) }\end{array}$ & 43 & Kyoto (JP) & 87 & Osaka (JP) & 15 & $\begin{array}{l}\text { Greater Vancouver } \\
\text { (CA) }\end{array}$ & 10 & Berkshire (UK) & 29 \\
\hline
\end{tabular}

Source: Data are extracted from the OECD REGPAT dataset. Counts of patents are weighted according to the methodology described in OECD (2008d), The OECD REGPAT Database: A Presentation OECD STI Working Paper, OECD, Paris. 
Why should cities and regions bear the costs of inventions while they could free-ride on knowledge developed elsewhere? The case for localized investments in green innovation rests on three main assertions:

- Innovation activity should be tailored to the local milieu, as geographical and historical differences are important for innovation dynamics;

- Regional policies are effective in supporting the development of new applications for the technologies of innovative firms;

- Significant constraints limit international and within-country technology transfer and deployment.

There is a strong awareness that knowledge creation and learning is critical to the competitive advantage of firms and cities. The availability of "knowledge systems" capable of producing new learning is particularly crucial for the development of green industries, where costs are constantly pushed down through innovative processes and technologies. The dynamism of a local knowledge systems has deep roots in the economic history of each territory: regional development is in fact based around pathdependent processes of learning, institution building and resource accumulation. Yet, local innovation policies can produce systemic improvements in the quality of the system. Two major roles for cities can be identified:

i) a facilitator role for information sharing, through the support to formal inter-organizational networks, and through the facilitation of informal knowledge spillovers, and

ii) an enabler role, through the identification of priority areas for investment in science, technology and development and well-designed support for R\&D and education.

Widening and generalizing access to knowledge through public-private partnerships and networking platforms for eco-innovation is a policy target within the reach of city and regional governments. Knowledge Transfer Networks (KTNs) are set up and funded by government, industry and academia. They bring together diverse organisations and provide activities and initiatives that promote the exchange of knowledge and the stimulation of innovation. KTNs in the field of eco-innovation have been initiated by regional development agencies in the UK. A major review of the KTNs in the UK showed that $75 \%$ of business respondents rated KTN services as effective; 50\% developed new R\&D and commercial relationships with people met through these networks; and 25\% made a change to their innovative activities as a result of their engagement within KTN (OECD, 2009n). The Lahti Cleantech cluster in Finland encouraged innovation and development of environmental technologies by bringing together small and large enterprises, educational organisations and regional authorities. As a result, 170 new jobs have been created, 20 new clean-tech companies have set up in the Lahti region and the project has attracted more than EUR 30 million in total investment ${ }^{100}$. The London Hydrogen Partnership is working to bring the hydrogen technology forward in the capital so as to improve energy security and air quality, reduce greenhouse gases and noise, and support London's green economy. ${ }^{101}$

100. For more information on the Lahti and the other clean-tech clusters of Finlands (Kuopio, Oulu, Uusimaa), see http://www.cleantechcluster.fi/en/.

101. The partnership, established in 2002, aims to maintain dialogue among all sectors/actors relevant to the hydrogen economy, prepare and disseminate relevant materials, provide a platform for funding bids and initiation of projects (see http://www.london.gov.uk/lhp/about/index.jsp). 
Research and Development (R\&D) activities are at the core of environmental innovation and are necessary for the development of new environmental technologies (OECD, 2009n). There are few data and assessments on public and private expenditure for R\&D programmes targeting environmental technologies and products. Cities and regions can be innovative by promoting pilot, small-scale R\&D projects within a framework that clearly specifies targets, outputs and indicators so as to allow monitoring and evaluation. Successful projects can qualify for access to other sources of financing and could provide large benefits through replication in other cities. Well-designed public technology infrastructures can leverage new private investments in R\&D. Examples of this type of technology infrastructure include the development of joint research projects between public and private laboratories (Cooperative Research and Development Agreements (CRADAs) and publicly sponsored Research Joint Ventures (RJV)), and Small Business Innovation Research Awards. In the Rhône-Alpes Region of France, regional and national investments in R\&D were instrumental to the development of the Tenerrdis competitiveness cluster, which is promoting scientific collabouration to develop clean technologies applied to construction, transport and energy production. Tenerddis brings together 185 stakeholders, who developed, between 2005-2008, 226 R\&D projects, for a total of EUR 440 million of investments, of which EUR 200 million came from public funding. ${ }^{102}$

Universities can facilitate local knowledge exchange - the local "buzz"- and become effective pipelines of information exchange with national and global markets. Universities can effectively contribute to the creation of local knowledge hubs for green technology by:

- $\quad$ Educating people (training graduates and continuing education)

- Increasing the local stock of codified knowledge (patents, publications)

- Providing public place for local and global exchange (hosting forums, meetings and conferences; networks of alumni, faculty exchanges)

- Problem-solving (contract research, incubation services, cooperative research with industry)

There is great potential in university involvement in green technologies, but efforts for consolidation of this involvement are just emerging. There is increasing empirical evidence that partnerships raise the innovative outputs of both firms and universities (OECD, 2009m). Policies aiming at boosting the innovation capacity (and thus the competitiveness) of local green firms can use local, public research facilities as a leverage. The competences in wind engineering and wind energy at the Danish Technological Institute and at Ålborg and Århus Universities have been essential for the development of the Danish wind energy clusters (Cooke, 2008).

It becomes important to generate incentives to speed up the move of environmental technologies from the laboratory to the market. This will be mainly done by increasing and focusing sponsored research projects on environmental technologies and by increasing the density of institutional and informal linkages between business and universities. Local governments have now more autonomy in this regard. One result is that city and regional governments now strongly encourage universities to open technology transfer offices (TTOs) and technology licensing offices (TLOs), whose activities are focused on translating of research findings into practical application for the benefit of the general public. Investments for consolidating these efforts are warranted, as TTOs and TLOs are often small and lack capacity, and can therefore be ineffective. An effort to strengthen and consolidate, particularly in fields where the technologies are new, is recommended. A recent case study on the Kitchener and Guelph metropolitan areas about $100 \mathrm{~km}$ west of Toronto (Bathelt et al, 2008), show that a larger number of firms related to

102. See www.tenerrdis.fr/en. 
information technology have been successfully launched since the 1970s around the activities of the University of Waterloo.

Local and regional governments can support private innovation by supporting the activities that follow the research and development of new environmental technologies. These activities can be summarized in four stages: demonstration, verification, commercialization, diffusion and utilization. Private R\&D expenditures in green innovations might be in fact limited given the novelty and complexity of the market for environmental products, and the associated difficulties in making new products known and properly valued. Local governments can take the forefront by promoting environmental technology verification schemes, supporting the development of marketing tools (web sites, targeted conferences, mailing lists), financing and disseminating results of demonstration tests, and removing regulatory barriers to the implementation of these technologies. 


\section{REFERENCES}

Bae, S. (2009), “The responses of manufacturing businesses to geographical differences in electricity prices”, The Annals of Regional Science, Vol. 43, No. 2, Springer Berlin / Heidelberg.

Bank of Japan, Kiatkyushu subsidiary (2008), "Recycling Industry in Kitakyushu City”, http://www3.boj.or.jp/kitakyushu/sonota/kitarecycle.pdf, accessed 2 October, 2009.

Bathelt, H., Kogler, D., Munro, A. (2008), “Social Foundations of Regional Innovation and the Role of University Spin-offs", http://www.utoronto.ca/isrn/publications/NatMeeting/NatSlides/Nat08/Bathelt_Spinoffs_Waterloo.pdf, accessed October 1, 2009.

Bettencourt, L.M, J. Lobo, D. Strumsky (2007), "Invention in the City: Increasing Returns to Patenting as a Scaling Function of Metropolitan Size”, Research Policy, Volume 36, Issue 1, February 2007, pp. 107-120.

Bloom N. et al. (2008), "Modern Management: Good for the Environment or Just Hot Air?" CEP Discussion Papers No. 0891, Centre for Economic Performance, LSE.

Bowen, A., et al. (2009), “An outline of the case for a 'green’ stimulus”, Grantham Research Institute Policy Brief February 2009, http://www.Ise.ac.uk/collections/granthamInstitute/publications/An\%20outline\%20of\%20the\%20cas e\%20for\%20a\%20'green'\%20stimulus\%20-\%20low\%20res.pdf, accessed 5 September 2009.

City of Toronto, Economic Development, Culture and Tourism (2006), "Catalyzing Economic Growth, Environmental Quality in the City of Toronto”, City of Toronto, 2006.

Clarke Annez, Patricia and Thomas Zuelgaray (2009) High Cost Carbon and Local Government Finance, 5th Urban Research Symposium 2009, Brookings Institution, Washington, DC.

Cooke, P. (2008), “Green Clusters: Green Innovation \& Jacobian Cluster Mutation”, International Journal of Innovation and Regional Development, (forthcoming).

Crandall, R., W. Lehr and R. Litan (2007), “The Effects of Broadband Deployment on Output and Employment: A Cross-sectional Analysis of U.S. Data”. Issues in Economic Policy, The Brookings Institution, 2007.

ECOTEC Ltd. (2002), Analysis of the EU Eco-industries, their employment and export potential, ec.europa.eu/environment/etap/pdfs/main_report.pdf,_accessed 10 August, 2009.

Edenhofer, O. and N. Stern (2009), “Towards a global green recovery. Recommendations for immediate G20 action”, http://www.pik-potsdam.de/members/edenh/publications-1/global-greenrecovery_pik_lse, accessed 20 September, 2009. 
Fankhauser S., Sehlleier F., and N. Stern (2008), “Climate Change, Innovation and Jobs”, Climate Policy, Vol.8, pp. 421-429.

Fitzgerald, M. (2009), “Urban retrofits How to make a city green -- without tearing it down”, http://www.boston.com/bostonglobe/ideas/articles/2009/06/28/urban_retrofits_how_to_make_a_city _green_ndash_without_tearing_it_down/, accessed September 10, 2009.

Gibbs, D. (2008), “Industrial Symbiosis and Eco-Industrial Development: An Introduction”, Geography Compass Vol. 2, No.4, pp. 1138-1154.

Glaeser, E., Kallal, H., Scheinkman, J., and Shleifer, A. (1992), “Growth of Cities”, Journal of Political Economy, 100, 1126-52.

Grover, S. (2007). “Energy, Economic, and Environmental Benefits of the Solar America Initiative”, www.nrel.gov/docs/fy07osti/41998.pdf.

Hidson, M. (2009) “Sustainable Procurement -actions to lead by example”, Presentation for ICLEI World Congress, Edmonton 2009, www.iclei.org/fileadmin/template/conference_templates/wcedmonton2009/files/Presentations/A6-Hidson.pdf,_accessed 25 September, 2009.

Hill, D., Goldberg, R., (2001), "Energy demand: impact assessment for the New York metropolitan region”, in: Rosenzweig, C., Solecki, W.D. (Eds.), Climate Change and a Global City: An Assessment of the Metropolitan East Coast Region. Columbia Earth Institute, New York.

HSBC (2009), “A Climate for Recovery, The colour of stimulus goes green”, HSBC Global research www.globaldashboard.org/wp-content/uploads/2009/HSBC_Green_New_Deal.pdf.

IEA (2009a), Cities and Towns and Renewable Energy -YIMFY: Yes In My Front Yard, 4 August, 2009, OECD/IEA, Paris.

ILO/UNEP (2009) "Green Jobs: Towards Decent Work in a Sustainable, Low-Carbon World", http://www.ilo.org/integration/themes/greenjobs/index.htm.

Johnstone, N. (2007), Environmental Policy and Corporate Behaviour, Edward Elgar, Cheltenham, UK.

Kahn M. and R.K. Vaughn (2009), “Green Market Geography: The Spatial Clustering of Hybrid Vehicles and LEED Registered Buildings” The B.E. Journal of Economic Analysis \& Policy.

Kahrl,F., W. Tao, and D. Roland-Holst (2009), "Municipal Climate Policies: Scope, Economics, and Institutions", Center for Energy, Resources, and Economic Sustainability, University of California at Berkeley.

Kammen, D. M., M. Fripp, and K. Kapadia (2006), "Putting Renewables to Work: How Many Jobs can the Clean Energy Industry Generate?” RAEL Report, University of California at Berkeley.

Kellenberg, D. K. (2009). "An empirical investigation of the pollution haven effect with strategic environment and trade policy," Journal of International Economics, Elsevier, Vol. 78(2), pp. 242255.

Lund, P. D. (2009), "Effects of Energy Policies on industry expansion in renewable energy", Renewable Energy, Vol. 34, July 2009, pp.53-64. 
Mansanet-Bataller, M., M. Herve-Mignucci and A. Leseur (2008). "Energy Infrastructures in France: Climate Change Vulnerabilities and Adaptation Possibilities”, Mission Climat Working Paper, Paris, Caisse des Depots.

Navigant Consulting, Inc. (NCI) (2008), "Economic Impacts of Extending Federal Solar Tax Credits.” Final Report Prepared for the Solar Energy Research and Education Foundation.

Newman, P., and P. Kenworthy (1999). Sustainability and Cities, Island Press, Washington, D.C.:.

O’Sullivan, A. (2000), Urban Economics (4th Edition). McGraw-Hill Companies, Boston.

OECD (2003), ICT and Economic Growth: Evidence from OECD Countries, Industries and Firms OECD, Paris.

OECD (2008c), Household Behaviour and the Environment: Reviewing the Evidence, OECD, Paris.

OECD (2008d), The OECD REGPAT Database: A Presentation OECD STI Working Paper, OECD, Paris

OECD (2009d), Regions Matter: Economic Recovery, Innovation and Sustainable Growth, OECD, Paris.

OECD (2009j), "Policy Responses to the Economic Crisis: Stimulus Packages, Innovation and Long-Term Growth”. OECD, Paris.

OECD (2009k), "Sub-national Dimension and Policy Responses to the Crisis”, OECD, Paris.

OECD (2009l), OECD Territorial Reviews: Trans-border Urban Cooperation in the Pan Yellow Sea Region, OECD, Paris.

OECD (2009m), “University inventions and entrepreneurship: a regional perspective”, OECD SDI working paper, OECD, Paris.

OECD (2009n), "Enabling the Green Growth: Sustainable Manufacturing and Eco-innovation, Synthesis Report”, OECD, Paris.

PCGG (Presidential Commission on Green Growth) (2009), "Road to our future: Green growth, a national strategy and the five-year plan (2009-2013)”, PCGG, Seoul, Korea.

Shaffer, R., S. Deller, and D. Marcouiller. (2004). Community Economics: Linking Theory and Practice. Blackwell Publishing, Ames, Iowa.

Shellenberger, M., et al. (2008), "Fast Clean Cheap: Cutting Global Warming's Gordian Knot", Harvard Law and Policy Review, VOl. 2 N.1 Spring 2008.

Shin, S. (2009), “An Empirical Assessment of the California Utilities’ Energy Efficiency Programs.” Unpublished Master’s Thesis.

Singh, V. and J. Fehrs (2001), “The Work that Goes into Renewable Energy”, Renewable Energy Policy Project (REPP) Research Report No. 13. http://www.repp.org/articles/static/1/binaries/LABOUR_FINAL_REV.pdf.

Swezey, B. and L. Bird (2001), “Utility Green Pricing Programs, What Determines Success?”, National Renewable Energy Laboratory, Technical paper 29831. 
Tudor T, E. Adam and M. Bates (2006), "Drivers and limitations for the successful development and functioning of EIPs (eco-industrial parks): A literature review” Ecological Economics Vol. 61, No. 2-3, pp. 199-207.

UNESCAP (2008), “The Green Growth approach for climate action” background paper for The 3rd Policy Consultation Forum of the Seoul Initiative Network on Green Growth, 18-20 September 2008 Cebu, Philippines.

Van Berkel, R. et al. (2008), "Industrial and urban symbiosis in Japan: Analysis of the Eco-Town program 1997-2006” Journal of Environmental Management Vol. 90, No. 3, pp. 1544-1556.

Van der Zwaan B. and A. Rabel, (2004), “The Learning Potential of Photovoltaics: Implications for Energy Policy”, Energy Policy Vol.5, pp.1545-1551.

Wiser, R., G. Barbose, and C. Peterman. (2009), “Tracking the Sun: The Installed Cost of Photovoltaics in the U.S. from 1998-2007”. Lawrence Berkeley National Laboratory eetd.lbl.gov/ea/EMS/reports/lbnl-1516e.pdf.

Wiser, R., S. Pickle, and J. Eto (1998), “Details, Details... The Impact of Market Rules on Emerging "Green" Energy Markets”, Lawrence Berkeley National Laboratory Working paper, No 41812. 


\section{ANNEX A: COMPUTABLE GENERAL EQUILIBRIUM MODEL OF CITIES AND CLIMATE CHANGE (IMACLIM-R AND OECD METROPOLITAN DATABASE)}

\section{A.1 The Model and Methodology}

\section{Approach and capabilities of the model}

Our methodology is based on a model that takes into account patterns in OECD metro-regions and the feedback mechanisms that can take place between cities and more aggregate dimensions of the economy. Thus, the OECD Metropolitan Database is used to model the behaviour of cities and a general equilibrium model that allows for the interaction of such metro-regions and the national macroeconomic activity as well as carbon emissions affecting climate change. Understanding those feedback mechanisms is crucial to better inform on long-run trends of aggregate indicators of local and global economic development that are relevant for policy scenario analysis.

The model that is developed in this paper will yield information on the spatial and economic dimensions of the metro-regions such as: $i$ ) the social and economic aspects of the spatial structure of the metro-regions; ii) the behaviour of the supply side of the metro-regional economies; iii) the behaviour of the demand side of the metro-regional economies. These dimensions of the urban economy will allow constructing an indicator of attractiveness for our metro-regions and differences in such attractiveness will determine the long-run spatial and economic development patterns of the 78 metro-regions through firms' migration decisions.

The model proposed in this paper has the capacity to predict the potential impacts of certain policies at the metro-region scale on energy consumption, carbon emissions and economic growth. Our analysis aims at comparing the impact of alternative policy measures at the metro-regional level on core economic and environmental variables. In terms of policy implications, the lesson emerging from the comparative analysis could provide useful information on the extent to which the role played by alternative setting of the spatial economy is relevant in combating carbon emissions. The modelling analysis can also be seen as a useful base for further studies of OECD metro-regions, since studies combining theoretical modelling approach and empirical dynamic computable general equilibrium technique applied to the relationship between spatial development of metro-regions, location choices, energy consumption pathways and climate change are, to the best of our knowledge, not available.

\section{The model}

In our model, the world is composed of many macro-regions each of which can be seen as a mass of metro-regions. We assume that each metro-region is monocentric and axi-symmetrical that spreads along an one-dimensional space $x \in[-d ; d]$, where $d$ is the overall city size. Like traditionally approached by urban and regional economics since von Thünen (1966), the central business district (CBD), situated at the origin $x=0$, is the location where firms choose to distribute once they locate in the metro-region. All economic activities take place in the $j$-CBD, whereas the urban population is distributed within circular peripheral areas surrounding it. In our economy three types of decision-makers exist: governments, producers, and consumers. We assume that the government chooses housing policies that maximise the utility of the representative consumer. Profit-maximizing firms do not consume land, while utility- 
maximizing workers do. Urban workers settled at a certain point $\mathrm{x}$ of $\mathrm{d}$ consume $\lambda_{j}(x)$ units of land and commute a distance $x$ to the CBD. The number of urban workers $L_{j}$ is given by:

$$
L_{j}=\int_{0 \leq x \leq d} \frac{d x}{\lambda_{j}(x)}
$$

At the land market equilibrium, workers are indifferent between any $x$-location around the CBD of metro-region $j \in J$. This comes down to assuming that all people living inside each peripheral rings at each point $x$ face identical external costs resulting from the interplay between different commuting costs (being different the distance from each individual's residential place and the CBD, where jobs and all varieties of the differentiated goods are available) and housing costs (being heterogeneous the value and the consumption of land throughout the periphery).

Government owns the available land and decides of the spatial distribution of housing supply. Hence, heterogeneity of density within the metro-region does not result from households' preferences over the available land but is rather exogenously set. We take the trend for the density function $\lambda_{j}(x)$ as given and choose a power functional form for the sake of simplicity.

$$
\lambda_{j}(x)=\lambda_{J}^{*} x^{\xi} \text {, with } \quad 0 \leq \xi \leq 1 \quad 103
$$

As in Murata and Thisse (2005), each urban worker supplies one unit of labour. Considering unitary commuting costs $\theta_{j} \geq 0$ in the iceberg form à la Samuelson (1954), ${ }^{104}$ the effective labour supply of a worker living in the urban area at a distance $x$ from the CBD is:

$$
s_{j}(x)=1-2 \theta_{j} x, \quad \text { with }-d_{j} \leq x \leq d_{j}
$$

Condition: $\theta_{j} \leq \frac{1}{2 d_{j}}$ ensures positive labour supply. The total effective labour supply throughout the urban area is therefore:

$$
S_{j}=\int_{-d_{j} \leq x \leq d_{j}} \frac{s_{j}(x)}{\lambda_{j}(x)} \mathrm{d} x=\frac{2 d_{j}^{1-\xi}}{\lambda_{J}^{*}(1-\xi)}\left(1-2 \theta_{j} \frac{1-\xi}{2-\xi} d_{j}\right)
$$

whereas the total potential labour supply is given by:

$$
L_{j}=\int_{-d_{j} \leq x \leq d_{j}} \frac{1}{\lambda_{j}(x)} \mathrm{d} x=\frac{2 d_{j}^{1-\xi}}{\lambda_{J}^{*}(1-\xi)}
$$

103. Condition $\xi \geq 0$ ensures that $\lambda_{j}(x)$ is an increasing function, so that the empirical evidence of higher population density in the centre of the city is captured. Condition $\xi \leq 1$ is necessary to have population convergence in (1).

104. Considering different unitary commuting costs ${ }^{\theta_{j}}$ across the agglomerations captures the specificities of each agglomeration in terms of modal shares and transport infrastructures. 
Letting $w_{j}$ be the wage rate firms pay to workers to carry out their activity within the $j$-urban area, commuting costs $C C_{j}$ faced by one worker in the metro-region $j$ result from the losses of effective labour. Combining (4) and (5), we obtain:

$$
C C_{j}=\frac{\left(L_{j}-S_{j}\right) w_{j}}{L_{j}}=\frac{2}{\lambda_{j}^{*}(1-\xi)} \frac{1-\xi}{2-\xi} \theta_{j} d_{j}
$$

We normalize at zero the rent value of the land located at the edges of the city: $R_{j}\left(d_{j}\right)=0$. Given that all urban workers are identical from a welfare perspective, using (3) the value of commuting costs $2 \theta_{j} x$ and rent costs $R_{j}(x)$ is the same throughout the urban city. Precisely:

$$
2 \theta_{j} d_{j} w_{j}+\lambda_{j}(x) R_{j}(x)=s_{j}\left(d_{j}\right) w_{j}+0=s_{j}\left(-d_{j}\right) w_{j}+0=\left(1-2 \theta_{j} d_{j}\right) w_{j}
$$

From (7), the equilibrium land rent is simply derived, as follows:

$$
R_{j}(x)=\frac{2 \theta_{j}\left(d_{j}-|x|\right)}{\lambda_{j}(x)} w_{j}
$$

In order to understand how the land rent is distributed among urban workers by the local government, we first calculate the aggregated land cost by integrating $R j(x)$ over distance $x$ that represents the available urban land, and then divide the resulting figure by the labour force that is active in the city:

$$
R C_{j}(x)=\frac{\int_{-d_{j} \leq x \leq d_{j}} \lambda_{j}(x) R_{j}(x) \frac{1}{\lambda_{j}(x)} \mathrm{d} x}{L_{j}}=2 \theta_{j} w_{j} \frac{1}{2-\xi}
$$

Combining (6) and (9) gives $\frac{C C_{j}}{R C_{j}}=1-\xi$ which determines the distribution of external costs over commuting and housing: the lower $\xi$, the more commuting costs are relatively important. From each labourer's income, an amount: $C C_{j}+R C_{j}=E C L_{j}$ is deduced as compensation to live in the urban area. This amount is expected to affect consumers' purchasing power $\Upsilon_{j}$.

\section{Consumption}

We consider a macro-regional economy comprised by a mass of metro-regions (labeled $j=(1 ; J)$ ), two sectors, one composite sector $D$ of the Imaclim-R manufacturing-plus-service type taking place in a $j$ metro-regional agglomeration, and one traditional sector $F$ that is active in the non-metro-regional land. We assume that the many firms of the manufacturing-plus-service type produce each one variety (labeled $i$ $=(1 ; N))$ of one type of the differentiated good $q$ under increasing returns to scale. Therefore, the number of available varieties in each metro-region $j, n_{j} \in N$, is equal to the number of firms that are active in the same metro-region. The traditional good is produced produces under Walrasian conditions (constant returns to scale and perfect competition) and can be freely traded across metro-regions. At any time, by assuming the well-known iceberg structure for transport costs (Samuelson, 1952), any variety of the composite good can be traded between the two regions. Transportation costs are zero for intraregional shipment of both goods. We extend the standard NEG literature (Krugman, 1991) by tracking bilateral 
flows for the mass of metro-regional agglomerations, so that a quantity $c_{j k}(\mathrm{i})$ of a variety produced in metro-region $j$ is consumed in $k$ and purchased at a price $p_{j k}$. We define a price index $P_{j}$ of the composite good available in $j$ in order to be able to treat the various products as a single group.

$$
P_{j}=\left[\int_{i=1}^{n_{j}} p_{j j}(i)^{1-\varepsilon} \mathrm{d} i+\iint_{k \neq j} \int_{i=1}^{n_{k}} p_{k j}(i)^{1-\varepsilon} \mathrm{d} i \mathrm{~d} k\right]^{\frac{1}{1-\varepsilon}}
$$

Here $\varepsilon>1$ is the elasticity of substitution between varieties. The economy employs a unit mass of mobile workers $L$ : wherever they are employed. Workers $(L)$ are both input production factors and output end-users. Given a certain net income $\Upsilon_{j}$, individuals should decide allocating over the consumption of the above described differentiated good $D$ (produced in the metro-regions), and a 'traditional' good $F$ (freely traded and purchased at a homogenous price $p_{F}$ ). We consider households that reach identical welfare levels and bare identical external costs $E C L_{j}$ stemming from being located in the $j$ - metro-region (see eq. (7)). Given individual's utility $U_{j}$ defined over the disposable income $\Upsilon_{j}$ for consumption in each $j$, welfare maximization behaviour imposes:

$$
\max U_{j}=U_{j}\left[D_{j}\left(\Upsilon_{j}\right), F_{j}\left(\Upsilon_{j}\right)\right]
$$

For the sake of simplicity, we choose a Cobb-Douglas functional form for the utility function:

$$
U_{j}=\left(D_{j}\right)^{\beta}\left(F_{j}\right)^{1-\beta}\left(Z_{j}\right)^{-\zeta}
$$

where, $Z_{j}=k_{j} Q_{j}=k_{j} n_{j} q_{j}$ captures the negative environmental externalities associated to production $Q_{j}$ via a $j$-specific coefficient $k$. The intensity of the environmental burden is measured by the parameter $\zeta$. Price and utility homogeneity throughout the $j$-metro-region impose that aggregate consumption of the composite good is independent on the distance $x$ from the $j$-core. The constant-across-metro-region subutility from aggregate consumption of all the varieties composing the manufacturing good is:

$$
D_{j}=\left[\int_{i=1}^{n_{j}} C_{j j}(i)^{\frac{\varepsilon-1}{\varepsilon}} \mathrm{d} i+\iint_{k \neq j} \int_{i=1}^{n_{k}} C_{k j}(i)^{\frac{\varepsilon-1}{\varepsilon}} \mathrm{d} i \mathrm{~d} k\right]^{\frac{\varepsilon}{1-\varepsilon}}
$$

The representative consumer has to satisfy the following budget constraint:

$$
\int_{i=1}^{n_{j}} p_{j j}(i) C_{j j}(i) d i+\int_{k \neq j} \int_{i=1}^{n_{k}} p_{k j}(i) C_{k j}(i) \operatorname{did} k=\Upsilon_{j}
$$


where $\Upsilon_{j}$ is the net disposable income for consumption, already discounted from external costs for workers $E C L_{j}$ (see eq. (7)). Maximizing utility given in (12) subject to (14) gives the aggregate demand in metro-region $j$ for the variety $i$ produced in metro-region $k$

$$
C_{k j}(i)=L_{j} \Upsilon_{j} \frac{\left(p_{k j}\right)^{-\varepsilon}}{\left(P_{j}\right)^{1-\varepsilon}}
$$

\section{Production}

All firms producing in a given metro-region $j$ incur the same production costs and rely upon capital and labour as the same spatially mobile input factors. We consider labour as subject to external economies of scale resulting from improved production process through some metro-region-specific technology spillover, as follows:

$$
l_{j}=\frac{l_{j, 0}}{n_{j}^{\alpha}}
$$

where $l_{j}$ is the effective unitary labour input requirement for production, $n_{j}$ is the given number of active firms in region $j, \alpha$ is a parameter that captures the non linearity of the external agglomeration effect (Fujita and Thisse, 1996; Grazi et al., 2007), and $l_{j, 0}$ is the agglomeration-specific unitary labour input requirement for production in absence of agglomeration effects $(\alpha=0)$

Due to the fixed input requirement, the amount of productive capital in metro-region $j, X_{j}$ is proportional to the number of domestic firms, $n_{j}$ :

$$
X_{j}=\chi n_{j}
$$

Firms of the above type find it profitable to join a certain metro-region $j$ to benefit from a specialised labour market. This brings about differences in terms of labour productivity between producing inside and outside the metro-region. To avoid all firms concentrating in the same place because of absent specific differentiation, we introduce inherent reasons for differential location choices. We therefore assume that firms choose to locate according to the trade-off between production benefits and costs that are specific of the metro-region $j$. Concerning the former, they take the form of heterogeneous labour productivity across different metro-regions (that is $l_{j} \neq l_{K}$ ), whereas the latter are indirectly captured by the different labour costs (namely, the wage rate $w_{j}$ ) firms face across the different metro-regions to compensate workers for the metro-region-specific external costs. Letting $r_{j}$ and $w_{j}$ the unitary returns of, respectively, capital $X_{j}$ and labour $l_{j}$, the total cost of producing $q_{j}$ for a firm $i \in n_{j}$ in region $j$ is expressed as:

$$
T C(i)=r_{j} \chi+l_{j} w_{j} q_{j}(i)
$$

Given its monopoly power, it is clear that each firm acts to maximise profit:

$$
\pi_{j}(i)=p_{j} q_{j}(i)-\left[r_{j} \chi+l_{j} w_{j} q_{j}(i)\right]
$$


In order to allow the model for the spatial dimension, trade is allowed between the metro-regions. We use the iceberg form of transport costs associated with trade of the composite goods (Samuelson, 1952). In particular, if one variety $i$ of manufactured goods is shipped from metro-region $j$ to metro-region $k$, only a fraction will arrive at the destination, the remainder will melt during shipment. This means that if a variety produced in location $j$ is sold in the same metro-region at price $p_{j j}$, then it will be charged in consumption location $k$ at a price

$$
p_{j k}=T_{j k} p_{j j}
$$

where $T_{j k}>1$ captures the trade cost from metro-region $j$ to metro-region $k$.

As already mentioned, the freely tradable traditional good $F$ is produced under constant returns to scale and perfect competition. Letting $r_{F}$ and $w_{F}$ the unitary returns of, respectively, capital $X_{F}$ and labour $l_{F}$, the total cost of producing $q_{F}$ for a firm settled outside the metro-regional area is expressed as follows:

$$
T C_{F}=\left[r_{F} X_{F}+l_{F} w_{F}\right] q_{F}
$$

In such a perfectly competitive market, the price of the traditional good is obtained directly from marginal production costs:

$$
p_{F}=r_{F} X_{F}+l_{F} w_{F}
$$

\section{Short-run market equilibrium}

Given $n_{j}$ firms operating in the metro-region $j$, the labour-market equilibrium condition posits that the total labour effectively supplied $S_{j}$ (see eq. (4)) is equal to the total labour requirements by production $l_{j} n_{j} q_{j}$ :

$$
S_{j}=L_{j}\left[1-2 \frac{1-\xi}{2-\xi} \theta_{j} d_{j}\right]=l_{j} n_{j} q_{j}
$$

where, we recall, $d_{j}$ is the size of metro-region $j, \theta_{j}$ is the unitary commuting cost in metro-region $j$ and $n_{j} q_{j}$ is the total domestic production of the composite good.

Moreover, market clearing condition imposes that all that is produced by firms is also consumed by individuals. Hence, production size $q_{j}(i)$ of a firm located in region $j$ is as follows:

$$
q_{j}(i)=c_{j j}(i)+\int_{k \neq j} T_{j k} c_{j k}(i) \mathrm{d} k
$$

For the sake of simplicity and without loss of generality we consider that all the varieties are identical. This allows us to drop the notation $i$ for the variety in the reminding of the analysis. In particular, the price index in (10) can be re-written as: $P_{j}=\left[n_{j} p_{j}^{1-\varepsilon}+\int_{k \neq j} n_{k}\left(T_{k j} p_{k}\right)^{1-\varepsilon} \mathrm{d} k\right]^{\frac{1}{1-\varepsilon}}$ 
By plugging (15) into (24), we obtain the equilibrium production of one firm operating in metro-region $j$.

$$
q_{j}=L_{j} \Upsilon_{j} \frac{\left(p_{j}\right)^{-\varepsilon}}{\left(P_{j}\right)^{1-\varepsilon}}+\int_{k \neq j} T_{j k} L_{k} \Upsilon_{k} \frac{\left(T_{j k} p_{k}\right)^{-\varepsilon}}{\left(P_{k}\right)^{1-\varepsilon}} \mathrm{d} k
$$

As a consequence of the profit maximization behaviour, firms will enter and exit the manufacturing sector until the point at which profits are zero, as an equilibrium condition of monopolistic competition. Therefore, by substituting (25) into (19) and setting $\pi_{j}=0$, the return to capital $r_{j}$ at equilibrium is straightforwardly obtained:

$$
r_{j}=\frac{\left(p_{j}-l_{j} w_{j}\right) q_{j}}{\chi}
$$

Recalling that $p_{j}$ is the price of a variety $i$ that is both produced and sold in metro-region $j$, under Dixit-Stiglitz monopolistic market we have that a profit-maximizing firm sets its price as a constant markup on variable cost by assuming a constant elasticity of substitution (CES), $\varepsilon>1$ :

$$
p_{j}=\frac{\varepsilon}{\varepsilon-1} \frac{\partial T C_{j}}{\partial q_{j}}=\frac{\varepsilon}{\varepsilon-1} \frac{l_{j} w_{j}}{n_{j}^{\alpha}}
$$

All varieties are sold in the metro-region at the same price and no trade costs occurs to spatially differentiate the market value of a given variety. It is now worth spending a few words in order to make clear what we consider as the wage rate $w_{j}$. In our spatial economy, a fraction of the whole available land hosts metro-regional activities. The equilibrium on workers' migration imposes that the utility level per unit of labour reached by living within the $j$-metro-regional area is identical to the one achieved within the $k$-one. This is because certain beneficial effects are expected to be homogeneously faced by individuals as they decide to enter the metro-regional market.

Workers will chose to enter the metro-regional market if the utility they reach in there is at least equal to level of (unitary, per unit of work) utility in the outside area, $u^{*}$.

$$
\frac{\left(D_{j}\right)^{\beta}\left(F_{j}\right)^{1-\beta}\left(\kappa_{j} n_{j} q_{j}\right)^{-\delta}}{l_{j} n_{j} q_{j}}=u^{*}
$$

Our model allows for income distributional effects and assumes that all revenues produced in metroregion $j$ are redistributed locally. In other words, the aggregate revenue in metro-region $j, L_{j} \Upsilon_{j}$ equals the sum of total wages $l_{j} w_{j} n_{j} q_{j}$ and return to capital $r_{j} X_{j}: L_{j} \Upsilon_{j}=l_{j} w_{j} n_{j} q_{j}+r_{j} X_{j} \cdot{ }^{105}$

105. Note that implicitly, this expression means that the housing rents are also redistributed across households, as they do not appear in the income formation. 
Utility maximization under the Cobb-Douglas specification in (1) leads to the following identities between prices and quantities for the two market goods: $P_{j} D_{j}=\beta \Upsilon_{j}$ and $p_{F} F_{j}=(1-\beta) \Upsilon_{j}$. Substituting the two identities into (28) gives the equilibrium wage rate for a worker in metro-region $j$ :

$$
w_{j}=u^{*} \frac{\varepsilon-1}{\varepsilon \beta^{\beta}(1-\beta)^{(1-\beta)}} P_{j}^{\beta} p_{F}^{(1-\beta)}\left(\kappa_{j} n_{j} q_{j}\right)^{\delta}
$$

\section{The long-run model}

This section extends the short-run model so as to address dynamics and ensure analytical consistency for its inclusion in the Imaclim-R framework as a specific module accounting for the spatial organization of the economy at the urban scale. Dynamics in our modeling framework is carried out in two steps.

\section{Spatial disaggregation}

We consider the Imaclim-R static equilibrium at time $t$. At this time, macroeconomic information at the macro-regional and national levels are disaggregated into a combination of local urban economies where the interactions between economic agents occur in the form developed in the previous sub-sections.

In each metro-region $j$ at time $t$, a fixed number of profit-maximizing firms $n_{j}(t)$ sets prices $p_{j}(t)$ and quantities $q_{j}(t)$ to meet households' demand for the composite good $D$, according to (25) and (27). Labour requirement for production drives population distribution $L_{j}(t)$ and metro-region size $d_{j}(t)$ through relations (23) and (5), respectively. Consistency between descriptions of the economy at the metro-regional and macro-regional or national scales requires ensuring that the average value of each spatially disaggregated (i.e., metro-regional) variable equals the value of the corresponding aggregate (macro-regional) variable resulting from the Imaclim-R equilibrium.

\section{Firm mobility}

The second step of the module describes firms' location decisions and induced changes in the spatial distribution of firms and productive capital in the national economy. Metro-regions differ in labour and infrastructure endowment, captured by labour productivity $l_{j}$ and unitary commuting costs $\theta_{j}$, respectively. These $j$-specificities act as constraints on production expectations (through (18)) and expected capital returns (through (26)), and hence influence the attractiveness of metro-regions for productive investment. The attractiveness of metro-regions ultimately affects the migration decisions of firms.

Location decisions across the set of available metro-regions at time $t$ are taken by firms on the basis of an index of relative attractiveness $a_{j}(t)$ that accounts for the capital return investors expect to receive from investing in a given metro-regional market. This reflects the active role of shareholders who want to maximise the return to capital, which is a priori a cost to firms. The relative attractiveness $a_{j}(t)$ helps determine the stable spatial distribution of firms across the available metro-regions at equilibrium time $t+$ $1, n_{j}(t+1)$.

Two types of firms base their location decisions on $a_{j}(t)$ : the existing firms at previous equilibrium time, and the newly created firms. For each of the two groups of firms we are able to establish the stable number of firms at a given equilibrium time. 
(i) First, consider the case of two metro-regions labeled $j$ and $k$, with $j, k=(1 ; 2) ; j \neq k$. For a generic old $j$-firm (that is a firm coming from previous equilibrium time and settled in metro-region $j$ ), the magnitude of the incentive to migrate to a $k$ depends on the relative attractiveness of metroregion $j$ :

$$
m_{j \rightarrow k}= \pm\left|a_{k}(t)-a_{j}(t)\right|^{\gamma_{1}}\left(\frac{1}{\delta_{j k}}\right)^{\gamma_{2}}\left|\frac{1}{l_{k}(t)-l_{j}(t)}\right|^{\gamma_{3}}
$$

were $\delta_{j k}$ is the distance between the metro-regions $j$ and $k, l_{k}(t)$ measures the productivity of labour in metro-region $k$, and $\gamma_{1}, \gamma_{2}, \gamma_{3}$ (such that $\gamma_{1}, \gamma_{2}, \gamma_{3}>0$ and $\gamma_{1}+\gamma_{2}+\gamma_{3}=1$ ) represent the measurement of the relative migration incentive of, respectively, attractiveness, distance, and labour productivity.

Equation (30) writes that a generic $j$-firm is encouraged to move to $k$ from metro-region $j$ if condition: $a_{k}(t)$ - $a_{j}(t)>0$ is verified (as this ensures $m_{j \rightarrow k}>0$ ). The magnitude of this incentive is a function of: a) the difference in relative attractiveness between metro-regions; b) the physical distance $\delta_{j k}$ between them; and c) the absolute difference between metro-regions in the structure of production, as captured by the labour productivity term $l_{k}(t)-l_{j}(t)$. Extending (30) to entail a more generic frame, in which many alternative metro-regions are spatially available, the incentive to move to an metro-region $j$ from any other $k$ (with $j, k$ $=(1 ; J)$ and $j \neq k)$ is derived as follows:

$$
M_{j}=\mu^{M} \int_{k \neq j} m_{j \rightarrow k} \mathrm{~d} k
$$

where $\mu^{\mathrm{M}}$ is a parameter that homogenizes the units of measurement.

(ii) Consider now the case of new firms that are created at the equilibrium time $t$. They spatially sort out themselves across the $J$ metro-regions according to the value of relative metro-regional attractiveness. The number of firms created in metro-region $j$ is proportional to the emerging force $E_{j}$ :

$$
E_{j}(t)=\mu^{E} a_{j}(t)
$$

where $\mu^{E}$ is a parameter that homogenizes the units of measurement. Given the economy size at the time $t$, the total number of firms in metro-region $j$ at the equilibrium time $t+1$ results from the interplay between firms' migration decisions from other metro-regions and entry of new firms:

$$
n_{j}(t+1)=n_{j}(t)+M_{j}(t)+E_{j}(t)
$$

The absolute attractiveness $A_{j}(t)$ of a $j$-metro-region is given by the absolute variation of firms between to consecutive equilibria, $n_{j}(t+1)-n_{j}(t)$, so that:

$$
A_{j}(t)=M_{j}(t)+E_{j}(t)
$$




\section{A. 2 Main results of the model with a climate policy only}

As section 3 aims at evaluating possible impacts of local policies, it is important to bear in mind the impacts that a carbon policy alone might entail without the urban module in the IMACLIM-R model. The results in terms of cost effects of implementing a single carbon tax can be expressed as the ratio of GDP under the carbon tax compared to the baseline scenario (no carbon tax). In the first 20 years of the carbon tax implementation period the OECD economy faces significant, yet temporary, losses with respect to the baseline (in which no tax is put into operation). This is due to the initially strong increase of the price of carbon, which tends to accelerate technical change despite the inertias characterizing the renewal of production equipment, technologies and infrastructure. By 2032, the improvement of energy efficiency confirms to be highly beneficial for the economic activity, especially because it renders the economy less vulnerable to oil shocks. This is captured by a rapid increase in GDP (Figure A.1).

Figure A.1. Economic Impact of a Climate Policy Alone using the Baseline Scenario

Ratio of OECD GDP under climate policy to OECD GDP under baseline scenario

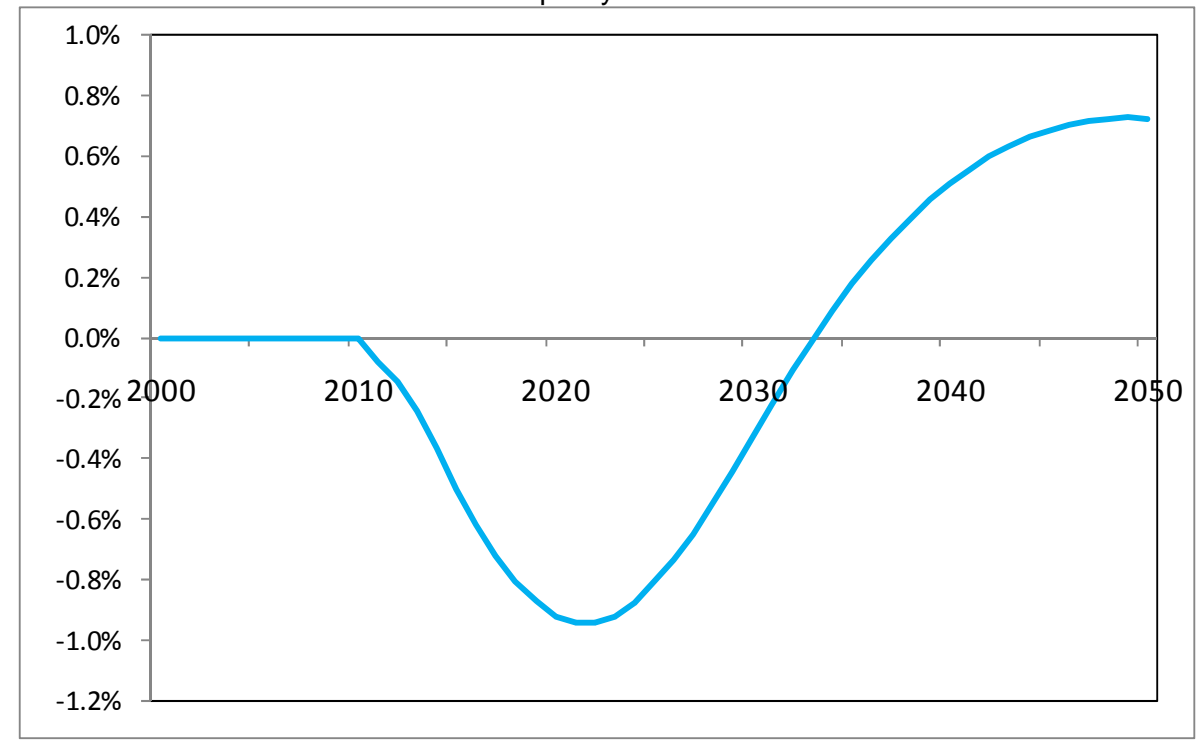

Source: Own calculations based on OECD Metropolitan Database and Imaclim-R 
Credits for cover photos (from left to right) are as follows:

Réf. 13649991 (C) MissMedia - Fotolia.com

Réf. 17570634 (c) shocky - Fotolia.com

Réf. 1010731 (c) Matt Poske - Fotolia.com 